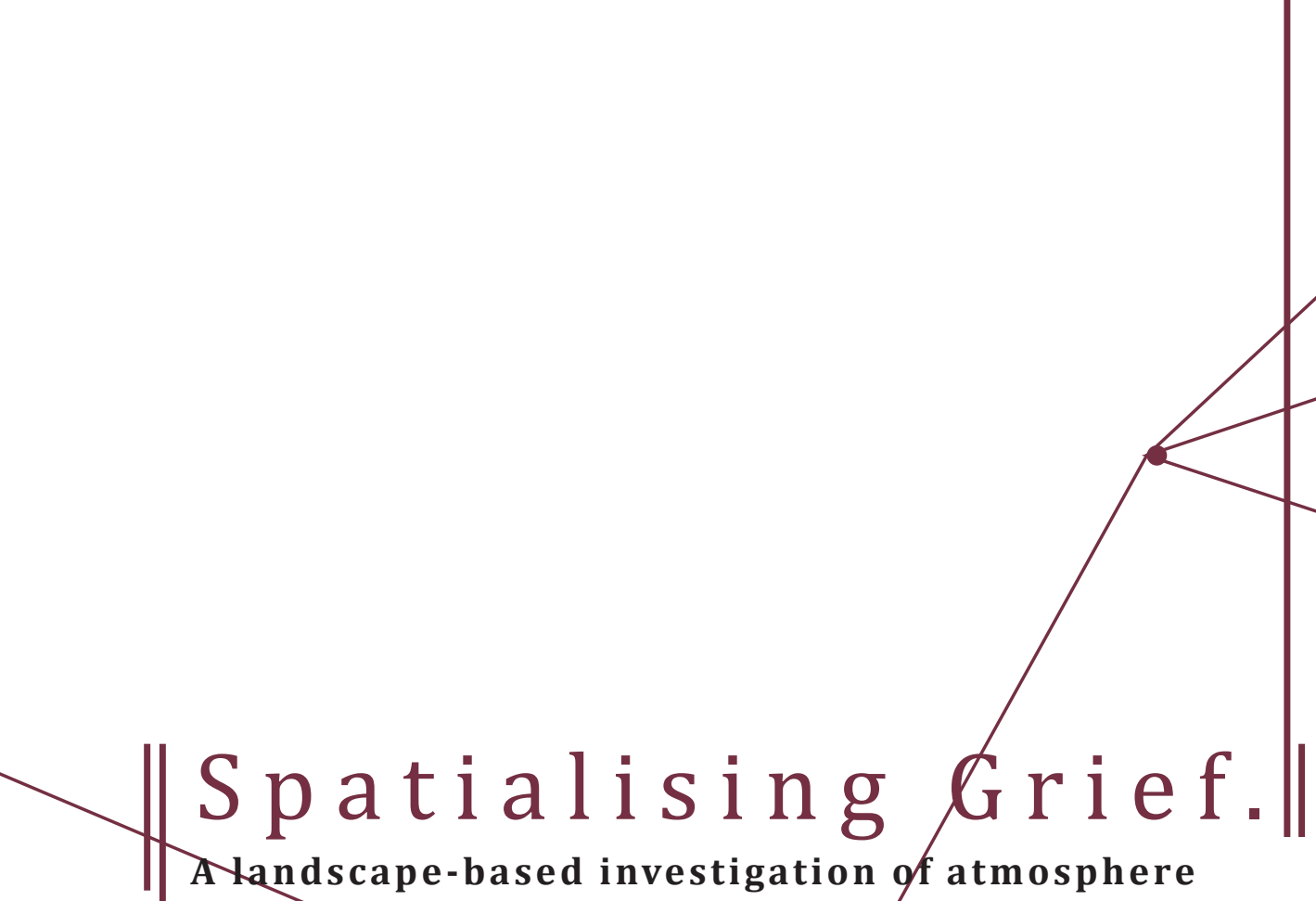

A landscape-based investigation of atmosphere and recovery.

Patyick Gregory 



\section{Spatialising Grief.}

A landscape-based investigation of atmosphere and recovery

a 120-Point thesis submitted to the Victoria University of Wellington in partial fulfilment of the requirements for the degree of <aters of Landscape Architecture.

Victoria University of Architecture

2019

Patrick Gregory 

In this landscape based research, I consider atmosphere as a spatial layer of a site and as such, a critical aspect of how urban landscapes are experienced. In this way atmosphere is understood as more than a feeling or sense of connection to a place, thus an intangible fixture that allows spaces to be both unique and general to a person at a given moment(Andersson 73 - 76) .Atmospheric space is thus nonphysical and engages a sensation of emotion and thought rather than the senses of sight, touch, and sound. I identify this layer of space lacks coherence within the urban fabric of cities which tend to focus on landscape as a focus of movement and functions. Spaces for reflection are most often formalised within the city, reflecting on a general scale rather than allowing for individual reflection. Memorials are designed to represent the grief of the city in regards to a specific event and work as a symbolic statement. In this way whilst memorials prompt a form of reflection on collective grief, they do not make a context for individuals personal connections to their own grieving process.. This design considers how landscape architecture can design urban spaces that carry such influence.

To approach this issue the project uses atmosphere, an ethereal layer of design, to create spaces that allow for positive reflection for those grieving by way of small triggers or 'vignettes'. These subtle aspects of design prompt a walker experiencing grief to transcend the space, if only for a moment, and aid their recovery process.

The project draws on both landscape design discourse and psychology.

Research on grief clinically and emotionally has demonstrated a general process of one's relationship to grief and its eventual transition from a hostile antagonist relation to a friendly companion (Vaughn 36 - 40). This recovery process, yielded in distinct shifts and changes, has formed the basis for the 'vignettes' in this design. These moments have informed the design and driven the composition of connection between space and griever.

The project explores how atmosphere can be used in design (method) as a 'connector' between the user and site. Existing atmospherics of the site are identified and used as a foundation with subtle and minimally noticeable elements. This design approach allows for both a more general engagement for the everyday user whilst creating a canvas for the more reflective walker to interpret.

This design research contributes to discourse that uses emotions to create subtle and light handed landscapes. It shows that when engaging with complex emotions, such as grief, joy, and fear, bold or literal gestures in the landscape are not always required. 


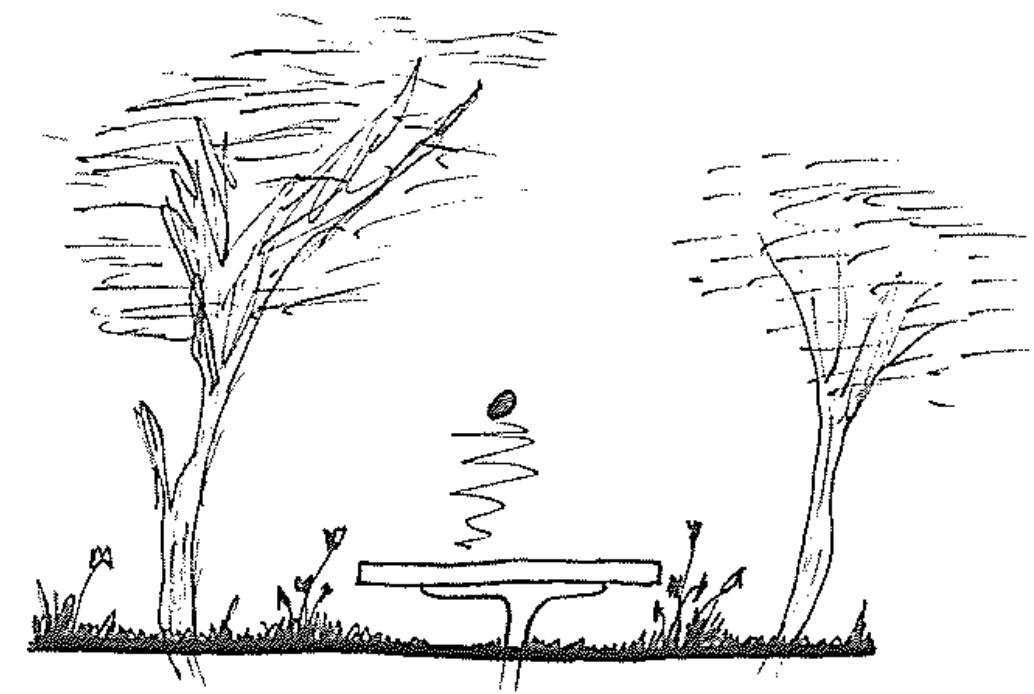

Figure 1 - Meaningful space section

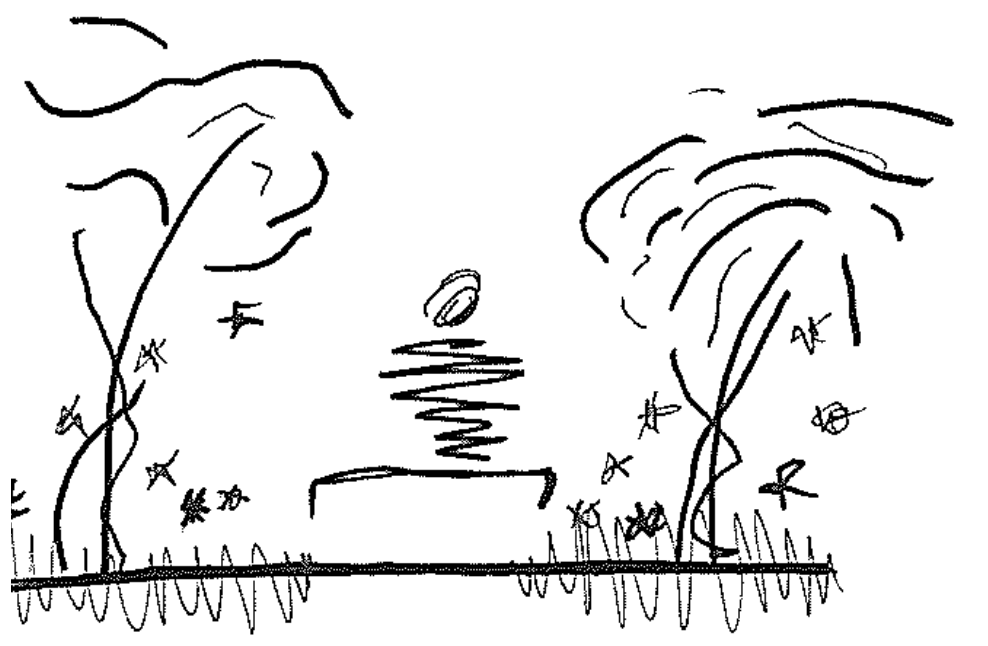

Figure 2 - Atmopheric section

R

e

$\mathrm{S}$

e

a

$r$

C

$\mathrm{h}$

How can

landscape design be used to promote an atmosphere of positive reflection to those in the grief recovery process, whilst

creating a meaningful space for the daily urban walker? 


\section{Table of Contents.}

Chapter 1 - Preface

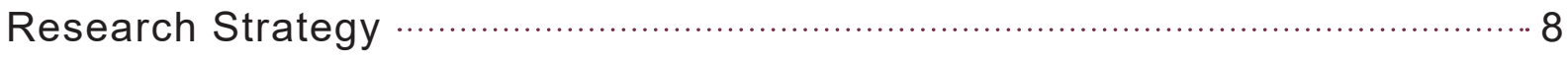

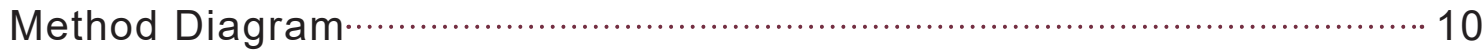

\section{Chapter 2 - Precedents}

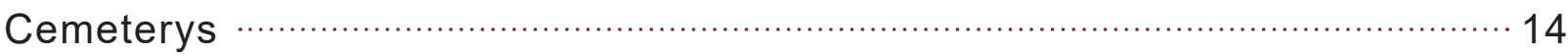

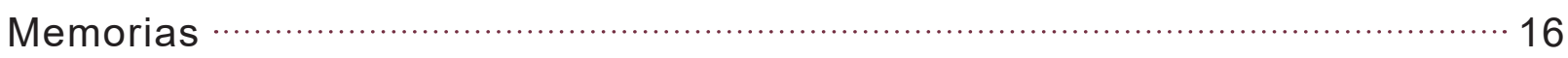

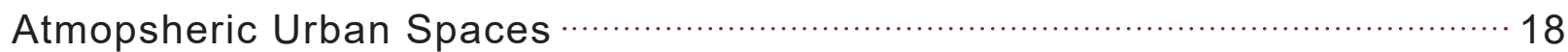

\section{Chapter 3 - Grief and Atmosphere}

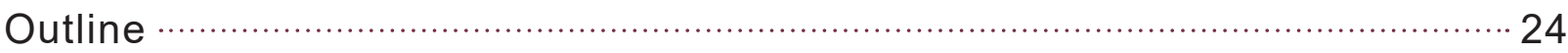

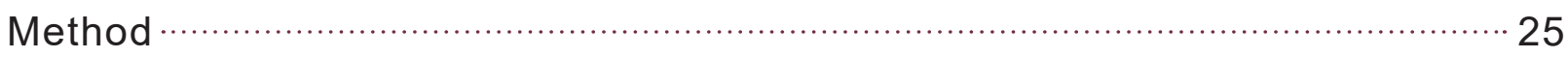

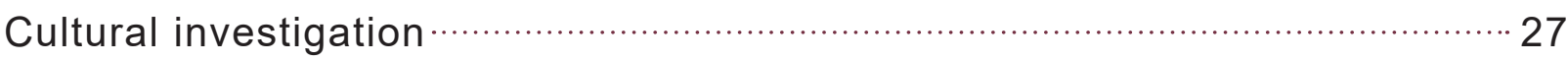

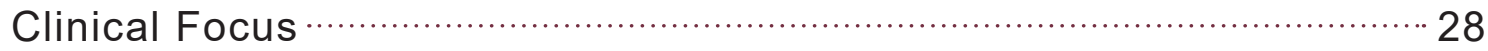

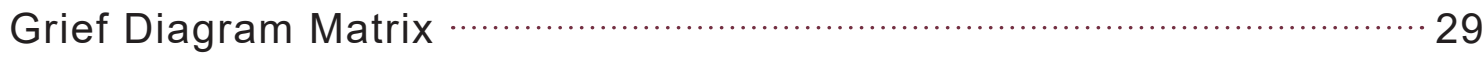

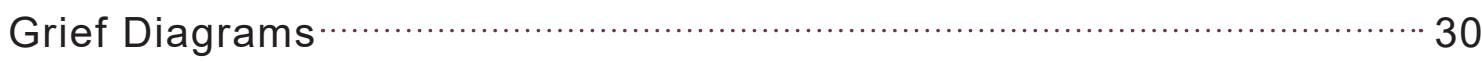

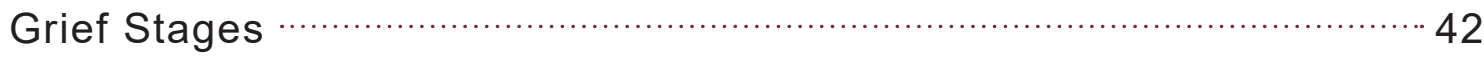

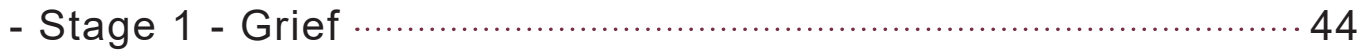

- Stage 2 - Healing …............................................................ 45

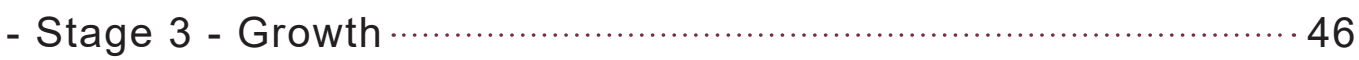

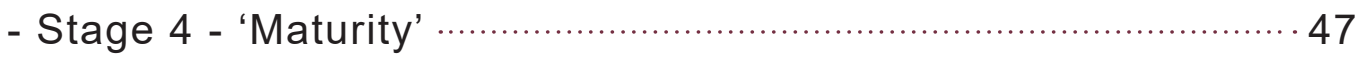

Atmosphere

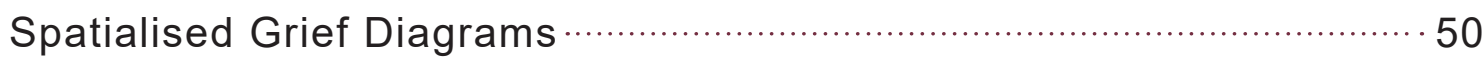

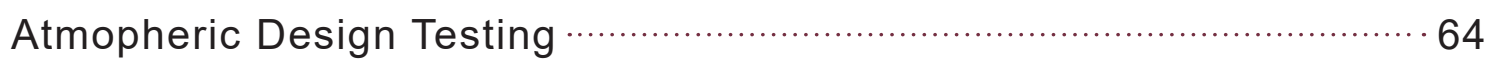

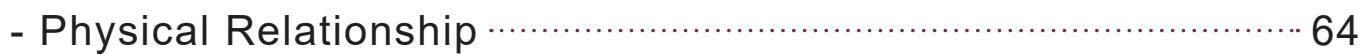

- Sensory Relationship …….......................................................6 68

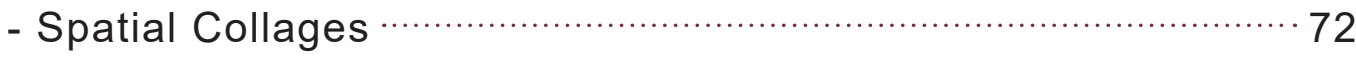

\section{Chapter 4 - Space and Site}

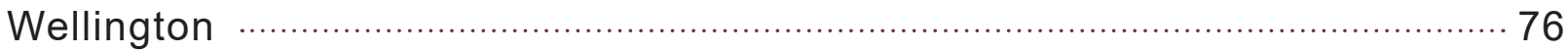

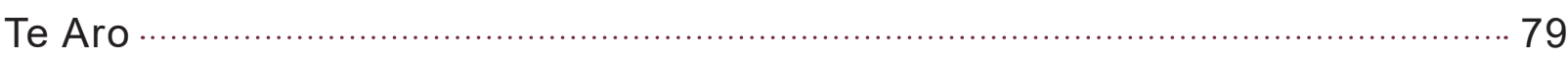

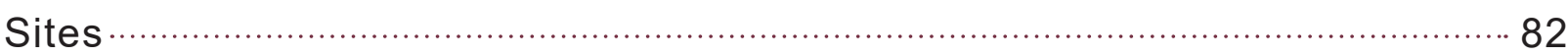




\section{Chapter 5 - Nuance and Time}

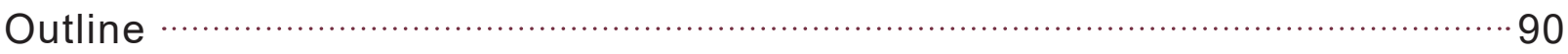

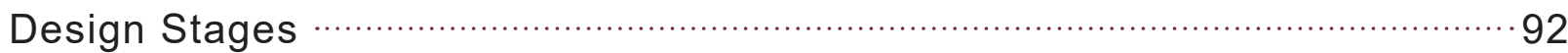

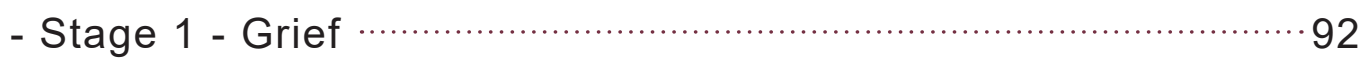

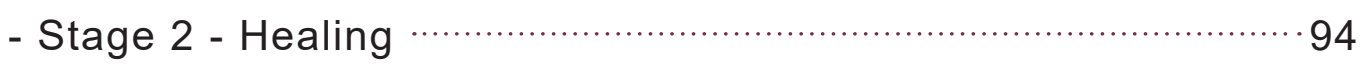

- Stage 3 - Growth ….......................................................... 95

- Stage 4 - 'Maturity'.............................................................. 96

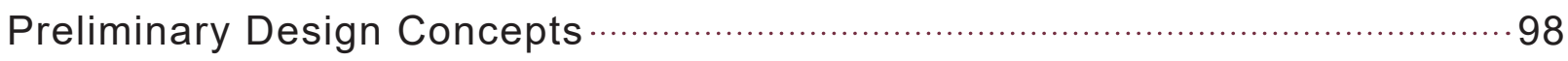

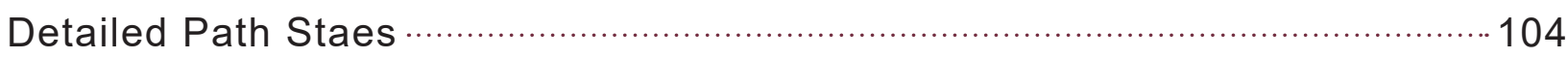

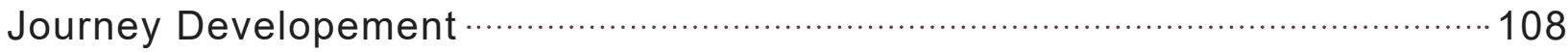

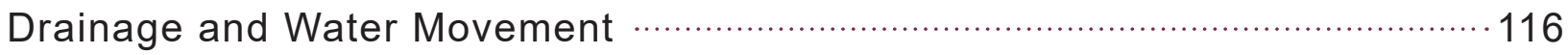

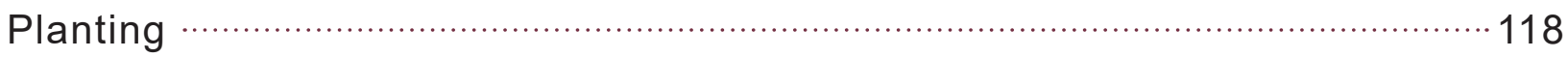

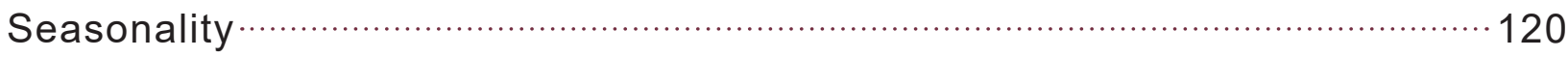

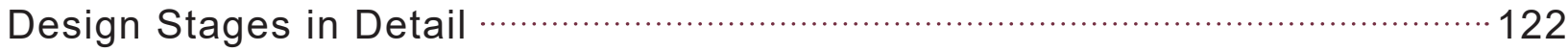

Design Response

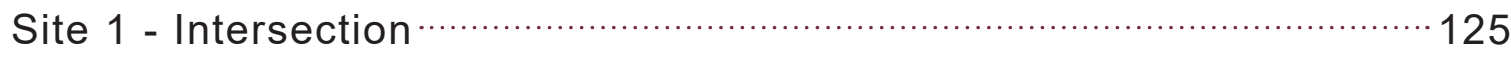

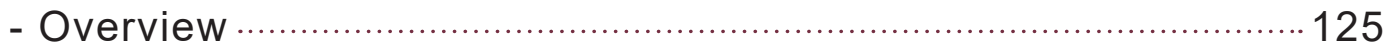

- Cafe Space …..................................................................... 131

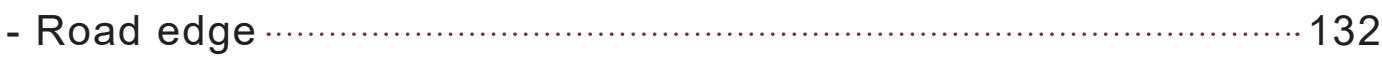

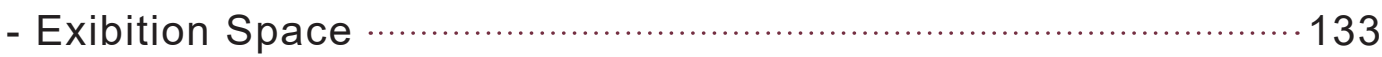

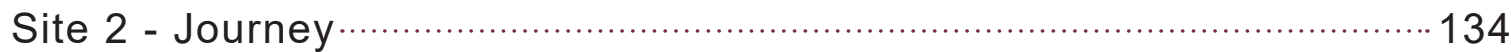

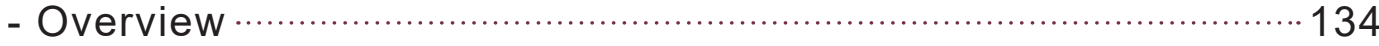

- Entrance …....................................................................... 139

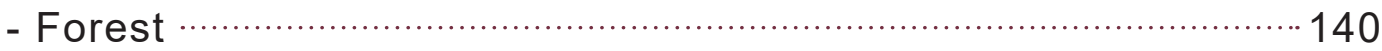

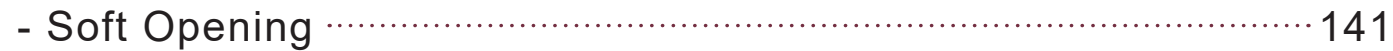

Perspectives

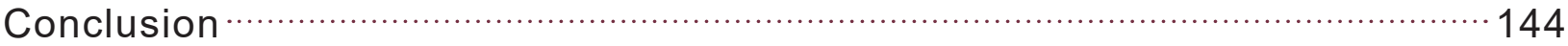

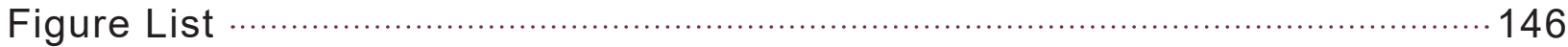

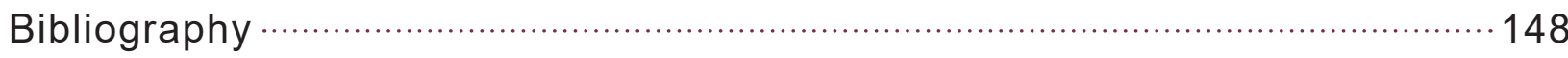


Chapter 1 What exists

How does landscape architecture deal with the question of grief? 


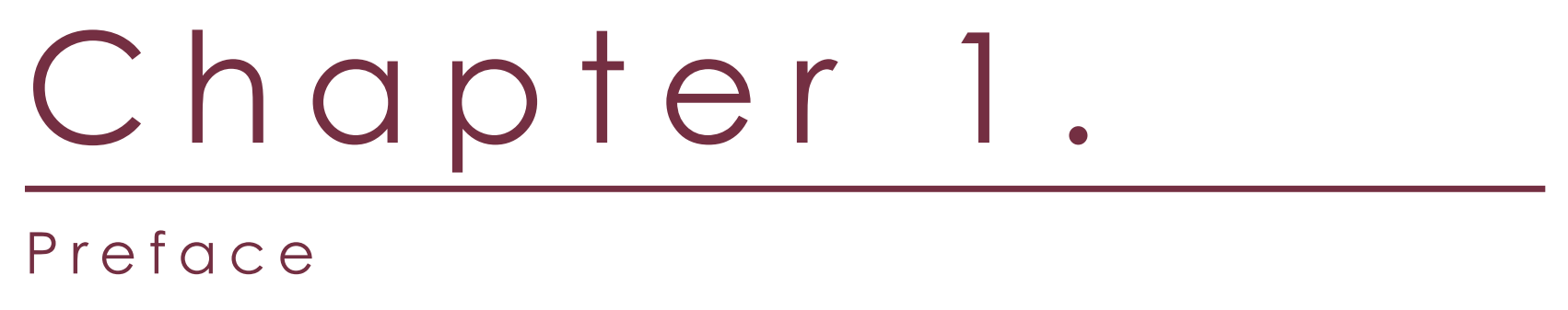


This document is purposed to outline how the design inquiry was undertaken and how it engages with the theoretical context gathered. This project seeks to understand the potential between design and psychology and how this relationship can be used in a symbiotic way.

In understanding and representing both grief and atmosphere this project tests and reviews its research rigorously to create a solid foundational understanding of grief and it's application to design. Because of the amorphous and idiosyncratic qualities of grief and atmosphere, the project experiences many failures, dead ends, and scope adjustments to ensure that this projects end result is engaging and real.

This research portfolio is structured as follows:

Chapter 1 is a summary of the objectives, rationale, approach and method of this project.

Chapter 2 focuses on the design profession and its main approaches to designing reflective spaces. This chapter is both a critique on how urban reflective spaces fail on an individual level, and a contribution to how daily spaces can engage with various levels of intimacy and recovery.

Chapter 3 looks into the theory of death and grief, and the steps one can take to recover in a positive way. This chapter first focuses on the attempts made to understand grief and recovering, explaining all successes, failures, and adjustments of scope. It then focuses on atmosphere and its relationship to grief as the connection between the mind and the space. Finally this section will explore testing of these atmospheric qualities in abstract space to understand how grief and recovery might be spatialized as well as the qualities that aid and hinder this atmospheric design. The key aspect of this stage of the research was to locate ways of bringing grief and atmosphere into design process.

Chapter 4 focuses on site and potential of location. Given the project aims to engage with daily walkers and create reflective spaces within the city, Wellington was seen as a representation of an urban space with pedestrian engagement and thus a good backdrop for urban experimentation. Although this design is site specific, using Te Aro in Wellington as an example of reflective urban design allows it to be applied to similar cityscapes. The site analysis phase used various styles and techniques that were developed unique to the inquiry content. This involved a more general and spatial understand of the city that produced a technical and wider network based analysis, and a more intimate study of the various car parks and urban culture that was represented through photography and guestural diagrams. The whole of the Te Aro area was analysed, before focusing on car parks, than finally the two example sites for this project. This research had some dead ends and failures as this project aimed to get a indepth and intimate relationship and understanding of these spaces. 
Chapter 5 begins with the culmination of the different theoretical and design investigations and the crafting of tools in order to mobilise the spatial inquiry. Psychology meets site through an understanding of atmospheric design and testing in the sites begins to shape the end response. What became clear when undertaking the literature review and situation study was that the project tasked itself with not a representation of grief as an idea, but devised a way of using grief as a process. It was important, at this stage, to push the design to be more than a representation of grief. The design was tested at this stage at all scales and referenced back against design and psychological tools that were created. It became clear i needed to develop a response to scale and test the initial designs at both the intimate, general site, and the urban situation scales. These tools were made so that the final design was a reflection of the research built on a foundation of understanding.

When reviewing the method of this project, a clear system was seen. In the method diagrams on the next page, a series or cycles can be seen where a step is taken, reviewed, and started over by looking into the landscape architecture profession. This process is an in depth one, with each stage following the same steps:

\section{- $\quad$ Design review}

- $\quad$ Site analysis informed by the design review

- $\quad$ Literature review informed by the design review

- $\quad$ Design based on the Design review, Site analysis and literature review.

- $\quad$ A final review of that stage.

The methodology was designed to produce stronger and more in-depth understanding of each of these parts of analysis because each new stage is approached with a new perspective and focus that is 'fed' into the process of design. This method also allows for acknowledgement of issues and failure as they are reviewed and dissected to understand their problems. As cyclical and synergistic, it allows for more stages and cycles depending on where the investigation is lacking. 
Method Diagram.

Western

Review of the Landscape Architectures - cement Perspective

Personal Journey with Grief

Stage 3

- Wood

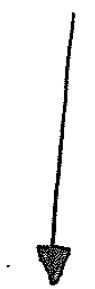

1 Profession
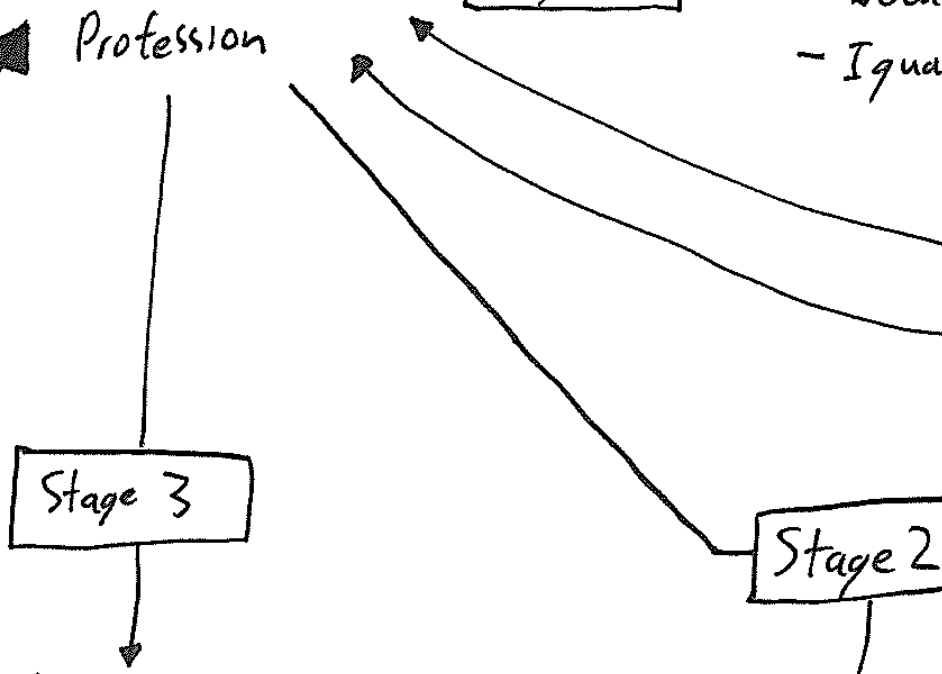

Atmospheric Designs

Criticism of Public Space

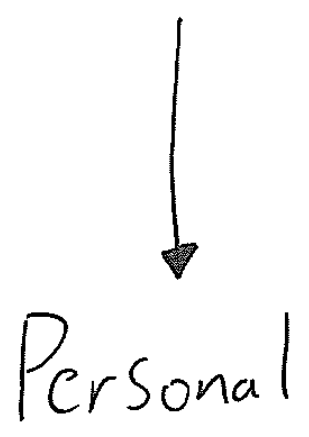

Want for Reflective Space review
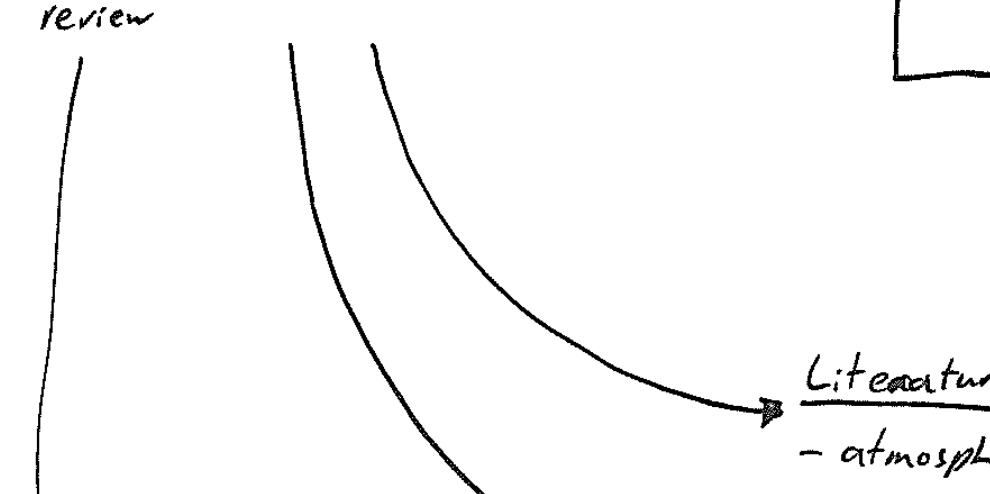

- time

Site Analysis

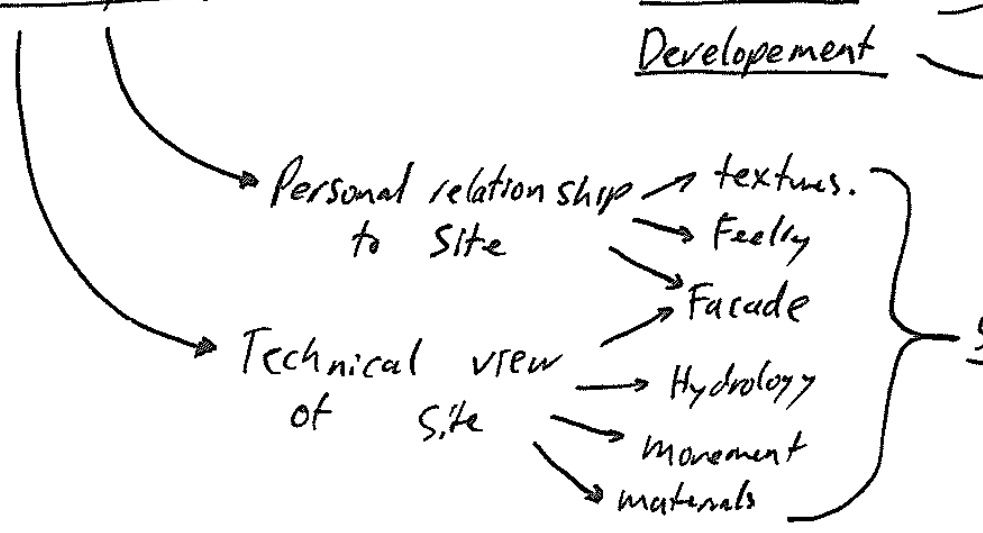

Figure 3 - Method Diagram

12 
Literature review

$\rightarrow$ Death customs $\rightarrow$ new Scope

- Cultural carsectus

Site Analysis
review
and Cemetery $\rightarrow-$ Photo graph $\rightarrow$ Tourney

lade Cemetery - Plans $\rightarrow$ movement

Review 1

- Review 2

Memorials

Review

- Memorial to Murdered Tens $\rightarrow$ - materials

- Victims of violence in mexico.

- textures

Disconnecting

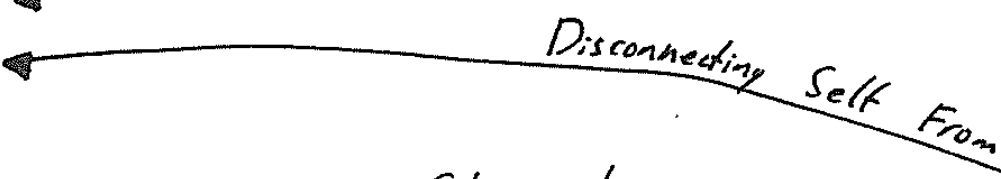

Site analysis

Poses

$\frac{\text { Design } 1}{- \text { Too Bald }}$

- Medical

$\rightarrow$-Grief Stages
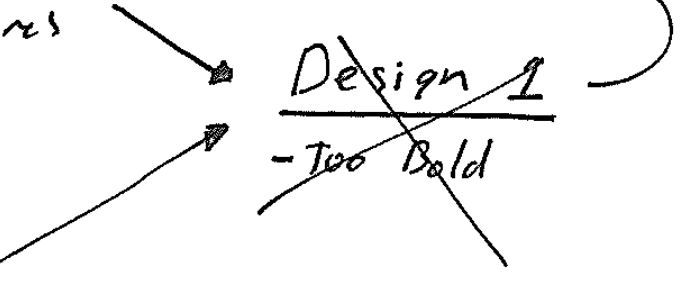

- Psychological

- Moments

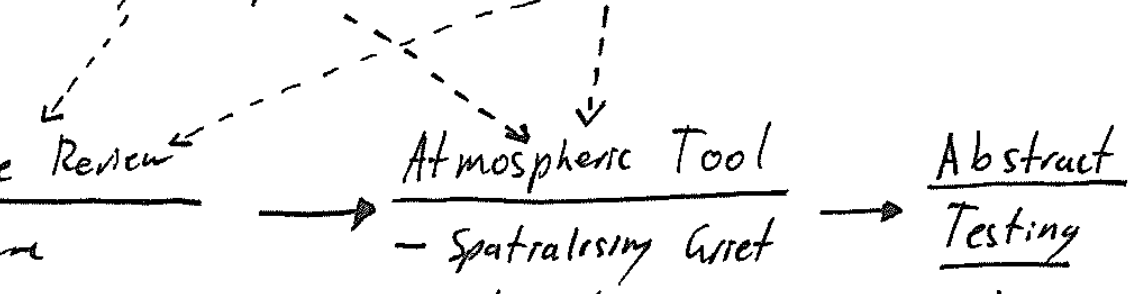
- networks.

Diagraming

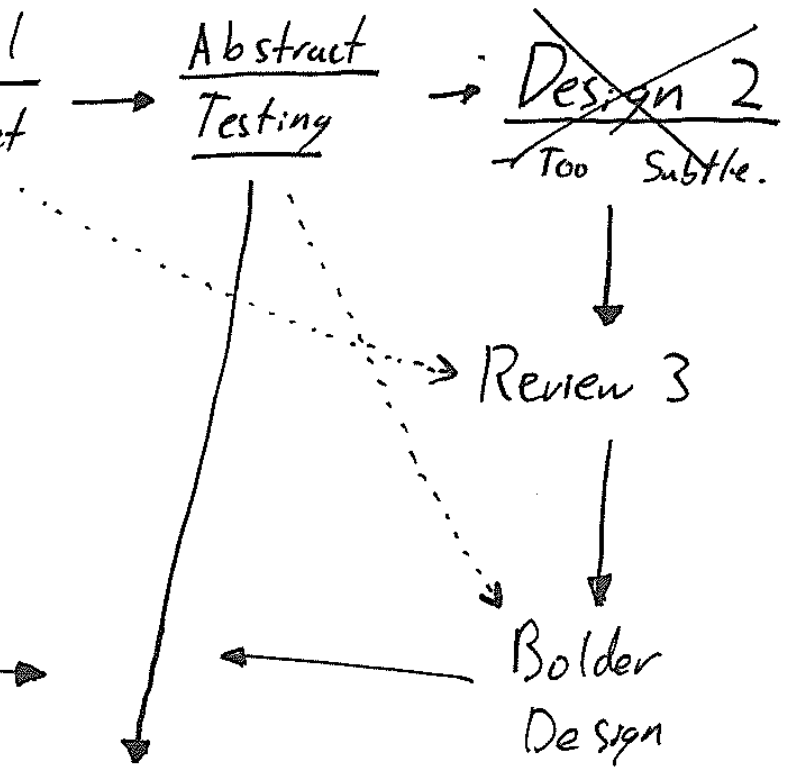

networks

$\gamma$

its Understanding

Design 3

13 


\section{Cemetery - Personal Grief.}

The cemetery is a personal space of grief. To those visiting, the connection to the space is lost in the mass of names and stones, but to those visiting there is a single name and stone that exist. Cemetery were an early focus in this project as, at the heart of it all, they are the spaces that can allow passage for a walker, while connecting intimately with those who need them. The downfall of the cemetery is that due to their practical and intimate nature, design is often simple and unengaging, to allow for a person to avoid distraction. Although these spaces are too bold and personal to fit into the everyday city they can be learnt from.

Igualada cemetery by Enric Miralles in Igulada, and the Woodland Cemetery by Erik Gunnar Asplund in Stockholm are examples of cemetery that design in a way to create a more atmospheric and general space. They use the spatial and emotional feeling that surrounds death and grief, and the implied sadness of a cemetery. These design use larger spaces to instill a sense of journey and recovery to metaphorically engage with the user, allowing for personal reflection to not only those visiting loved ones, but those who travel here for their own reflection. The use of vegetation, orthogonal design and materiality again creates a network of elements for the walker to engage with, rather than a larger monument or memorial. These networks of themes allow for a more personal engagement and use the surrounding atmosphere to their advantage.
'And ever has it been that love knows not its own depth until the hour of separation.'

- Kahlil Gibran 


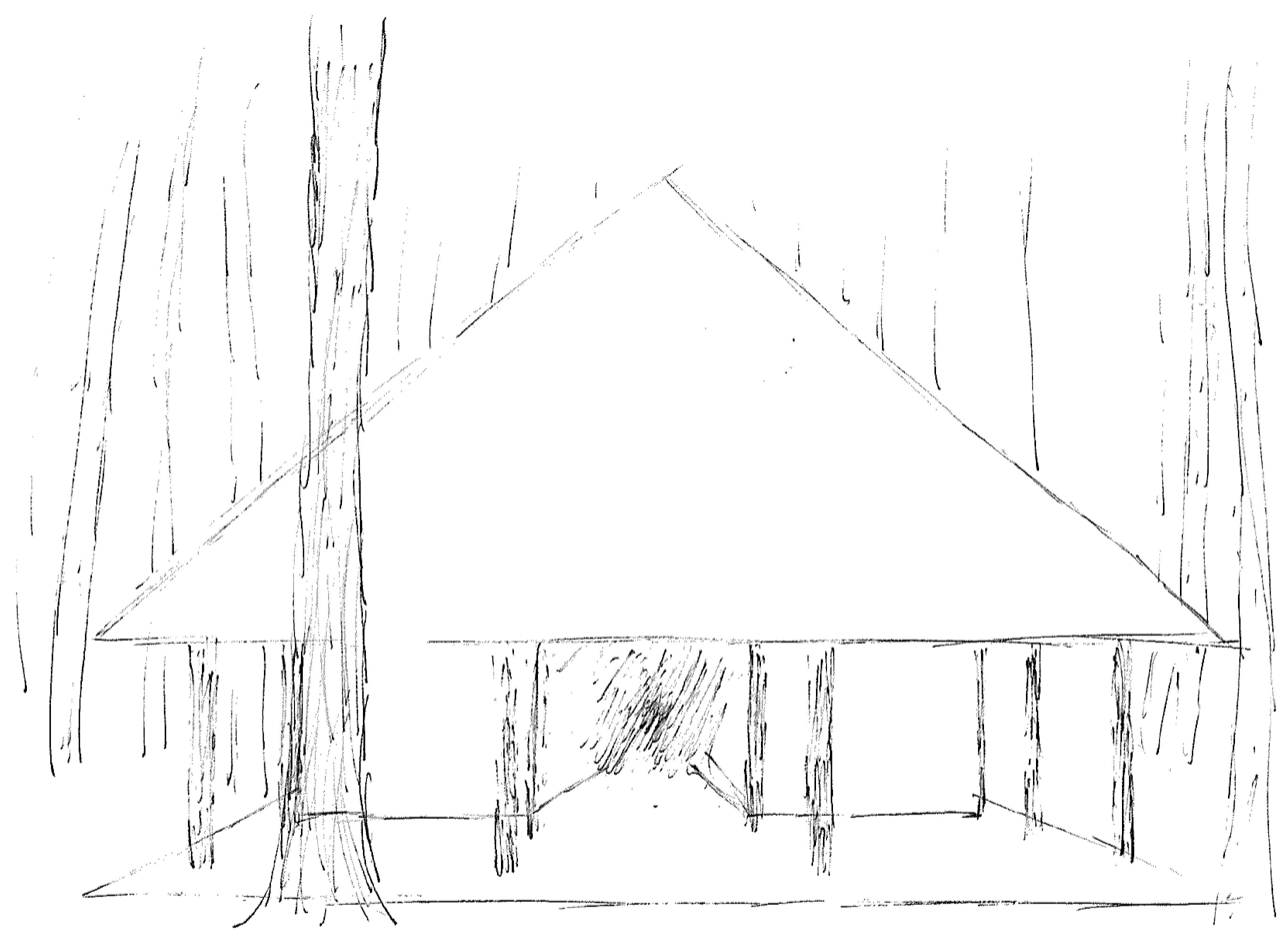

Figure 4 - Woodland cemetery sketch

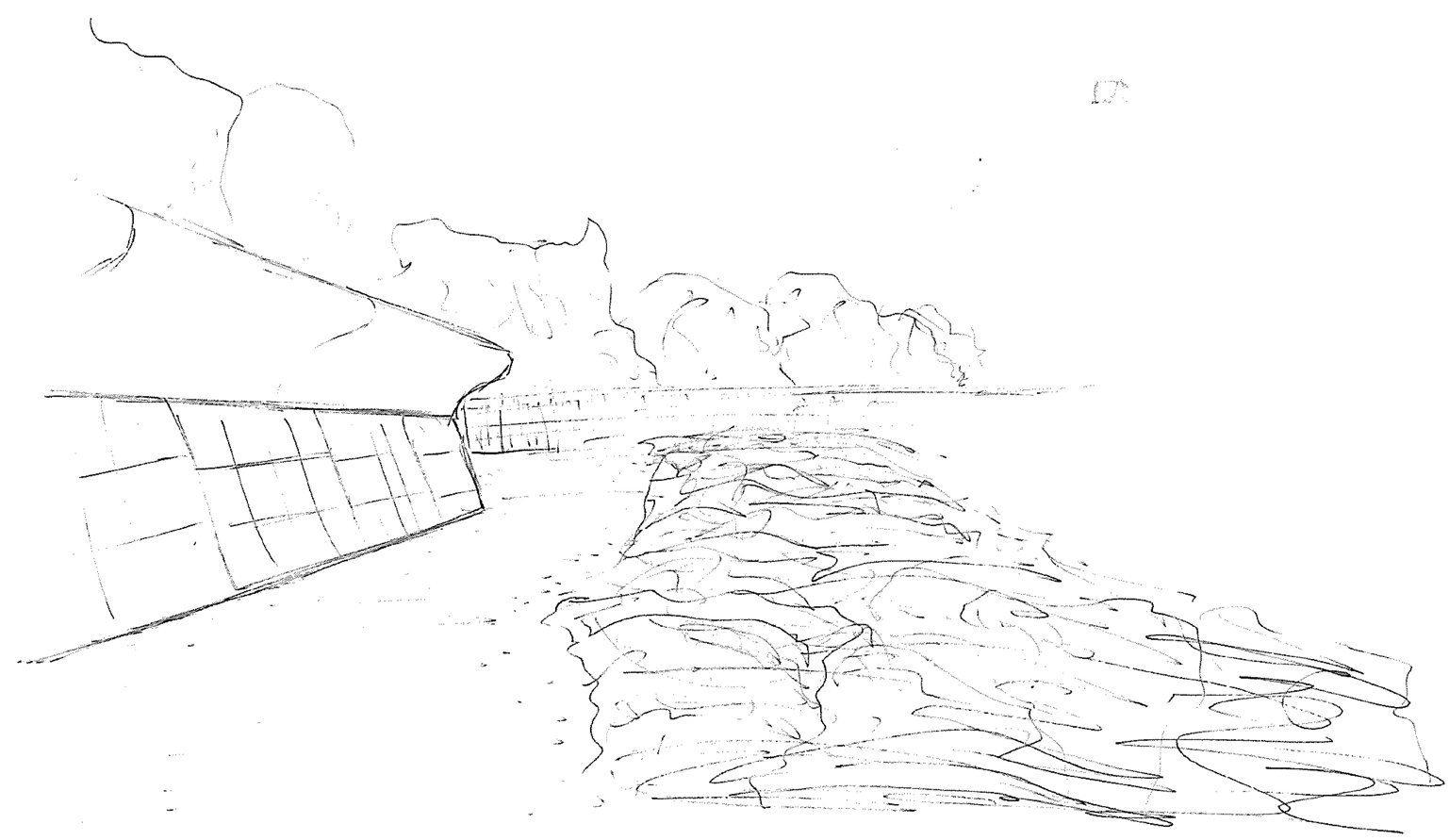

Figure 5 - Igualada cemetery sketch 


\section{Memorials - Reflective spaces.}

When reviewing how landscape architecture tends to design places of grief, it was important to find designs that could be learnt from, both in what to do and what could be taken further. It is important to note that the critique of these design is based in their design intentions. These designs were aimed to be large urban statements rather than engaging with the individual which leads to a less personally reflective design.

Reflective spaces are currently designed as memorial spaces. There has been a theme where each reflective space is dedicated to an event or specific grief, creating large monuments that impress the need to reflect. There is a place for these designs in the world, but what they lack is the engagement with the daily walker.

These monumental spaces dont allow for a person to reflect on their own life, and rather than creating the foundation for their own memories to inhabit, they create a large gesture to a tragedy. People are not given the opportunity to grieve or reflect in these spaces.

What's more is these spaces are relegated to the fringes of the city. Cemetery are locations that have to be driven to, and monuments are found in larger squares, separated from the city. This disconnect from daily life means these spaces are designed to impress on the user, not for the users own grief.

Memorial to the Murdered Jews of Europe ,by Buro Happold \& Peter Eisenman in Berlin, as well as Memorial to Victims of Violence in Mexico, by Gaeta Springall Architects in Mexico city are examples of memorial spaces and how they are designed today. These spaces are engaging and allow for a user to wander. In terms of memorial spaces these are good examples of how a space can allow for reflection while still impressing the symbolic grief the space was commissioned for. Although this design aims for a lighter touch, the use of materiality and juxtaposition are important when understanding the power of these sites. Orthogonal designs have strong connection to the built form of the city, and can be used in contrast to create a sense of reflection. In this case the design in mexico uses is orthogonal design to contrast the natural form, creating a sense of disconnection and distance from the oxidized forms, while the Berlin project creates comparison with the surrounding buildings, creating a deeper connection to the city and a more immersive design.

These designs use networks of symbolism to creates feelings and , rather than a single monument, create larger spaces for the user to engage with. This interactivity between user and space creates a more atmospheric and unique engagement with the design, allowing for a more enriching experience. They have this ability due to their larger size. When applying this knowledge to this design, the large size and bold gestures were substituted for a network of spaces that subtly intervene with a person life.

'All life is a process of connection and interaction.'

- Claire Colebrook 


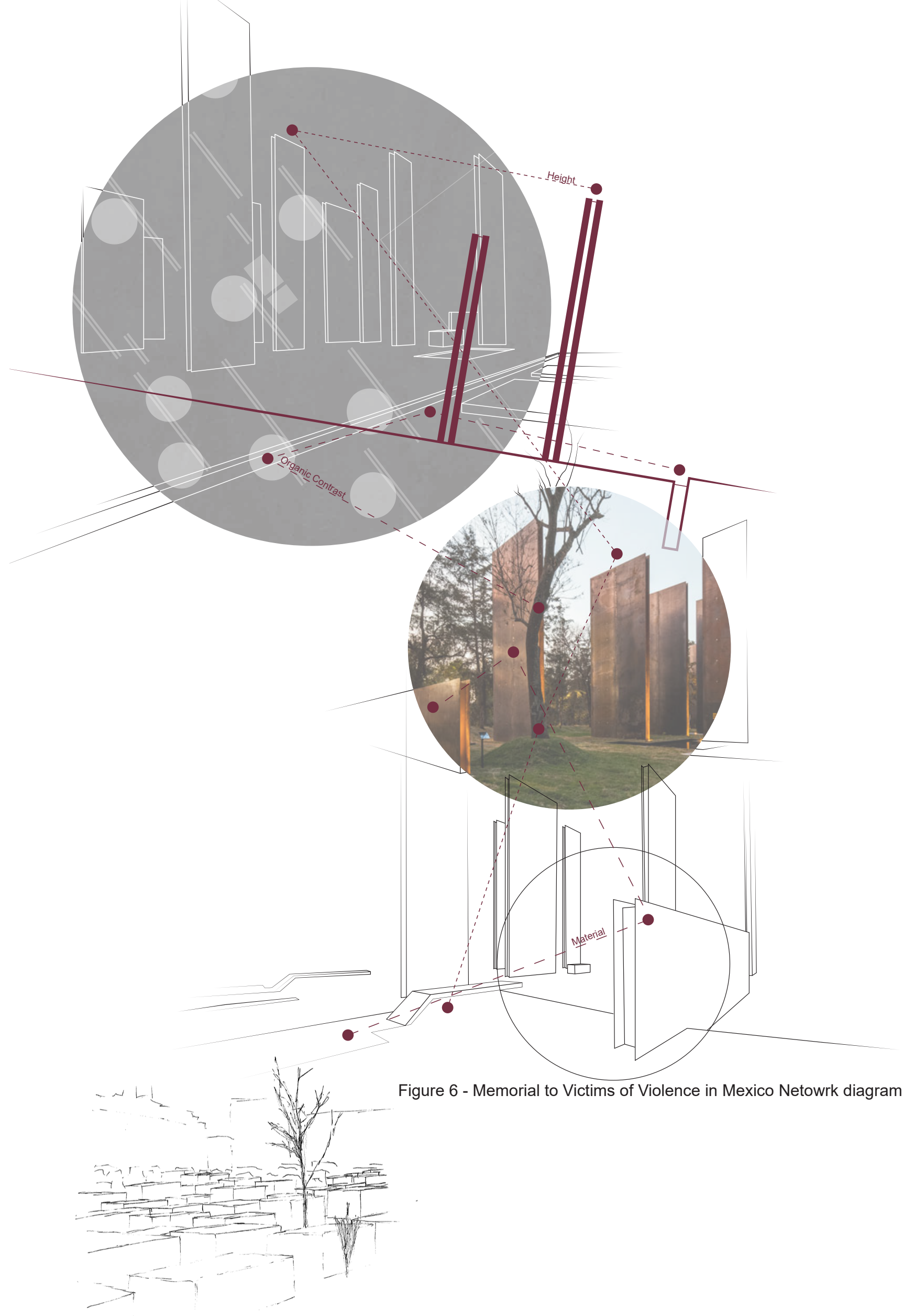

Figure 7 - Memorial to the murdered Jews of Europre sketch 


\section{Atmospheric urban spaces.}

The previous designs had larger space to be designed in, allowing them to have more elements to create an atmosphere, as well as more distance from the urban surroundings. This is part of why these spaces are relegated to the edges of the city, and are generally uninviting spaces. This projects aim for a network of smaller spaces and thus looked into urban spaces that have a strong engagement with those walking through small areas and how they achieve a shorter atmospheric connection. There are some similar trends as the above examples of work and this helps create a foundation for what makes a atmospheric and reflective space, and what the profession lacks.

Farum Midtpunkt by Ramboll Denmark A/S in Denmark, and Symantec Chengdu Campus by SWA Group in China are examples of spaces that use the small urban spaces they are given to create atmospheric spaces. Atmosphere is difficult to propagate in smaller areas because it is, at its core, an immersive thing. The longer one is submerged the stronger their connect to space and the more inspiration they draw on. When a person is allowed to ponder, they tend to impress themselves on the space more, so managing a strong connection in such a small space requires a strong use of the surroundings to create these atmospheric metaphors. With less space and less time spent within a design it means less engagement and intimacy with the user, creating a challenge in smaller designs to create an engaging and thick network of elements that can immerse the walker quickly. (Andersson 72, 74, 76-78)

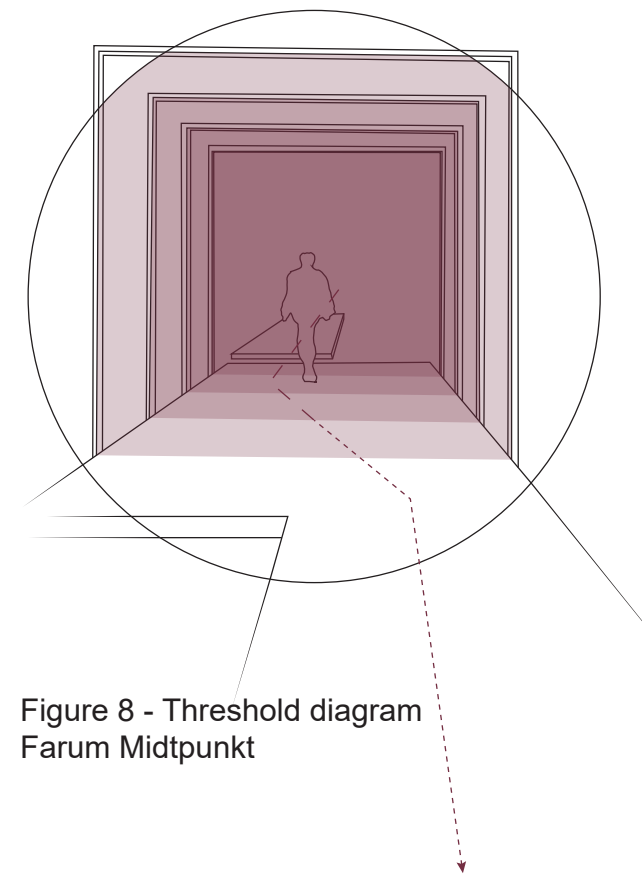

These spaces use internal means, such as angular paths and changing elevation, to create more variance and path within these smaller spaces. This is combined with spatial shifts throughout the space to create the sense of journey which elongates the site experience and allows for a stronger connection to the space. These 'shifts' throughout create small moments where the design presents a new collection of parts for the walker to relate to.

These spaces also use networks of themes and parts to create a feeling, using the surrounding building facades to add to or juxtaposed the site. These small and intense networks allow for more engaging relationships to site

This aesthetic engages all the senses, not just sight, but sound, smell, touch, and taste as well. This aesthetic includes both the making of things and places and the sensing, using, and contemplating of them.'

- Elizabeth K. Meyer (121) 


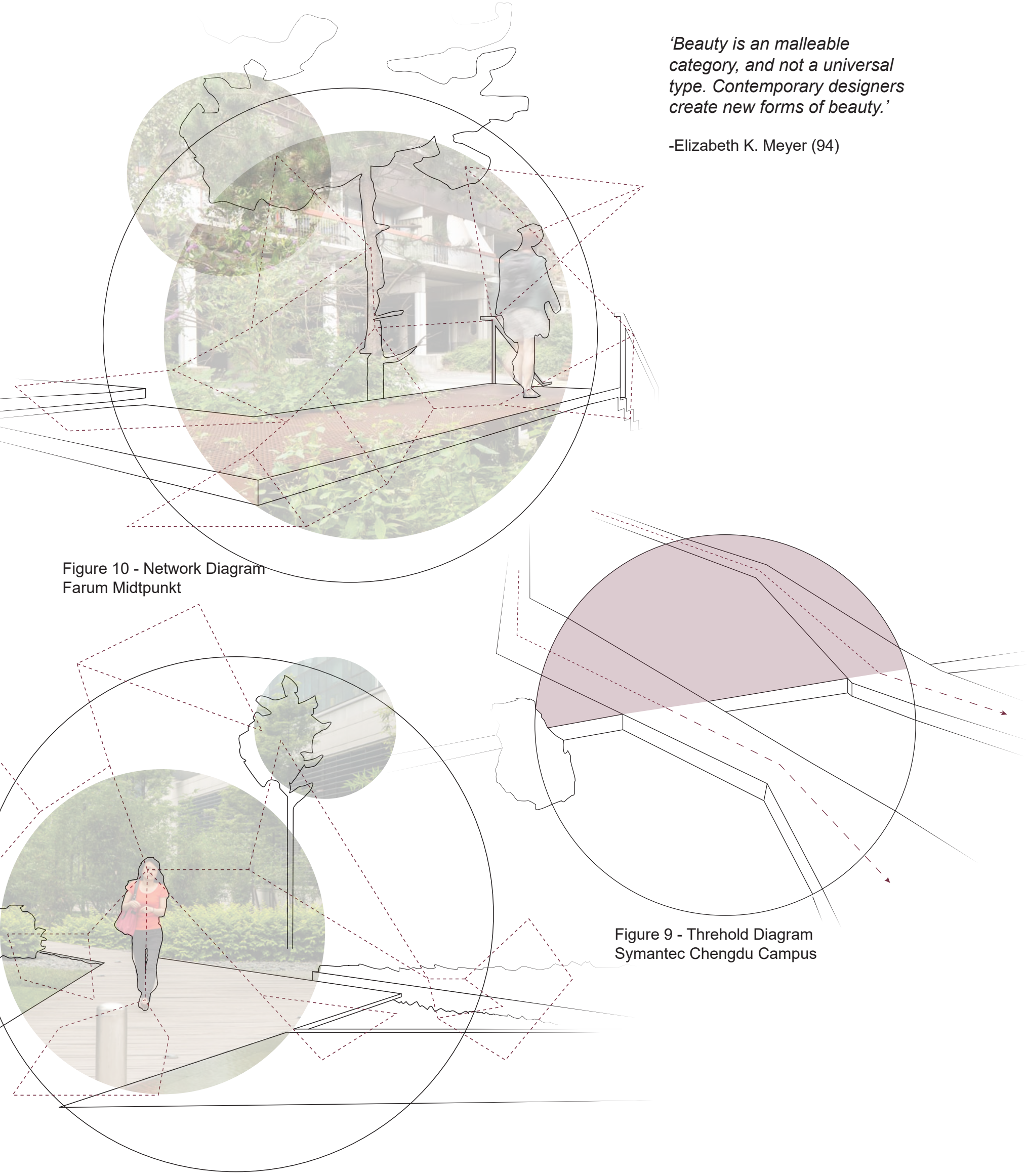

Figure 11 - Network diagram Symantec Chengdu Campus 
This projects aim was to take the important features of these spatial typologies to create a small, reflective, engaging and atmospheric space within the city. Using the key elements of these different design types allowed this project to make up for the issues of these types of designs. Creating a network of smaller ideas for a person to connect to will allow for a more intimate relationship to the space designed.

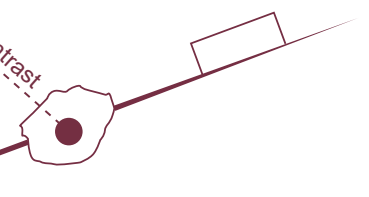

This investigation into these smaller spaces has lead to an understanding and discovery of the subtlety of atmospheric design and the importance of utilization of space to allow for an intimate engagement with the atmospheric network.

Figure 12 - Multilevel spatial analysis network Symantec Chengdu Campus 


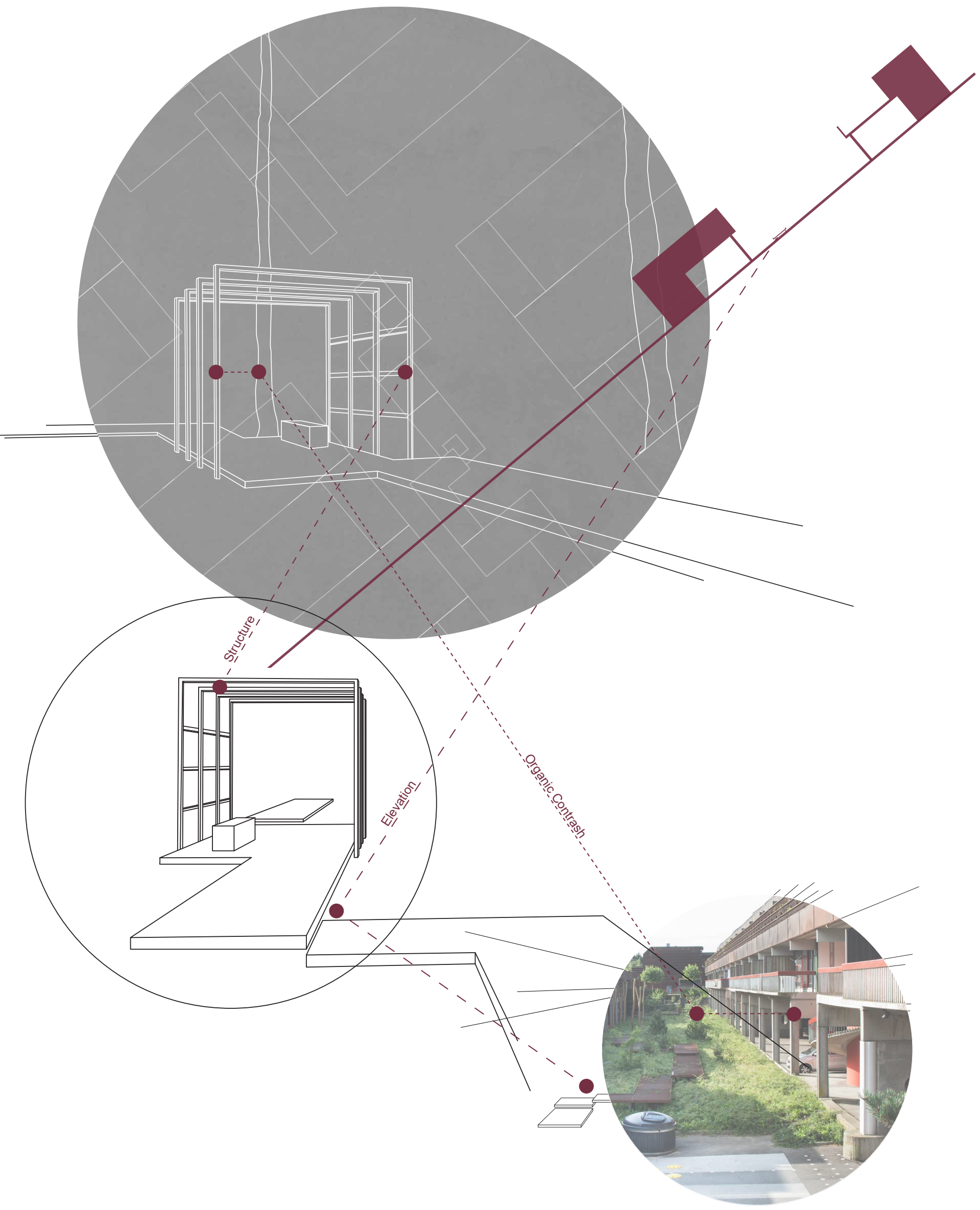

Figure 13 - Multilevel spatial analysis network Farum Midtpunkt 


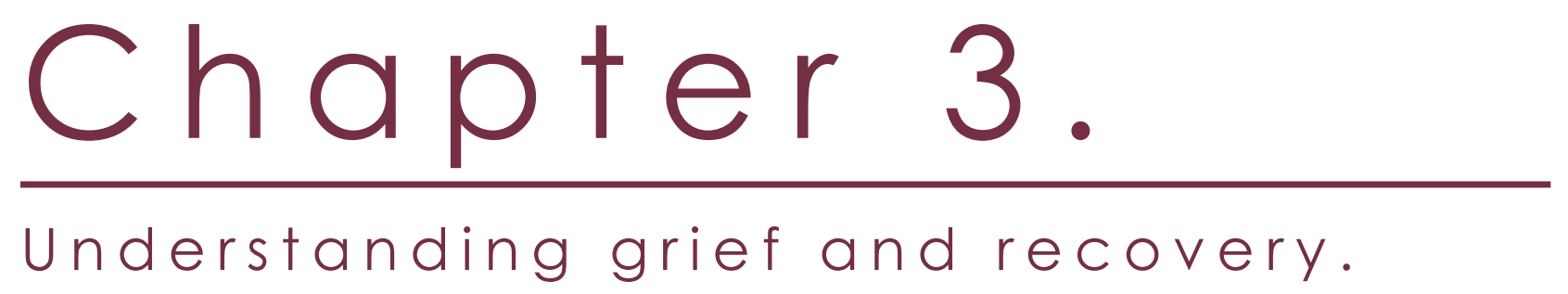

How can design engage with and impact on a person's grief? 
This section focuses on a series of investigations into grief and recovery. It looks into a variety of literature and produces tools to not only understand the process and recovery of grief but also how to utilize it indesign

"Mourning constitutes the soil from which the enjoyment of life springs."

- Bruce Vaughn (40)

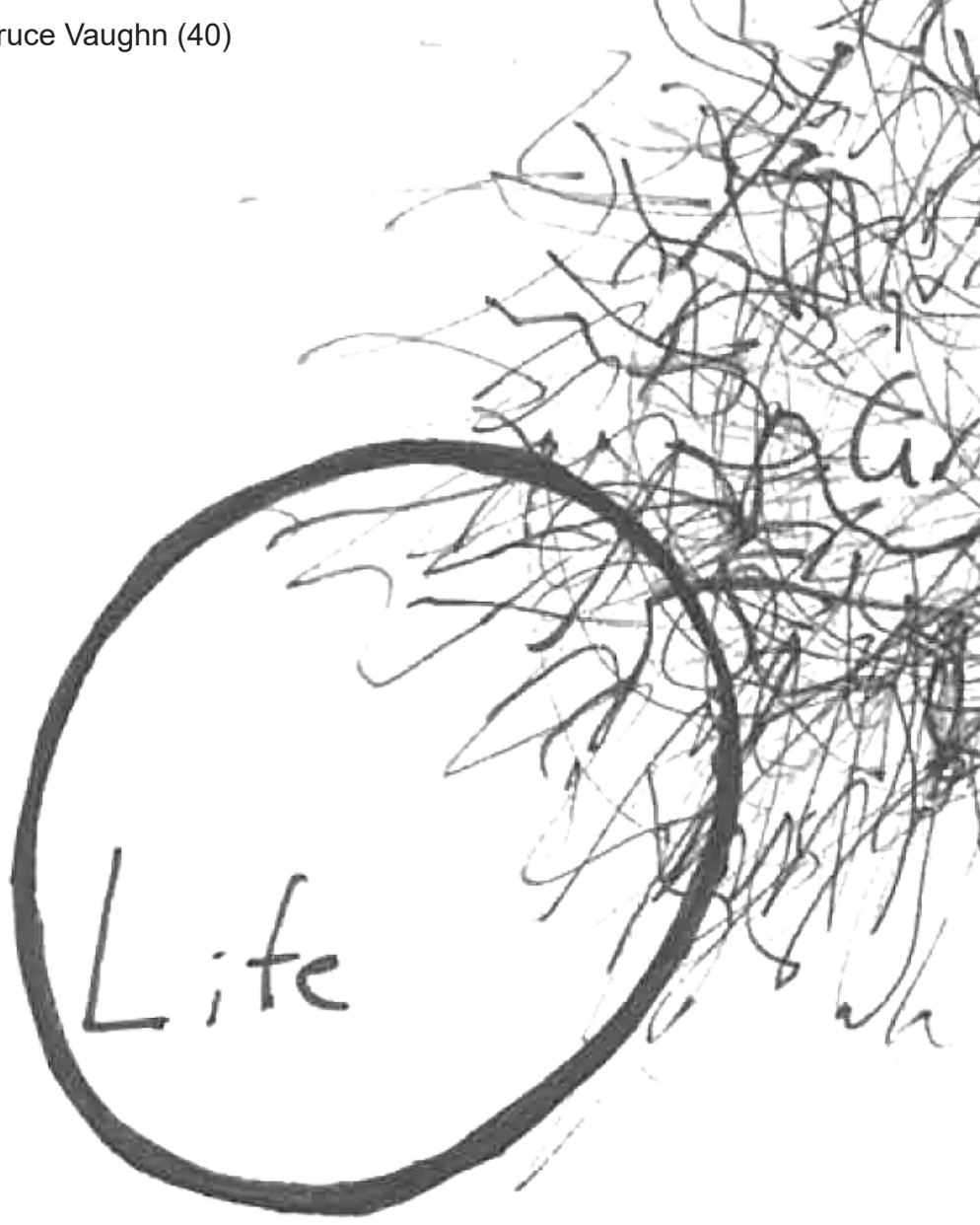

Figure 14 - Drawing

Life and grief relationship interpretation

Grief is a broad term for the state a person finds themselves after a loss, whether it be great or small. This can range from the personal loss of a friend or family member, to the loss of public space in the city (Down 18). Grief is natural, and one of the most universal feelings there is, and it is healthy. The modern city is not built to accommodate grief, it suppresses it. Grief can create an opening to a new perspective on the world, if experienced in a healthy way.

The multidimensionality and complexity of grief makes it difficult to design with. It is hard to understand and is rooted in personal experience. This unique and turbulent quality does not lend itself to design due to

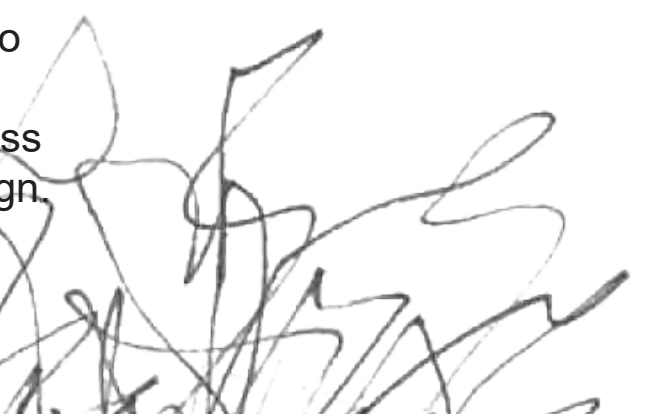
(iet

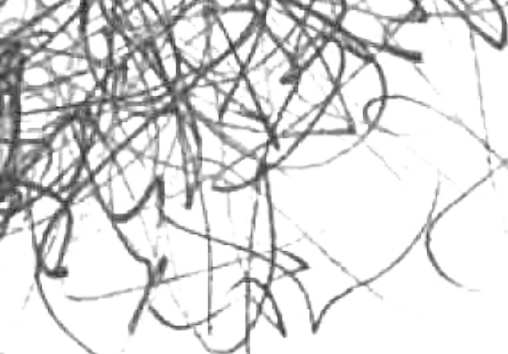
the more rigorous and grounded reality of design, there for to both understand and use grief a series of tools would be produced through thorough investigation. (Hyrlas, Kaunonen, Paunonen 775-779) .Grief can be used to create one of the most intimate relationships with space through positive reflection, but can also alter the perspective of a space in a negative way so would have to be understood fully to incoorperate into a design. (Vaughn 4045) (Hyrlas, Kaunonen, Paunonen 778) 
Firstly, this investigation starts with an attempt to understand the broad human psyche to produce process that can be applied to a design. It looks into personal accounts and group studies from different cultures and religions to find a series of connections that a design can be based off.
"The grief started before she'd gone."”

- Jennifer down (17)
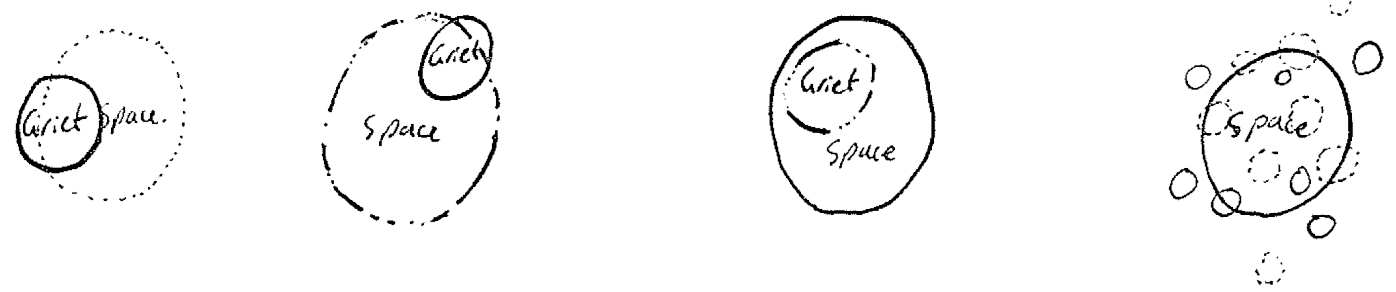

Figure 15 - Drawing

Eveolution of relationship between space and grief from the grievers perspective

The second section begins to narrow scope, finding the useful and clear information that can inform design. This sections looks into more clinical and psychological studies of the grieving process to create a sense of stages and moment people shift through. This produced two important tools to support the design inquiry; The four mental shifts or 'stages' a person makes throughout their grief journey, and the various elements or 'moments' that a person reacts to positively at these stages. These were distilled through a variety of literature investigation and were named to give each stage a design focus and meaning.

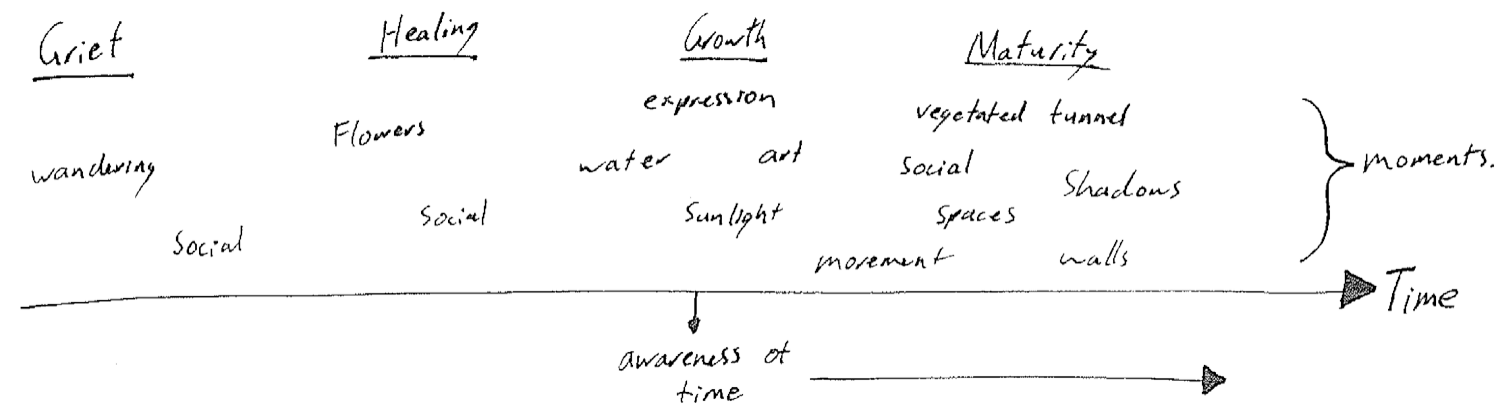

Figure 16 - Drawing

Moments and stages of grief 
Thirdly this project analyses atmosphere in design and the various elements that can be manipulated to create a strong or more specific atmosphere. This is used to connect grief to design and creates design counterparts to to the 'moments' and 'stages'.

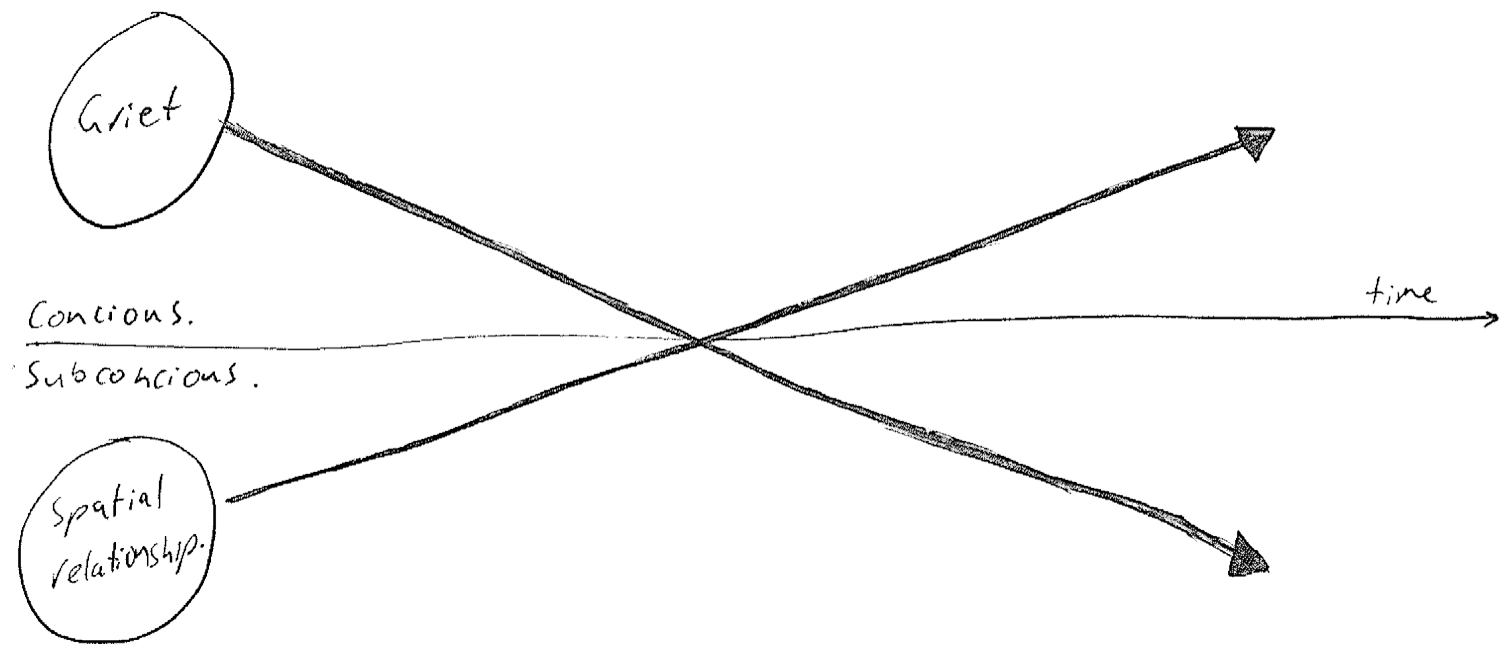

Figure 16 - Drawing

Concious and subconcious shifts of spacetial relationship and grief - Grievers perspective

Finally this chapter takes the connection between atmosphere and grief and applies it to design, testing in an abstract space. This section focuses on creating a series of typological design elements that can be incorporated in the site applied design.

'According to various studies, there is no time schedule for recovery nor any single way to grieve. As a unique individual, each person may experience the grieving process in a different fashion.'

- Kristiina Hyrkäs (777) 


\section{Cultural investigation.}

This review of literature began with a study into cultures, focusing at first on studies of each groups grieving traditions, and finishing with personal and first hand accounts of a person's journey through grief.

The findings of this literature review promoted a scope adjustment was required in this project as the goal was to distill a large group of cultures and stories into a universally applicable set of stages.

The information gathered was not useless, but was not concrete enough to create a foundation for a real design. There were moments and shifts that linked the readings and helped inform the next investigation, as well as parts of the design.

This investigation showed the challenges of working with such an intangible element as grief. The individuality and pure uniqueness of it meant that any understanding of it would have to be formed through a strategic, precise and rigorous investigation within the particular situation i am composing, rather than seeking and claiming any such thing as universal norms. .
Grieving has been described as timeless.

- Kristiina Hyrkäs (775) 
After discovering the difficulties of first hand accounts that are muddied with inaccuracies, personal details and hyperbole, it was clear that a more clinical and psychological study was needed.

These medical and psychological studies strip back the personal content of grief, removing all the details and find the fundamental shifts a human goes through. These studies were focused more on the broad development of people and, most importantly, how to aid them.

The misconception with grief is that it is a negative impact on our lives when in reality it can become a tool for bettering a person's life and perspective (Vaughn). It can create a new, enriched relationship with the world and allow a person to find more meaning in their surroundings. (Dellasega)

This is not to say that grief isn't a hostile force. It is volatile and with its potential to enrich a person's life comes the possibility of it having a negative impact (Vaughn).

The ones relationship with grief is adversarial at first, but through a healthy recovery process grief can transition into a friendly companion, retelling and mentioning good times and stories(Vaughn). This is done through 'positive reflection' which engages the more positive side of memory and allows for a fond remembrance. The idea is not to cling to loss but to embrace the life that was (Wilson). Those who cling to life, along with those who reject it have the threat of becoming resentful and jaded, while those who embrace it can open new avenues of appreciation of both life, and beauty (Vaughn).

Positive reflection is represented in 'moment'. Small instances when something sparks a story or memory. A smell, sound, view..etc can all lead to positive reflection (Hyrkäs). Throughout the city there are opportunities for these sparks but for them to catch alight and truly affect a person require a space that allows for it. The city demands attention with cars, people and shortcuts and to truly be able to internalise and positively reflect one must be allowed to by the space. (Vaughn) (Andersson).
These 'Moments' were similarities throughout the different readings which marked ways people can positively reflect through the world. They are small feelings or shifts that can be spatial or sensory that help a person reflect (Dellasega). Mobilising these moments in the design process was a key motivation for my inquiry. These were used as tools to make sure the end design would be able to engage with the user. The goal of these tools are to create spatial elements that can create a network of parts that have the potential to spark positive reflect, while the space allows for it to catch.

'Man, when he does not grieve, hardly exists. "

- Antonio Porchia (85) 


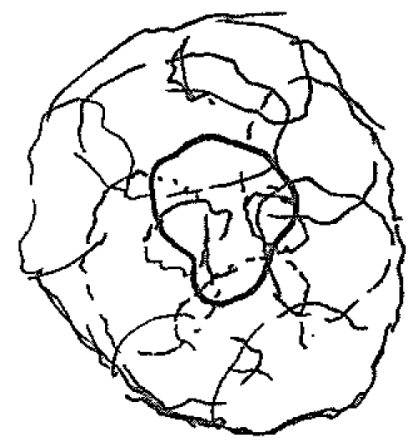

Atmosphere

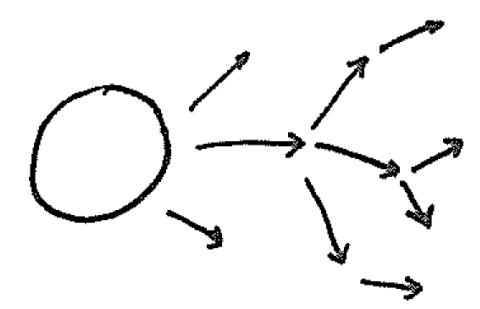

Change

internal
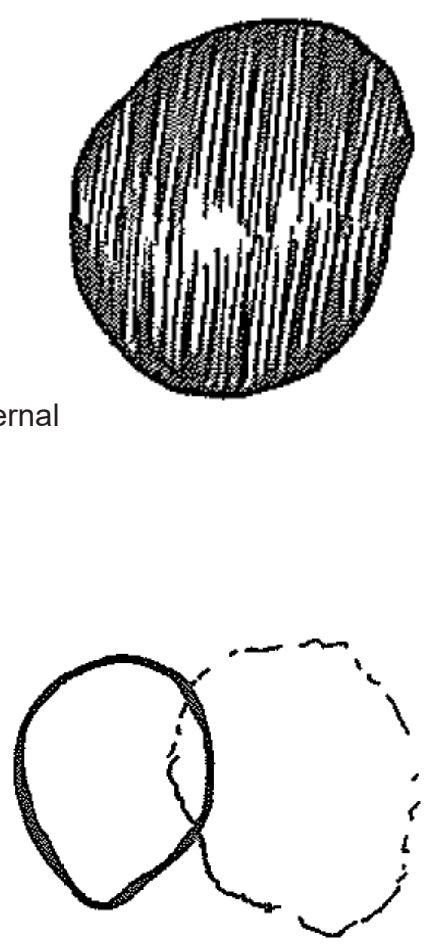

Outerlife

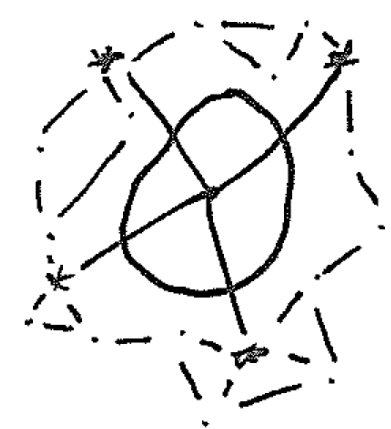

Beauty

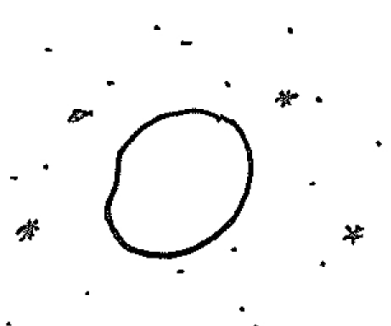

Detail

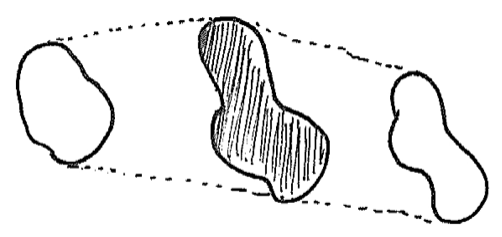

Expression

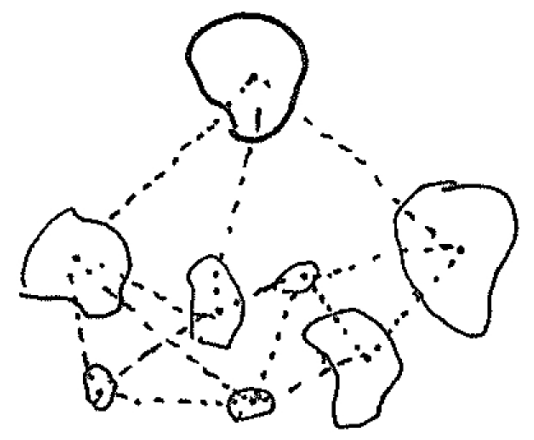

Social

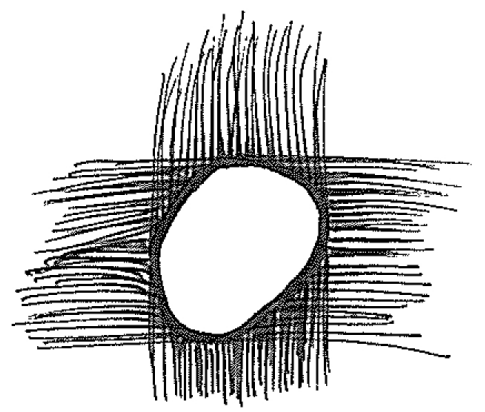

Dilluted solitude

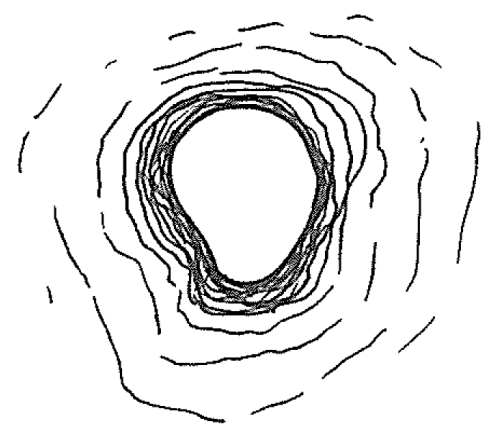

Disconnection

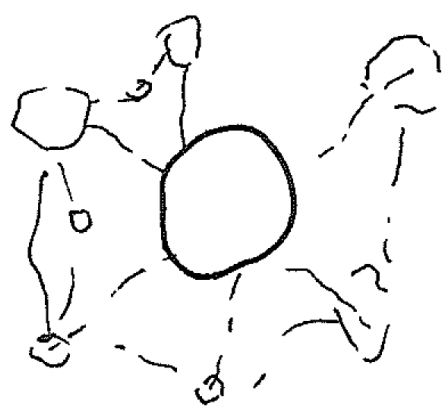

Notions of life

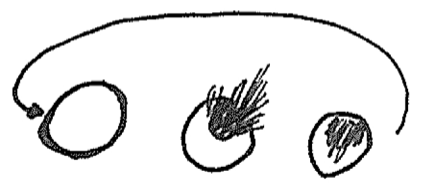




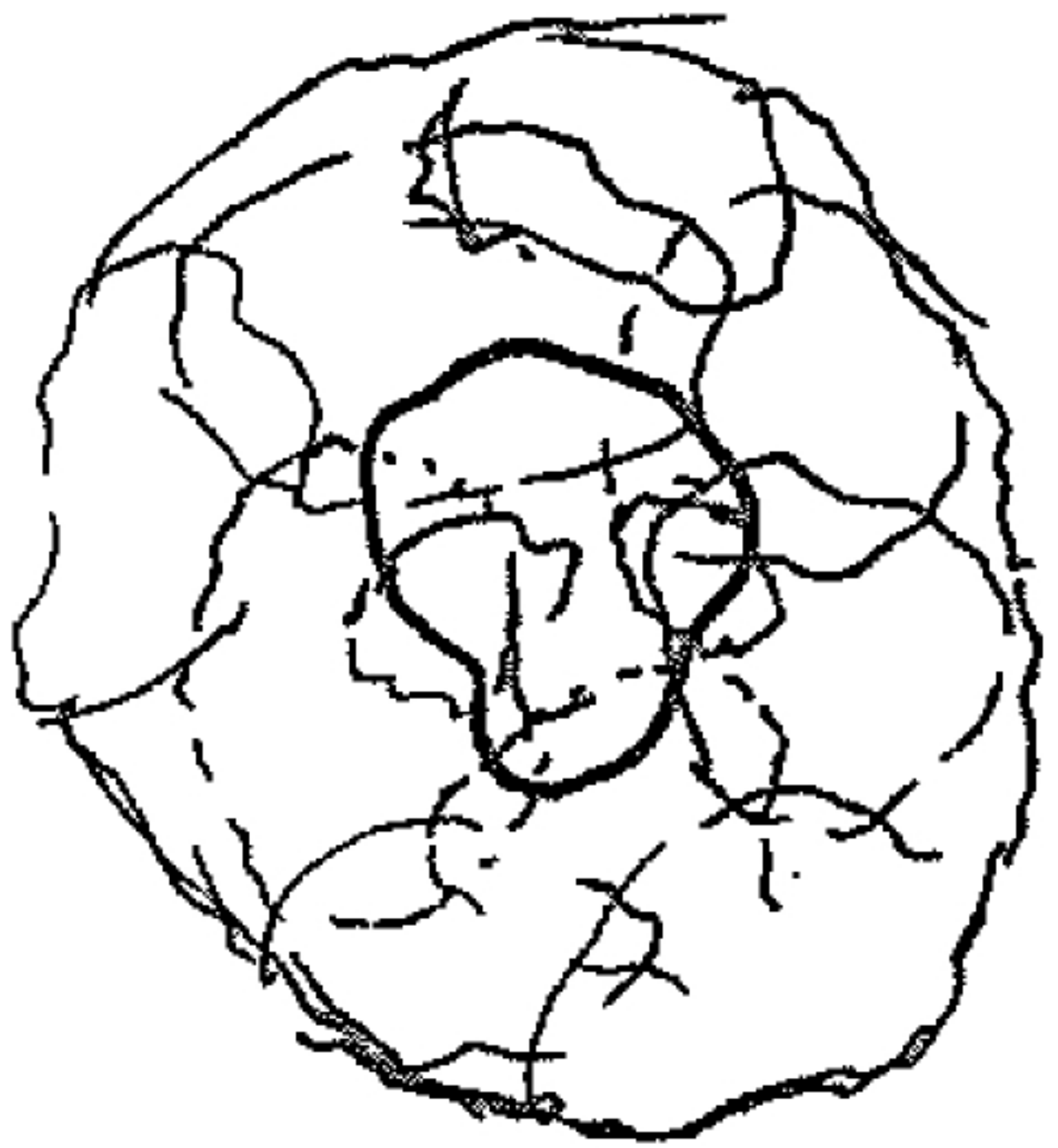

Atmosphere is the

interlocking of different elements. The meeting points of sensory

elements allows the body to interpret atmosphere as a feeling that transcends conventional senses. 


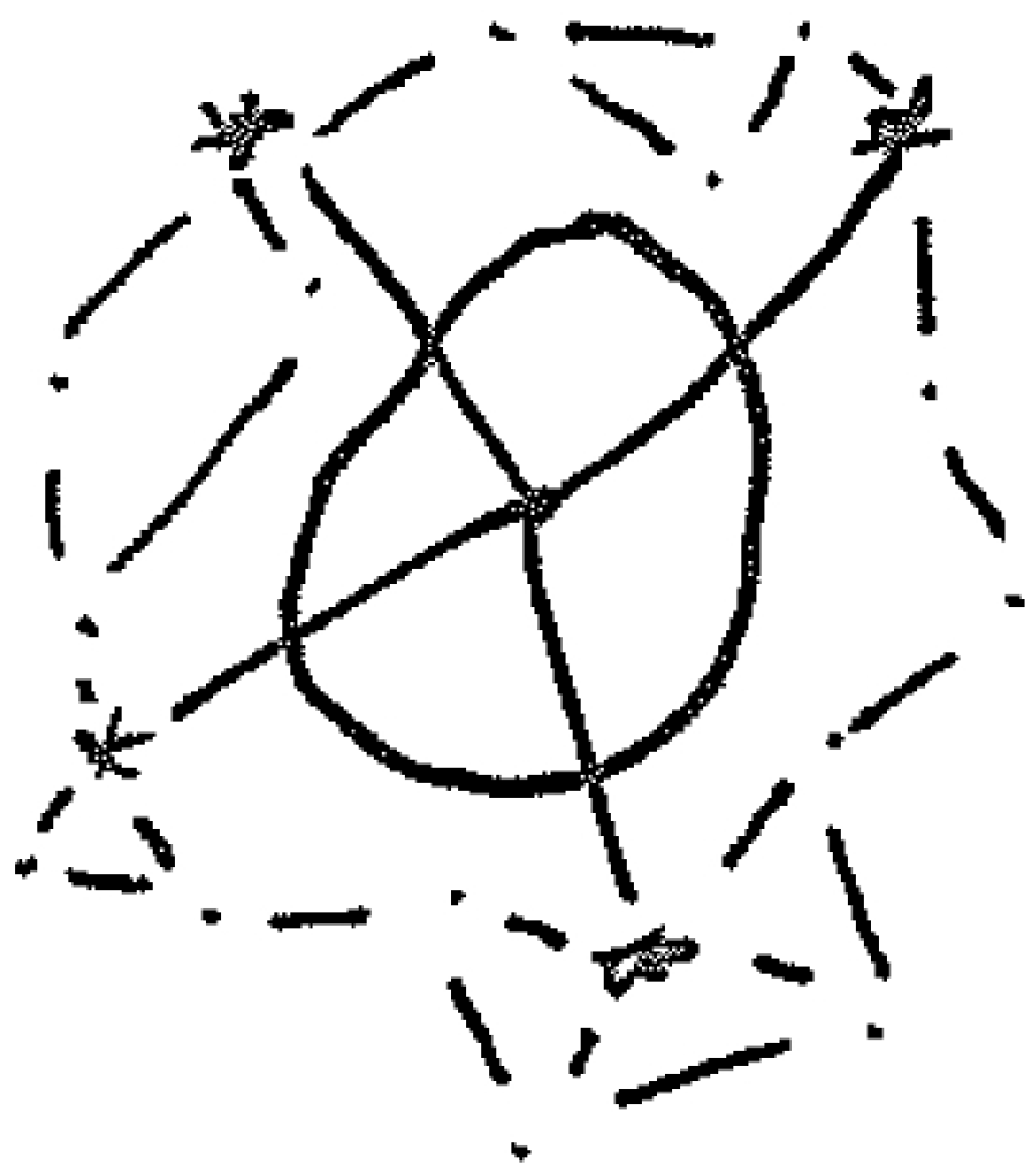

Beauty is how an

individual perceives

networks and the

elements that make each network. 


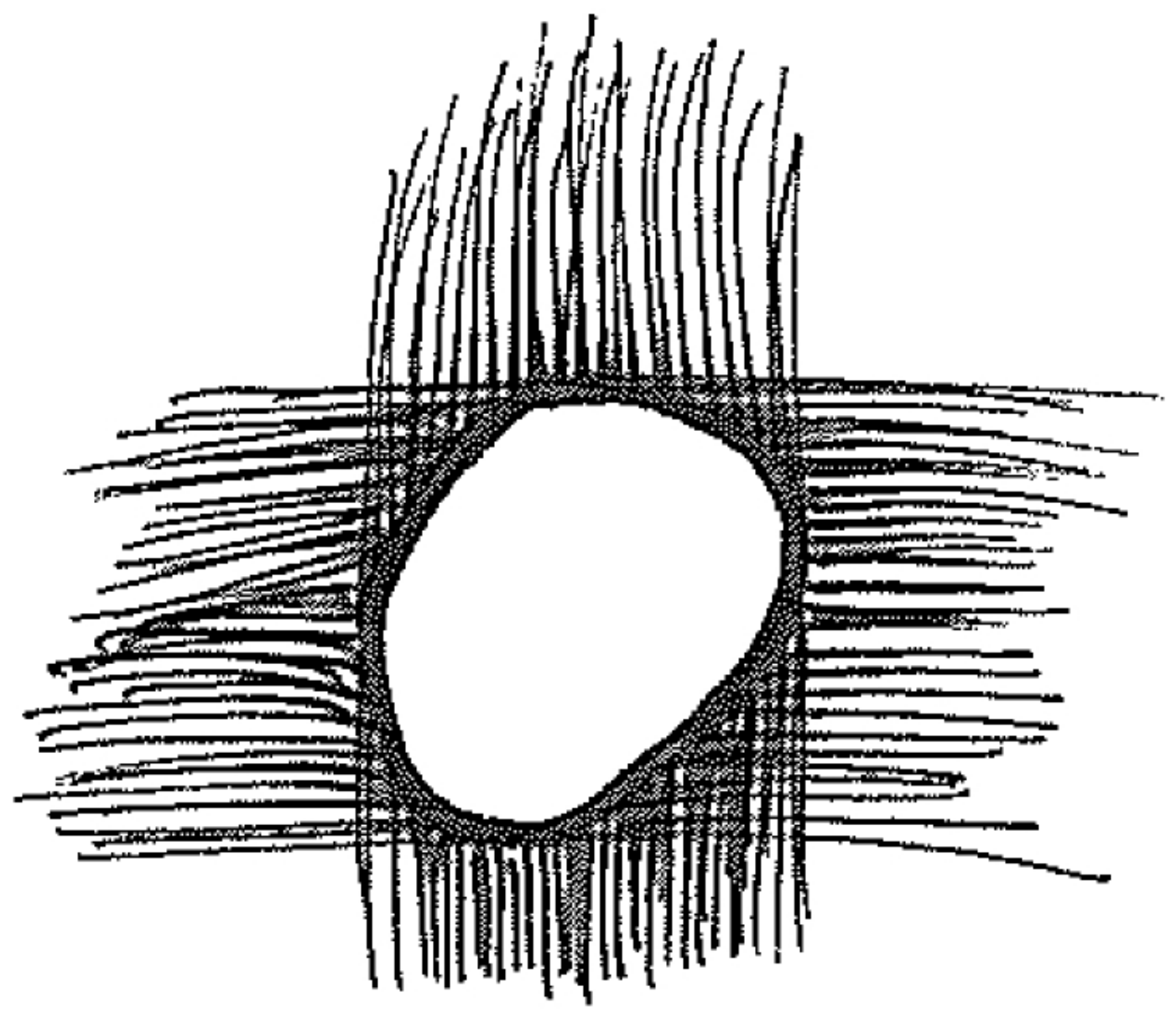

Diluted solitude is the notion of an individual in seclusion understanding the various elements of life and movement around them. 


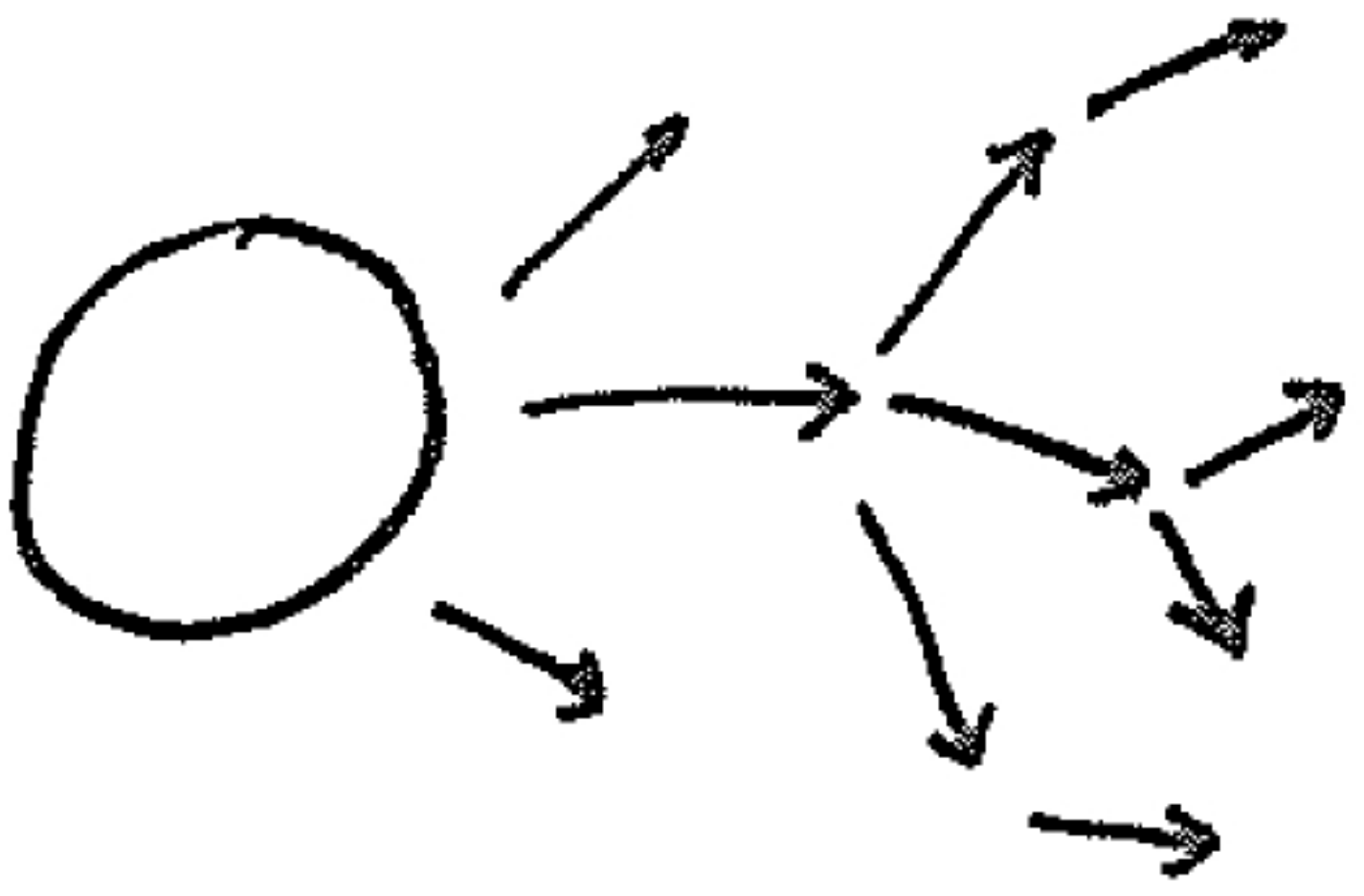

Change is the natural progression of life. The movement of life is not a line but a series of intersections that shapes future choices. 

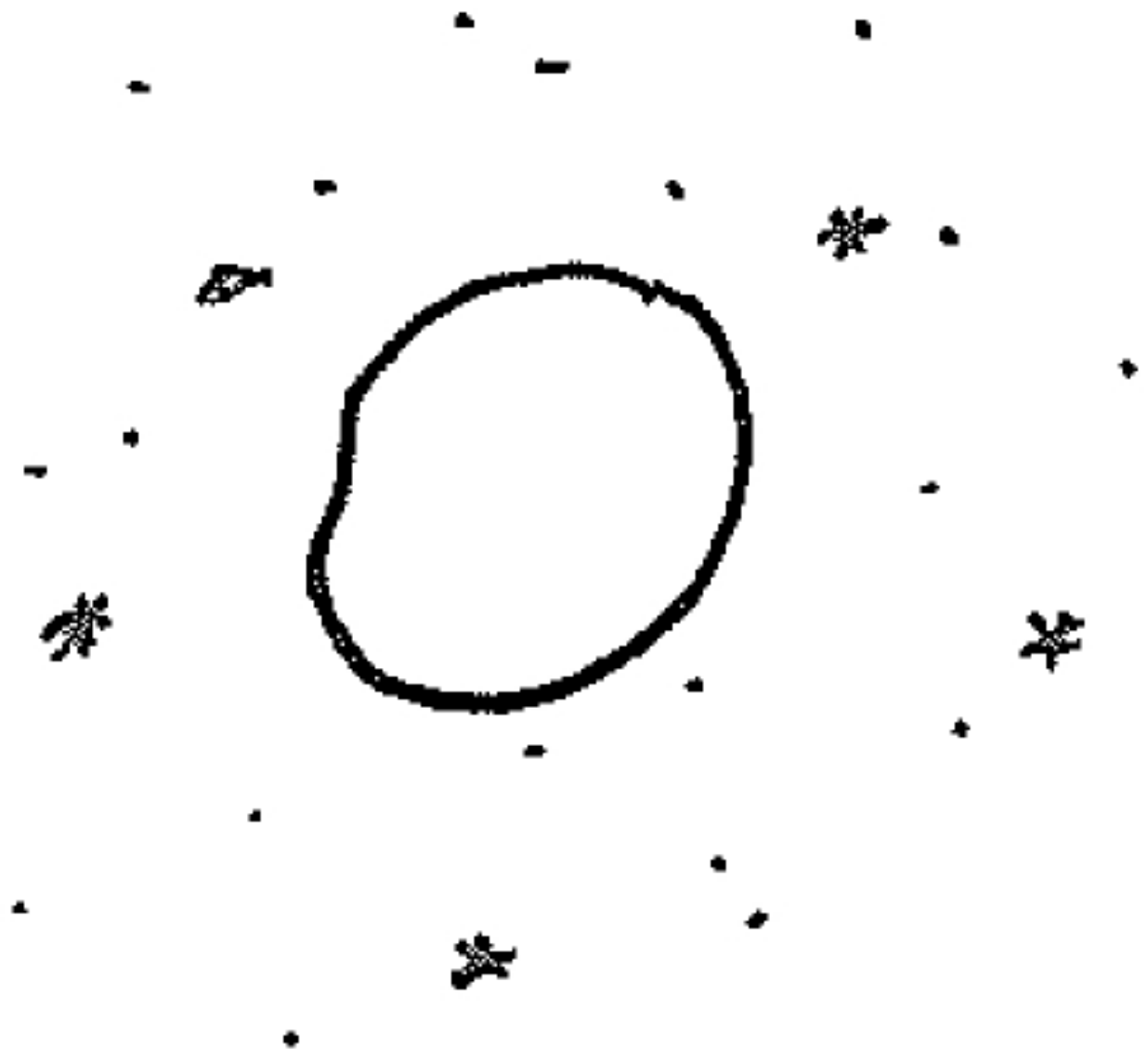

Detail is what gives life a personal scale. Without it human scale would not exist and the world would lack substance and texture. It is important when engaging with individuals. 


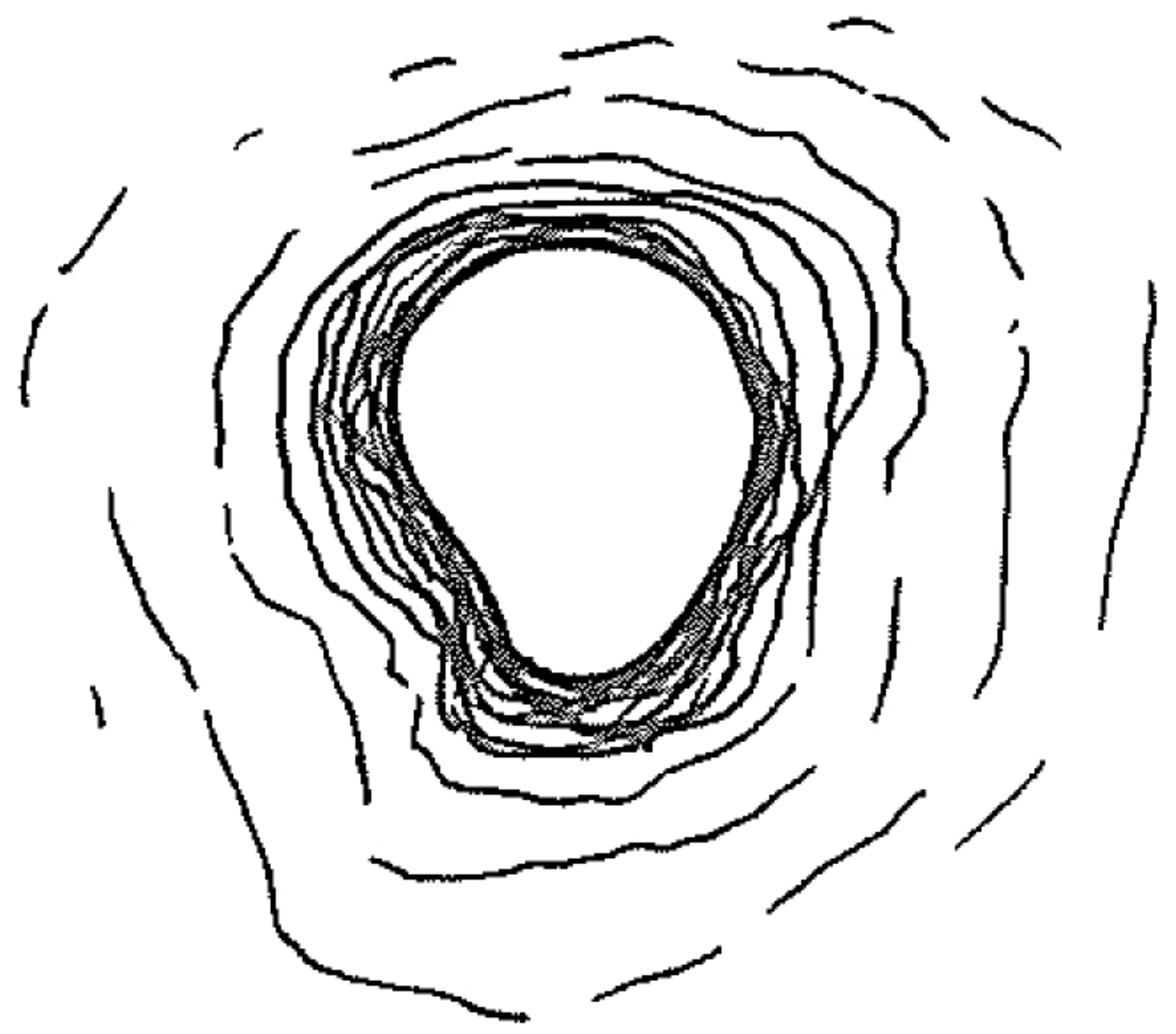

Disconnection is mental distance. It can be felt during conversation or in a social group. It is usually a negative feeling but can be healthy when used for self reflection. 


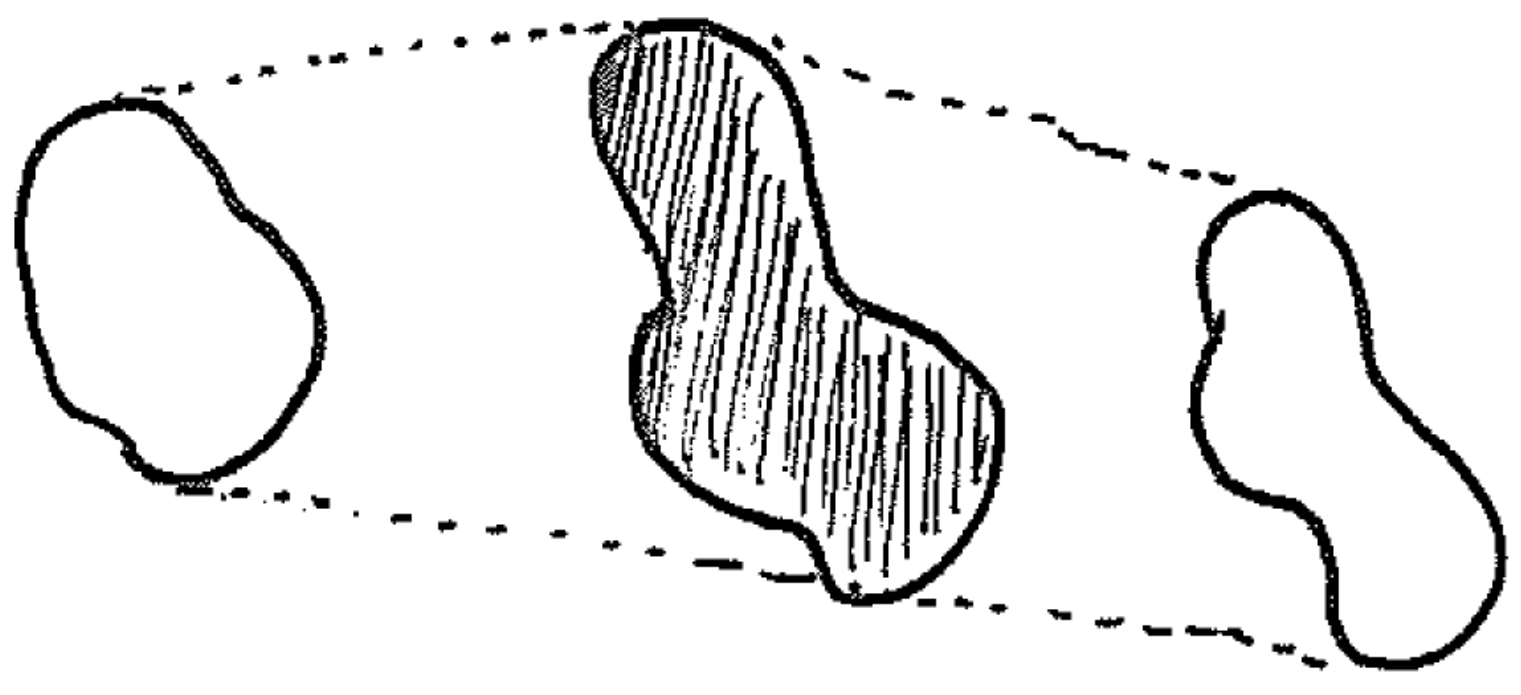

Expression is how an individual interprets and self reflects through an object. It is personal and each person perception of an expression element will be different and personal. 


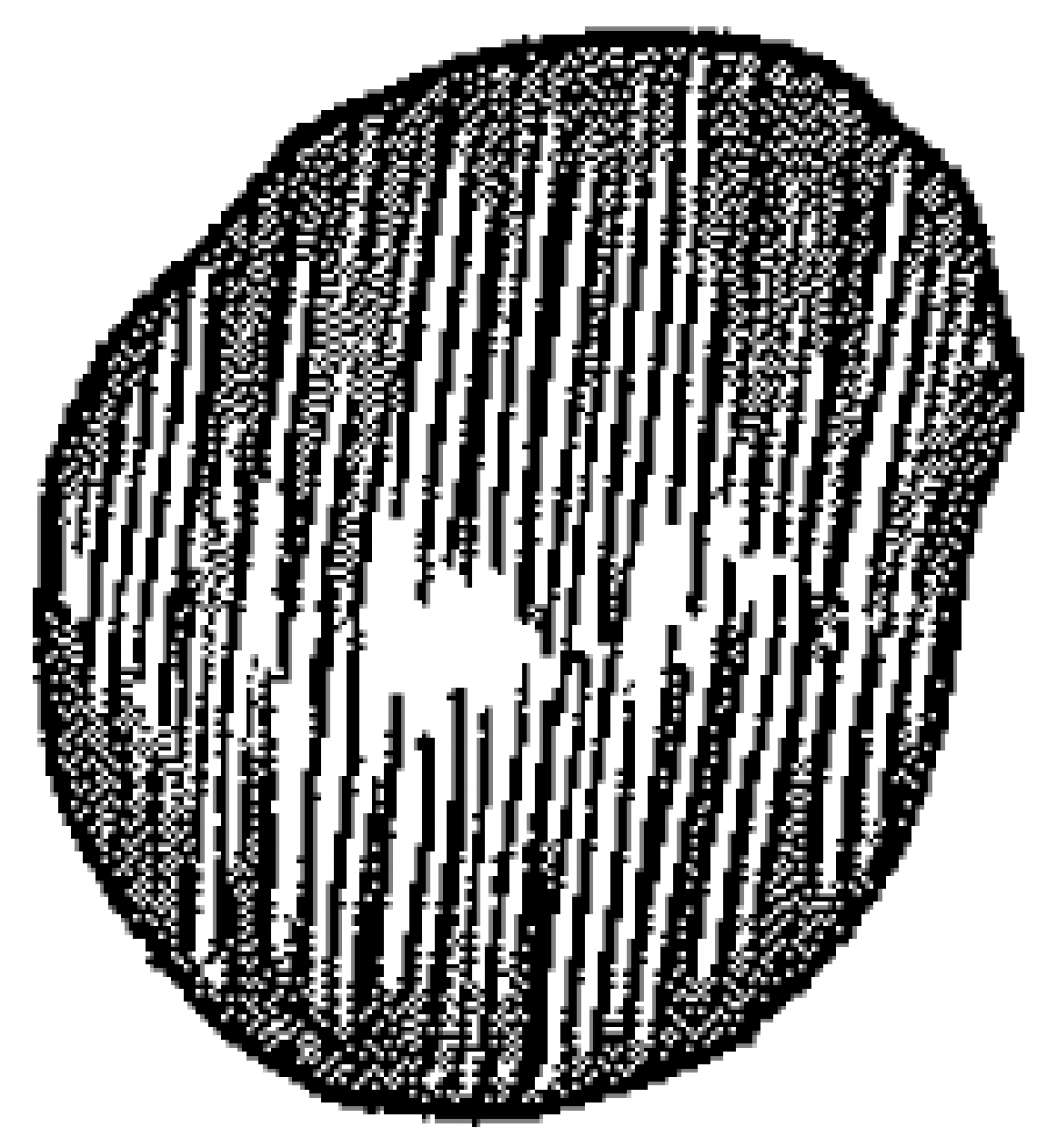

Internal or internal through is the ability and action of examining one's self. Usually negative due to the lens individuals tend to apply to themselves, but can be a healthy tool. 


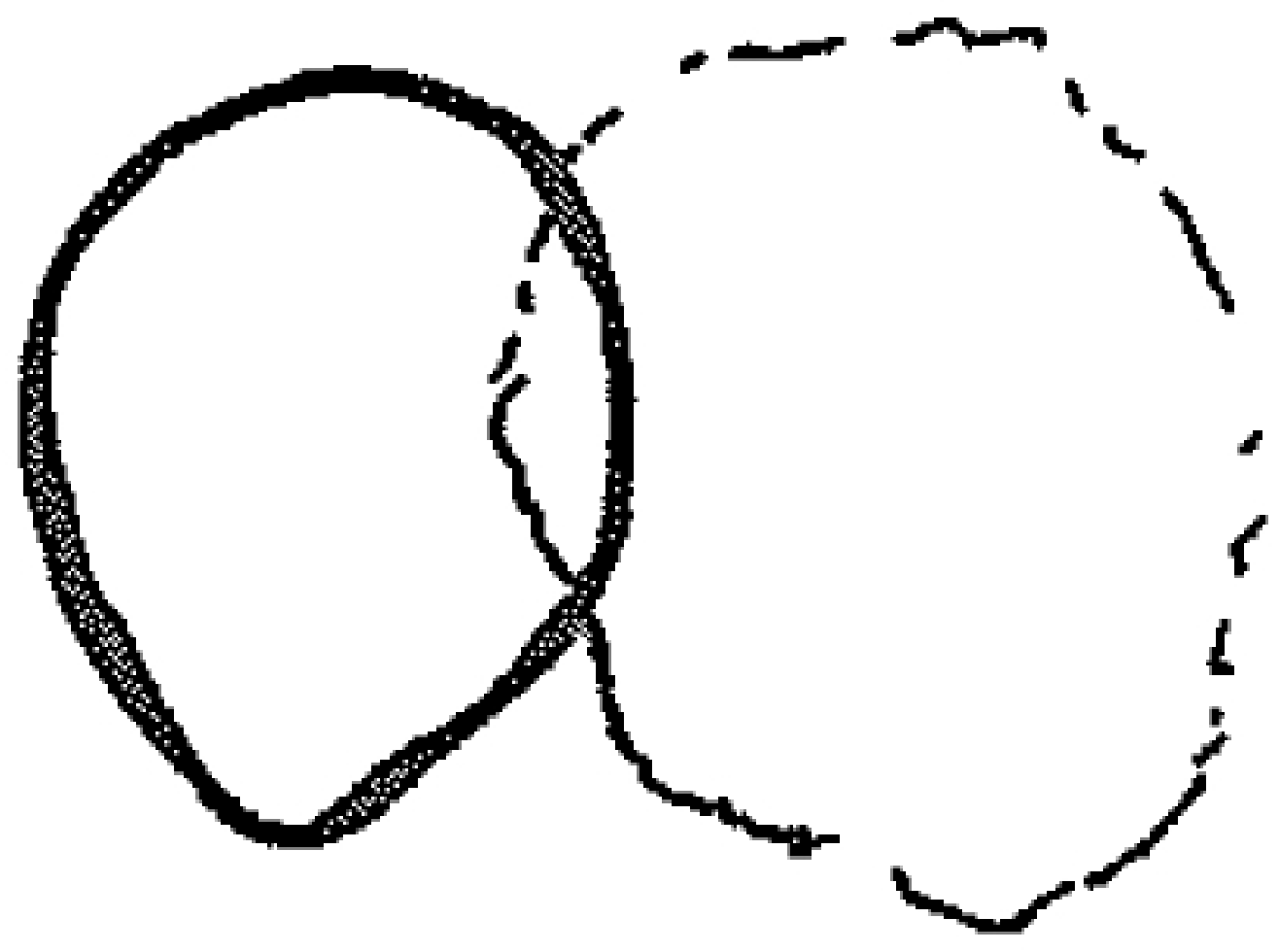

Notions of life is not the interaction between living networks but the implication of their existence. The tracks left by people, the rustling of leaves implying bird life or the distant sound of what could be footsteps. 


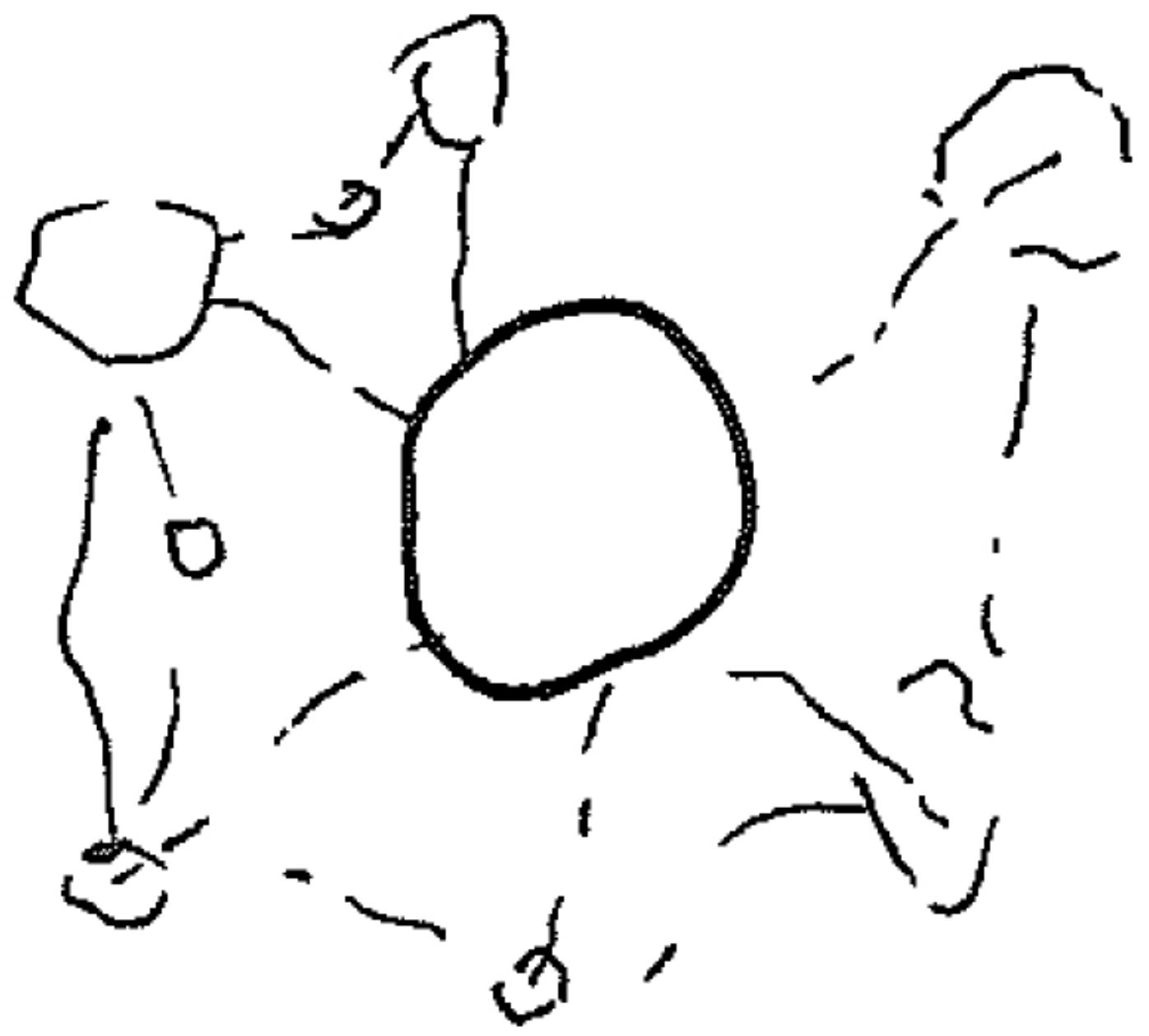

Outerlife is the network of living things constantly around each person that reminds them of the outside world. These networks are built up of various sensory elements that create an atmosphere of life, movement and change around a person. 


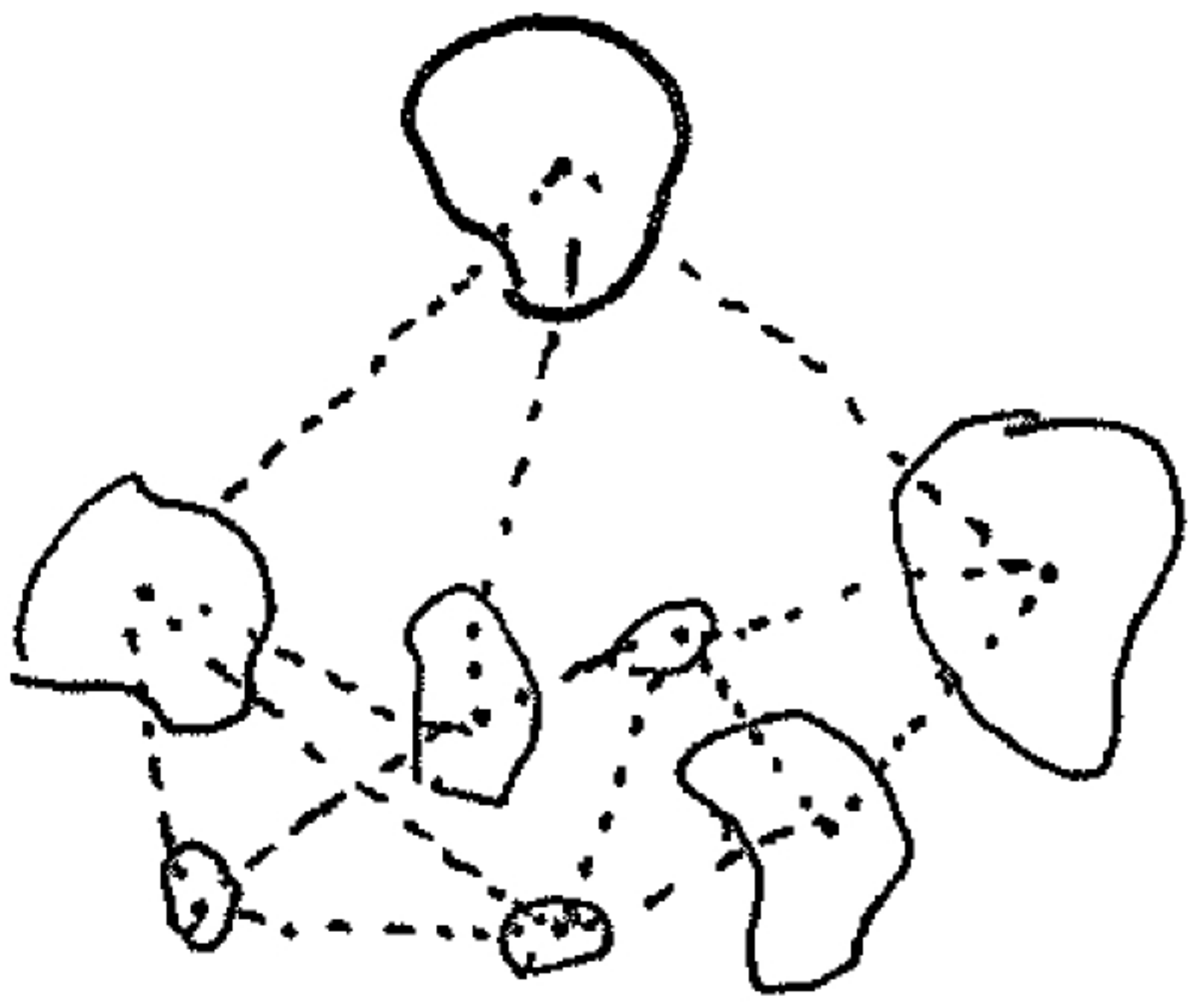

Social atmosphere is similar to outer life but focuses mostly on the passing engagement with other people. How the overlap of sensory elements that make up each person create an atmospheric interaction. 


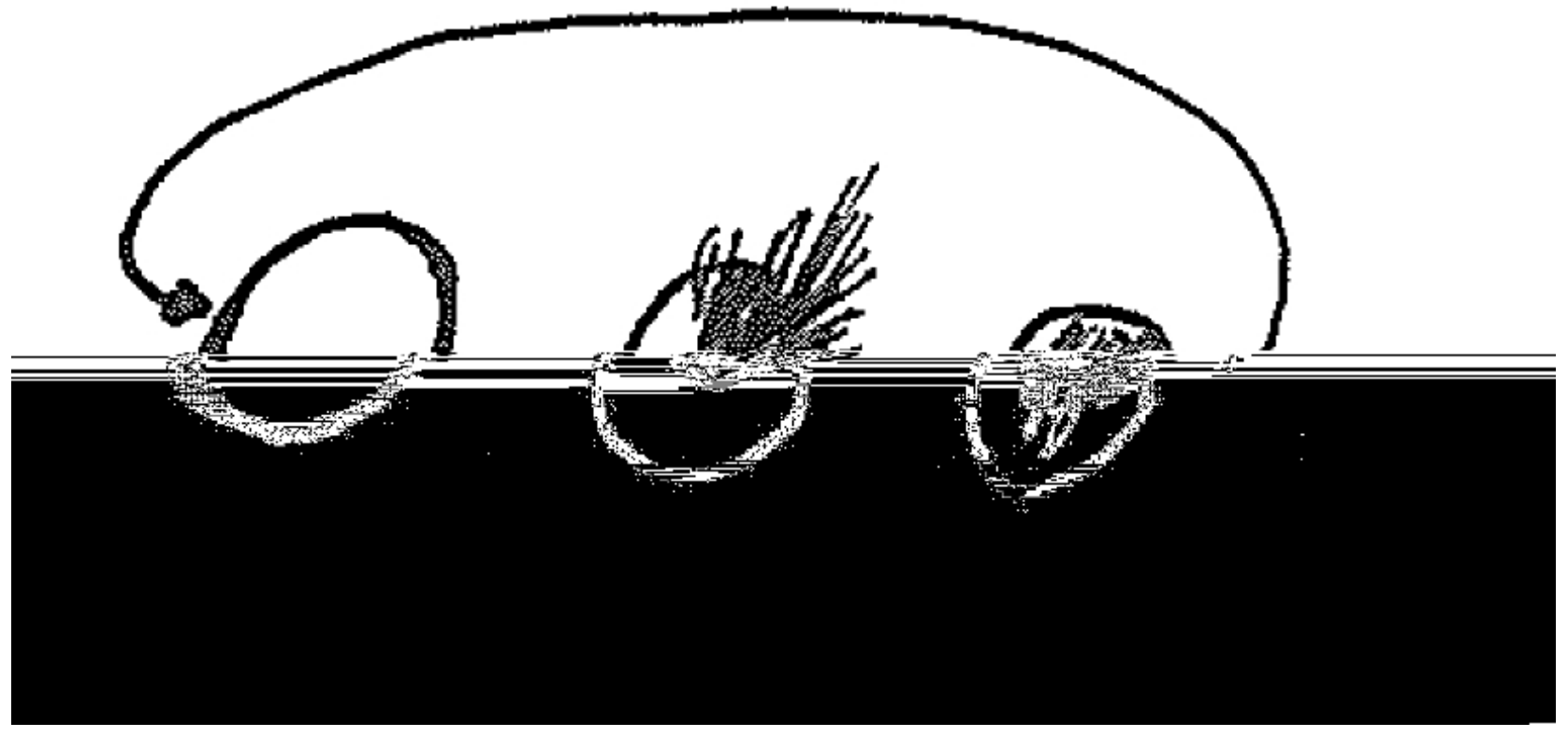

Time is also a series of cycles and miniature griefs. Grief and sadness is a part of life and understanding and accepting that can aid a healthy lifestyle and outlook. 
Along with these moments was a general shift. As stated above, grief starts off as a hostile creature, taking up all of one's consciousness with questions and loss, but has the potentially to transition into a subconscious companion (Dellasega 72). This shift from conscious to subconscious is mirrored by the person's relationship with the world and surrounding spaces. As grief demands more attention, the world becomes grey and disconnected, but as grief becomes more subconscious the world is reintroduced to the person (Vaughn 38). This reintroduction to the world comes the world becomes more important, with just small parts making it through the wall of grief at first, but then eventually they get the whole image and finally the full scope of it (Andersson 73 - 78). It was this transition that served to catalyse my design motivation.People become aware of time, changes, and the imperfections of the world, and how these all make it more beautiful and engaging (Dellasega 72) (Vaughn 38 - 41).
To help me make sense of these learnings this diagram became a key function in my design thinking.

The length of these shifts are individual and person, and can take place in many different ways and times.

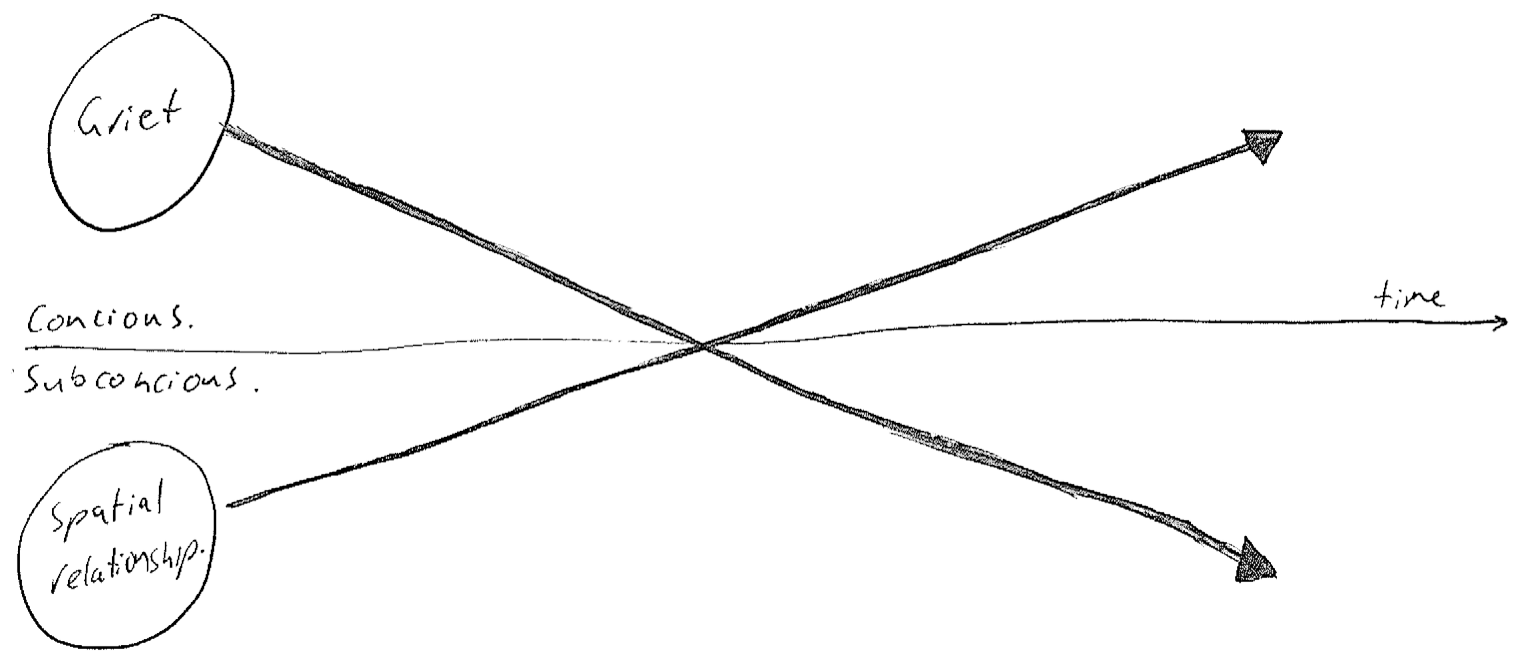

Figure 16 - Drawing

Concious and subconcious shifts of spacetial relationship and grief - Grievers perspective
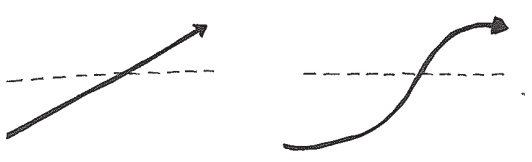

Figure 29 - Drawing

Interpretations of various ways to move through grief
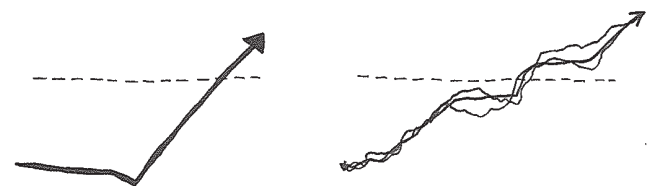
Due to this variability, the recovery process could not be split based on time and a new way of understanding the shifts a person goes through would need to be discovered. Breaking down the general shift from conscious to subconscious would provide a more in depth understanding of how and when a person can engage with positive reflection as well as how the site can aid them in their personal struggles (Vaughn 40 42).

This identified shift can be conceptualised as four wasMy approach here is similar to Elisabeth KüblerRoss's stages of grieving, (Denial, Anger, Bargaining, Depression and acceptance) which follow directly after a loss, but not posed as any counter nor intended to supercede her discoveries. 'Grief and mourning' is merely the first step to a healthy recovery (Vaughn 43).

These four shifts or 'stages' we broken down by the person's relationship to space and the needs they have for a healthy recovery. These shifts were important in this work due to their use establishing and understanding the miasma of grief, and such are my own original way of organising process to take such ideas into design generation.

The following more fully outlines these four stages which I have formulated with respect to the design problems.
' Grief is a process in which we learn how to go on loving someone who is no longer there. Grief is essentially love under the condition of absence "

- Bruce Vaughn (37)
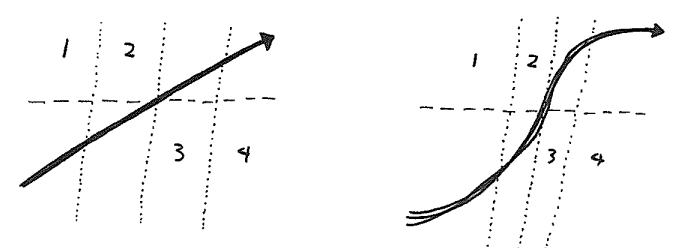

Figure 30 - Drawing Interpretations of various stage lengths through grief
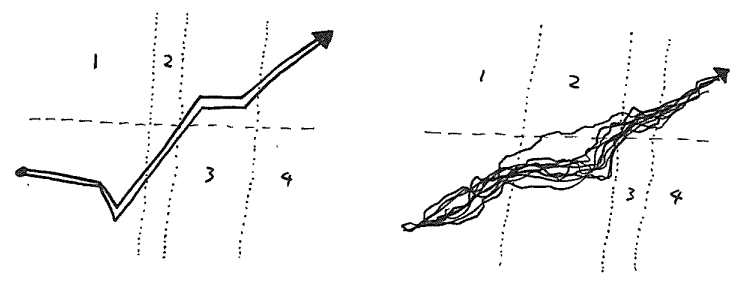
The first stage is when a person is first introduced to grief. They are plunged into a new world, whether it be from the grief of loss, or a small daily grievances. In This new state they are focused solely on grief and that around them begins to fade into ambiguity and haze. 'Grief and mourning' is merely the first step to a healthy recovery (Vaughn 36 - 40). The healthiest option for people experiencing this stage are to internalise (Dellasega 72). Having an introspective look at your own health, life and wellbeing allows for one to come to term with this new perspective and world they are experiencing (Hyrkäs 777).

This stage is the most personal. A person will reflect but it is to cope with the loss and loving someone or something in absence (Andersson 74).

Because this stage is internal and is a difficult and instant reaction to loss, it was labeled

... Grief
' Suffering has a way of turning everything upside down.

And from that overturned perspectivem it makes no sense to resume one's ordinary life - because one knowns now the truths it was designed to keep hidden '

- Bruce Vaughn (40)

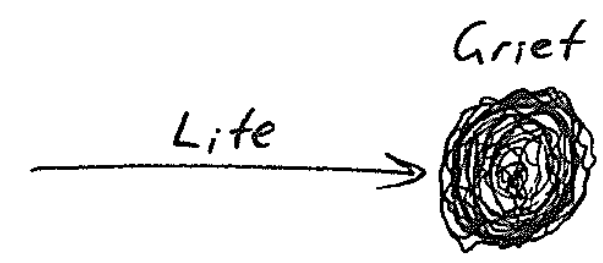

Figure 31 - Drawing

Grief as a process 
The second stage is based around when the outer world begins to creep into consciousness. It is a lateral step in life, away from normal life. It is the first step to viewing the world in a different way, and can allow for more understanding of the beauty of life, not just the sadness (Vaughn 40). At this stage there is more focus and attention to the 'Little things' (Down 18).

This stage is focused around starting to look outwards and appreciate the new perspective. People start searching and looking for meaning with this new lens and allows for the world and design to engage with them (Down 19 - 20). Positive reflection is important to this stage as it allows for the person to engage with these smaller and more subtle features in the world and create a positive association with the new space and their memories (Andersson 74). The risk of entering this new world is that without this intimate and personal connection, it can give the world a grey and hostiles feeling, disconnecting the person further from their surroundings. These small sparks of detail, expression, or life create that positive association and allows a more fulfilling grieving process (Down 20).

These sparks are simple points in the world that can engage with a memory. Senses become more important as smell and sounds carry more meaning as in this new, grieving state the mind creates more connection between the past and the senses (Vaughn 40) . Expression is also important as those grieving will attempt to find meaning in art work (Down 20).

This stage is based around recovering from the initial grief and accepting a new world. This stage is named

... Healing

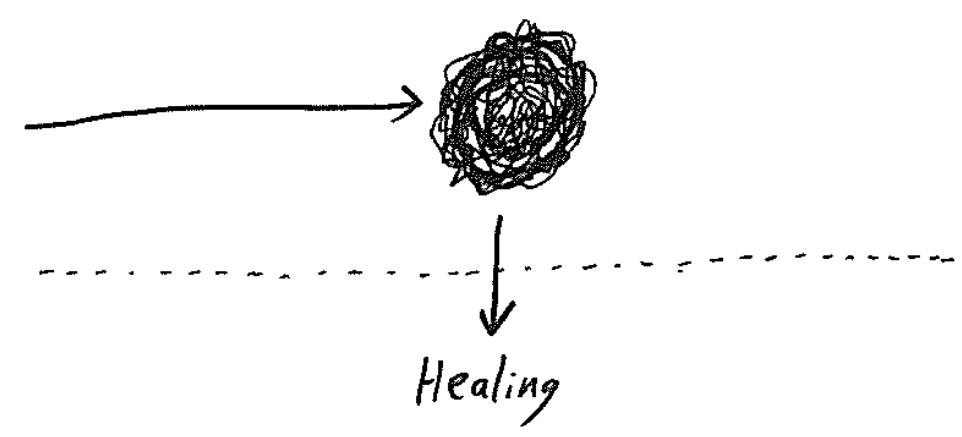

Figure 32 - Drawing

Healing as a process
'But this is all new. l've been getting hung up on the small, fresh things "

- Jennifer Down (18) 
Beyond this state a person begins to adjust to the new world and progress onwards with their lives (Hyrkäs 776). It is important to give people a sense of achievement as grief feel never ended and never finished, which is isn't. To give a sense of accomplishment to something that is never truly finished requires a greater perspective on the development someone has been able to do (Vaughn 42-44). This goes beyond showing someone their current relationship to grief, and introduces a wider element to them. Time.

Time is one of the best forms of medicine for grief as it can create a look back of both fondness and accomplishment (Hyrkäs 777) . Time allows from to see how they have transformed and be amazed at their own ability to continue. Time also allows for a memory. Looking back at how long its been allows one to look further back (Vaughn 42) (Dellasega 72).

This stage focuses on time, allowing for a person to acknowledge their own journey, hence this stage is labeled

... Growth

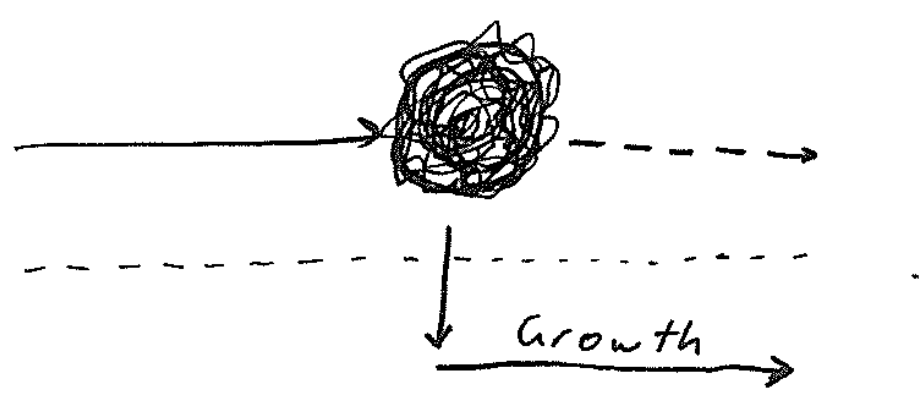

Figure 33 - Drawing

Grwoth as a process 
The final stage is somewhat of an illusion because in reality it never ends. At this point a person has come to terms with their existence and has either welcomed it and progressed or fought it and regressed (Hyrkäs 778). From here they continue to learn from their history and experience life. The biggest lie a person can be told is that it's behind them now, because it's always behind them but also always in front of them (Vaughn 44). Grief has affected their perspective and shouldn't be something eventually discarded but something to be a part of dzaily life (Down 20).

What this final stage focuses on is allowing a person to accept grief as a part of life, and that there will be more grief to come and learn from (Dellasega 72). Each grief, no matter the size, is new and fresh and has its own journey and this stage focuses on the continuation of life (Hyrkäs 779).

Imperfection is part of life, and allowing those who have grieved to come to terms with the beauty of imperfection (Andersson 75). This allows them to more maturely embrace changes in their own lives and how they can grow from said changes (Dellasega 72).

This stage is focused around the never ending process of grief and allowing someone to continue to be effect by their grief. A healthy recovery process can reach this point and demand that grief be put in the past, regressing their journey to a pointless process.

This process is named

... 'Maturity'

Because maturity implies an end but 'maturity' never ends.
The understanding and use of these stages became the foundation for the design generations in the sites of this project. Each stage informs not only the steps to interpreting one's relationship with grief, but also how to than transition that into an reflective design. This allows the end result to be not only an engaging atmospheric design, but a design that helps with positive reflection.

' Grief has been described as a timeless phenomenon "

- Kristiina Hyrkas (776)

Figure 34 - Drawing

The continuation or 'Maturity' of grief 
As I have demonstrated grief is, at its core, invisible and independant. Each person experiences each grief in a unique and internal way, both consciously and unconsciously . To truly engage with a grieving user, a space must take an soft approach, meeting the user with the tools to facilitate their independent states in a positive way, but without dictation and controlling their
"Atmosphere is the air in a particular place. Atmosphere is what you sense in a particular situation. Atmosphere is made of both the specific object and the context of the object.'

- Stig L. Andersson (72)

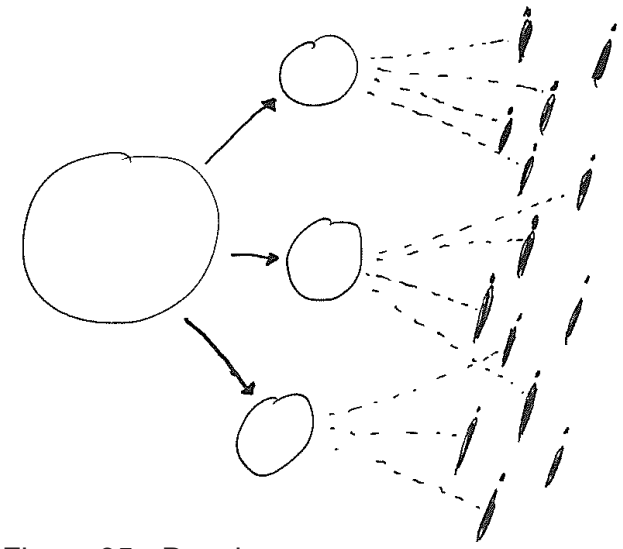

Figure 35 - Drawing

Monumental atmosphere

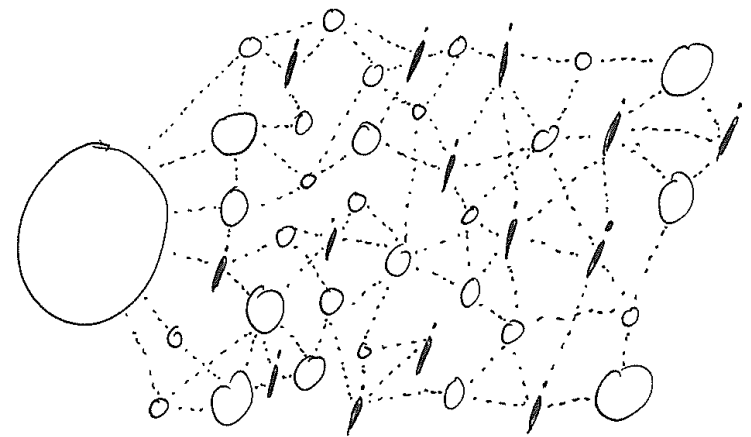

Figure 36 - Drawing Integrated atmosphere
Atmosphere is important within a softer and subtle design due to its interaction with a person. Atmosphere is not a physical element, nor is it identifiable. It is a network of parts that allows a walker to subconsciously pick and choose what elements to engage with.

This interaction between a user and a design is an 'Atmosphere' which adds to both the bodily and ethereal experience of a site. This project aims to understand atmosphere and use it as a tool to create a more engaging space.

Atmosphere is the space between spaces. It is where the individual meets design, meaning a space can be designed to have a specific atmosphere but the background of the individual will skew this perception and create a similar, but unique atmosphere for each individual (Andersson 72).

Atmosphere is built on networks. These networks are various parts that engage with the user in different ways. Atmospheric spaces have specific spaces built up on a foundation of interworking parts that, when experienced together, create a sensation (Griffero 17) (Meyer 95). the possibilities is to lose or dilute it with people. The addition of more people into a specific space or moment reduces the immersion and intimacy of the atmosphere with the person (Andersson 76 78).

To create a sensation and feeling that engages with grief and positive reflection, we need the parts that network to create grief, which we have in the discovered 'moments'. By applying spatialising these elements, a network of parts and feelings begins to for. These parts themselves are only atmospheric qualities which are than themselves built up on a network of inter linking parts. 
The elements of the networks that create these atmospheric spaces are sensory or time based.

Atmosphere is essentially the 6th sense. It is the feeling we get when all our senses are combined and is a visceral and physical feeling (Meyer 92 - 95). Everyone has experienced an atmosphere that resonated with them, and knows the power atmosphere holds (Andersson 72).

In design, sensory engagement tends to become a novelty(Colebrook). Designers focus on a specific sense in design to create an experience and distinction in design. What is not looked into is the relationships between these different parts, all together (Andersson). How do spaces balance all their senses so none are totally taken over or reliant. The spaces that manage this become the atmospheric spaces and are the ones that have the opportunity to have the deepest connection to the user (Meyer 96 - 120).

Senses are frozen in time and although they can create a wider feeling in the moment, they lack the temporal element of time. Time , aging, imperfection... add to a site. They are more than a metaphor added to the site (Andersson 78). The idea of growth and aging carries weight and allows for a strong connection with those engaging with space. Time also provides change in a space (Tonder 359). A space that is experienced once will have a strong and immersive experience that is diluted as it is experienced more and more. As a space is visited more, it becomes predictable (Viladas). But a space that shift and changes, if only slightly, creates a new environment each time, and is experienced for the first time each visit (Andersson 77) (Hazinga 779).

The goal of this part of the investigation is to create a series of short spatial feelings that relate to the psychological moments found above. These small design moments create a canvas for those in the site to interpret. By providing a short story or 'Vignette' but not forcing a specific reflection on the walker, it allows the user to engage with it, creating the opportunity for positive reflection (Griffero 17).
These vignettes are dimensions of experience that frequently go unrecorded in urban design. They are valuable in this investigation because they are the mediator between the user and site. Each vignette represents an aspect of grief that has been spatialised, creating a bridge between the walking griever and the design.

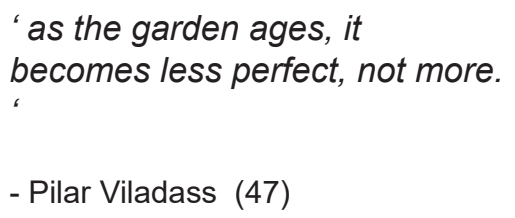




\section{Internal}

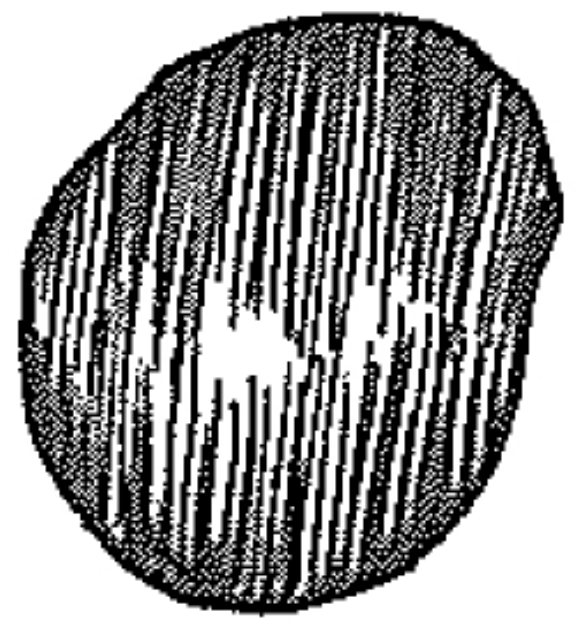

Creating an internal feeling can be implemented through the path structure. Having paths easy enough to meander through subconsciously allows the walker to let their movement be subconscious and frees their consciousness for through and engaging with the design.

\section{Wandering}

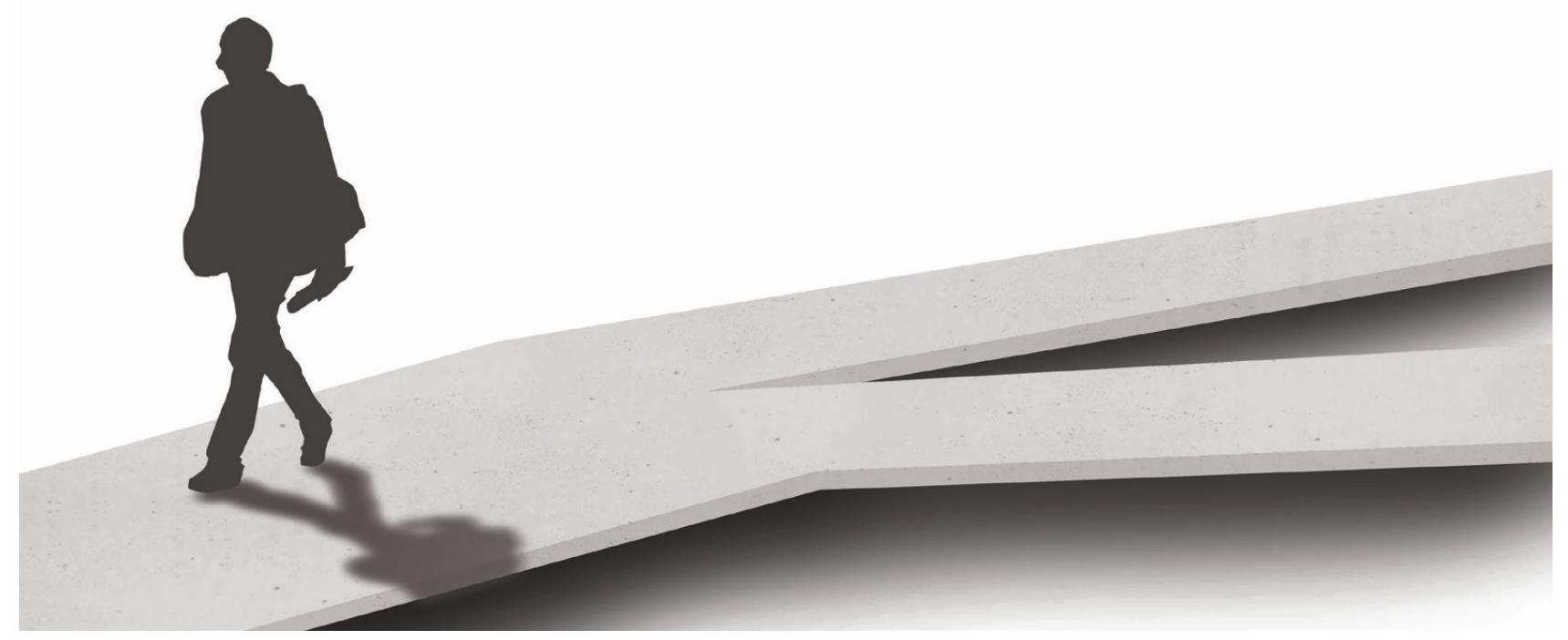

Figure 39 - Diagram

Wandering 


$$
21
$$




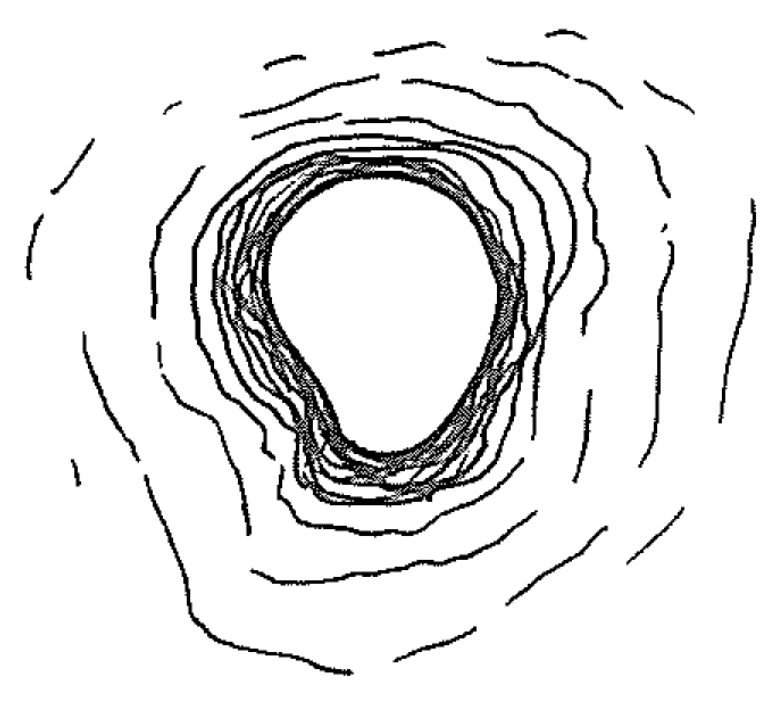

Disconnected

Disconnecting the walking from their surroundings can be creating through a path that elevates as it moves through the space, creating a distance between the compex vegetation and the very simple path.

\section{Threshold}

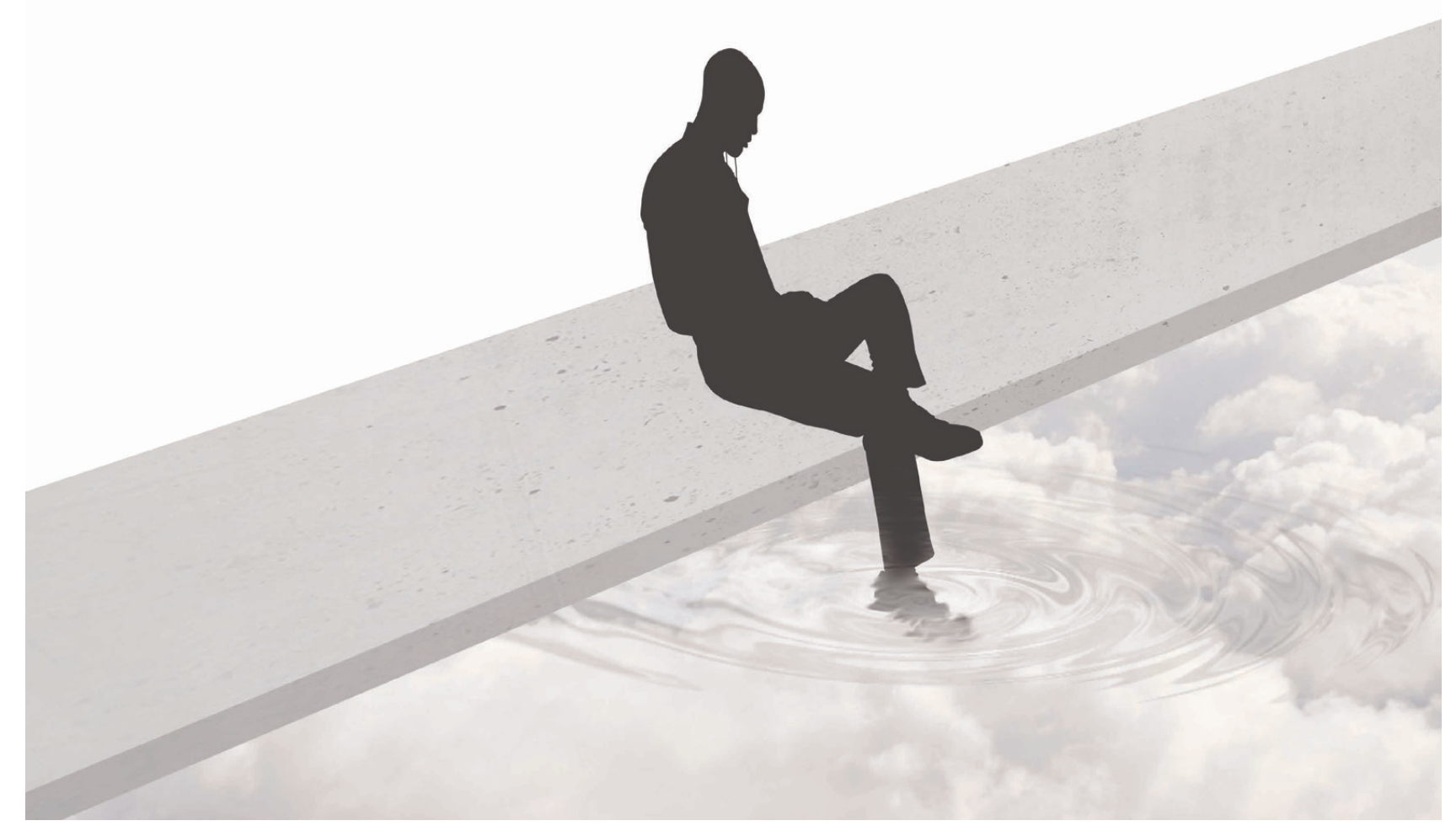




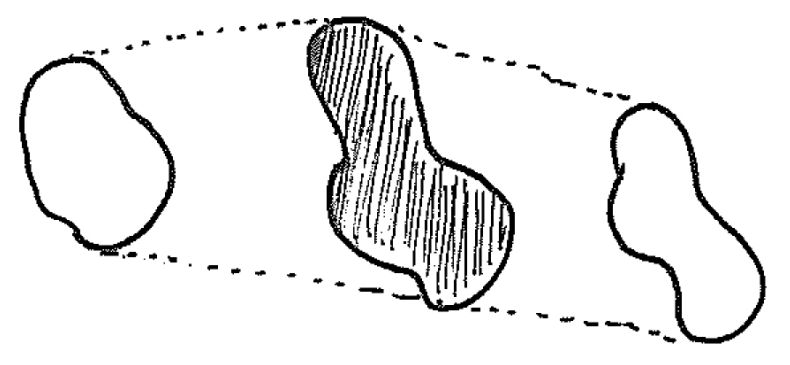

Expression

Expression is represented in the site already through the numerous tagging and street artworks on the surrounding facades.

Local Artists

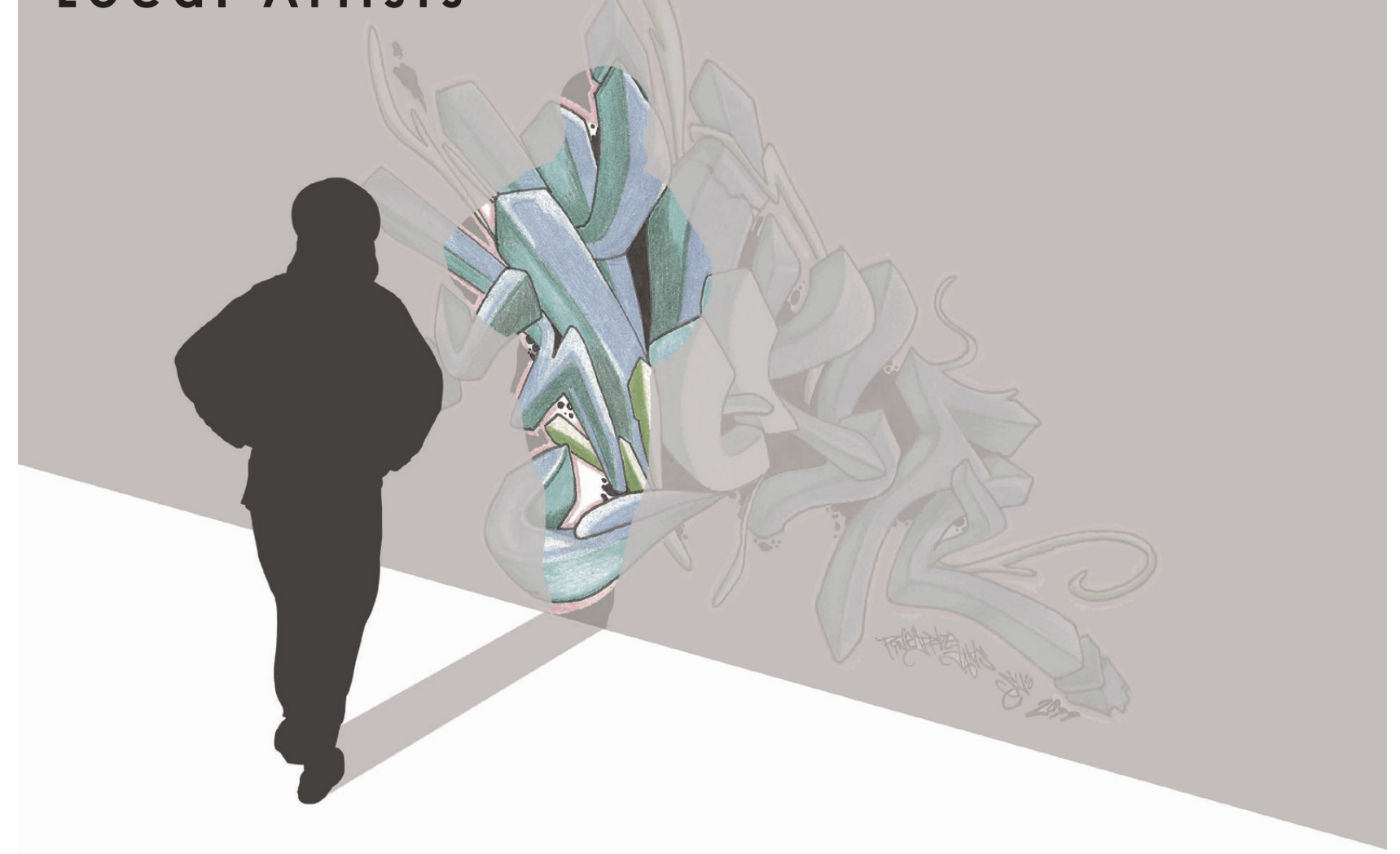

Figure 42 - Diagram Local Artosts

53 


\section{Beauty}

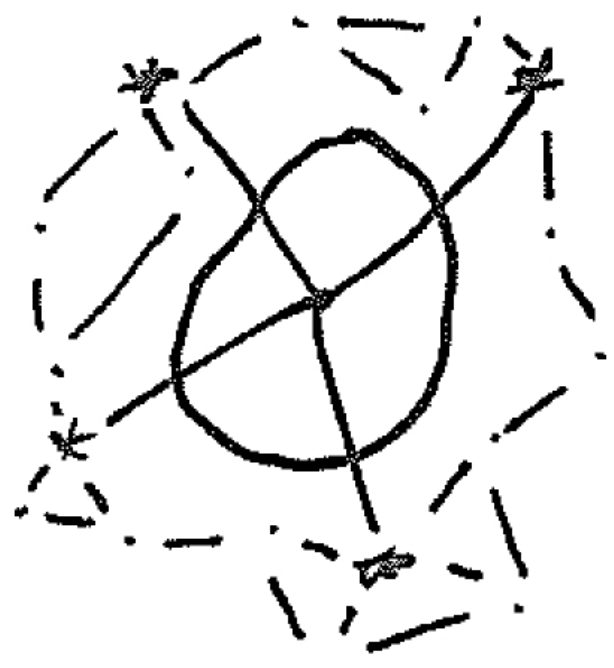

Beauty is subjective but there are themes and standards. Flora is an elements that is usually perceived as an element of beauty and life and is used as such in the site.

\section{Flora}

Figure 43 - Diagram Flora 


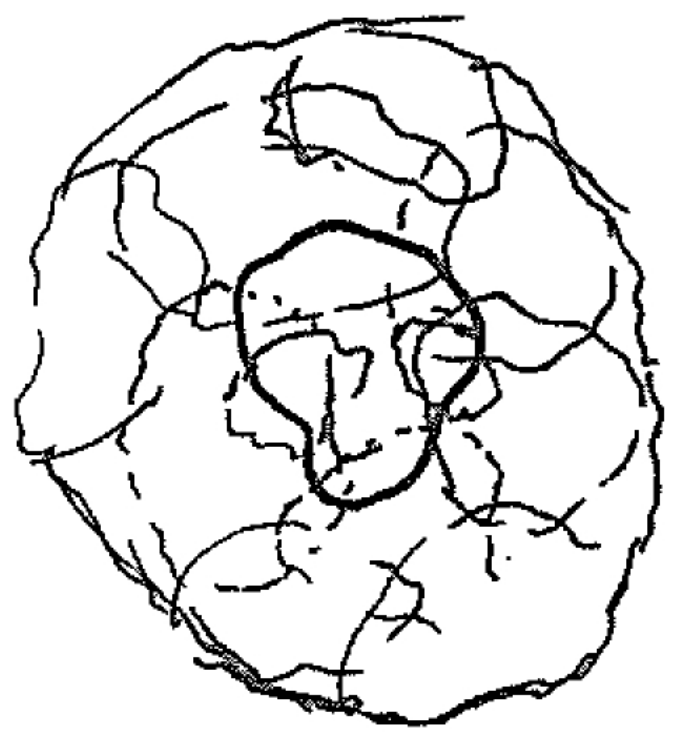

Atmopshiere

Atmosphere is the connection of many parts making a while. This is represented in the site as the cohesive nature of the space and how all the elements are balanced.

\section{Space}

Figure 44 - Diagram

Space 
Notions of life

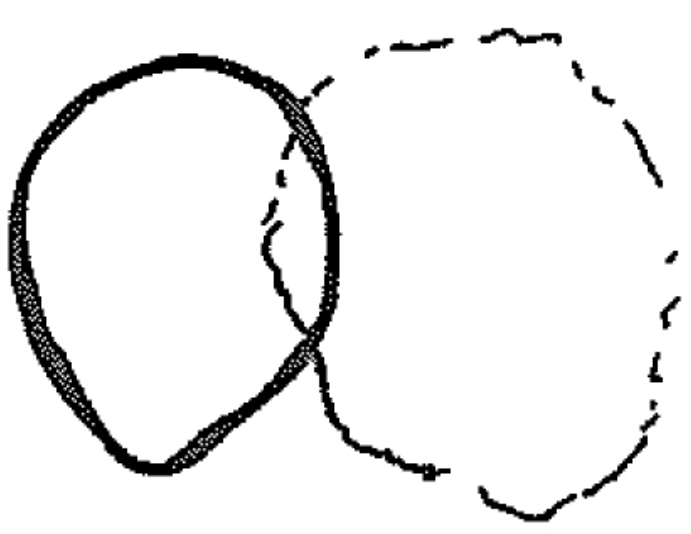

Notions of life is also represented through the flora and its ability to attract insect and bird life. The soft interaction with these elements gives a distant and subconscious acceptance of surrounding life.

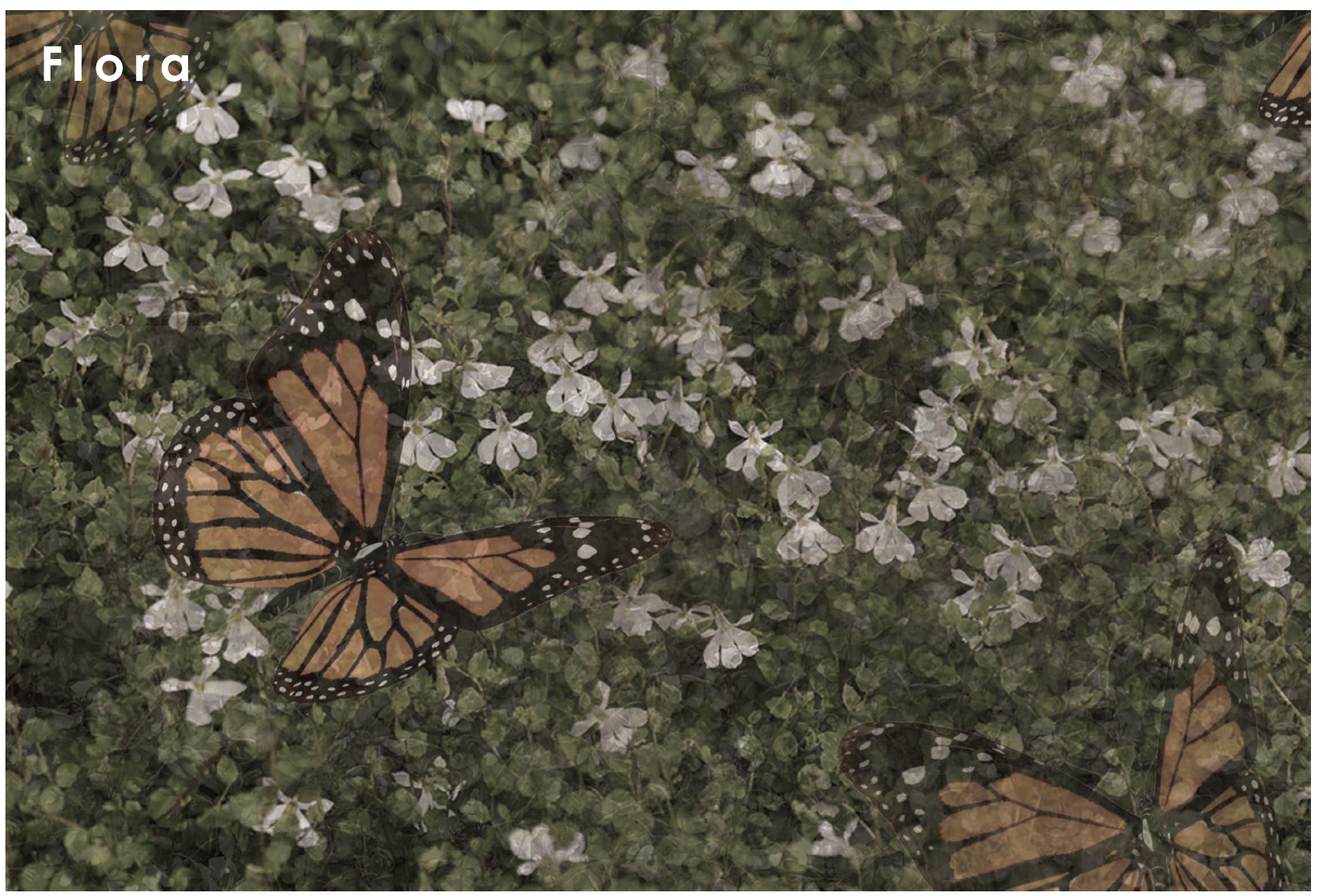

Figure 45 - Diagram Flora 


\section{Details}

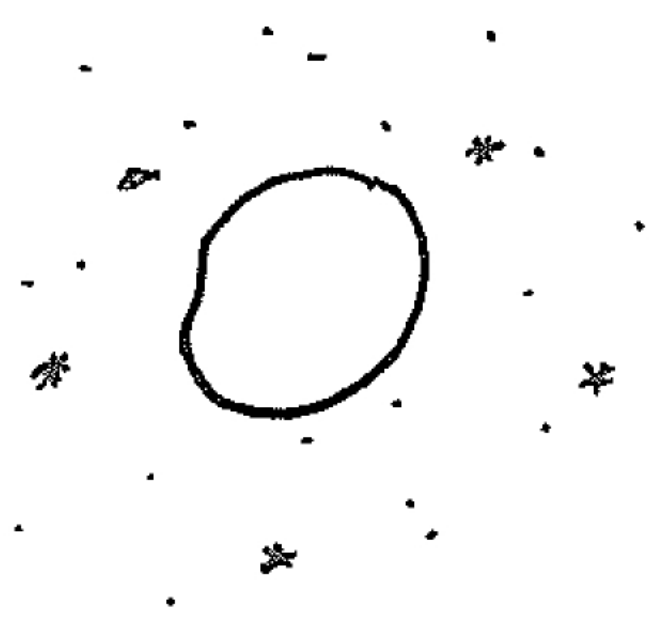

Detail is represented through all the hidden and small elements in the design, such as materials from the previous carpark hidden throughout.

\section{Space}

Figure 46 - Diagram Space 


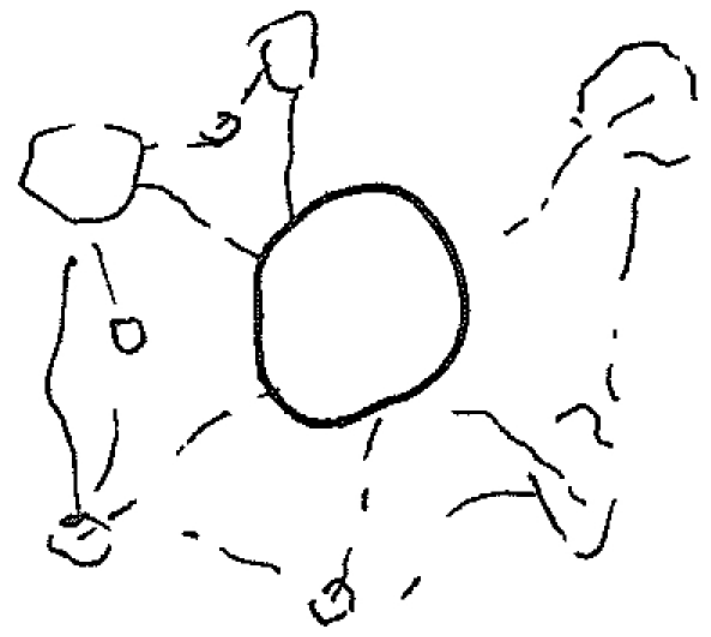

Outerlife

Outer life is also represented through the flora and its ability to attract insect and bird life. The soft interaction with these elements gives a distant and subconscious acceptance of surrounding life.

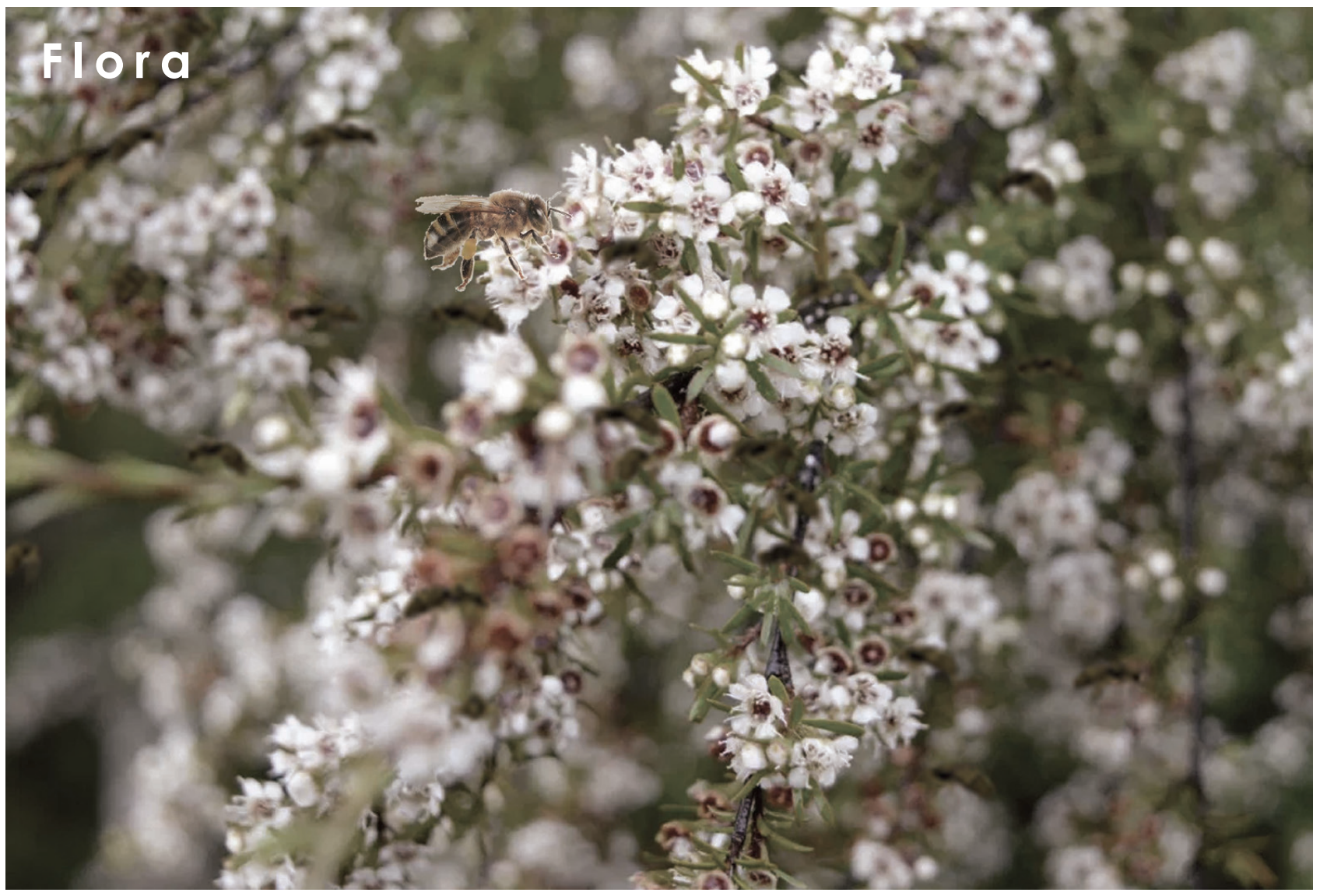

Figure 47 - Diagram Flora 


\section{Change}

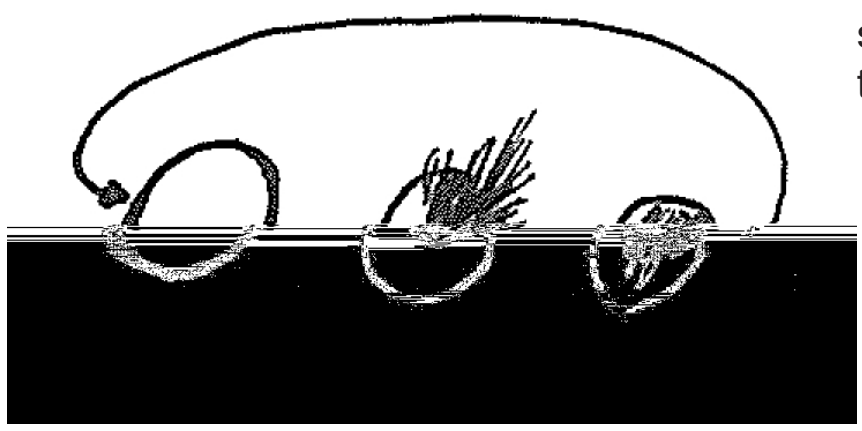

Change is represented in the way the space moves on a larger scale as well as through individual days and seasons.

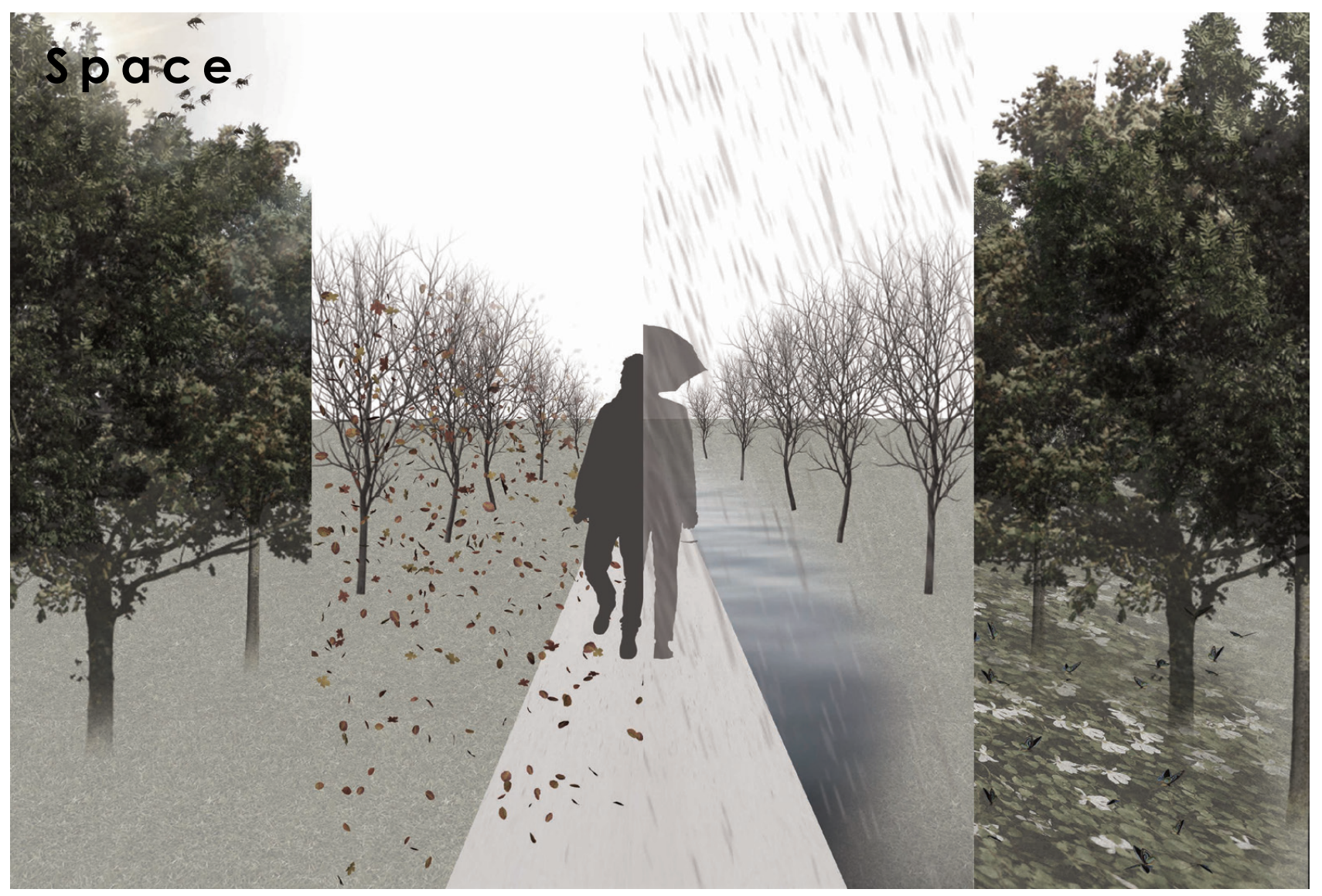

Figure 48 - Diagram Space 


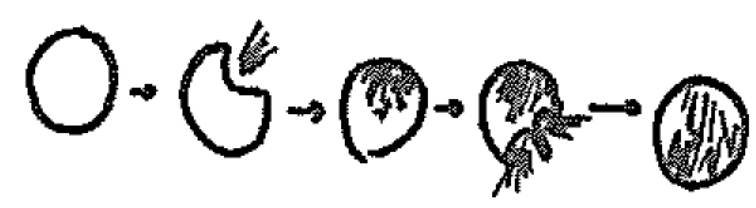

Time is represented through the evolution and growth of the surrounding vegetation.

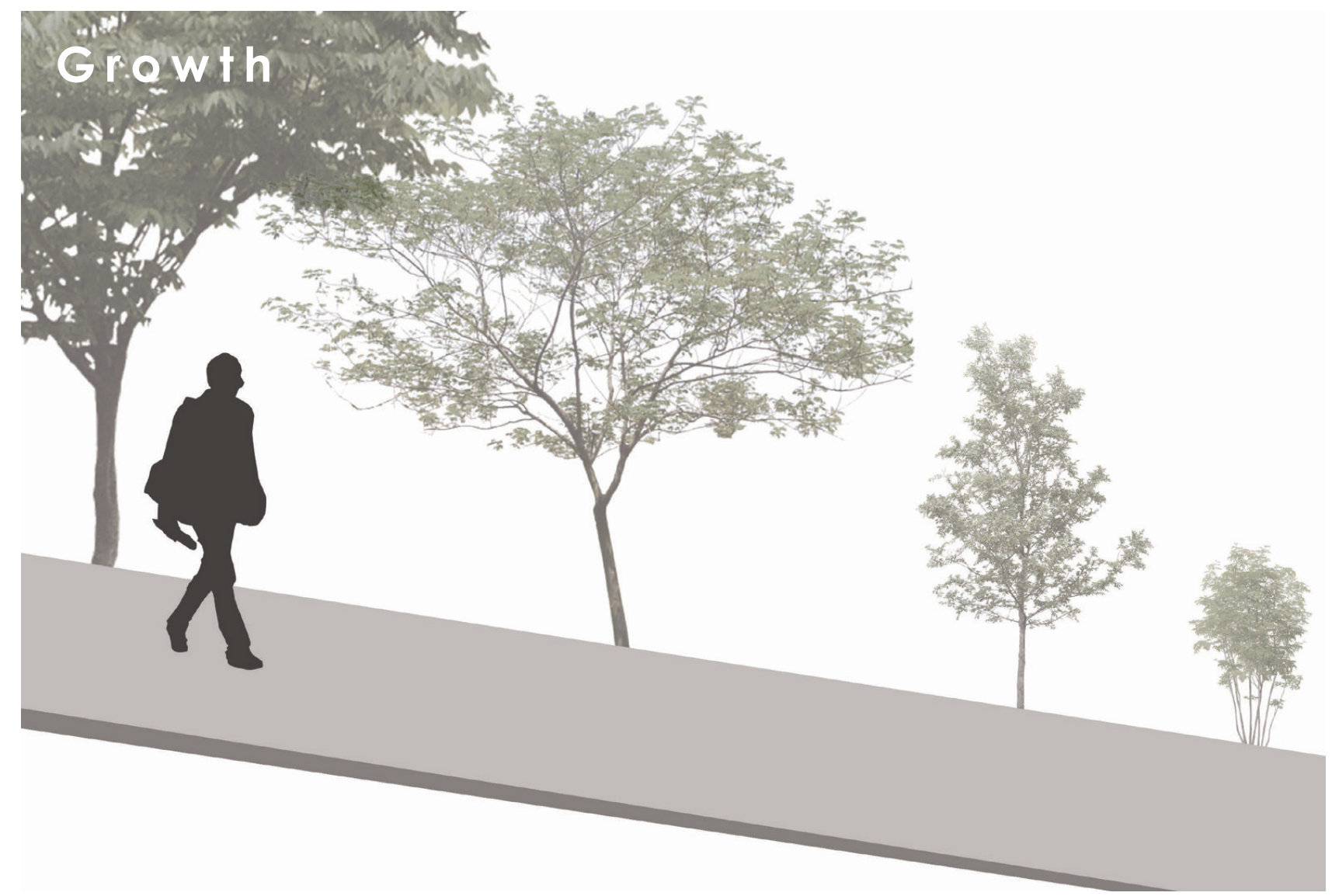

Figure 49 - Diagram Growth 


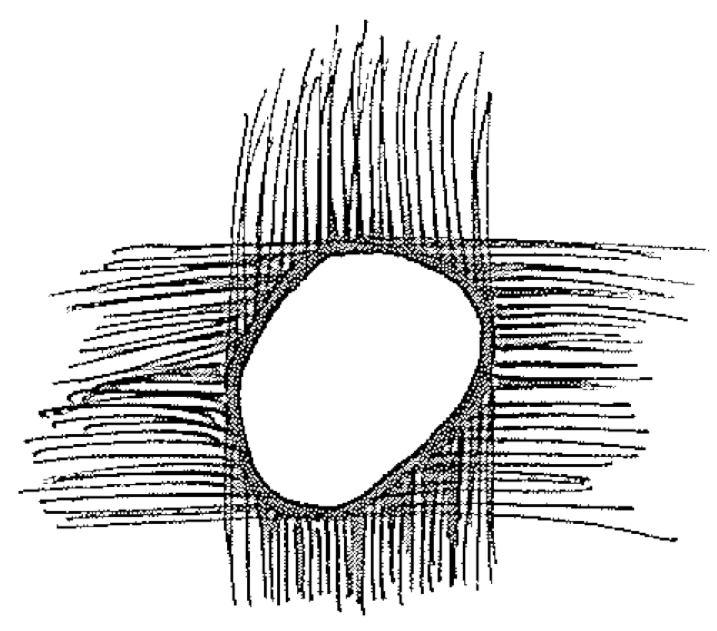

Dilluted solitude

By using a softer canopy overhead, it allows for a partial separation from the surrounding space and people, while hinting to the surrounding city, creating a diluted solitude.

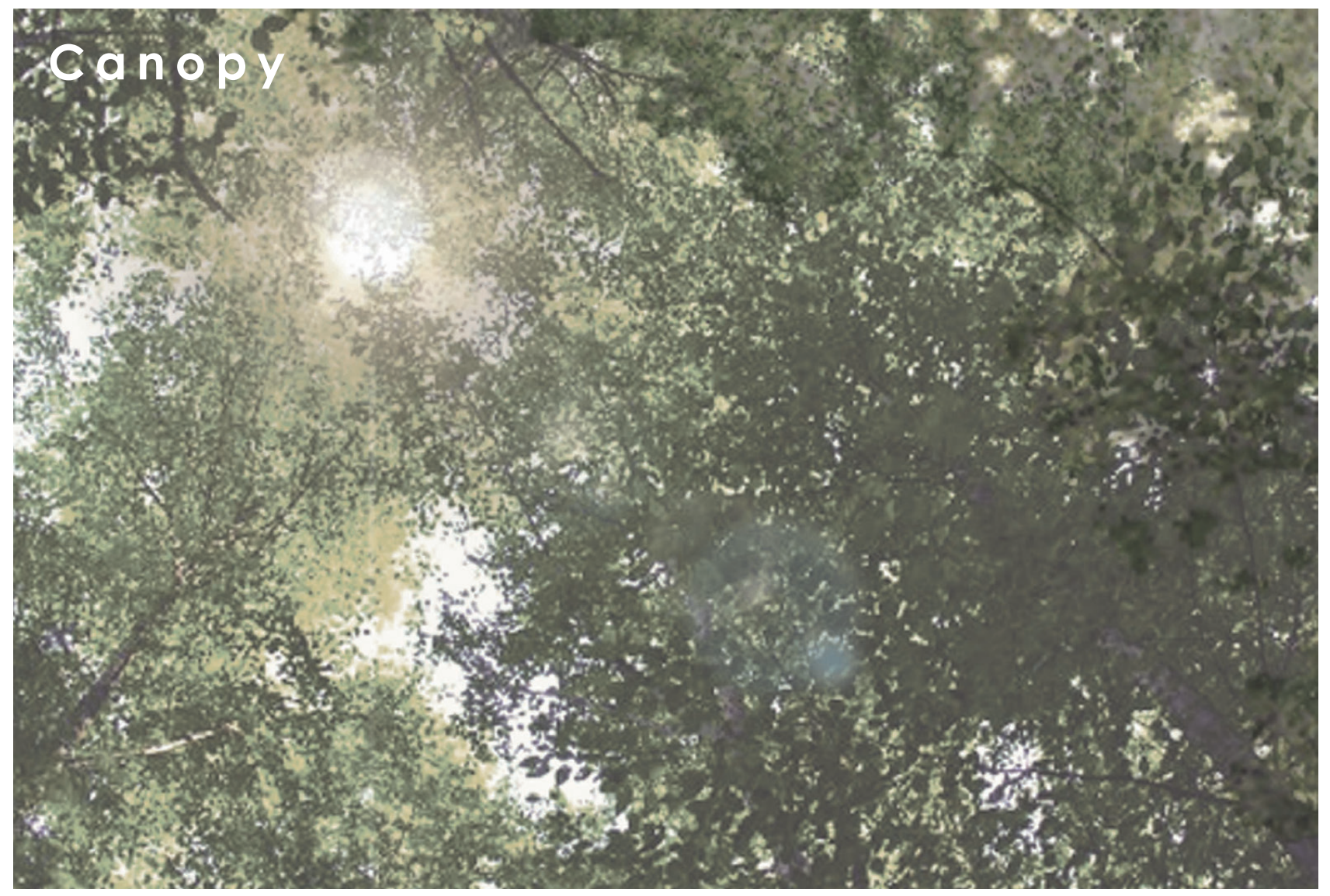

Figure 50 - Diagram Canopy 


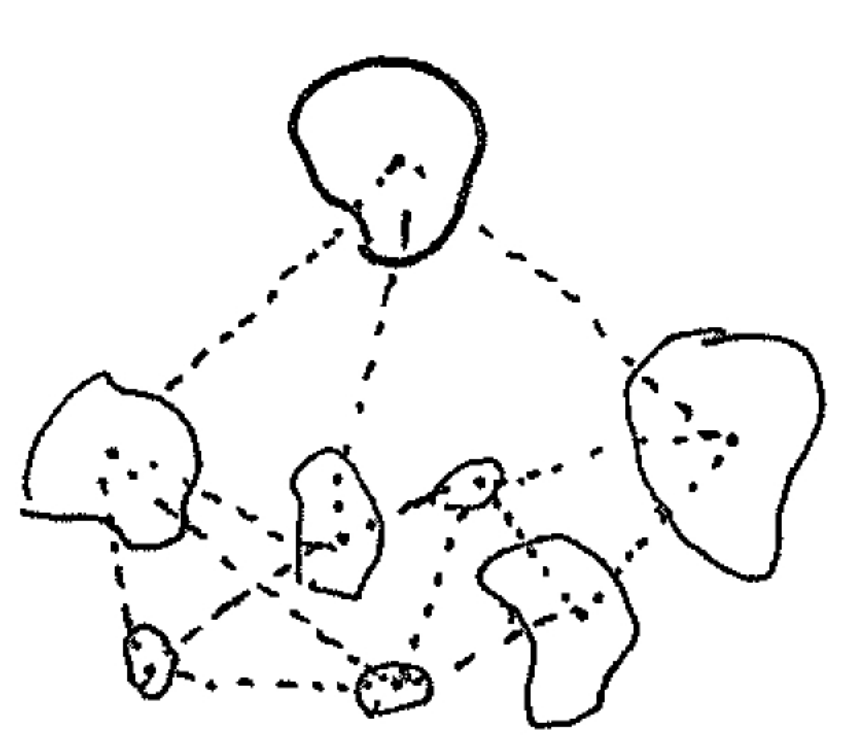

Social

Social aspects are represented in long site lines and adjacents paths that allow for a soft connection without diluting the effects of the design.

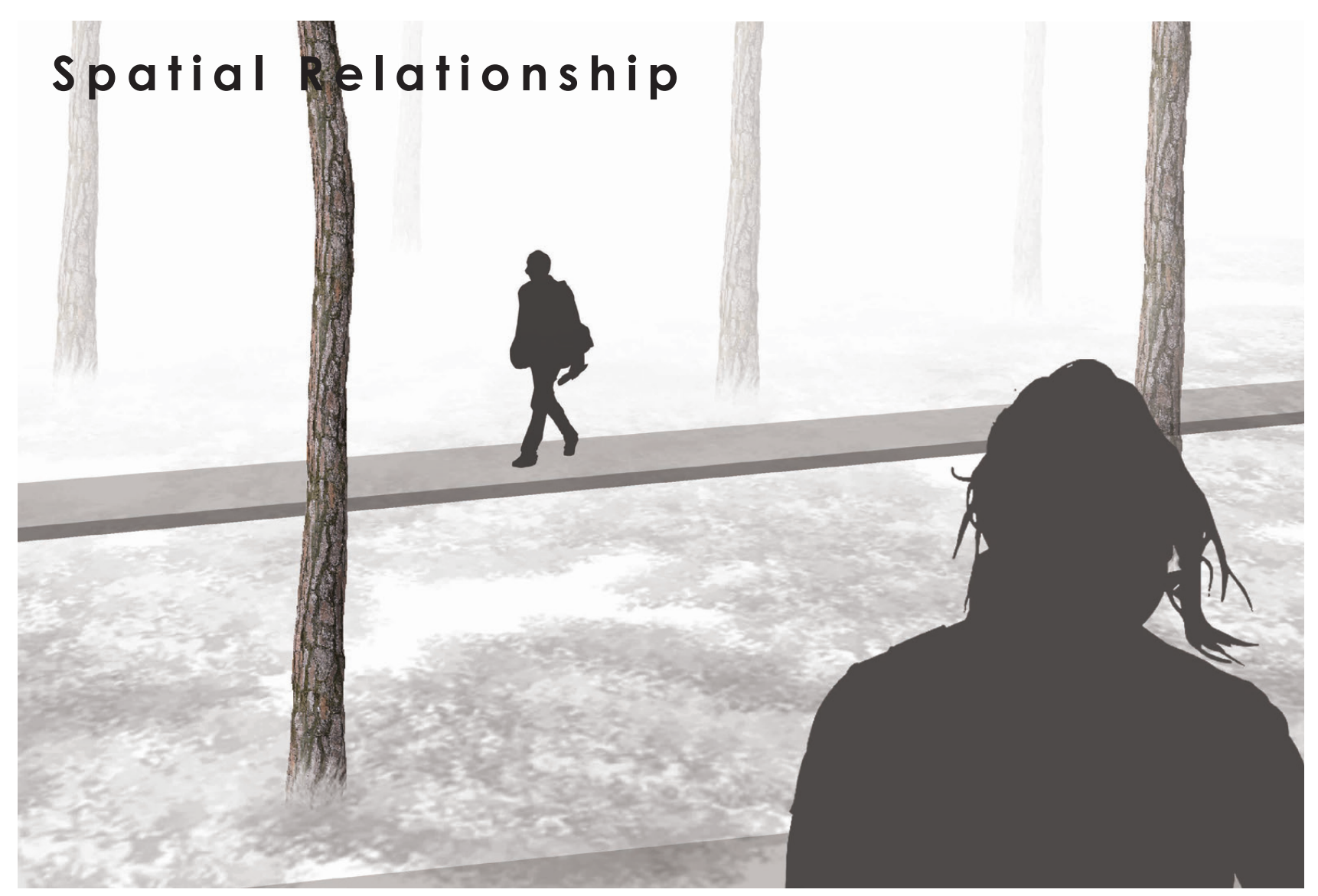




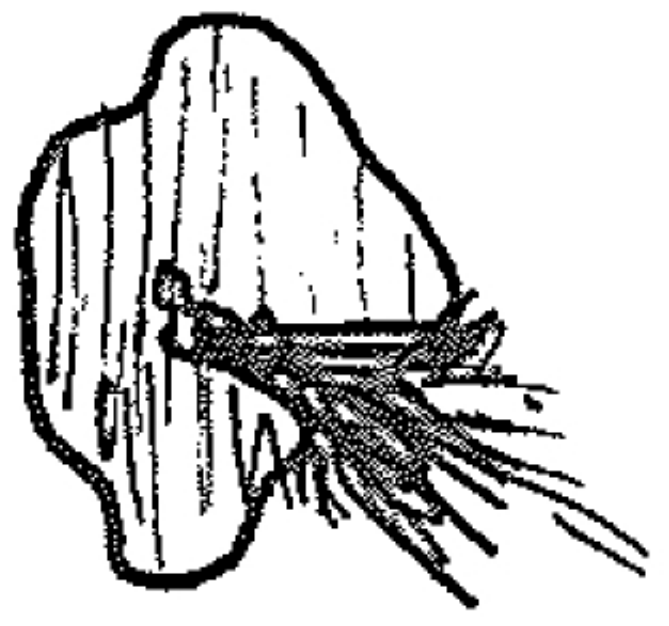

Allow the space to age and become imperfect allows for daily grief and changes that introduce the walker to the idea that grief and imperfection is a crucial part of life.

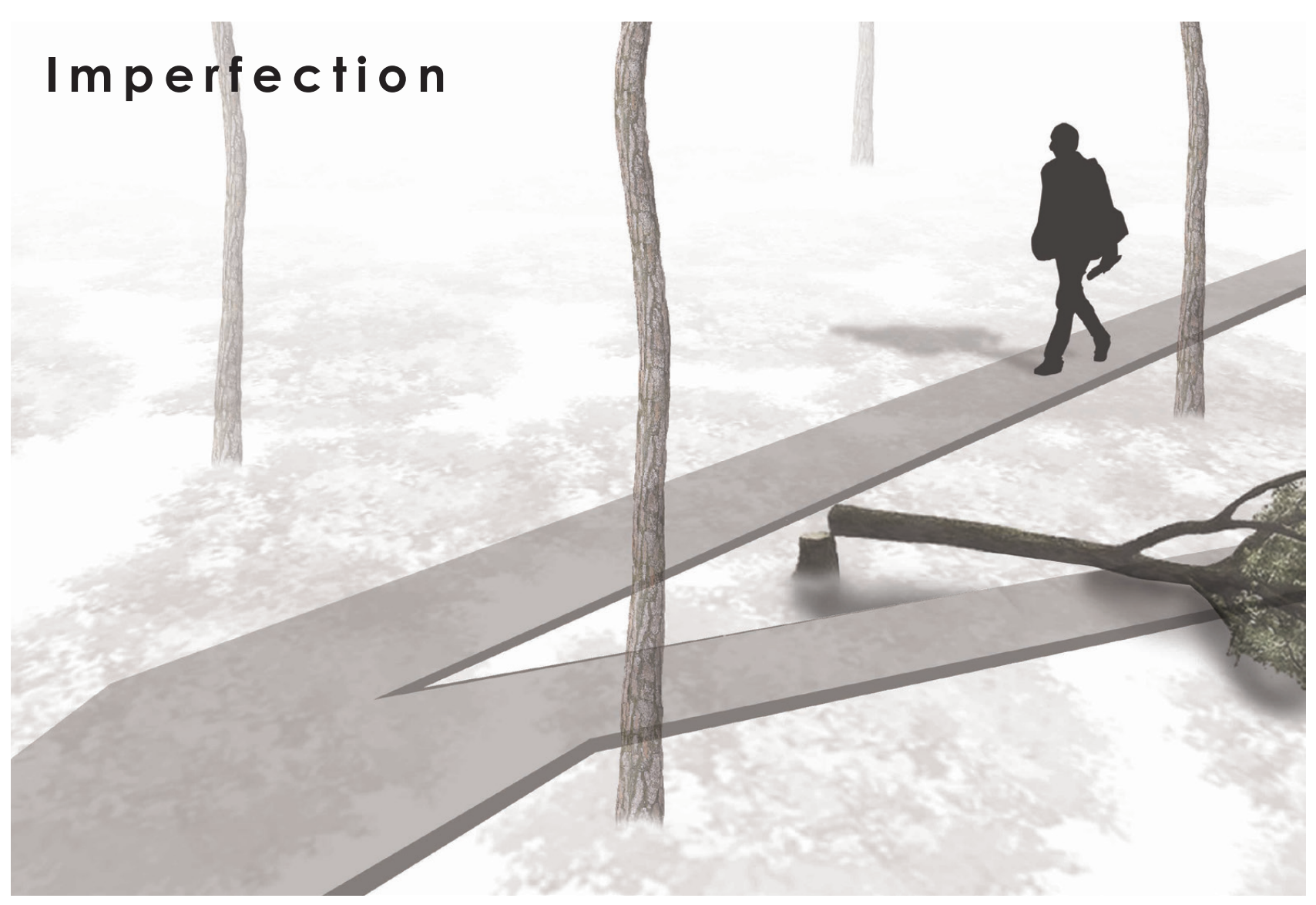

Figure 52 - Diagram Imperfection 
Identifying these vignettes catalysed a combination of various networks. The vignettes create an idea of spatiality in a space but elements such as path width, height, and layout will add to or hinder the atmosphere each space. They are built and designed in abstract space and are small pieces of a design to be applied to a site. the next phase of design was testing various elements and networks in abstract space. By testing these parts individually, disconnected from site, it aids understanding of their individual relationship and builds a palette of measurements and feeling. To understand the effects of physical conditions of the path socially, physically and atmospherically they were tested as a plan and section firstly in their physical reactions, and then secondly as an atmospheric property. These elements becomes tools to eventually 'claim' site.

The physical and social testing was to test how the space interacted with people and how it affects behaviour. This would be used to create different movement typologies within the end design and allowed for the manipulation of journey and groups. The atmospheric testing investigated how the physical elements becomes interpreted by the walker, and how the various elements of the design would be perceived by the walker.

\begin{abstract}
'Whether it is its superficial or intensely lived image, urban atmosphere is still as ever "a being that has bewitched us, from which we cannot be parted; we remain its children or its timid visitors ;
\end{abstract}

- Tonino Griffero (17)
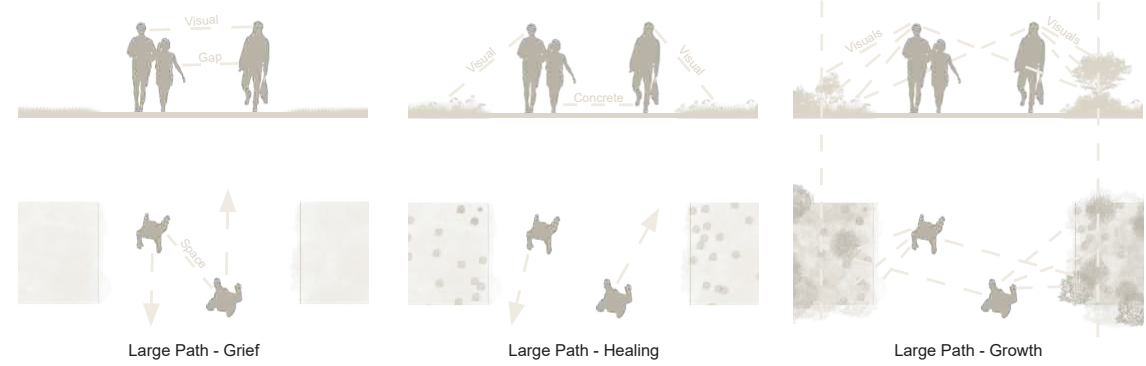

Large Path - Growth

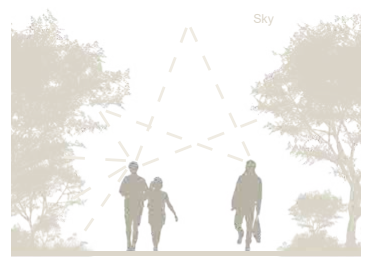

Large Path - Healing
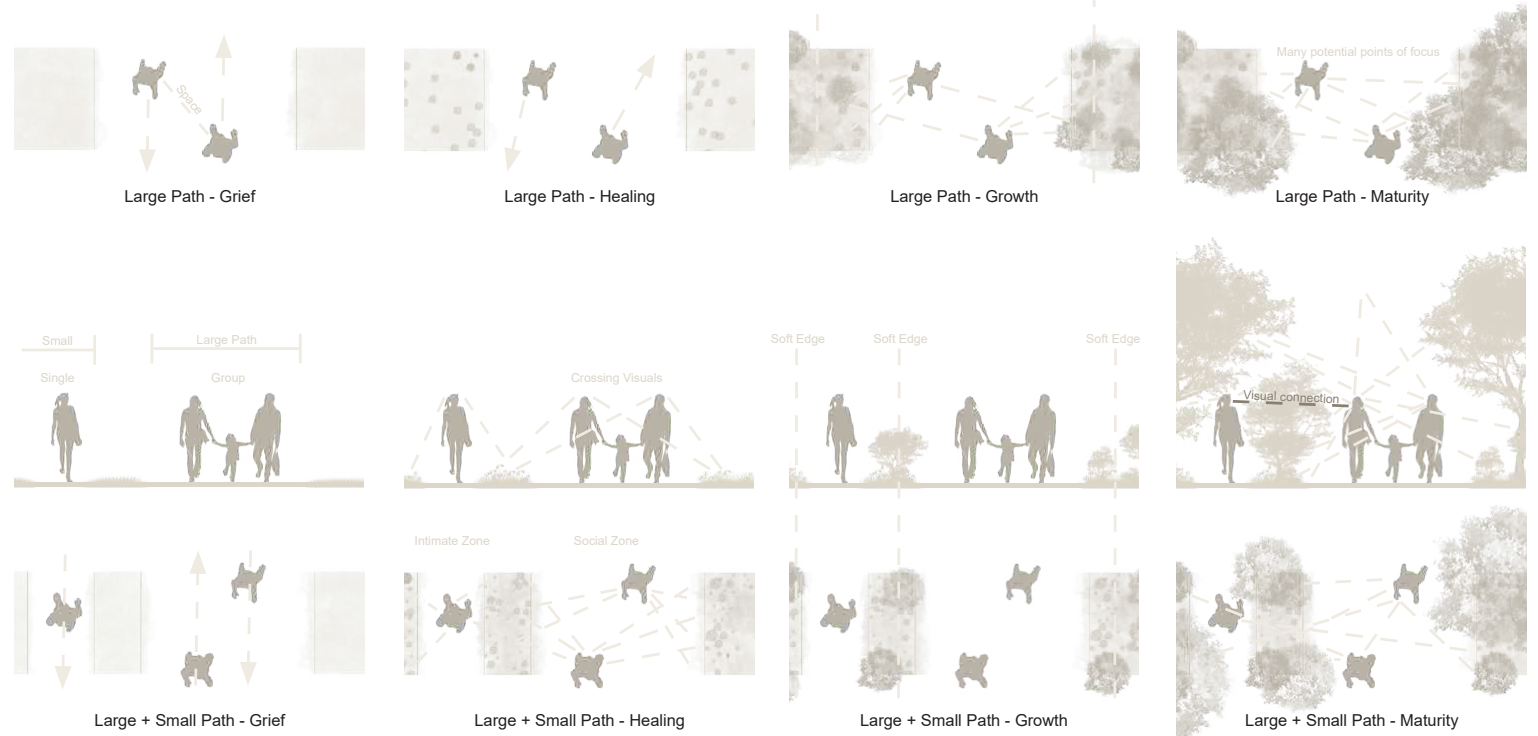

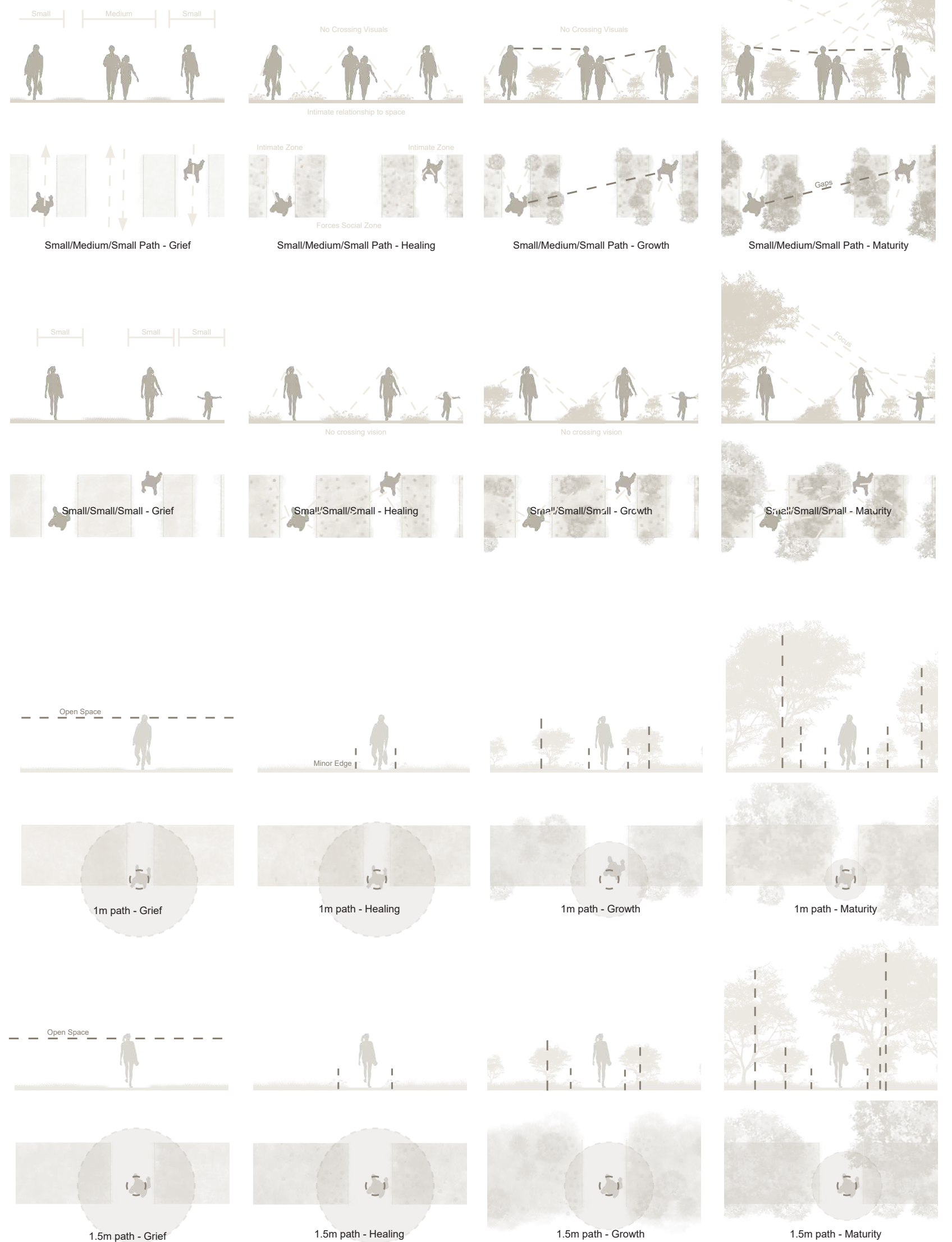

$1.5 \mathrm{~m}$ path - Growth

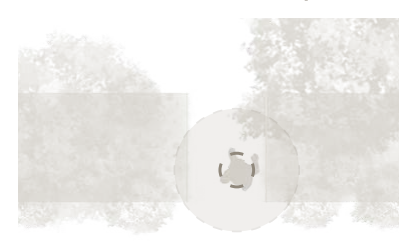

$1.5 \mathrm{~m}$ path - Maturity 

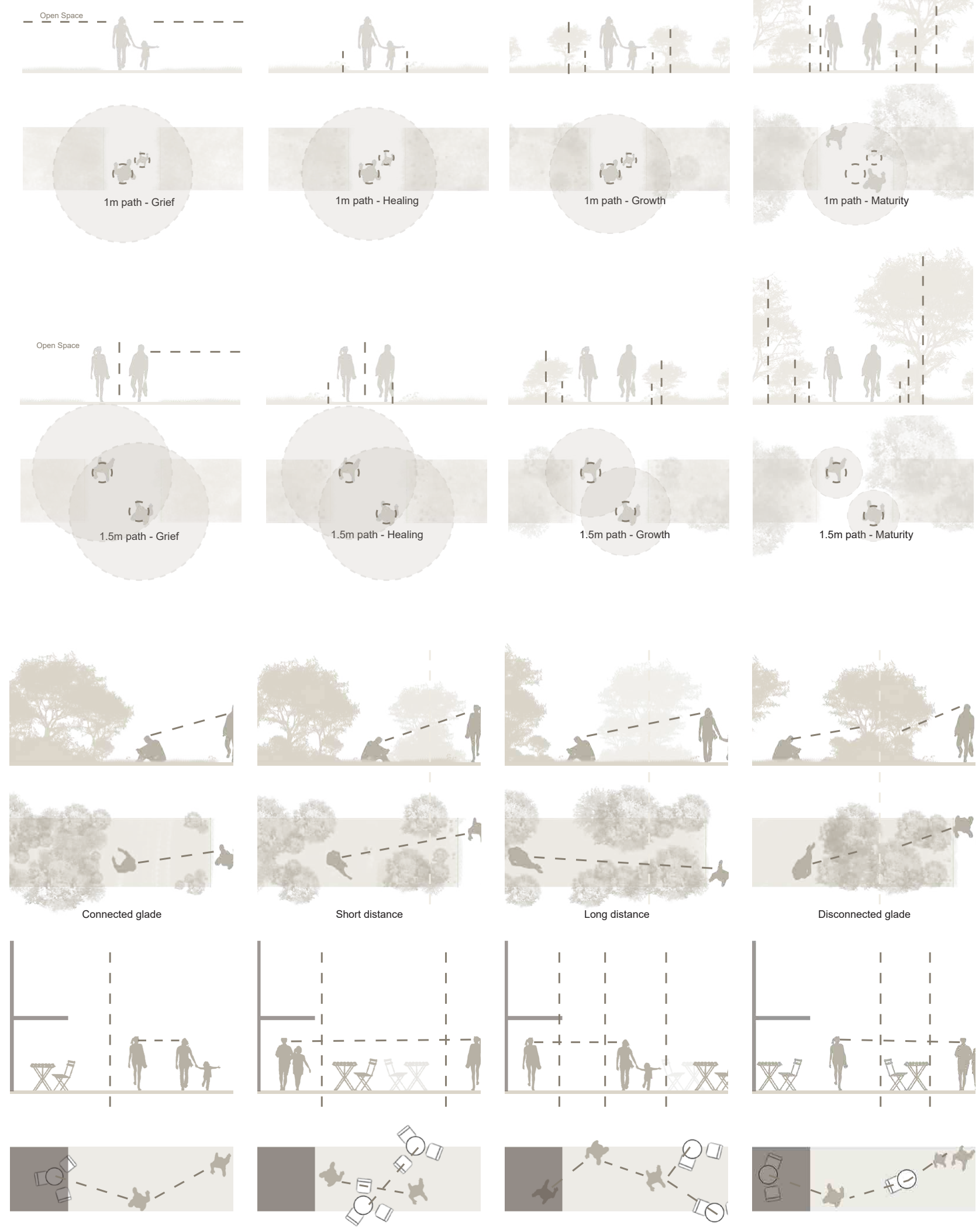

Meander

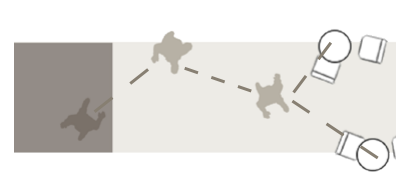

Social Space
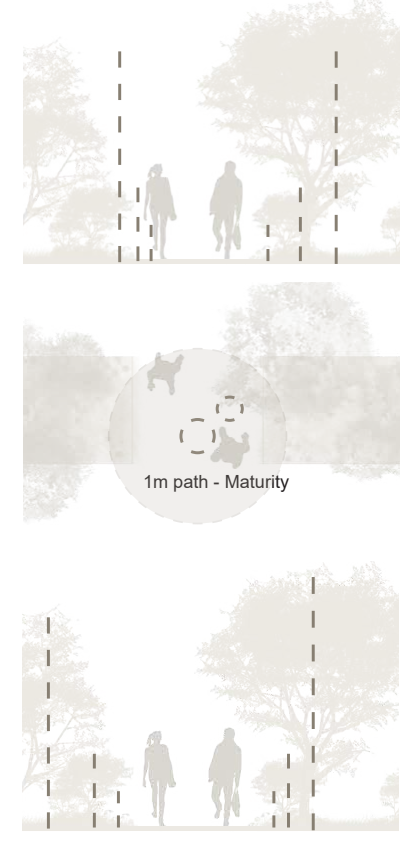

5

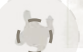

$1.5 \mathrm{~m}$ path - Maturity

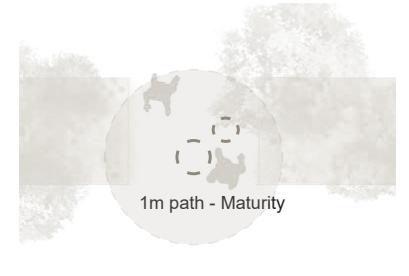



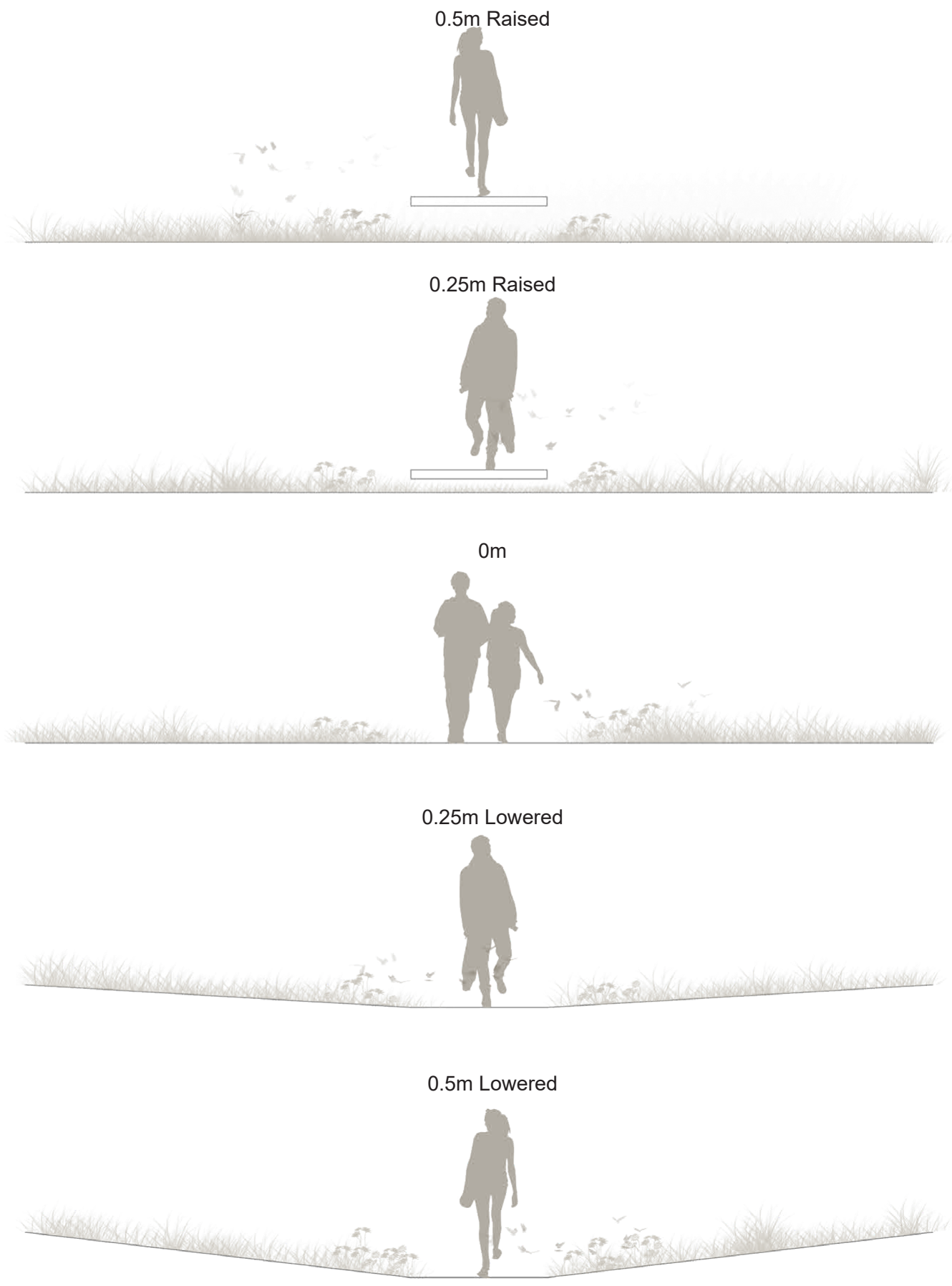

This investigation produced a variety of tools and spatial typologies that can engage with the walker, both atmospherically and physically, in a variety of different ways. Using these elements in a network will aid in creating not only a more atmospheric space, but in creating the right atmosphere. 


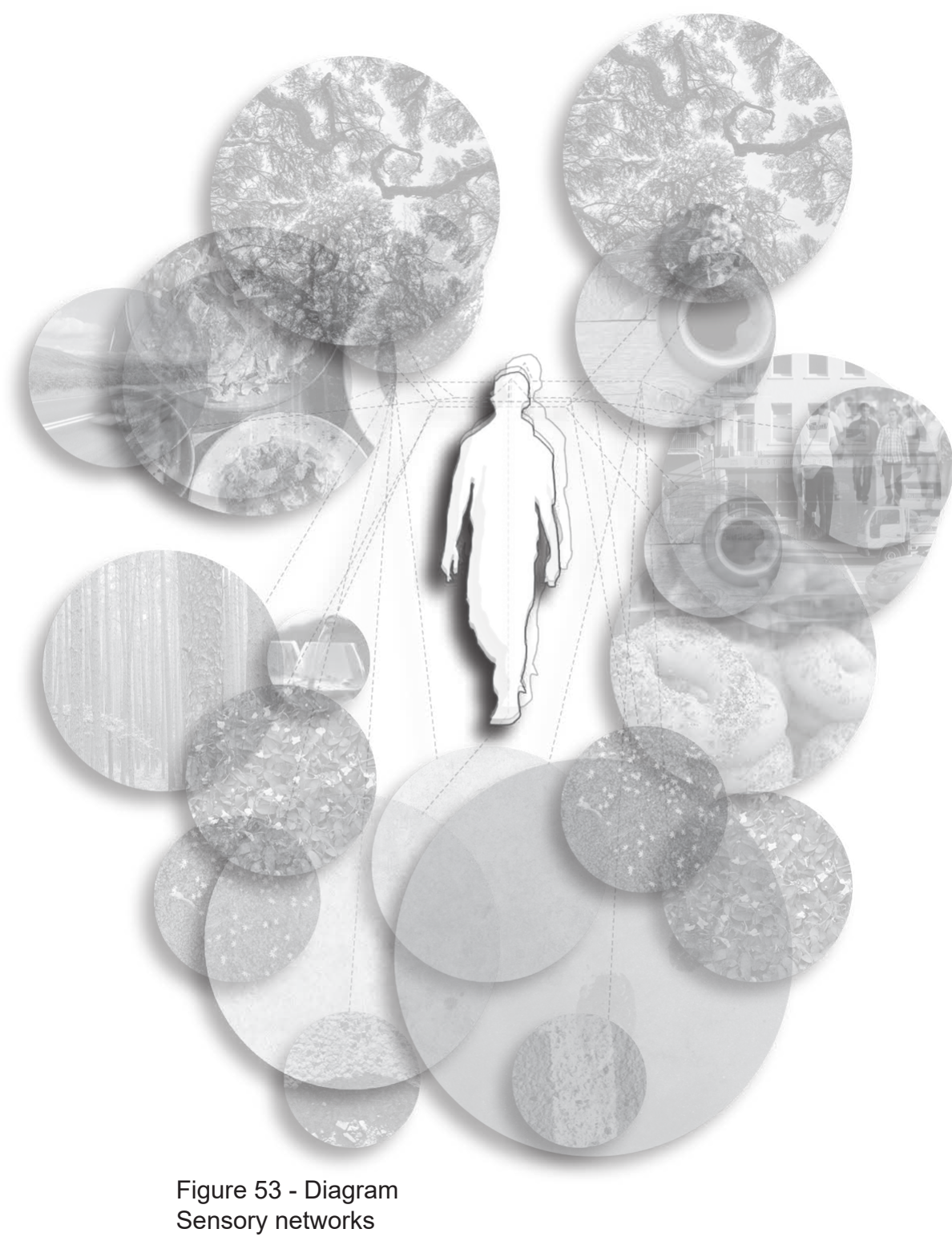

Figure 53 - Diagram

Sensory networks
The first investigation was how the senses would be engaged in the end design and create small networks of elements. The main focus of this was to create a network that could engage with all senses in a space, but only engaged touch minimally with the path below the walker. The other senses connect the user to the space, all blending into a haze rather than becoming points of focus. This relationship between senses is what creates an atmosphere as when these senses blend together they create a sense of space, where as if they stand out and demand attention they lose nuance. By minimal engagement with touch, a reliable and safe sense, a design creates subconscious distance between the walker and space that creates a more intimate and wanting relationship between the walker and this atmospheric haze. 


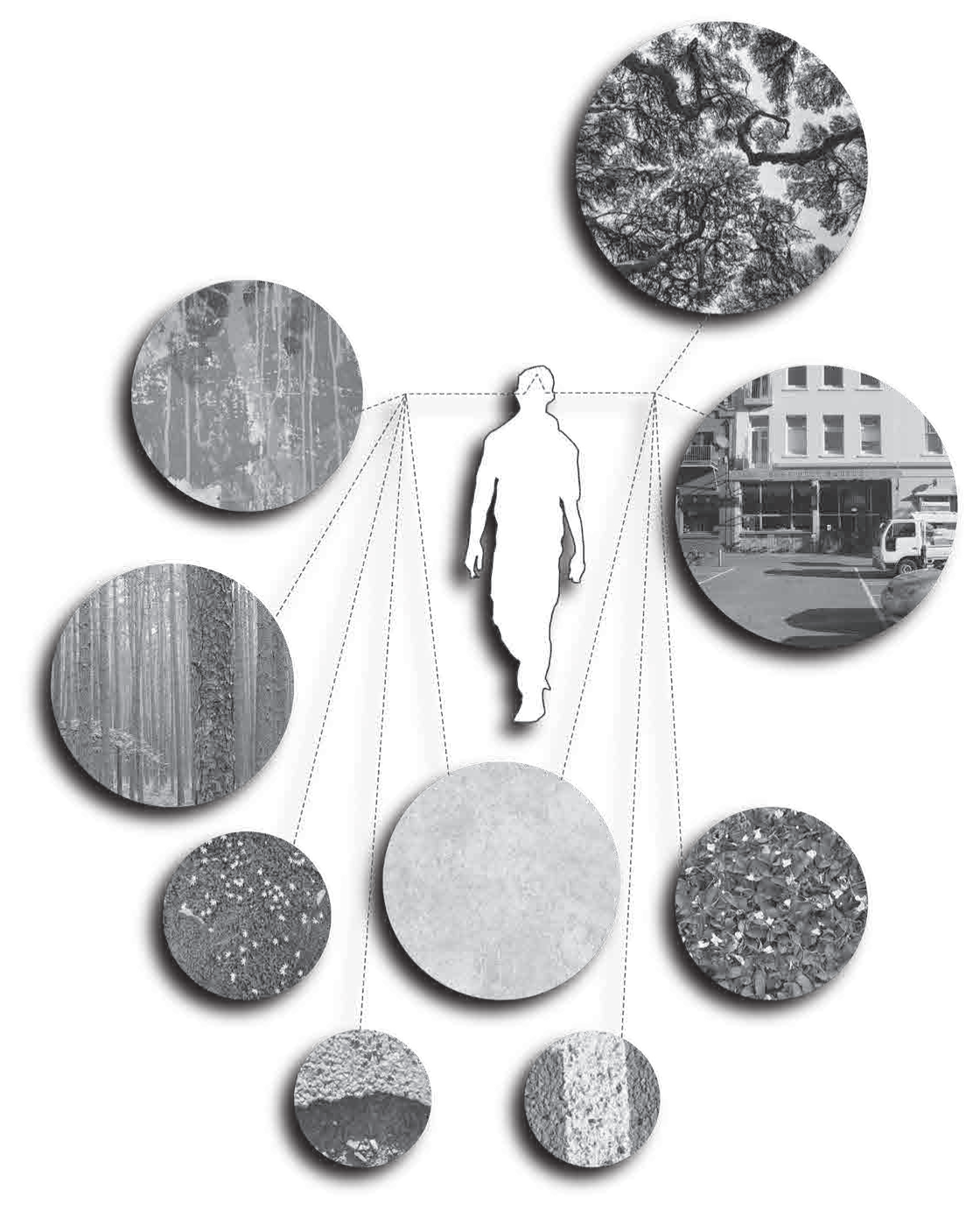

Figure 54 - Diagram

Visual network

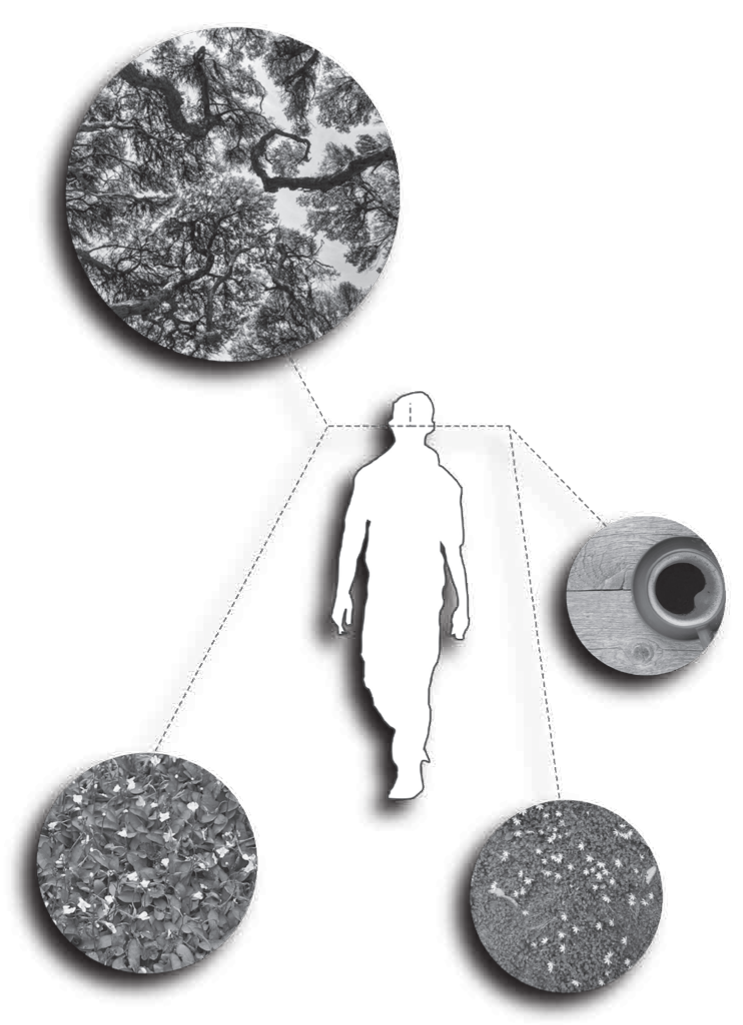

Figure 55 - Diagram

Aromatic network 


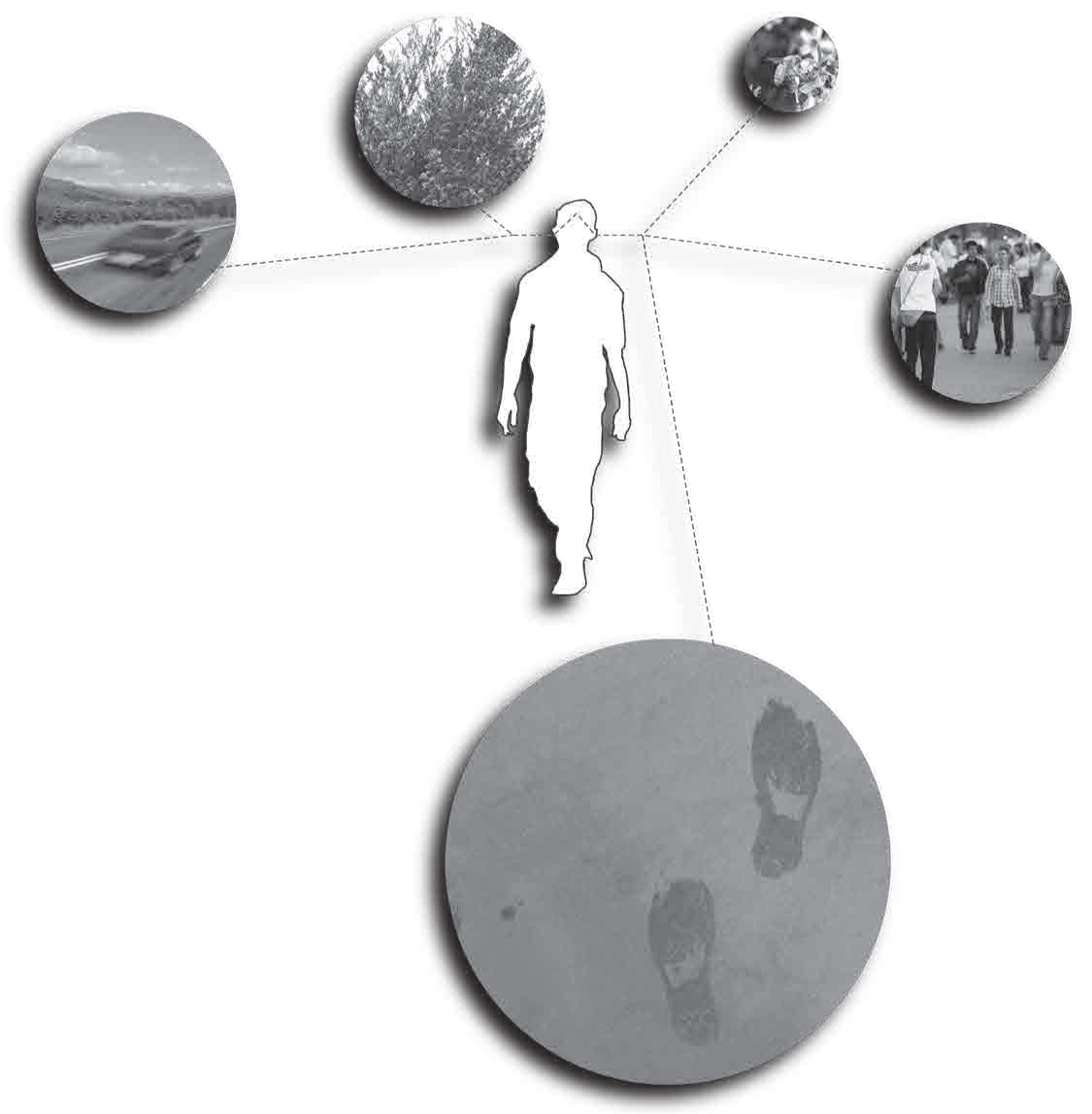

Figure 56 - Diagram

Audio network

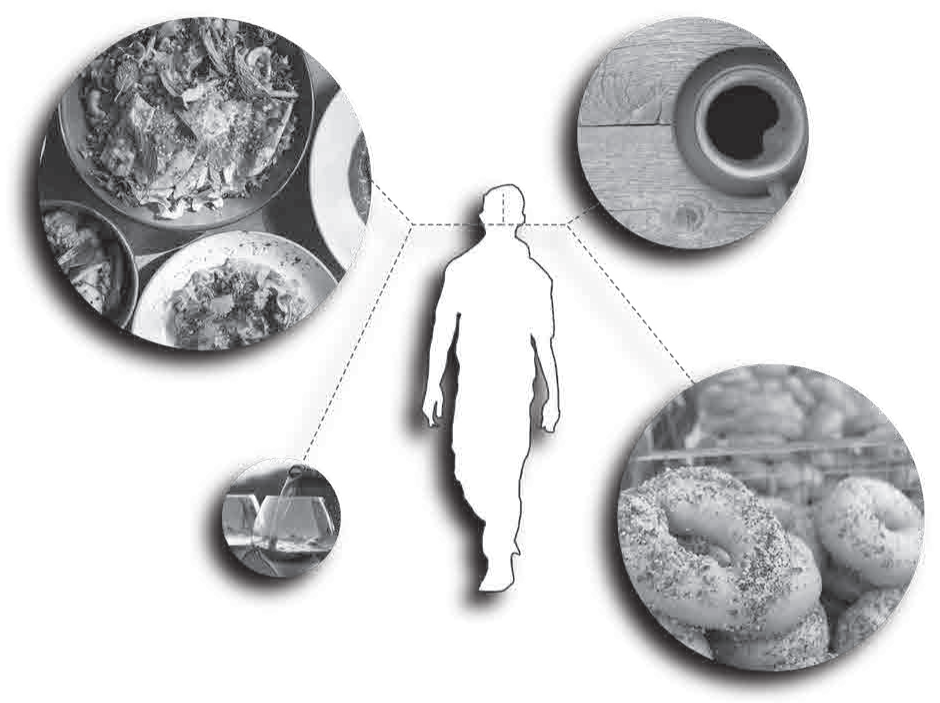

Figure 57 - Diagram

Taste network 


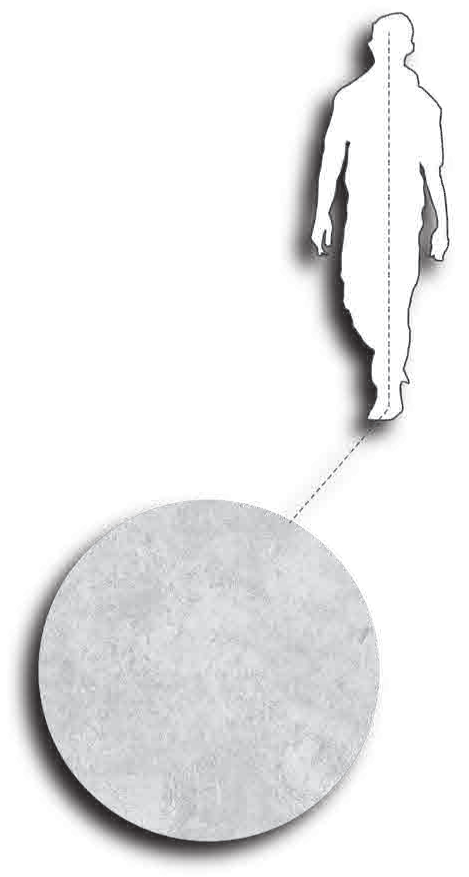

Figure 58 - Diagram

Kinethetic network

The second testing site is creating collages of parts. These are networks of textures that aid the general feeling of each space. Here typologies of space begin to emerge, looking at potential engagement points and spatial types.

These typologies of space naturally began to form when applying information for the literature review to abstract design. The forest space creates a more secluded and intimate space for those internalising to wander. The open clearing creates an open area that introduces colour and light to the walker, allowing for walkers to see seasonal changes and large collections of flowers and insect life. The cafe space creates a more open and engaging edge for the walker to add life and movement to the atmosphere. The exhibition space allows for the walker to engage with expression and art, potentially finding meaning or metaphor.
The goal is to use these assemblage as tools to create a spatial representation of both recovery and the desired atmosphere. 


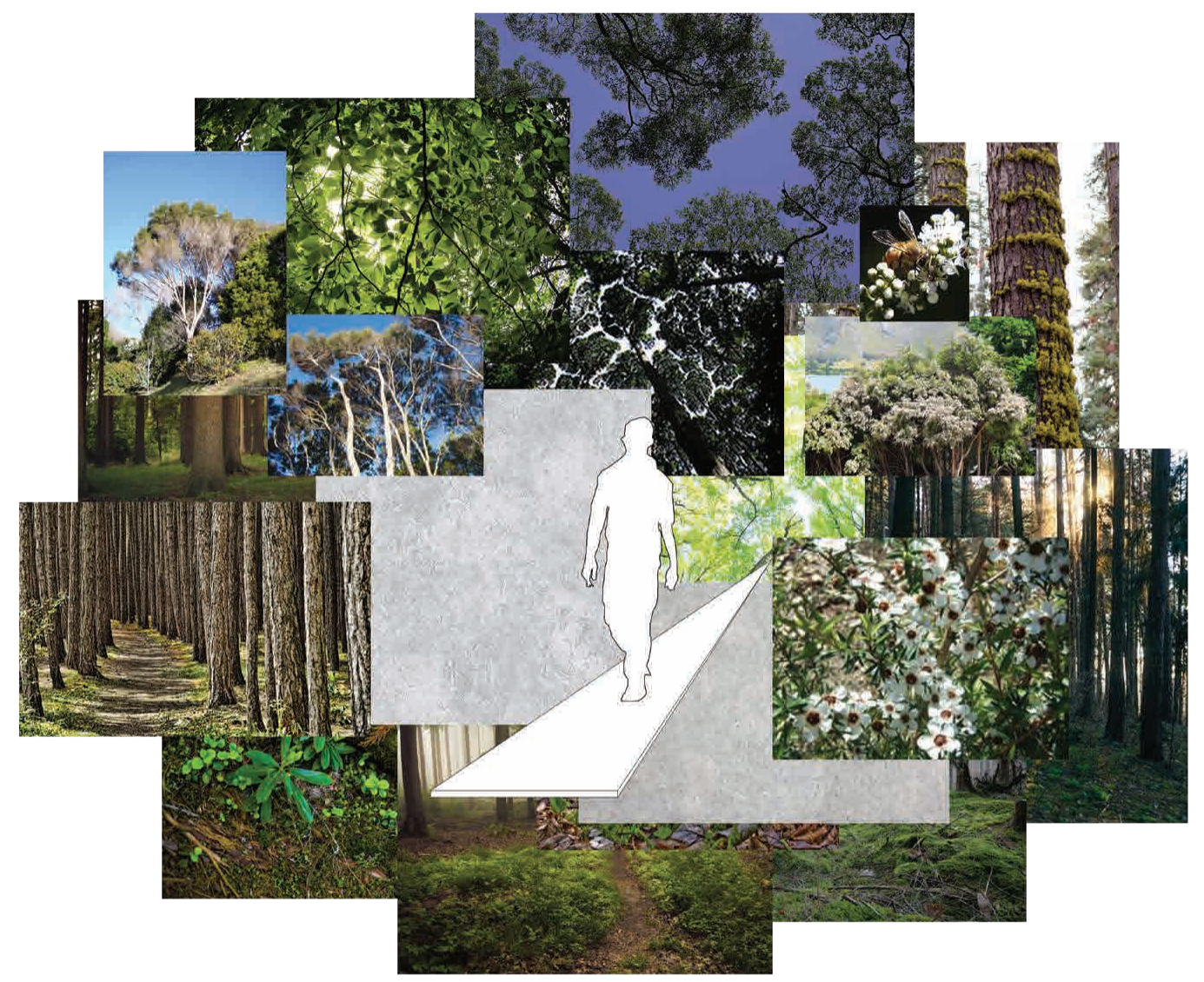

Figure 59 - Photo collage

Forest

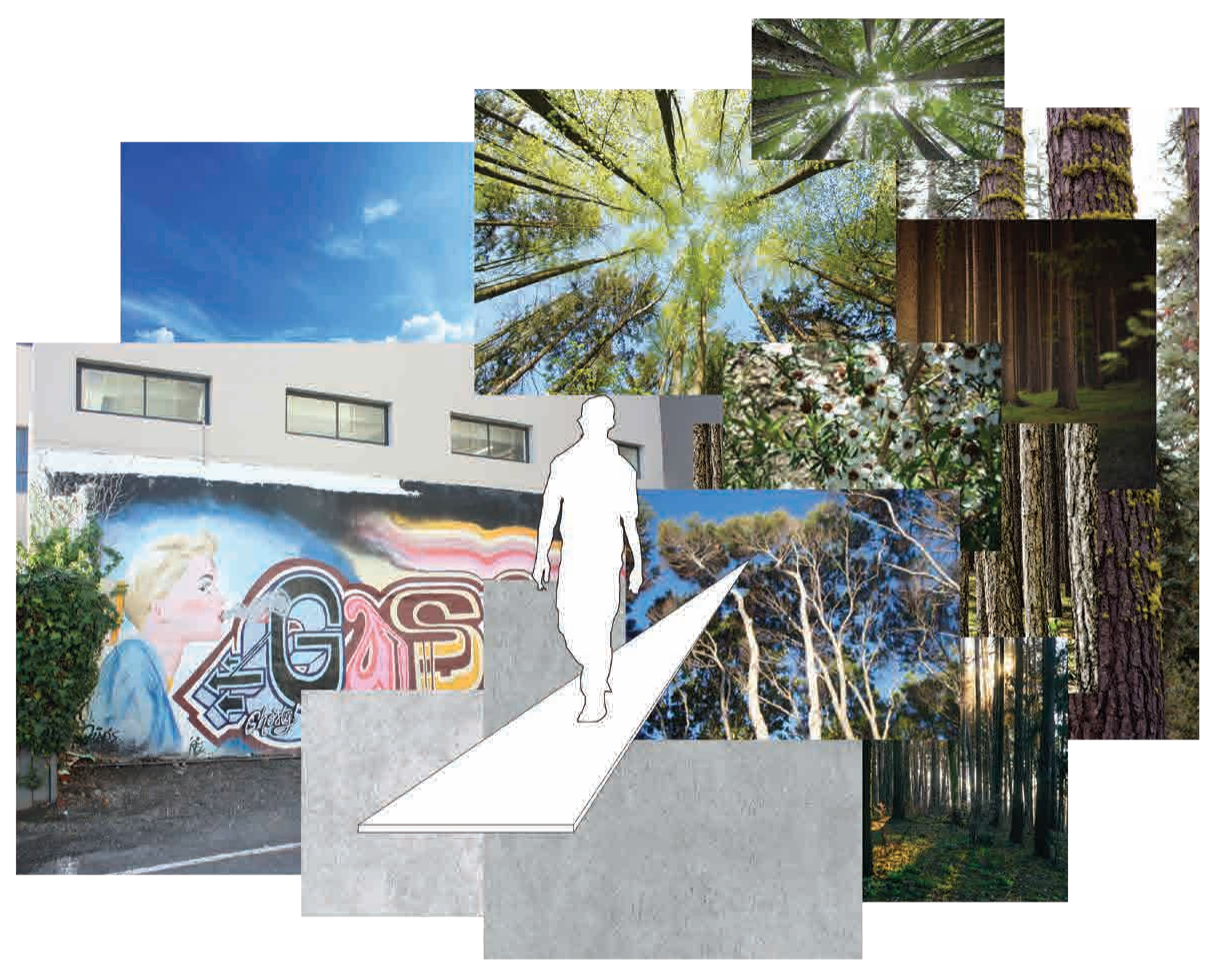

Figure 60 - Photo collage

Exhibition 
Figure 61 - Photo collage Soft clearing

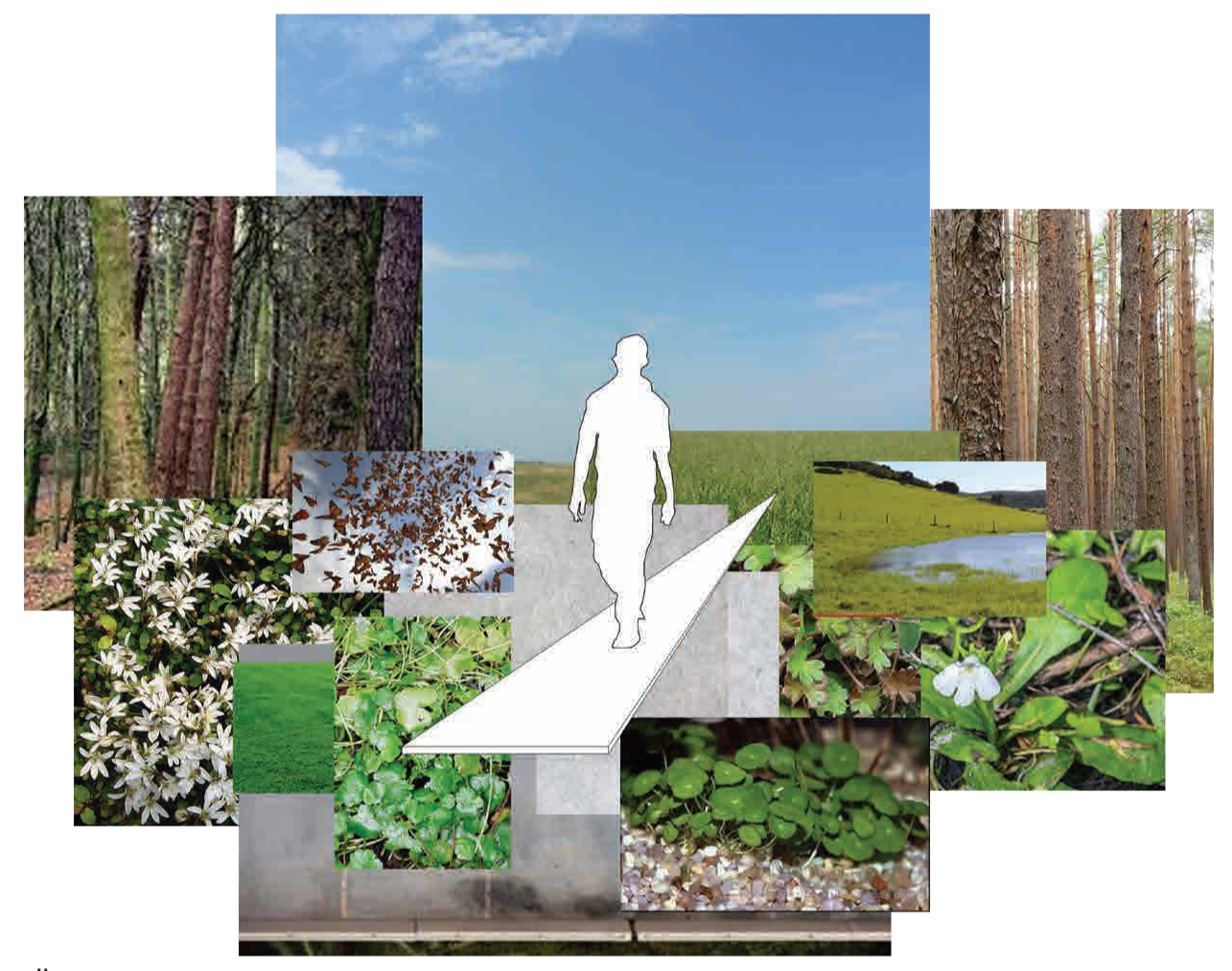

Figure 62 - Photo collage

Cafe frontage

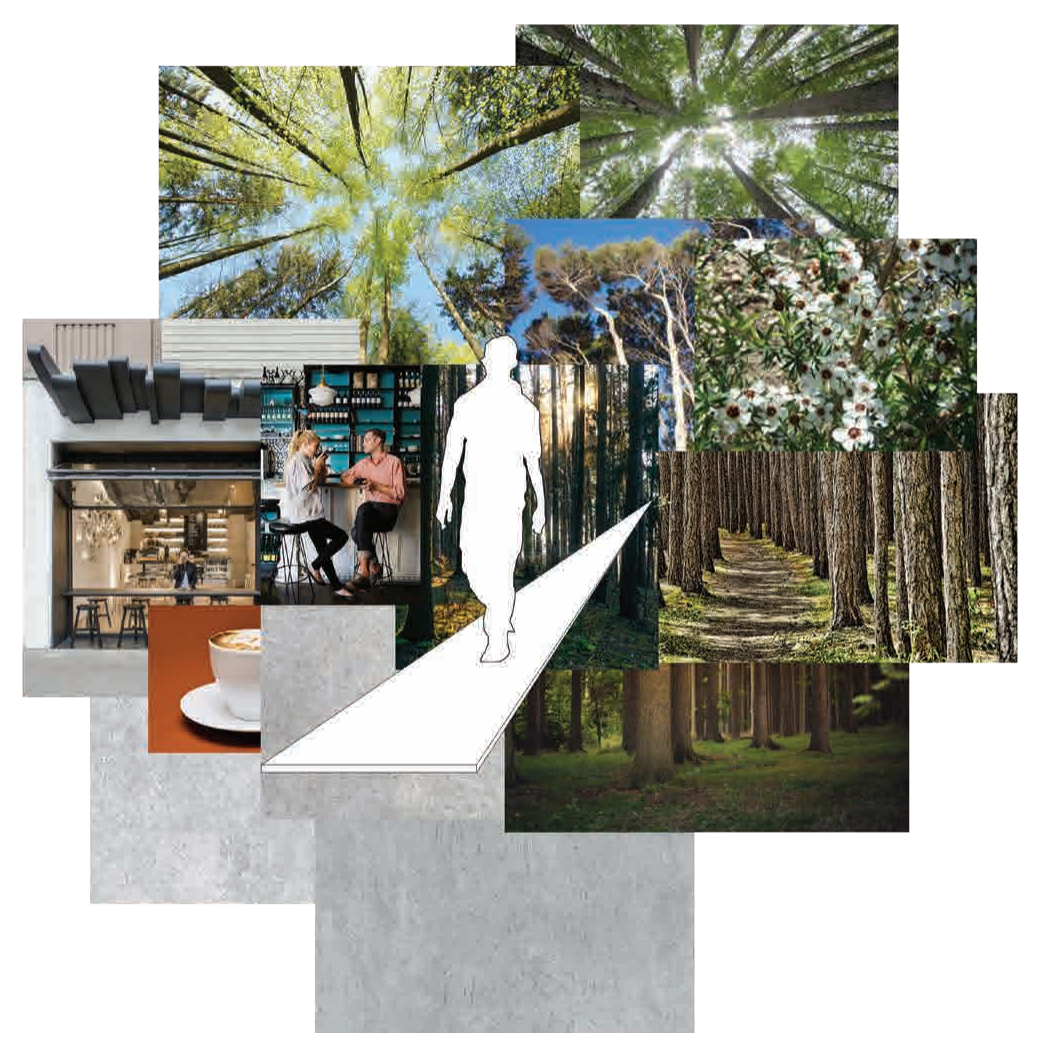


$\frac{\text { Chapter } 4 .}{\text { space and site }}$ 
The nature of this design is unconventional in that it is less of a design on site, and more of a design that claim a site, recovering it and redeeming it. This transformation mirroring that a person will go through on their own road to recovery. The site analysis therefore is also unconventiational, focusing on not only the spatial elements of the site, but also the atmospheric elements.

Wellington was chosen for this study due to its pedestrian nature as well as my relationship with the city. Throughout my four years of study I have created an intimate relationship with Wellington through analysis, life and design projects. Because of the intimate nature of this design, starting with a base understanding of the city will help to render more atmospheric understanding of how spaces affect the daily walker, as I myself have been said walker. 
This project aimed for a soft and subtle engagement with daily walker's allowing them a space to address or aid their personal journey with grief. For this a more pedestrian focused city, such as Wellington, created the right social ecosystem for this kind of intervention. The nature of Wellingtons layout means that those traveling to town, be it by walking, bussing or driving, are able to wander through the city along key pedestrian walkways and through pedestrian focused alleys and streets.

This diagram is highlighting the Te Aro area, as well as the main pedestrian walkways through and towards this area.
Spaces such as the waterfront and Cuba street are examples of pedestrian spaces that are full of use and provide well-used conduits through the city for the daily walker.

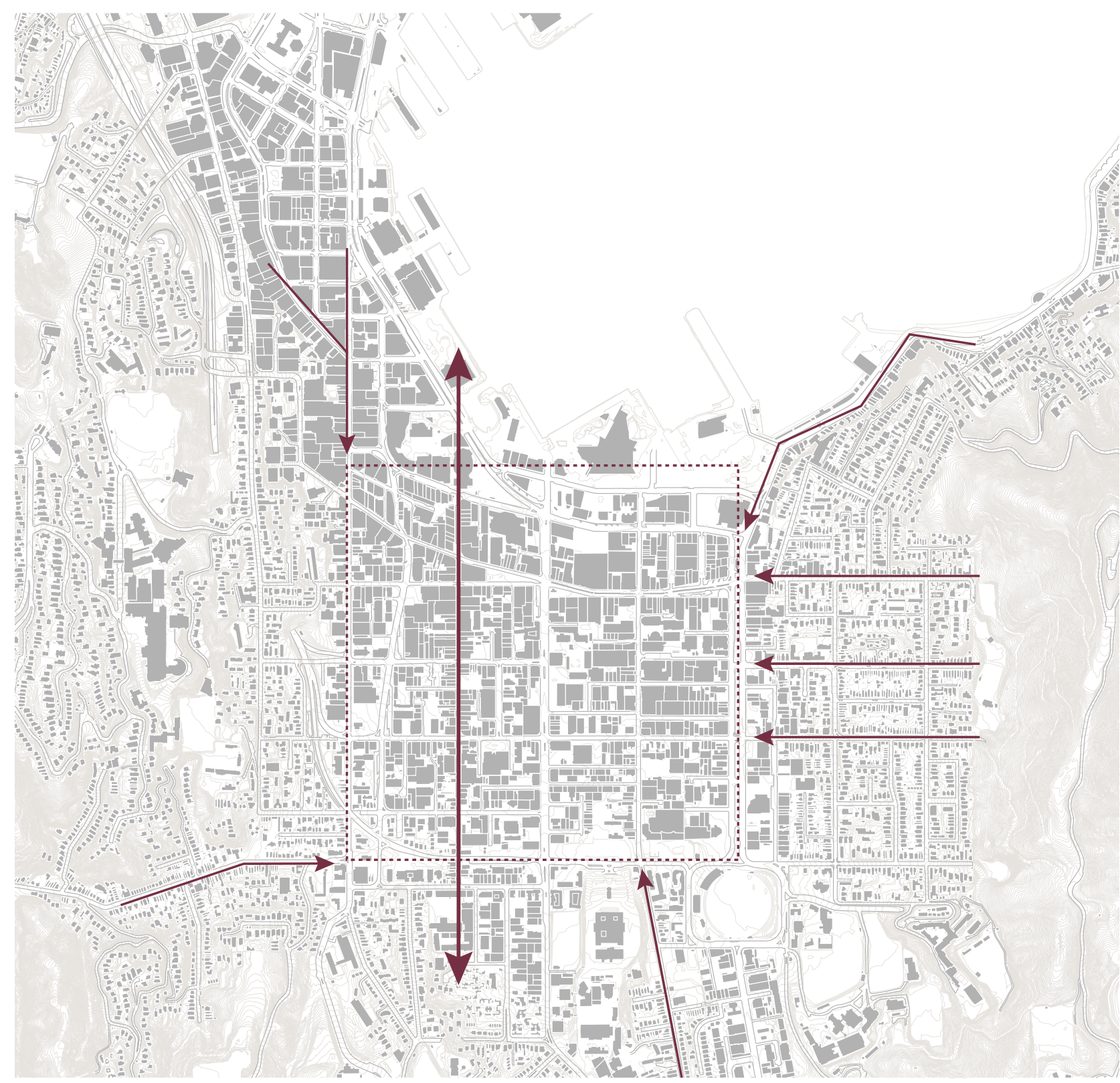

Figure 63 - Plan - $1: 15000$

Te Aro Movement 
The reflective spaces in Wellington are, as is the case with cities in general, relegated to the edges of these daily walks. I define reflective spaces as memorials and cemetery that are dedicated to events or people, creating a narrow and specific reflective space and alienating those with more personal grief.

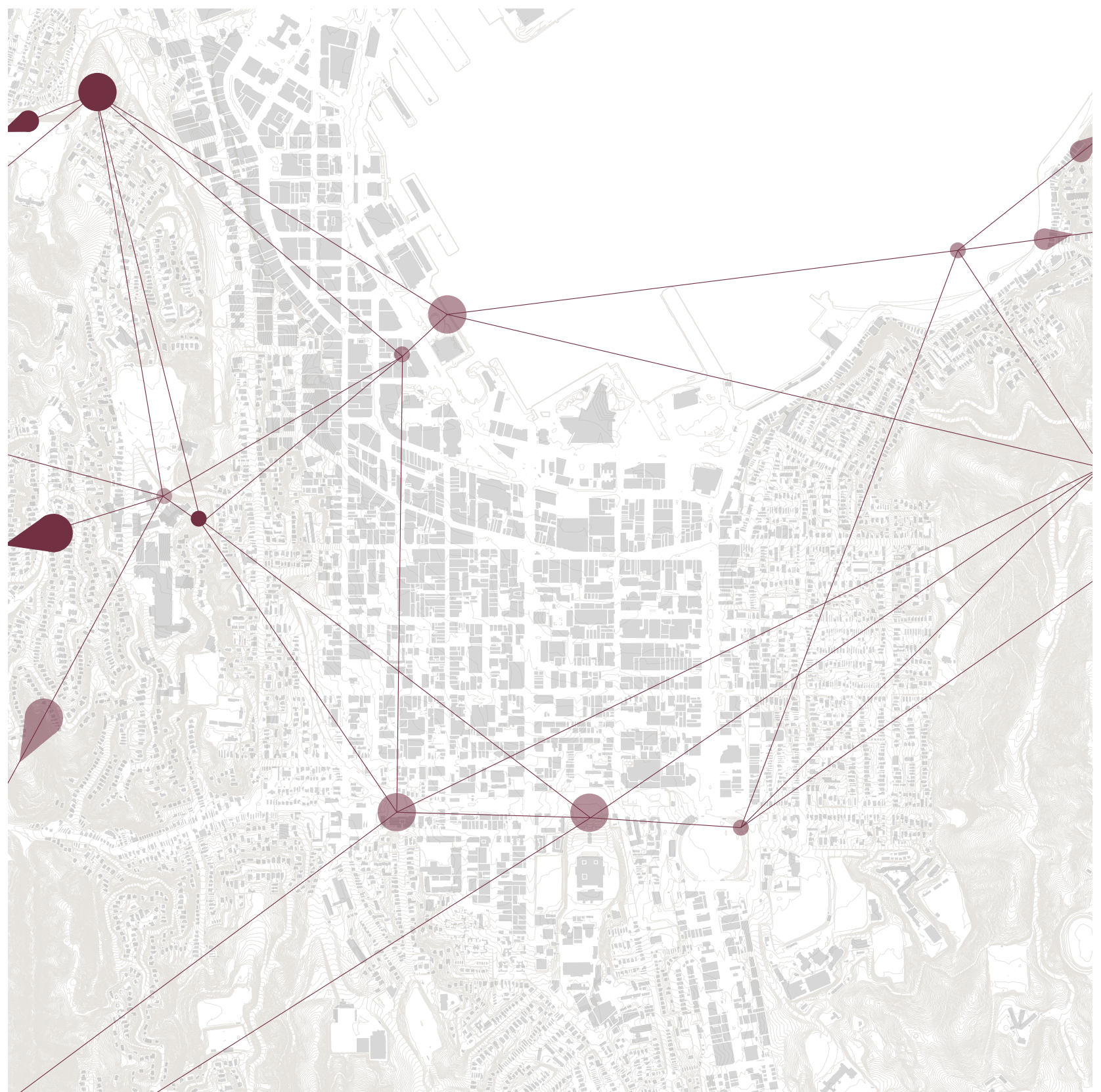

Figure 64 - Plan - 1: 15000

Reflective space network in Te Aro 
Pedestrian movement and traffic shows an area that becomes a pedestrian focused island surrounded by traffic.

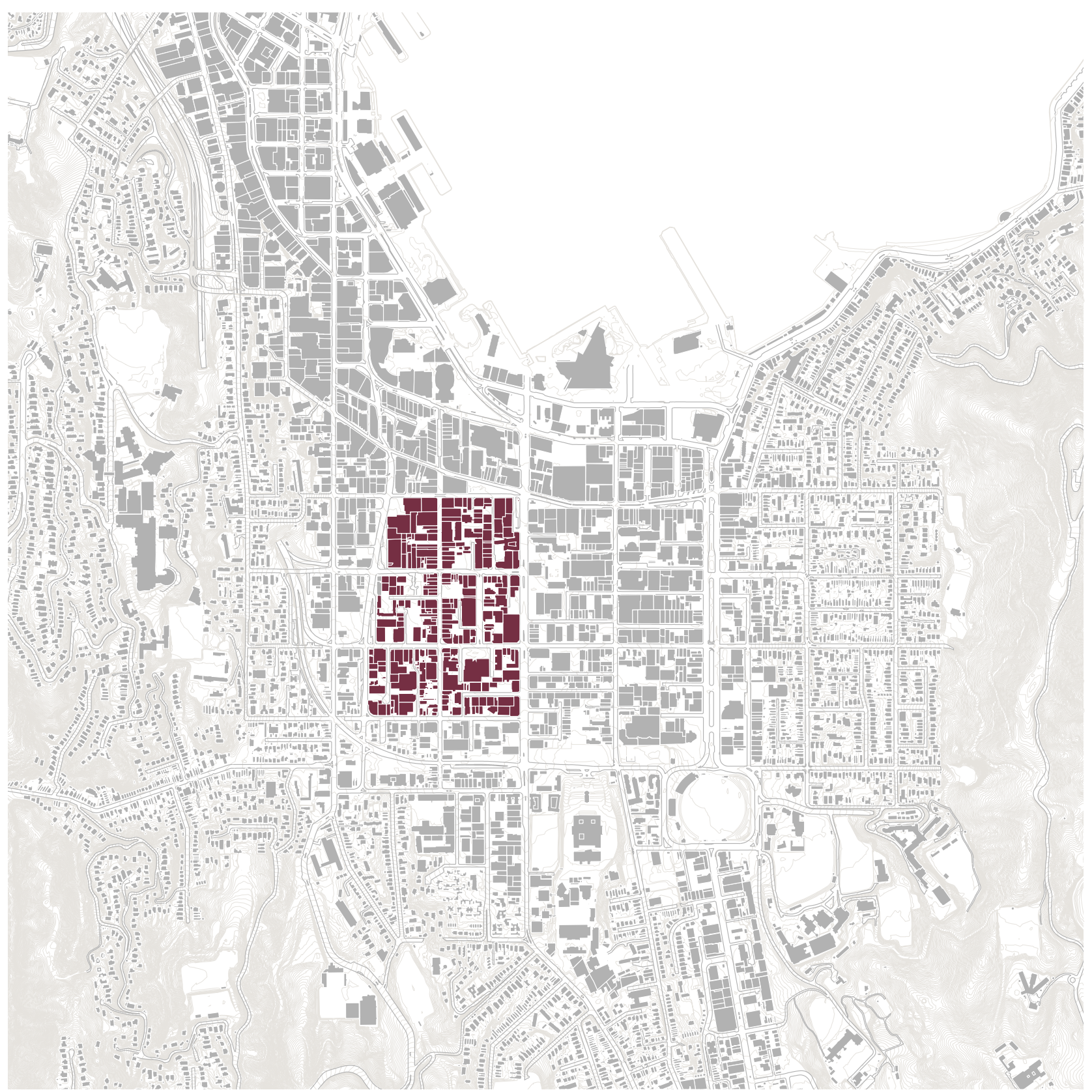

Figure 65 - Plan - 1: 15000

Chosen focus area 
This area, Te aro, is also a large gap within the reflective space network and provides a key space that allows for power to pedestrians. Those walking through this space are often placed above cars in hierarchy, having large pedestrian spaces or shared spaces.

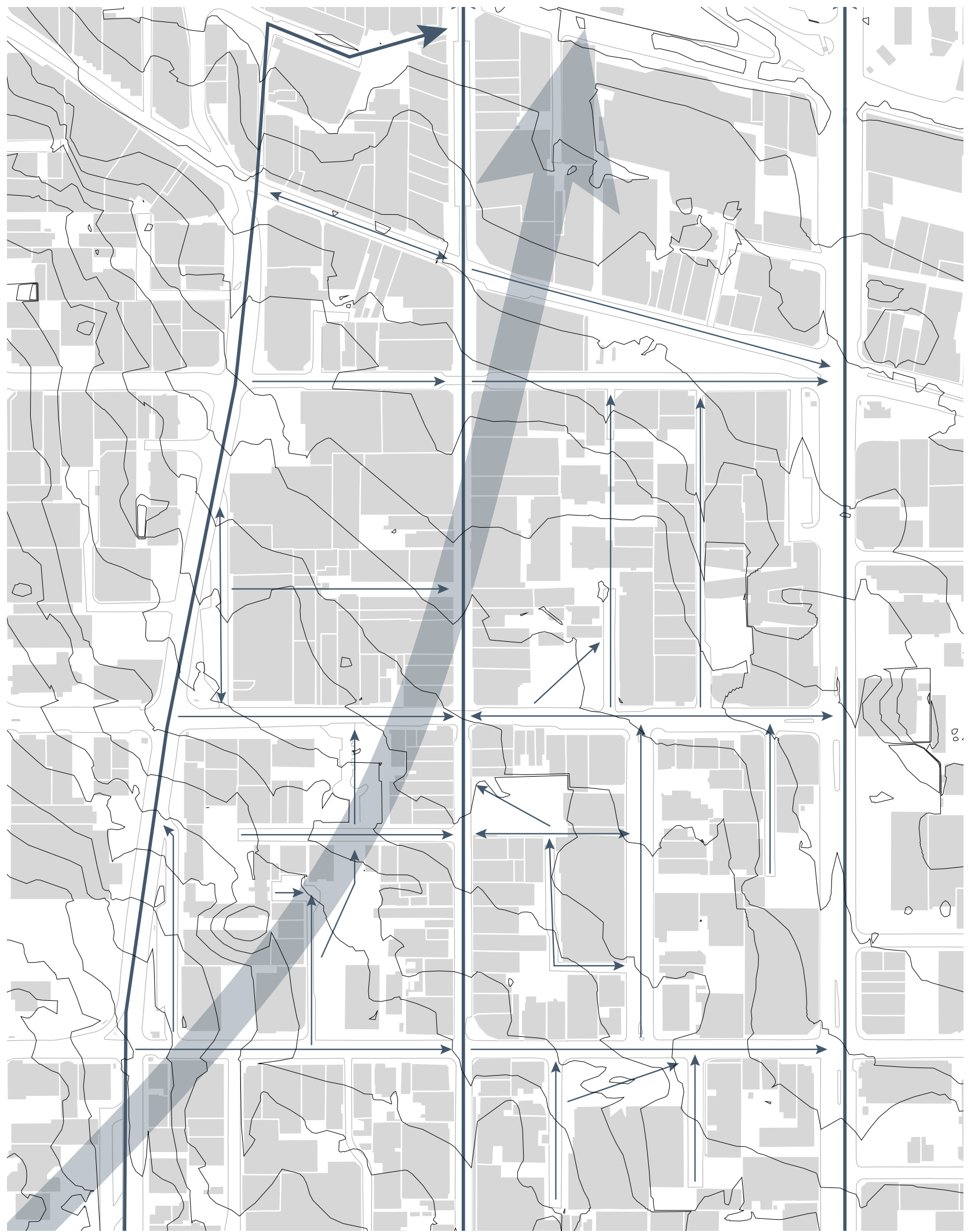

Figure 66 - Plan - $1: 3000$ Te Aro drainage 
The hypocrisy of Te Aro is it's juxtaposition between a space that places the walker first, but is populated by a network of car parks that will generally impact the daily walker's journey. These walkers that are given refuge from the traffic of the city are interpreted still by cars in the form of large open spaces dedicated to their parking.

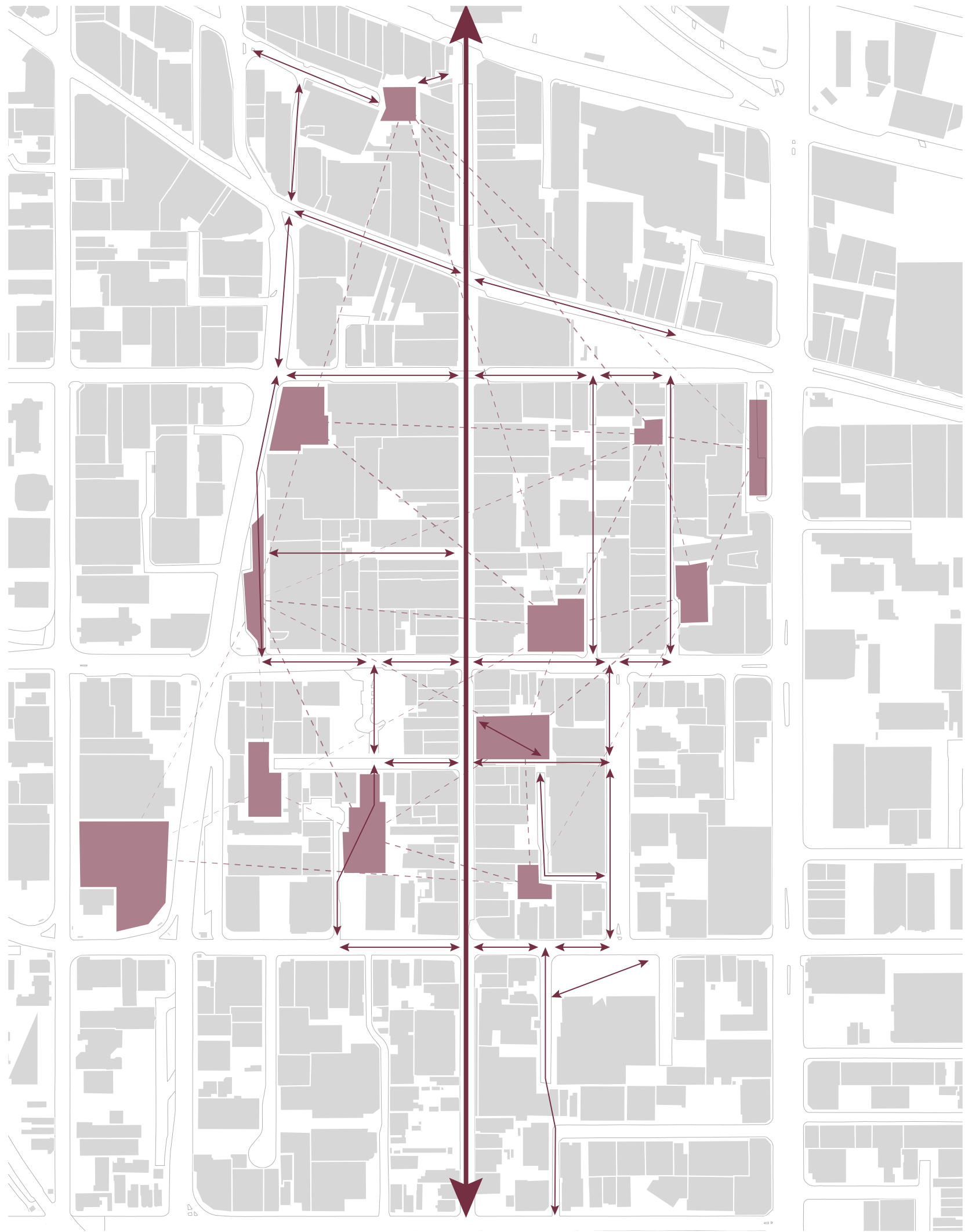

Figure 67 - Plan - 1: 4000

Pedestrain movement vs Car park network 
Whilst car parks are numerous as Figure 67 demonstrates, they often dilapidated and become a broken grey patch on the walk through the lively and colourful Te Aro area

These car parks create a possible series of spaces for intervention. The carpark marks a point of grief for the walker as a space that interrupt their lives and expected journey, starting them on a changed journey to their destination. Developing these spaces does more than create a metaphor for one's personal journey through recovery. The car parks create a network that those walking through Te Aro are highly likely to encounter, and has the potential to be a series of smaller, subtle designs that allow for a more intimate and person engagement.

From the network of Te Aro car parks, two main typologies of space emerge. Although the spaces themselves are similar, the edges and surrounding program dictate the atmosphere existing in the space. The design of the spaces are all similar and all atmospheric values are built from its surroundings. This project investigated these networks of elements to understand what parts were helping build an atmosphere in the space, and what elements were hindering a positive atmosphere.

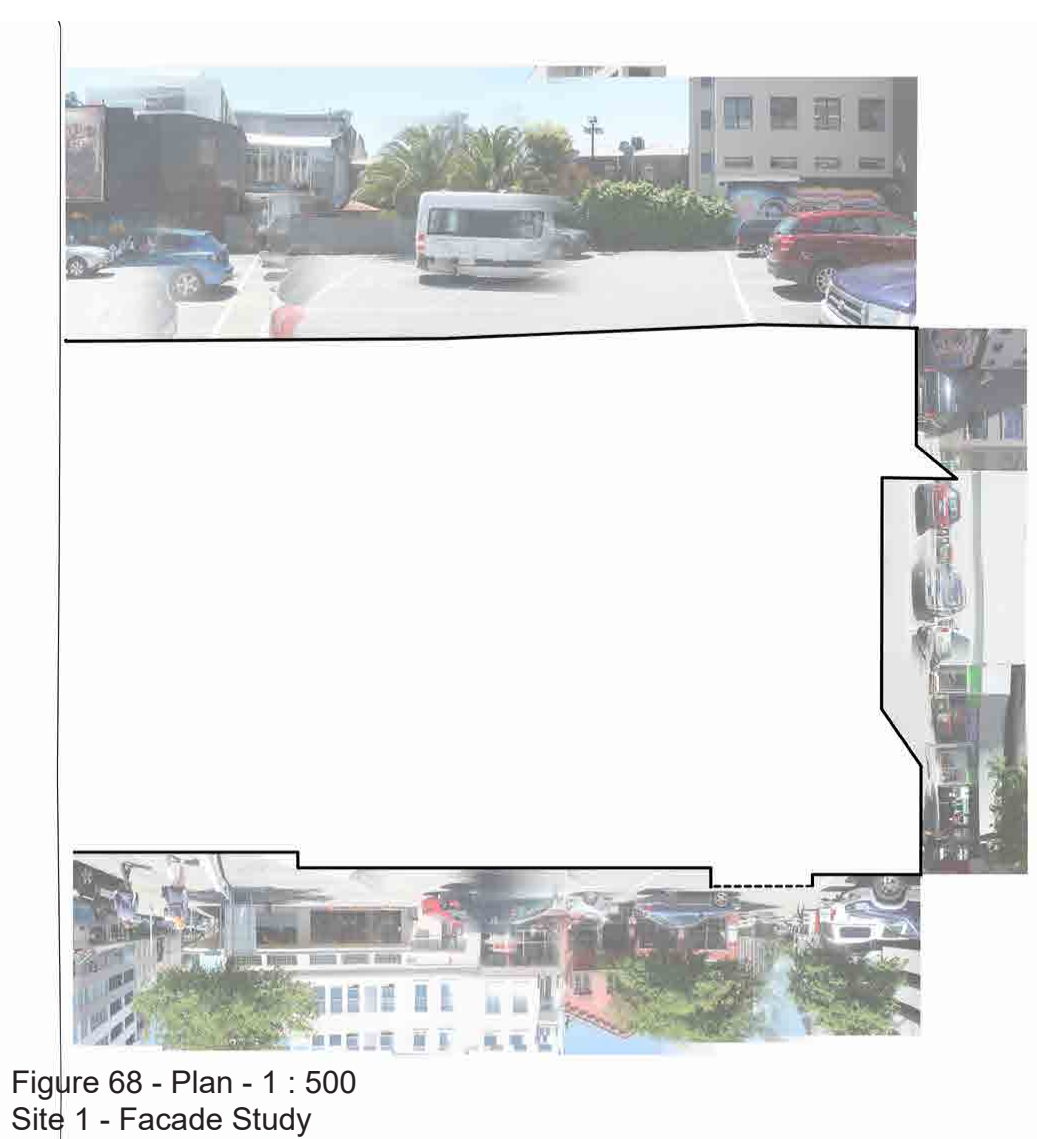

When exiting the car , the driver is placed into 2 types of atmosphere, a public and social atmosphere, or a private and disconnected atmosphere. This creates separate spaces to engage with the aily walkers, and different atmospheric elements to use in a design.

Social atmosphere are spaces with inclusive edges. Space where people can be seen and heard. In these cases the surrounding facade are those with inclusive values. Cafes, social edges, street art and vegetation are edges that help build a more lively and atmospheric space.

One of these spaces was selected to be designed as an example of how the others could be designed. It is the best example for a design that engages with its urban surroundings due to it's collection of interactive facades and it's more lively atmosphere. 
Car parks that lack these interactive and social edges feel more distant and disconnected from the city. These spaces juxtapose the colourful and expressive nature of Te Aro and create spaces that are void areas in the city. This is currently a negative atmosphere, but when applying principles of healthy recovery, spaces that allow for this disconnection from the city can allow for internal processing of grief and an individual's journey.

A car park was chosen to be an example for how all the other sites should be addressed in terms of reflective design. This space was a good example due to its size and proximity to the chosen social space. Having two end designs that are close but offer a variety of different atmospheric qualities with similar designs whos the importance of all the small elements in atmospheric

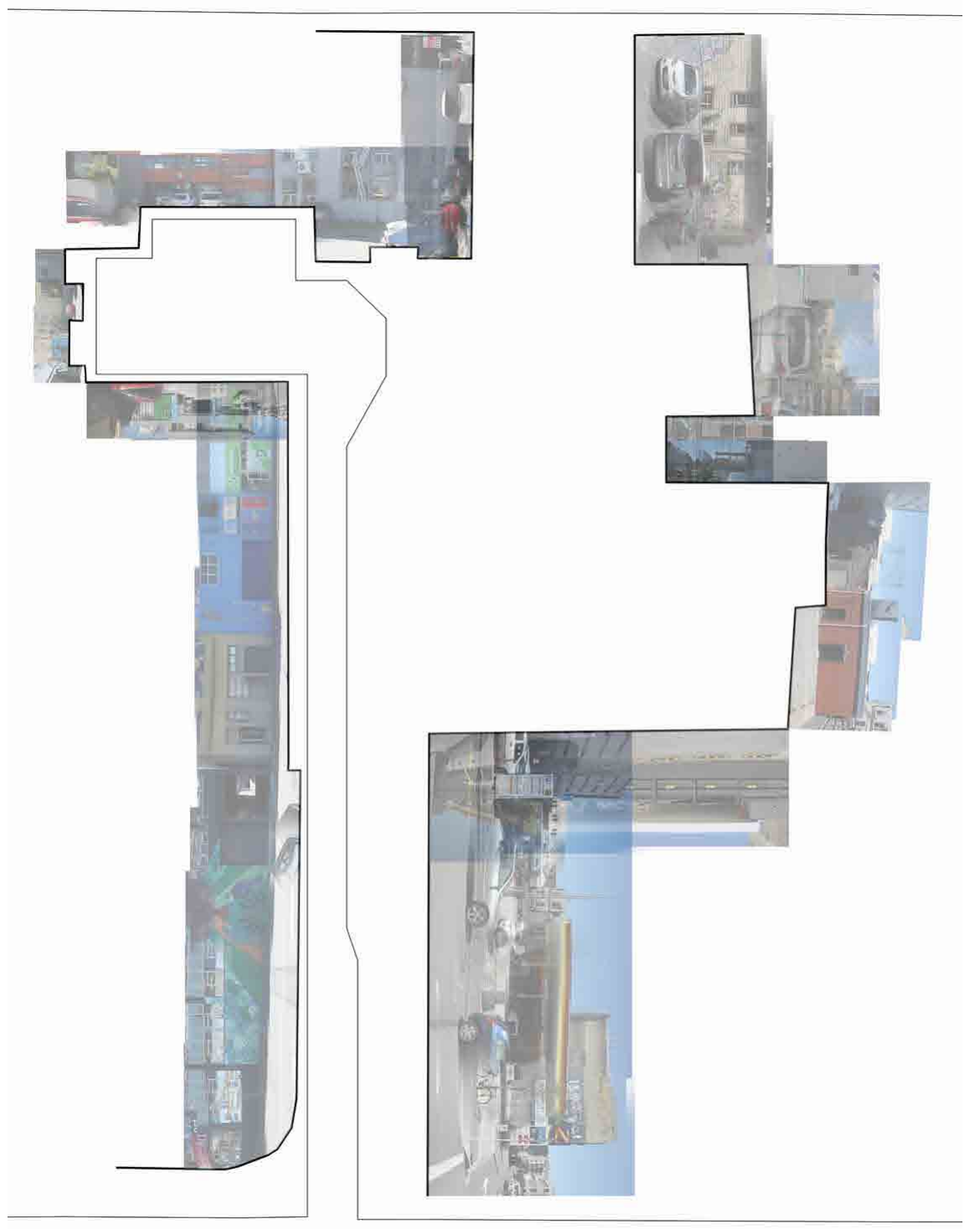

This car park also have a mostly disconnected set of facades in building backs and fences. There is little for a design to engage with and where as the other design focuses on using the existing edges to enhance atmosphere, this type of space is designed to focus on introducing elements that change the atmosphere from disconnected and desolate.

These chosen spaces represent the social and disconnected examples, but also each car park has its own feeling and urban texture, seperate from these typologies. Due to it's longer narrower nature, the disconnected example is identified in this design as 'Journey', where as the other is identified as 'intersection' as it has a variety of different paths and directional decisions. 


\section{Intersection: Site}

This space, and similar social spaces, are more circular in directionality to other parking spaces. Due to interactive edges and program within the space, there is a collection of different paths people take when journeying through the site.

This creates a series of smaller social engagements when passing others and introduces stopping and visiting to the site. This stopping and visiting is important as it creates a reason for people to come and engage with the site. The surrounding edges are cafe's , street art, and other engaging fronts that create a more central faceing space, with all facades providing surveillance towards the center of the space.

The challenges with creating a recovery space within this setting is with the social and engaging atmosphere. Although the people in the space add to to the liveliness of the space, the introduction of people dilutes the effect of the atmosphere. Building on the social use of the space and engaging with the facade, while creating spaces of disconnect and recovery, creates a rich atmosphere but too much either way would either take away form the positives of the space, or not allow for a full engagement with the site.

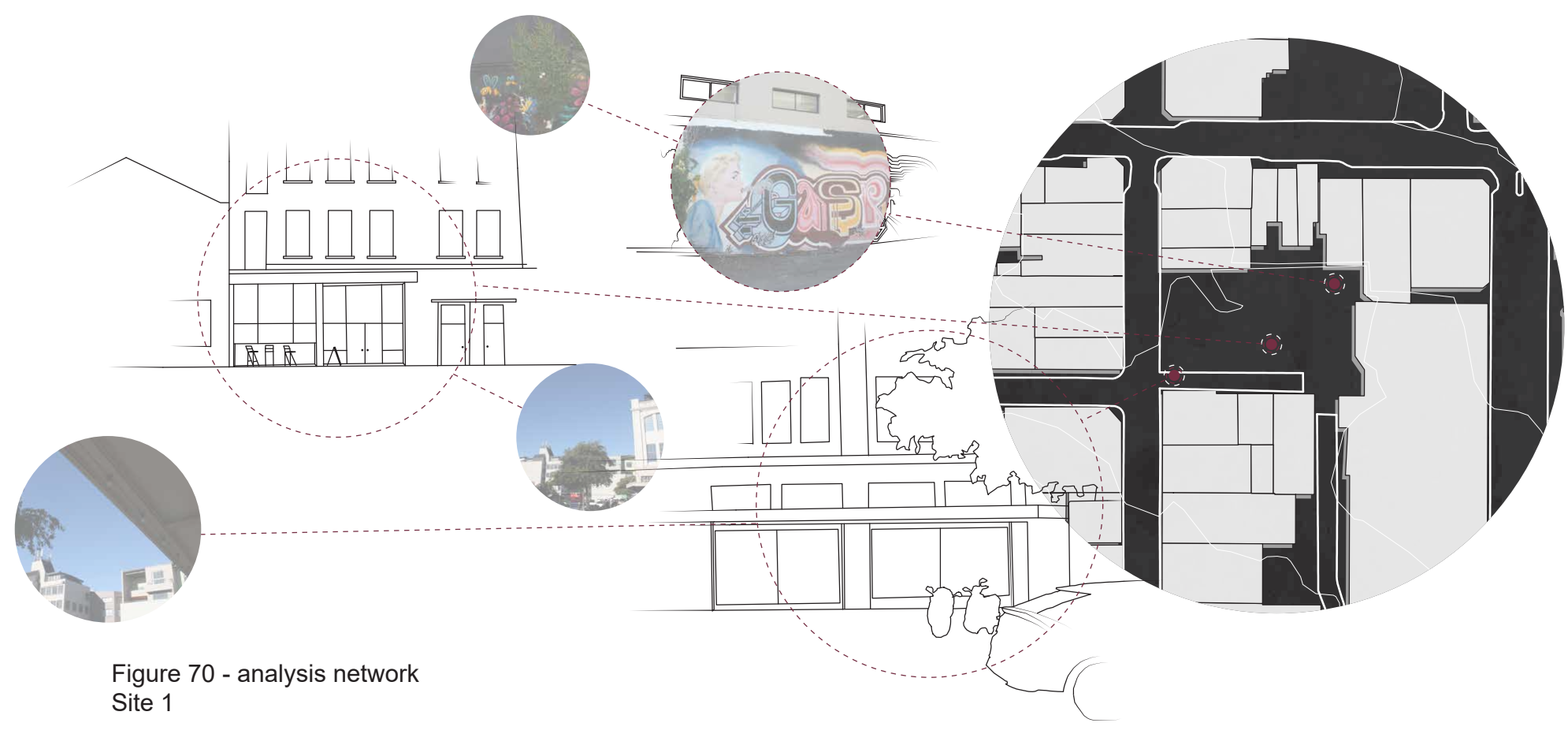




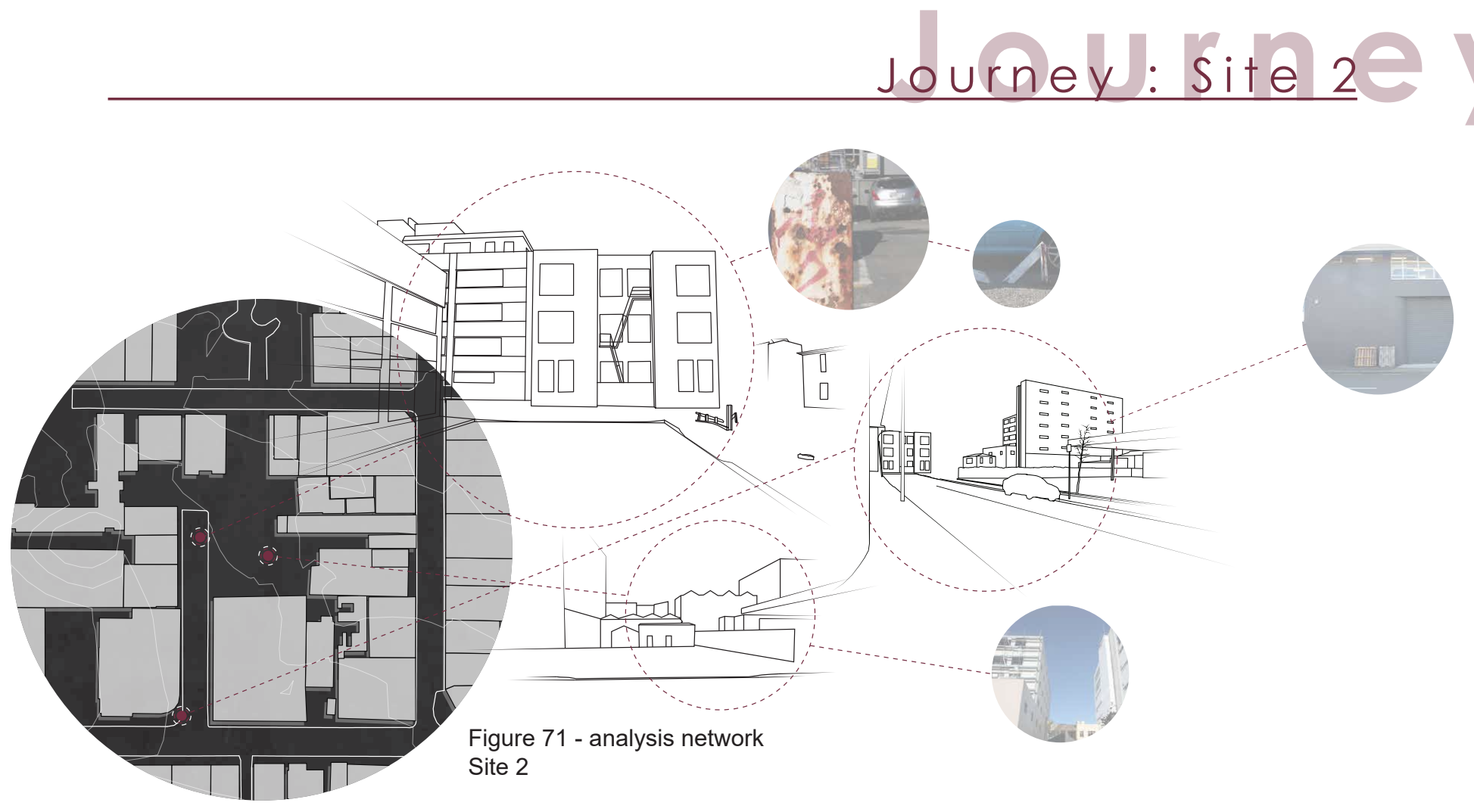

Because of their closed facades these disconnected spaces have a tendency to become linear spaces. The space gives the walker little reason to alter their course as they move through which creates a very linear and focused space. These spaces are only used as shortcuts in the city due to their current condition.

It creates a point of removal in the city, where the social and survailed atmosphere of the city is excited and a haze of dilapidation engulfs the walker. This feeling effects walkers differently throughout the day, creating a faster walk or changing their course at lower light.

The challenge with design recovery spaces in these disconnect areas come in the feeling of safety and ease. To have a reflective space engage with a person it requires submersion and unconscious thought when in the space. The city and it's concerns becoming unconscious and secondary while either the space or one's own mental process becomes primary. 
The social space is surrounded by large building but it's northern edge has the least stories. This creates a space that has large facades with glass to catch the sunlight, while the space itself is vibrant and well lit during the day.

The eclectic collection of planting expression ranges from large commissioned art and carefully placed tree, to smaller hints of colour and expression, and vines growing up walls and from cracks. The space becomes a collection of parts that already aid in creating an atmosphere, and provide a canvas for a design to engage with.

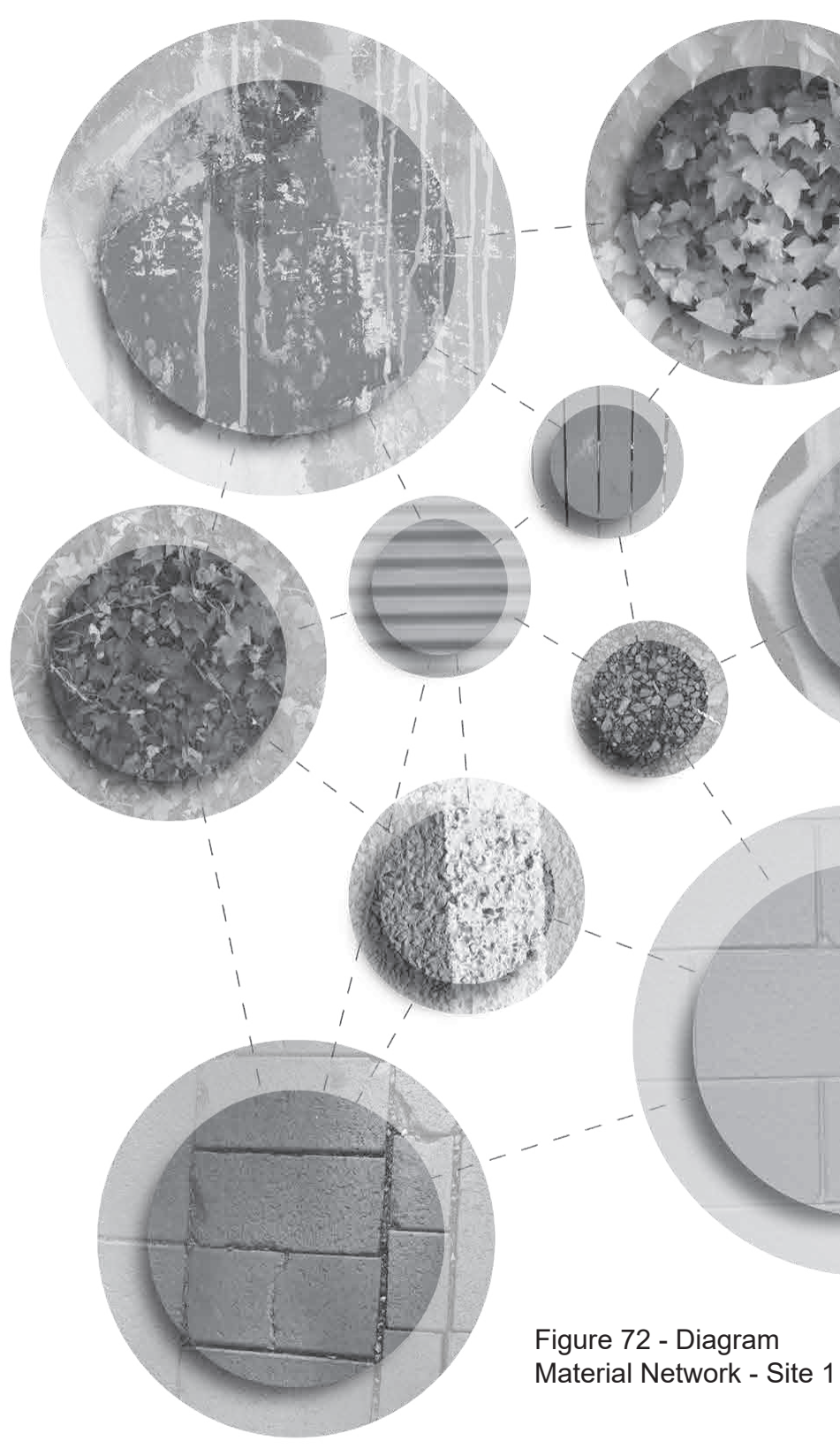

Variation in this space makes it conducive to a design with variation. It's shifts and changes in materiality create a spatial network of change that design can add to. Although the materials in spaces changes, they have a cohesive narrative throughout the space, style and colour of art might change, but expression is connecting them. International vines might contrast with the rising weeds, but they both represent growth. One facade is blank apart from street art, while another is open and social, but both engage with a person in some way. 
This space is longer, with shorter buildings generally, although towards the north east edge there is a large building that towers above the site and blocks morning to afternoon sun. On the western side is taller buildings and less space for sunlight to permeate creating a generally dark space outside of midday. Designing with this to create atmosphere would require working with this darker space, and embracing it in a way.

Unlike the social space, this space is a collection of similar elements. It has a simple and desolated network of cracks, rust, tagging and general dilapidation.

Designing in this space requires a separation from the surrounding, creating focus on the journey through the space as opposed to the space itself.
This spatial network shows clear narrative. A space that is left to age. A space of use and nothing more. The walker is secondary, and the cars themselves are even of low concern. Old materials show aging they were not designed for and new materials are quickly scarred with taggings and names.

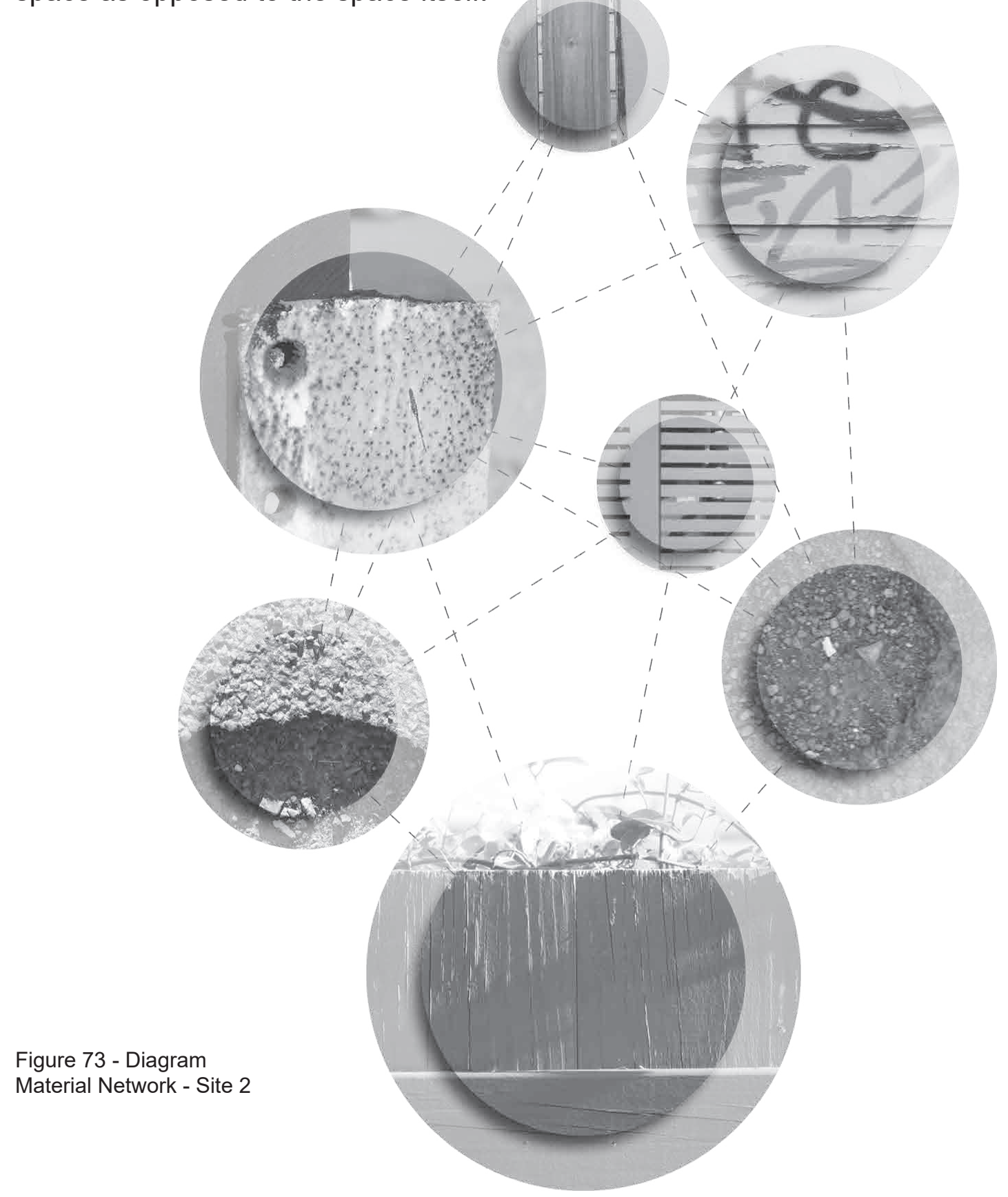


Chapter 5 . Nuance and Time 
In order to create a space for positive reflection $\mathrm{i}$ needed to balance theoretical investigations with site investigations. These two elements are joined by atmosphere to create a meaningful design, something that is often overlook in landscape architecture. Spaces that carefully and meticulously balance the theory of the design, and the space are outnumbered by designs that are intent on making a comment or statement through the design.
This section first bridges the gap between the shifts and stages of grief and the stages of design, creating a design process that both reflects and aids a healthy grief recovery.

Figure 74 - Drawing

Atmospheric relationship of space and research
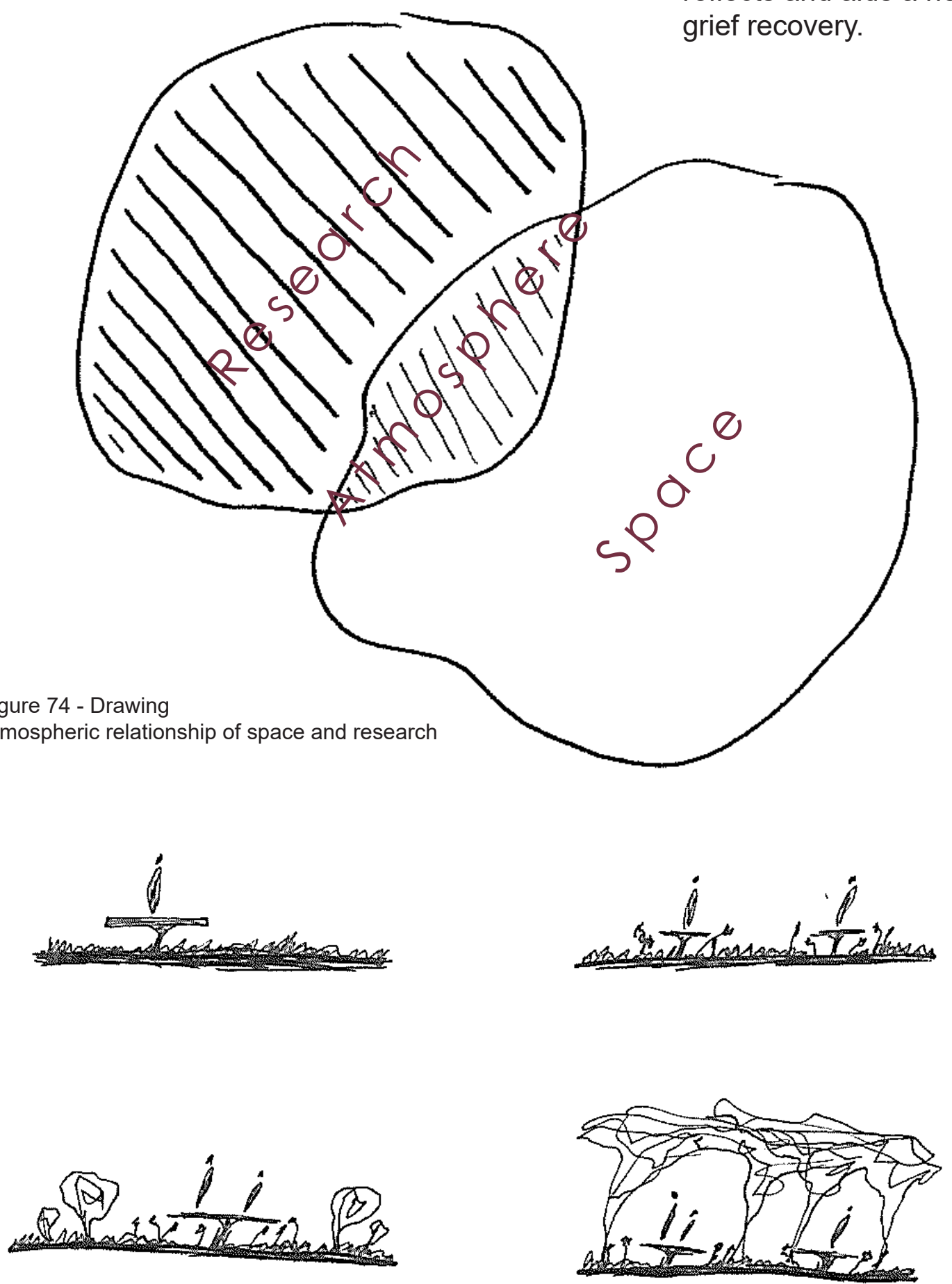

Figure 75 - Drawing

Four design stages 


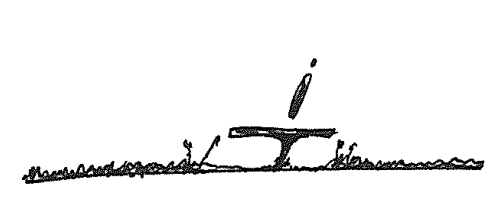

Figure 76 - Drawing

Elevation possibilities

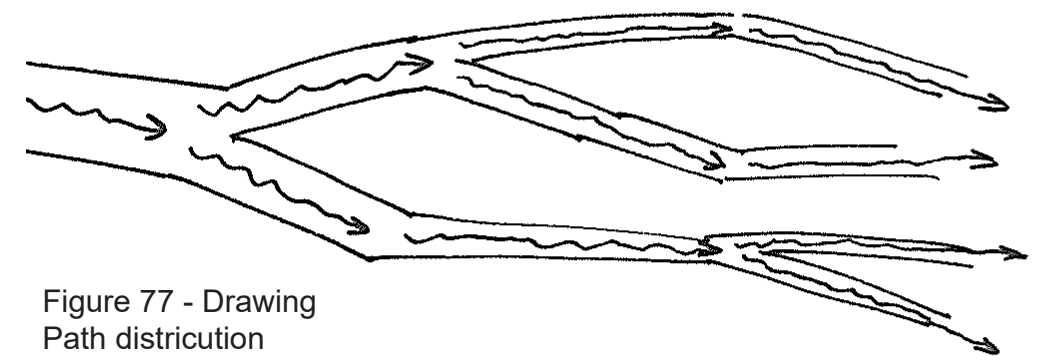

Figure 77 - Drawing

Path districution

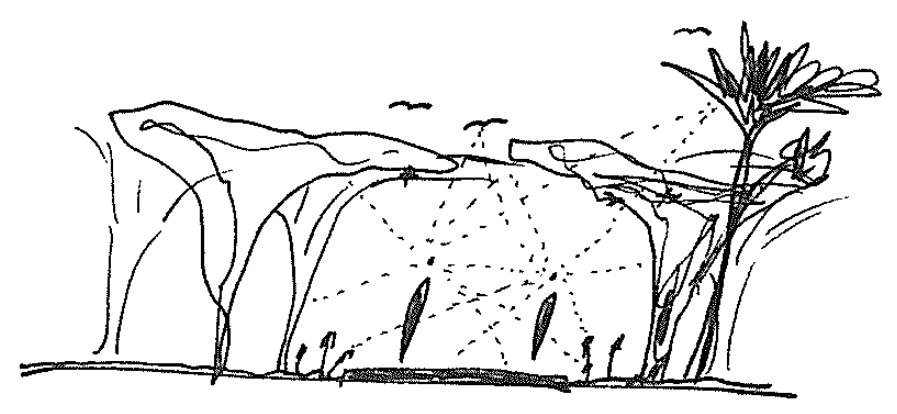

It then tests 3 methods of design that focus on the designs relation to the city and how this affects both the atmosphere, and they grieving process.

This produces a path typology that is tested both in detailed scale, to create a sense of variation and hydrology, and in large space, to develop the shape and stages of the path.

Drainage and planting is applied to this design shape to lay the foundation of design and investigate their individual effects on the walker and atmosphere.

Finally each design response reaches their end point, being investigated and tested against the site and physiological tools.

Figure 78 - Drawing

Spatial Network Diagrams 
The shift from conflict with grief to acceptance and improvement from it is the foundation of this design strategy. Rather than producing a design that is built and finished, the design process for this investigation more reflects that of a healthy grieving process. It starts with a new problem and through a series of smaller shifts creates a space that will continue to age and develop beyond any final design.

This more organic process of design allows for imperfection and embraces the chaotic nature of the landscape profession. Planting, the public and water are all elements with randomness that the design profession often attempts to predict to create a clean end result, which will eventually age and become imperfect.

The first stage of the grief recovery process is grief, which is internal. This can be seen from the tools created earlier to understand the grieving process. At this stage a person is self reflecting, adjusting to their new world and perspective and coming to terms with their individual loss. At this stage it is healthy for them to get moments of internal thought, something rare within a journey through the city.

In terms of design, this is the stage that lays the foundation of the design. Regrassing the area and introducing a simple path to the site will not only create a better space, but will allow less distraction within the city. A simple path that breaks off from one large path, to four smaller paths allows for separation of groups, creating smaller intimate relationships to space. These paths also start off at ground level, but as the path gets towards the centre of the design the ground level slowly drops away, creating a disconnection between the walker and the surroundings and creating a threshold between them and the city. 

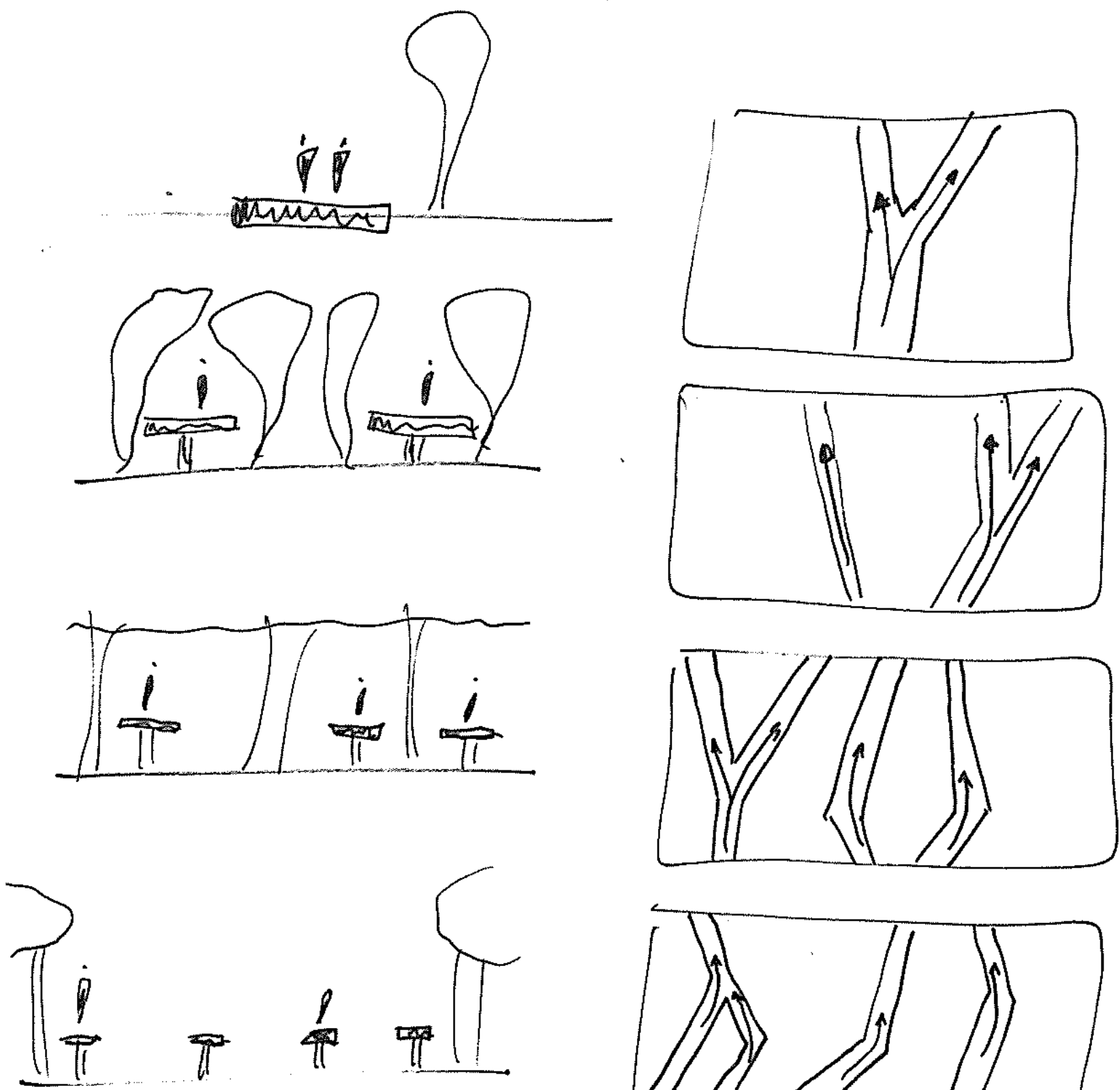

Figure 79 - Drawing

Staging drawings

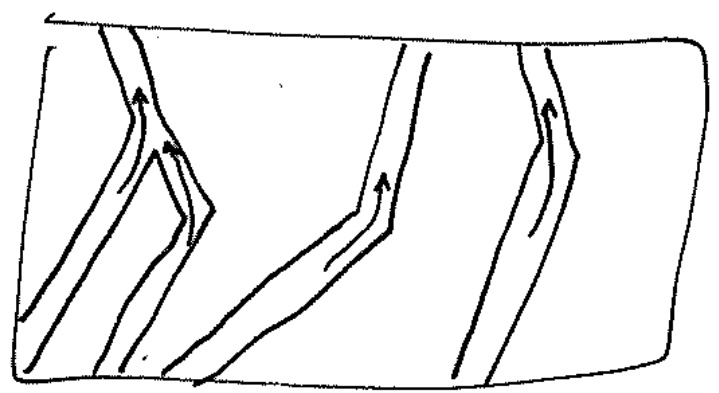


The second stage is about detail and expression. Healing is a stage of reintroduction to the world, focusing on the small details and parts that at first might be mundane, but now hold meaning. This design stage is about details and smaller planting. The paths begin to be lined with small ephemeral turf, and simple flowers are introduced into the space. Public expression is encouraged from this state, allowing for new shifts and changes as new designs are added to various walls in the design. This stage is a minor shift, but has a large impact for those at the stages of their journey where they are looking for beauty and meaning.

The third stage, growth, emphasises the journey one has taken to get to this point and acknowledges their development. It is healthy to be able to reflect and understand the amount of time that has passed and the time to come. The design introduces planting at this stage but at a juvenile and small state. This allows for the space to slowly grow, creating a variety of different atmosphere as a daily walker experiences it on different walks. This allows for a progression of time to be seen in the space as well as creating a space that, rathern than one day existing, grows as people experience it more. Seasonal planting is used, such as ephemeral turfs that hold water and deciduous trees that change in autumn, to create a yearly shift as well, so that the space changes both on a grand scale, and yearly cycle.

Finally the last stage of 'maturity' is about allowing a person to understand that their journey never has a complete end. Grief is never healed but converted to a positive feature in a person's life and they will continue to face new grief throughout their lives. It's healthy to build up an understanding, acceptance and appreciation for imperfection and challenges in life. Similar to this process, this design process has no end point. The space is allowed to continue to age and change, creating a randomness that might partially interrupt a walker, or create a more meaningful space. 
The next factor in this design was how it would integrate with the surroundings city in a way that added to the atmosphere and healing properties of the city. Three strategies were tested as very basic designs to give an understanding of how it's incorporation might look, and to understand its effects on both the people and the surroundings.

The first investigation tested an integrated approach. This would focus around interacting with the surrounding spaces and creating a space that is additive to the city. This test focused on simple lines and direction that allowed the walker quick movement, with spaces near the edge for stopping and interacting. It lowered the path into the space to give it a more connected feeling to space.

This investigation produced a space that was atmospherically lacking. Although there were points of interest, the design became an extension of surrounding spaces and thus was lacking its own unique network of feeling. Without the strong atmosphere, the space would struggle to connect to the walker and would lack the ability to create positive reflection. 
The first investigation tested an integrated approach. This would focus around interacting with the surrounding spaces and creating a space that is additive to the city. This test focused on simple lines and direction that allowed the walker quick movement, with spaces near the edge for stopping and interacting. It lowered the path into the space to give it a more connected feeling to space.

Figure 80 - Compilation Intergrated design concept - Site 1
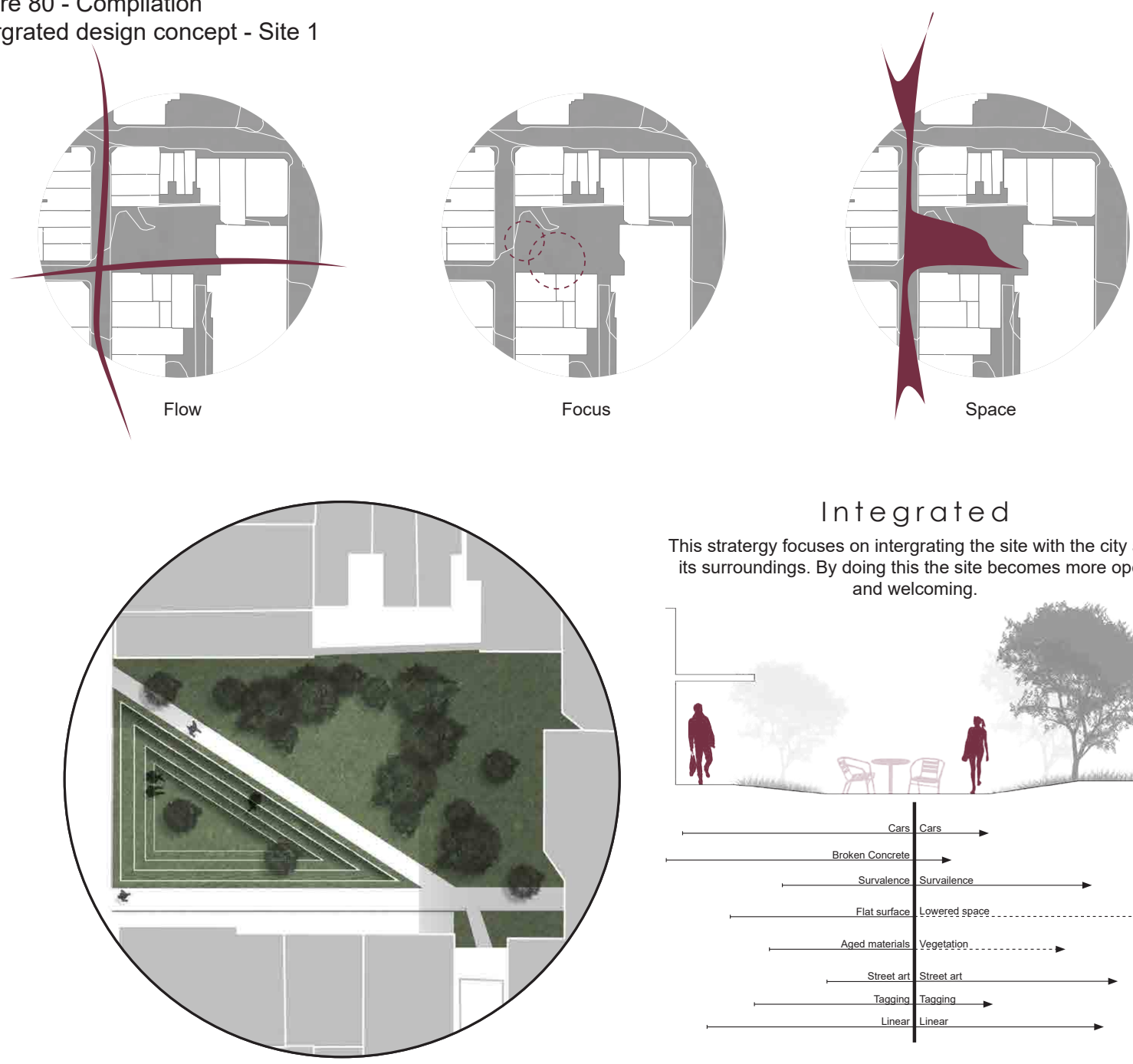

Integrated

This stratergy focuses on intergrating the site with the city and its surroundings. By doing this the site becomes more open
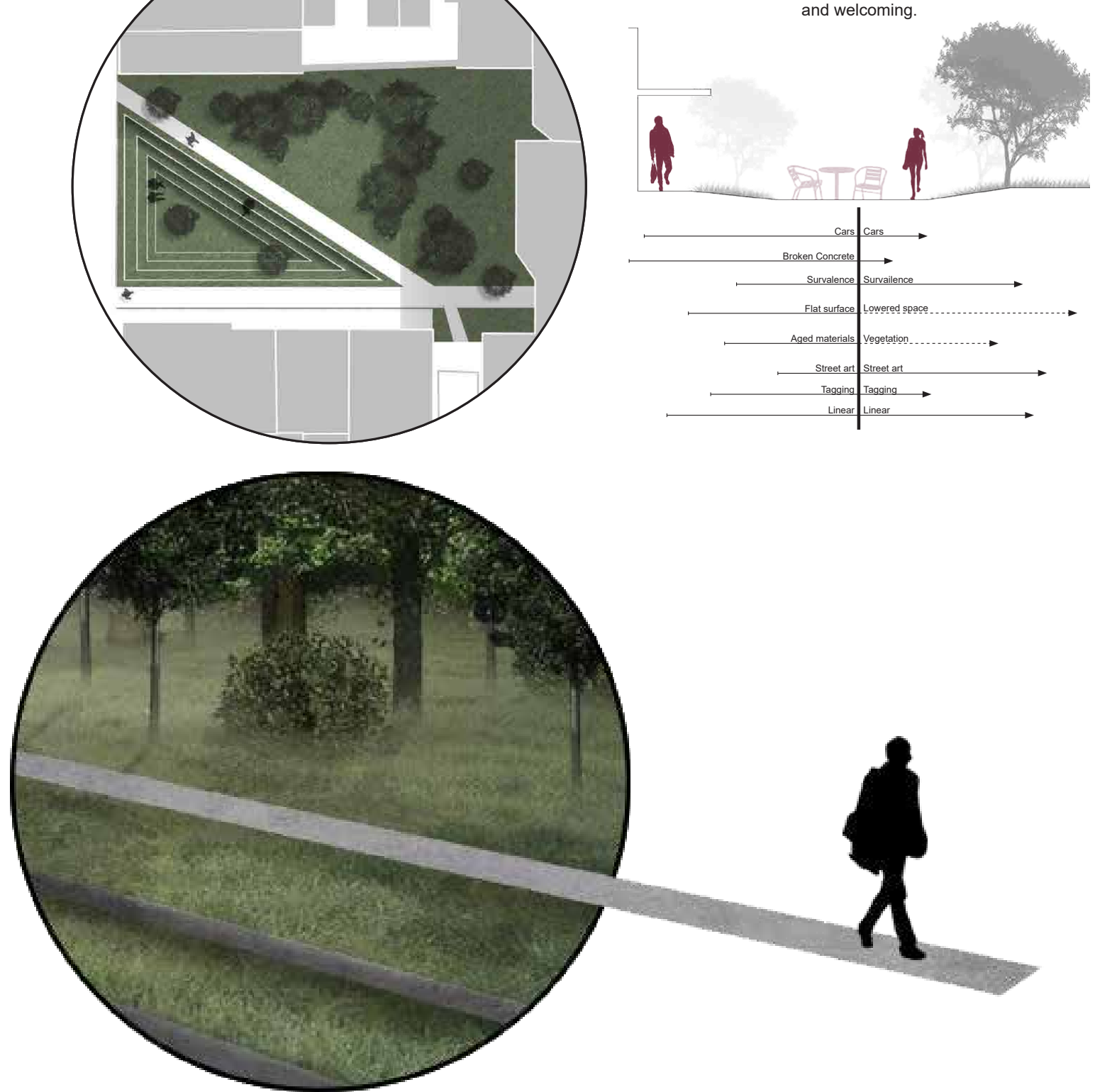
The first investigation tested an integrated approach. This would focus around interacting with the surrounding spaces and creating a space that is additive to the city. This test focused on simple lines and direction that allowed the walker quick movement, with spaces near the edge for stopping and interacting. It lowered the path into the space to give it a more connected feeling to space.

Figure 81 - Compilation

Intergrated design concept - Site 2
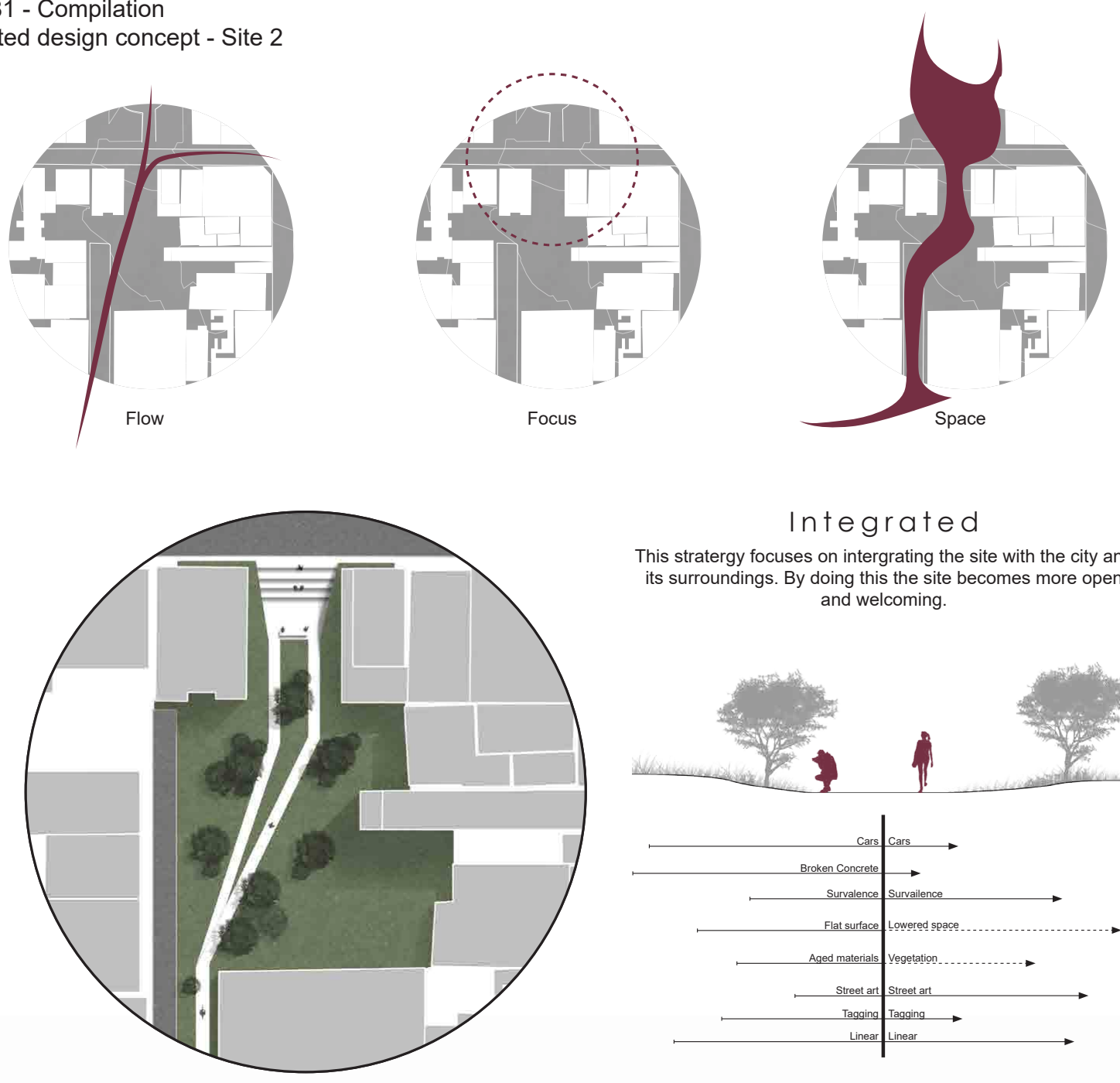

Integrated

This stratergy focuses on intergrating the site with the city and its surroundings. By doing this the site becomes more open and welcoming
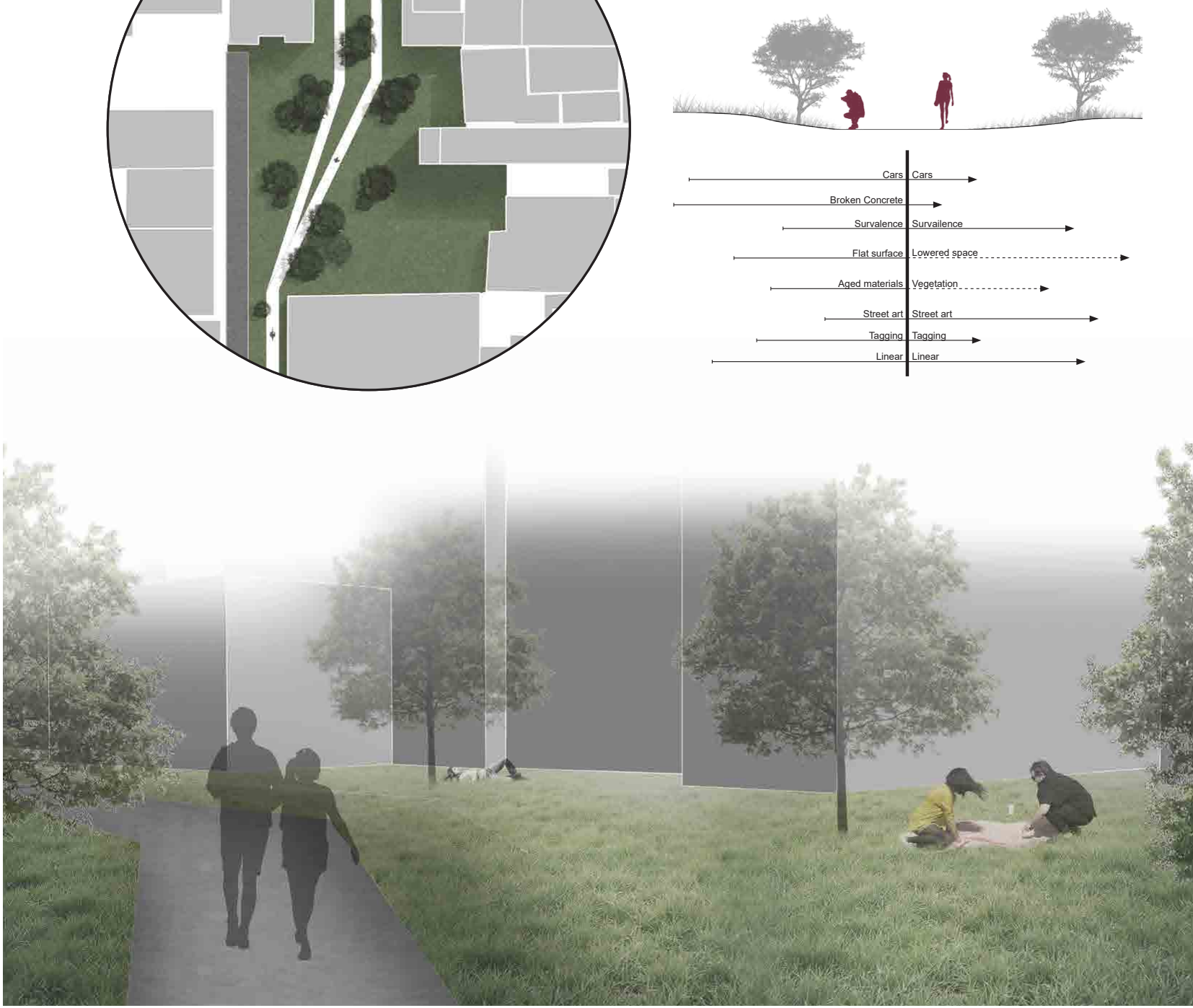
The next investigation aimed to create a more social space by breaking up walkways. The use of a constant elevation throughout the space allowed for an equal height among the walkers, creating an equal hierarchy. There are circular spaces and single paths to allow for, and promote, social engagement between walkers. The aim of this design was to engage with the social aspect of recovery and use the variation of people as a constant shift in the space.

Figure 82 - Compilation

Social design concept - Site 1
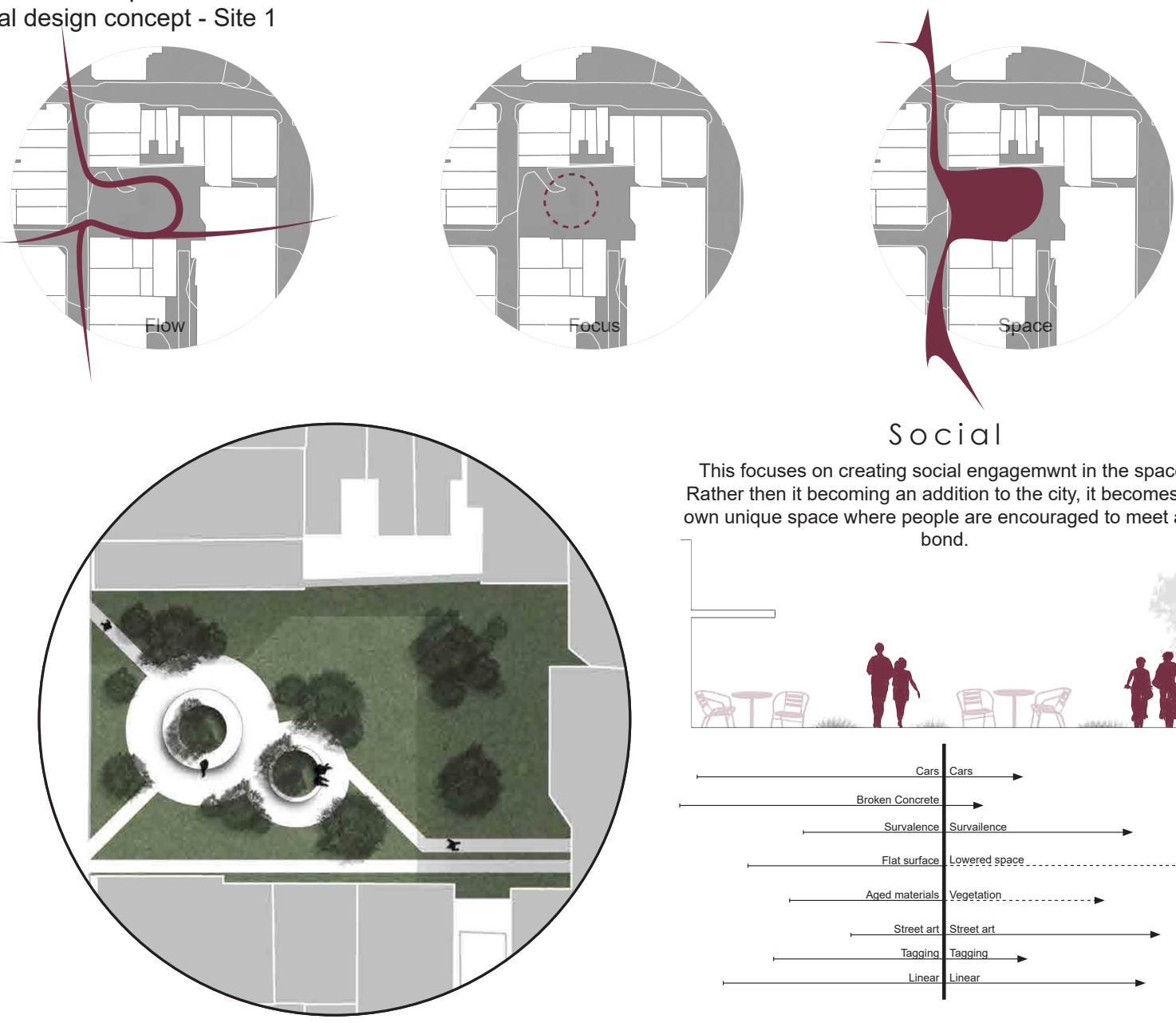

Social

This focuses on creating social engagemwnt in the space. Rather then it becoming an addition to the city, it becomes its own unique space where people are encouraged to meet and 7 bond.

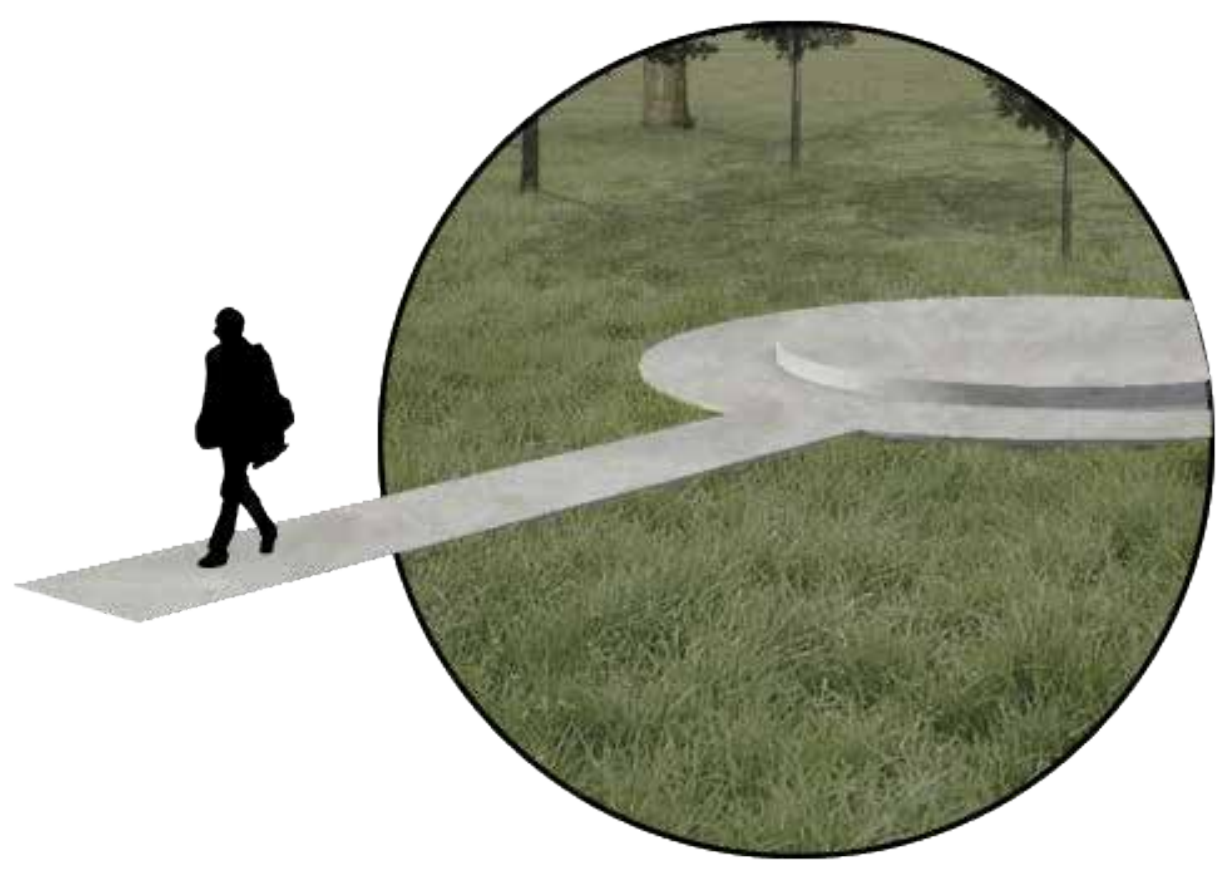


This investigation again struggled to create a strong atmosphere due to the people within the design. The goal of the atmosphere is to allow people to submerge themselves into the experience of the site, and great a mindless wandering for a small moment in the city. Creating social contact points, similar to that on a walk through the city, can dilute or even ruin an atmosphere as a person becomes more aware of their surroundings and is engaging with those being passed.

Figure 82 - Compilation

Social design concept - Site 2
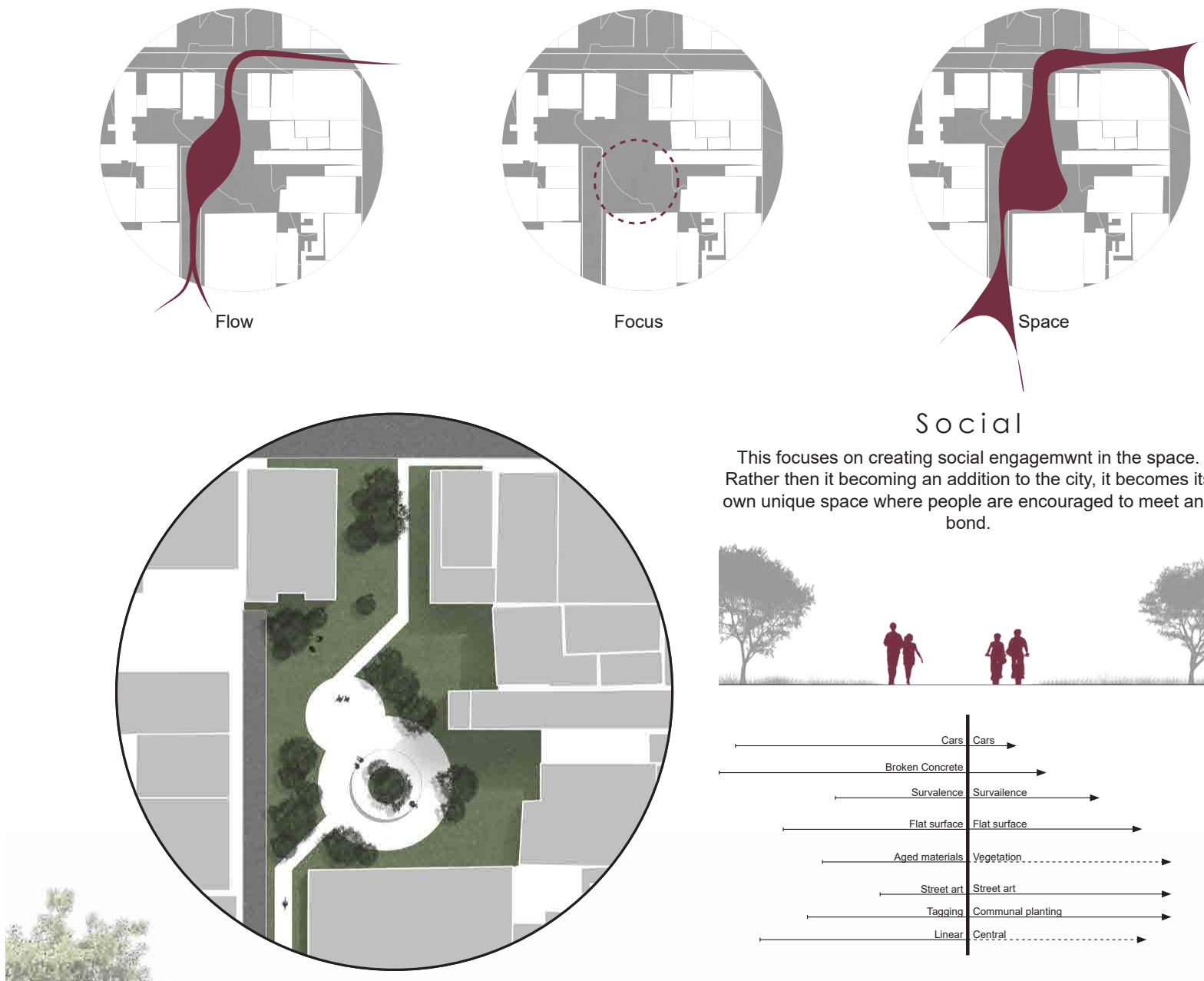

Social

This focuses on creating social engagemwnt in the space. Rather then it becoming an addition to the city, it becomes its own unique space where people are encouraged to meet and
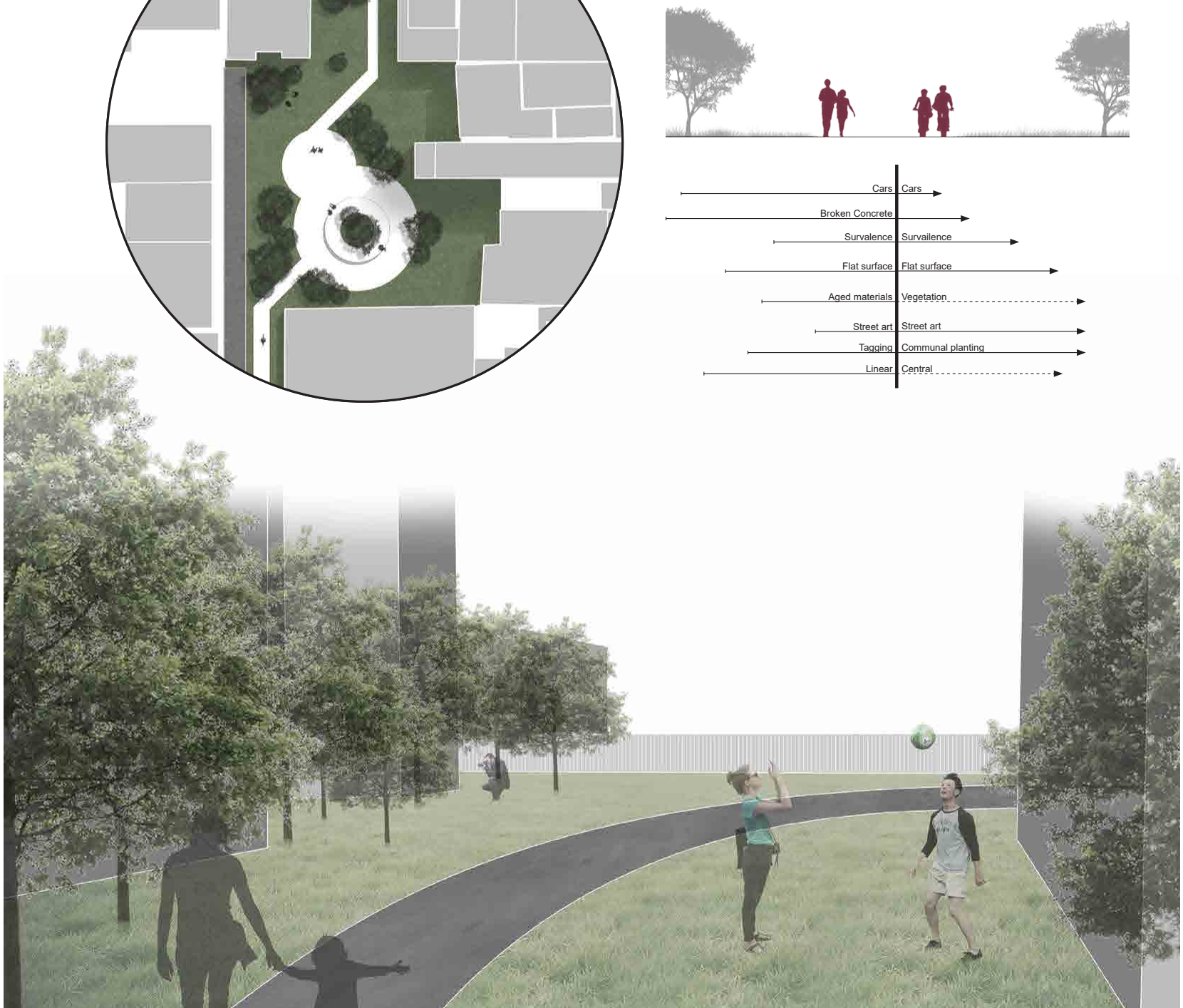
The final investigation was that of disconnection. This isn't disconnecting the walker from the city, as this design aims to allow them to still feel at home within the city, this project aims to disconnect the site from the city and walker. Using a raised pathways and series of different walkways, the site dips below the walker, creating a disconnection between them and site.

Figure 84 - Compilation

Disconnected design concept - Site 1
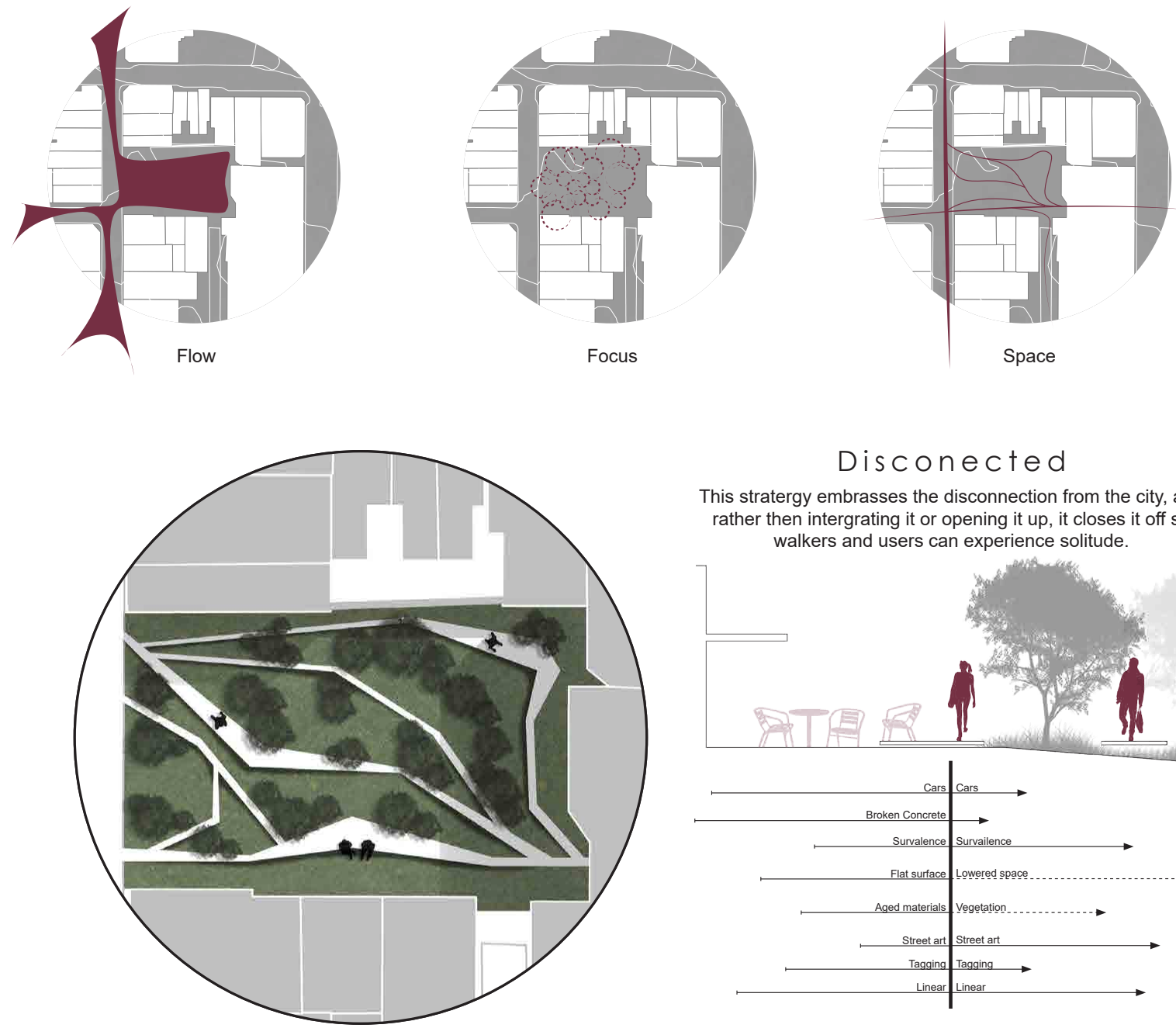

Disconected

This stratergy embrasses the disconnection from the city, and rather then intergrating it or opening it up, it closes it off so walkers and users can experience solitude.
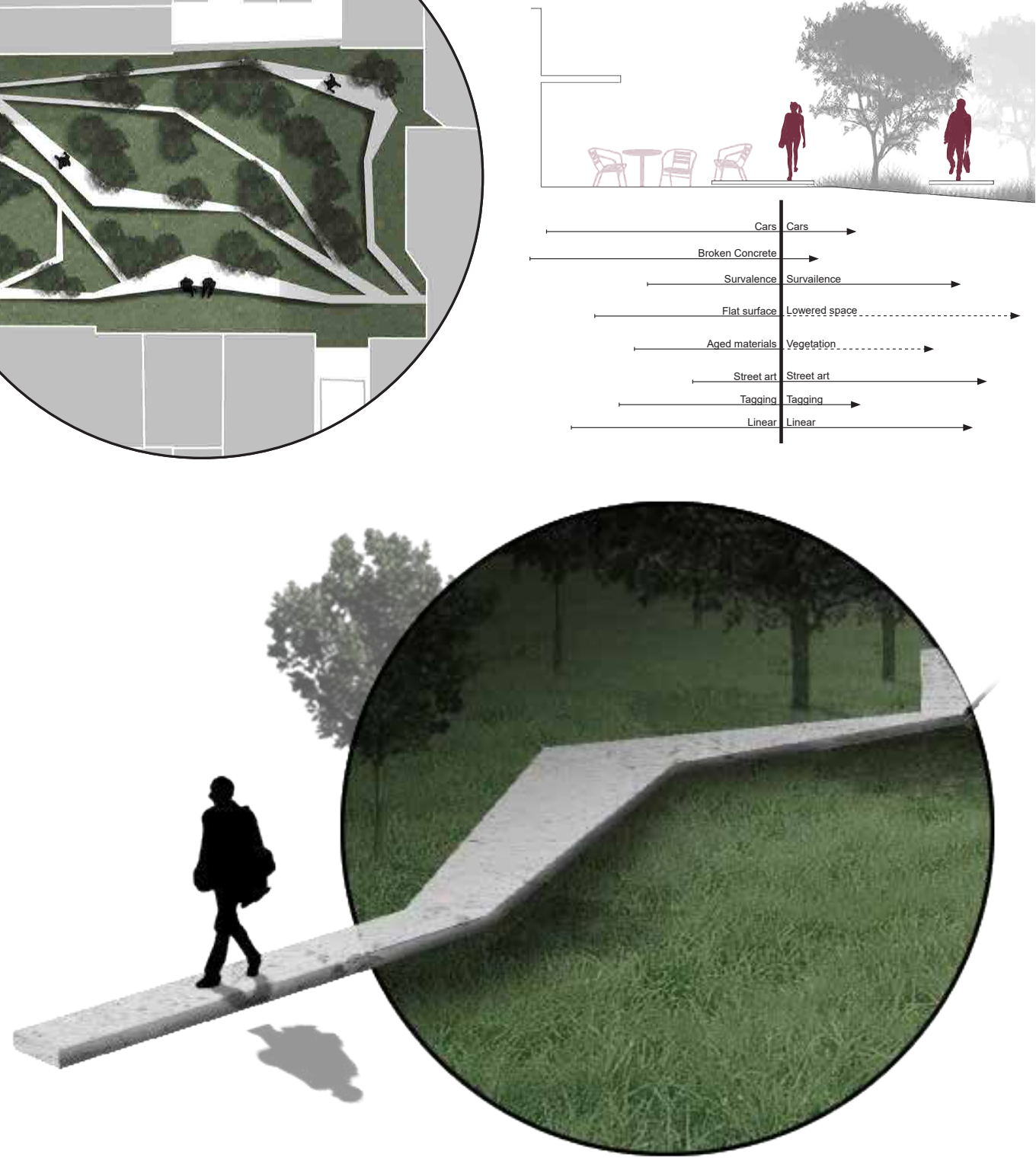
This distance between the walker and the site, and the walker and other walkers, creates a softer and more subtle atmosphere. It allows them a softer connection to space and people, while isolating them to their path and their walk. This allows for a more intimate engagement with space.

Figure 85 - Compilation

Disconnected design concept - Site 2
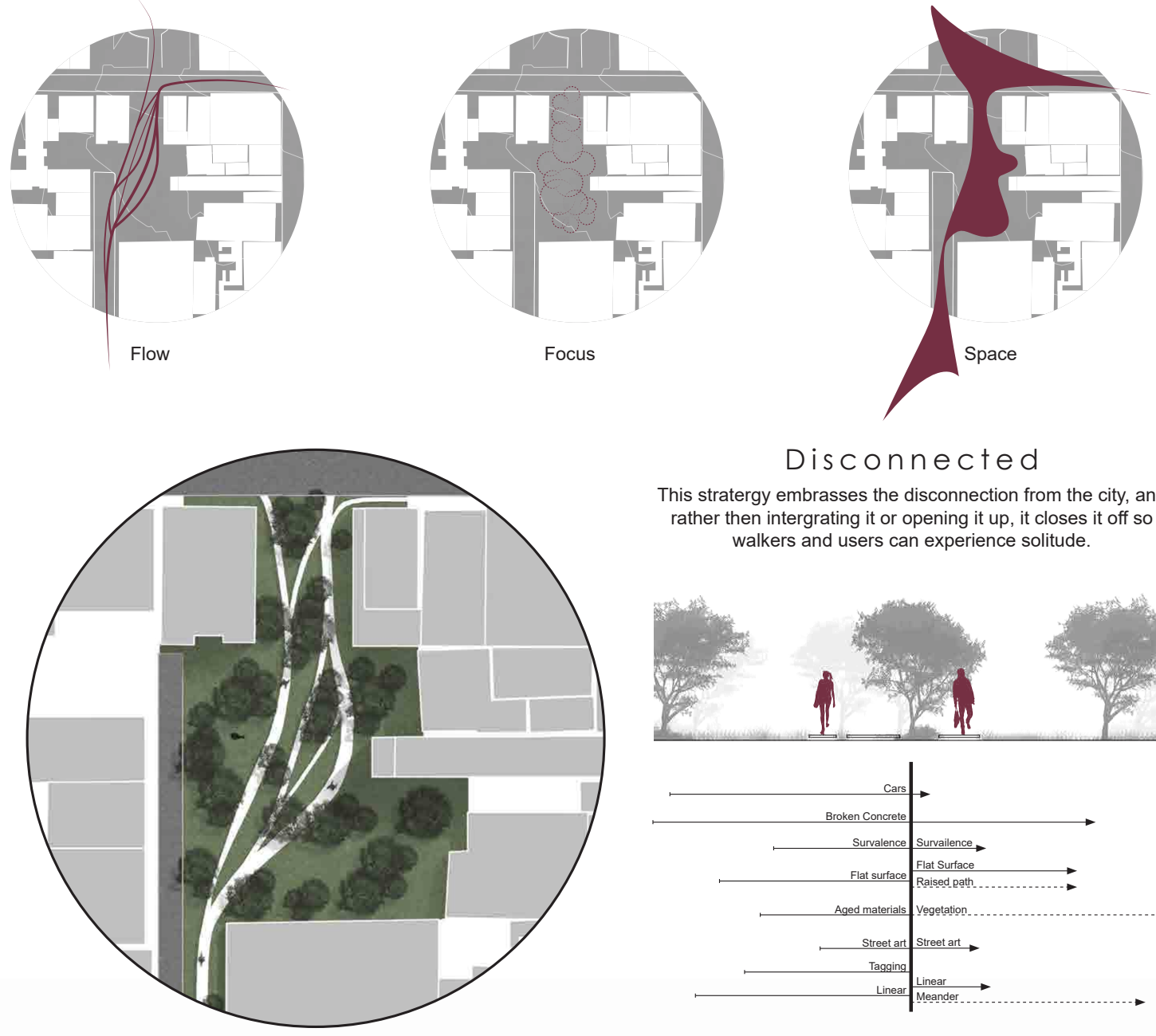

Disconnected

This stratergy embrasses the disconnection from the city, and rather then intergrating it or opening it up, it closes it off so walkers and users can experience solitude.
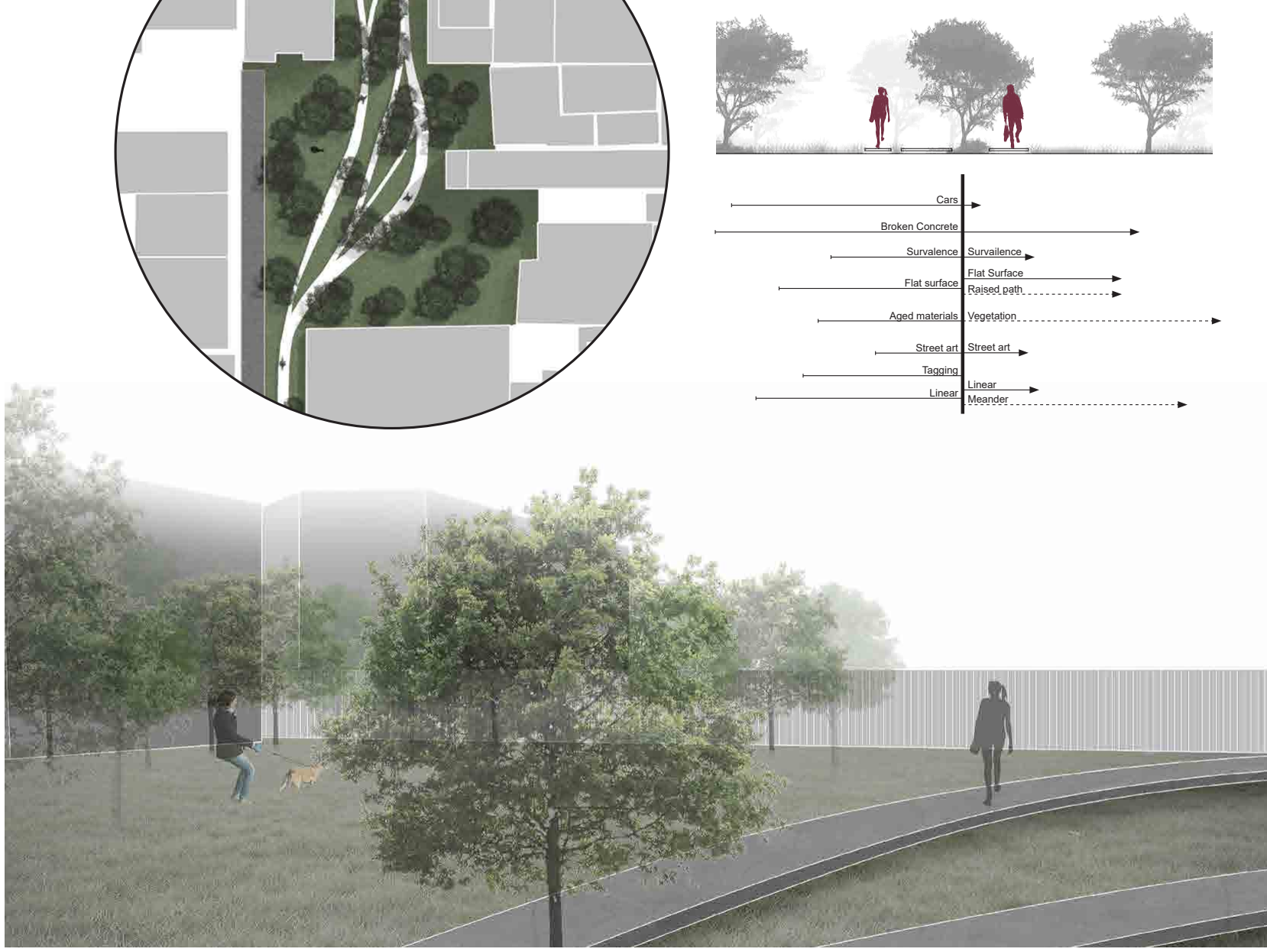

Although the ideology behind the disconnected space became the driving force for further design in this project, there were social and integrated elements introduced in areas that would have more social or urban atmosphere. 


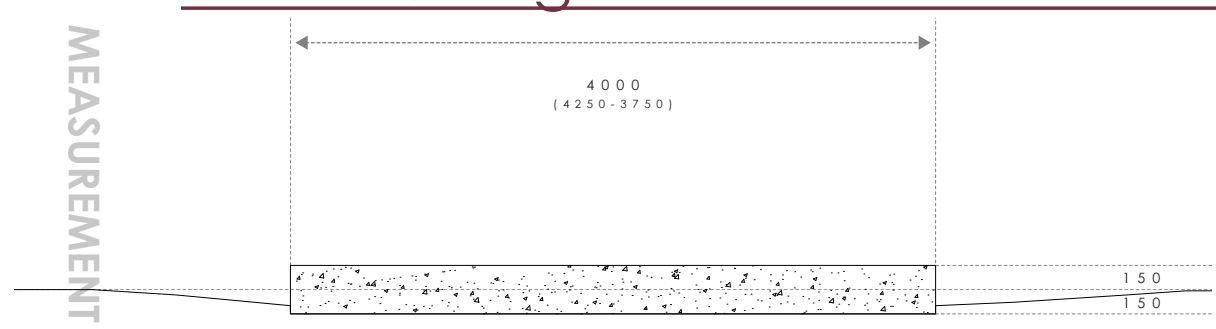

This design aims to create

a path that gradually changes as a person journeys through the site. This next section is an investigation into the four stages chosen to mark shifts within the site. Although these changes are gradual as paths get higher and lower, these four path stages mark the path design used in each respective zone.

These zones are tested first in scale to ensure their shape and form fits their purpose. Secondly they are tested in terms of hydrology and how they will transport water throughout the space and towards the central ephemeral wetland. Finally these are tested spatial, looking at social interactions and their relationship to space.

The first stages begins grounded as a person enters the site. There are small gutters along the side of the path that will flow under the path at later spaces. Using a thick concrete slab to give off a sense of groundedness and thickness to the path introduces the walker to a path that is still inherently part of the city. Spatially it comfortably allows for walkers to pass by and larger groups to travel. 

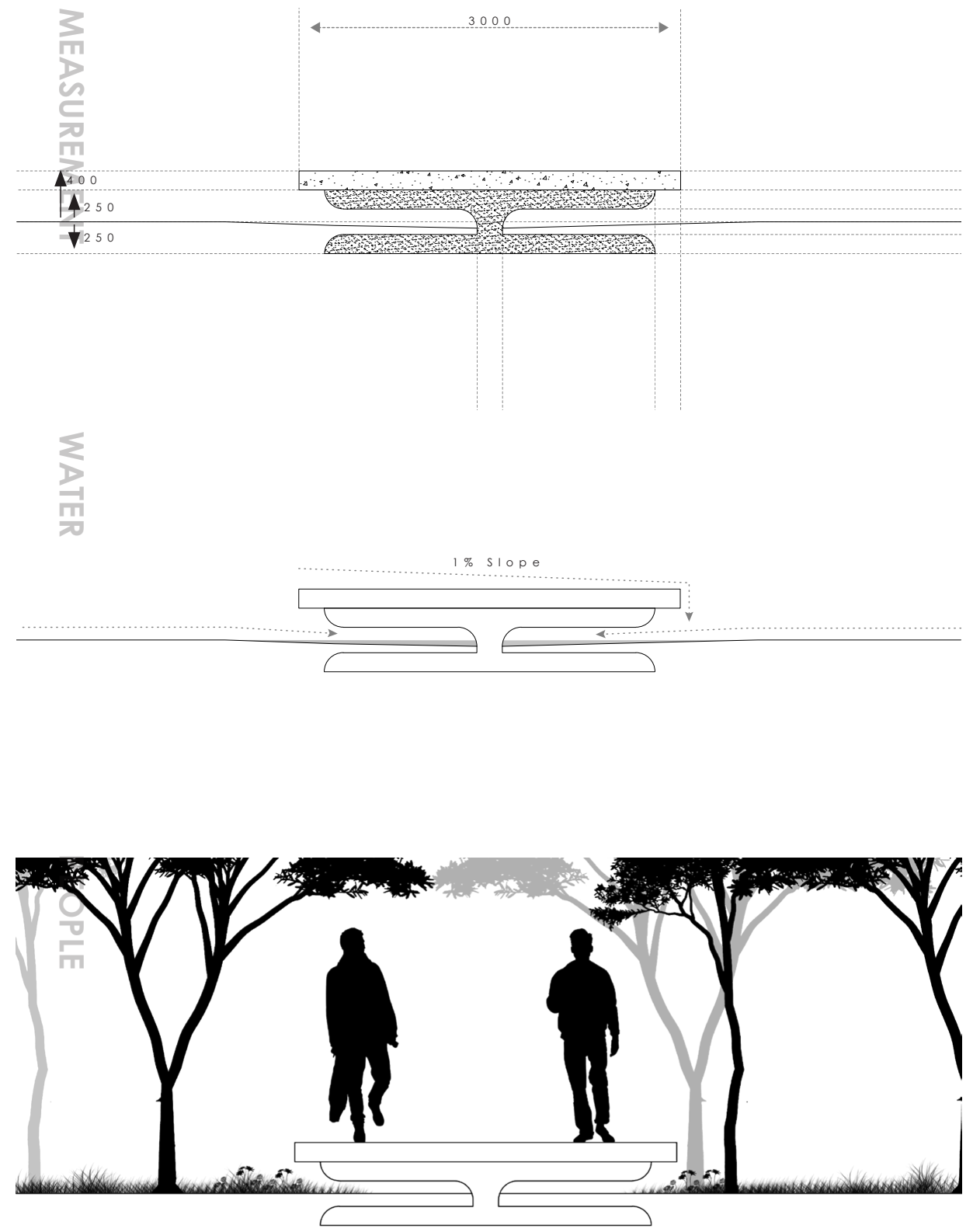

The second stage begins the elevation in site. The large slab is thinned and reveals a more elegant sized path. The structure is recessed to allow it to be hidden at this stage to give off the sense that the path, representing the city, is being stripped away. Although thin, it is still present, allowing the walker to never have the jarring experience of being totally disconnected from the city. This integrates the design as a part of the city, rather than rejecting the urban surroundings. The water is than hidden below the path, although chunks of the previous carpark are hidden below the path creating ripples and hidden elements. 


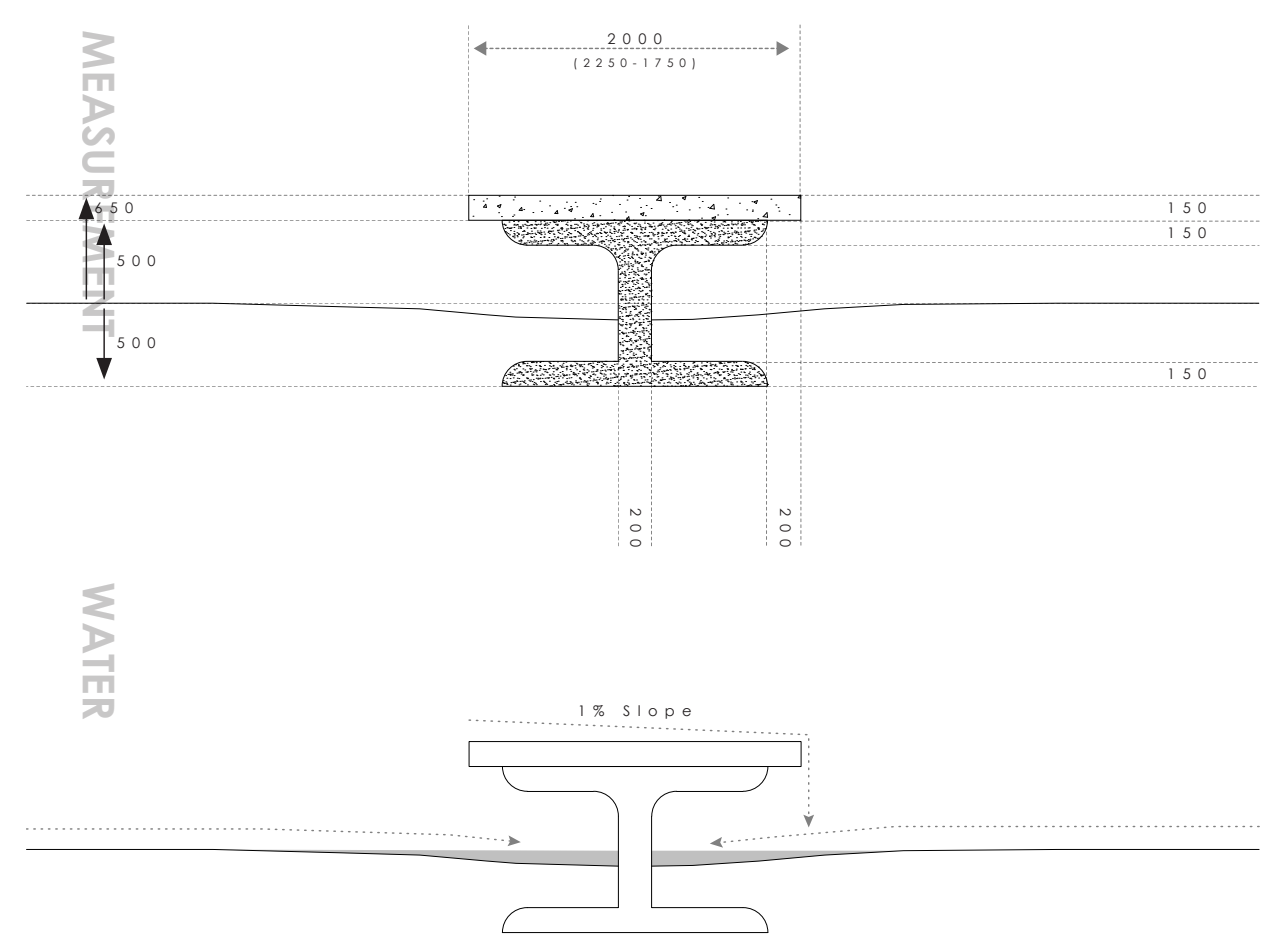

The third stage starts to become more intimate. The structure and water below, along with the chunks of the car park concrete, are show to those walking on different paths, but never to the walker. This creates a sense of mystery and expectation, making the walker expect that there are these features below their own path, but never allowing them to see it. This adds to the more nuanced atmosphere of the space.

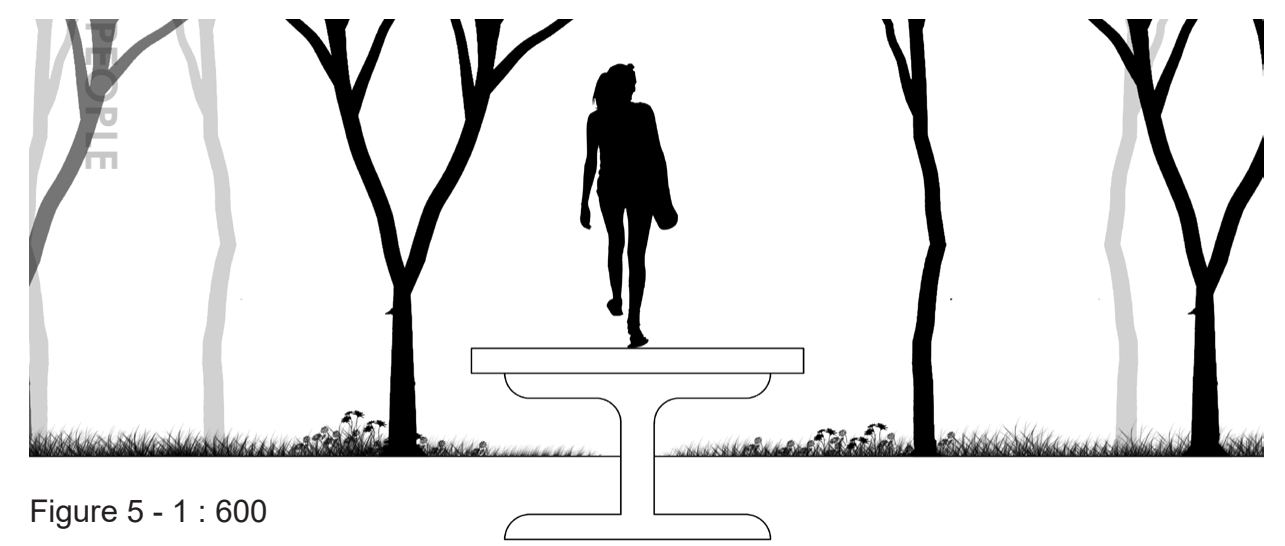


Finally the path becomes very thin, seeming as if it will almost disappear. This is at the centre of the space, maintaining the connection to the city, while allowing for a deeper immersion into the atmosphere of the space.

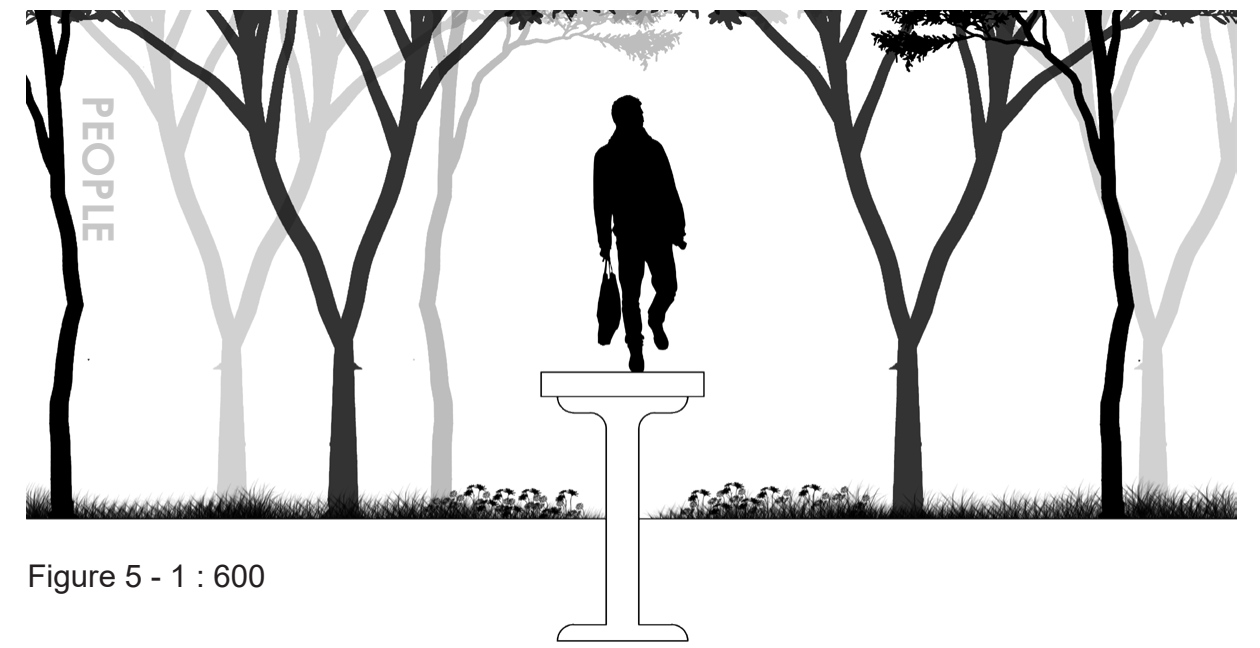


This stage focuses on the basic shape and desire lines of the site. Unlike the other site, there are a series of different journeys through the space, creating a series of conflicting lines throughout the space.

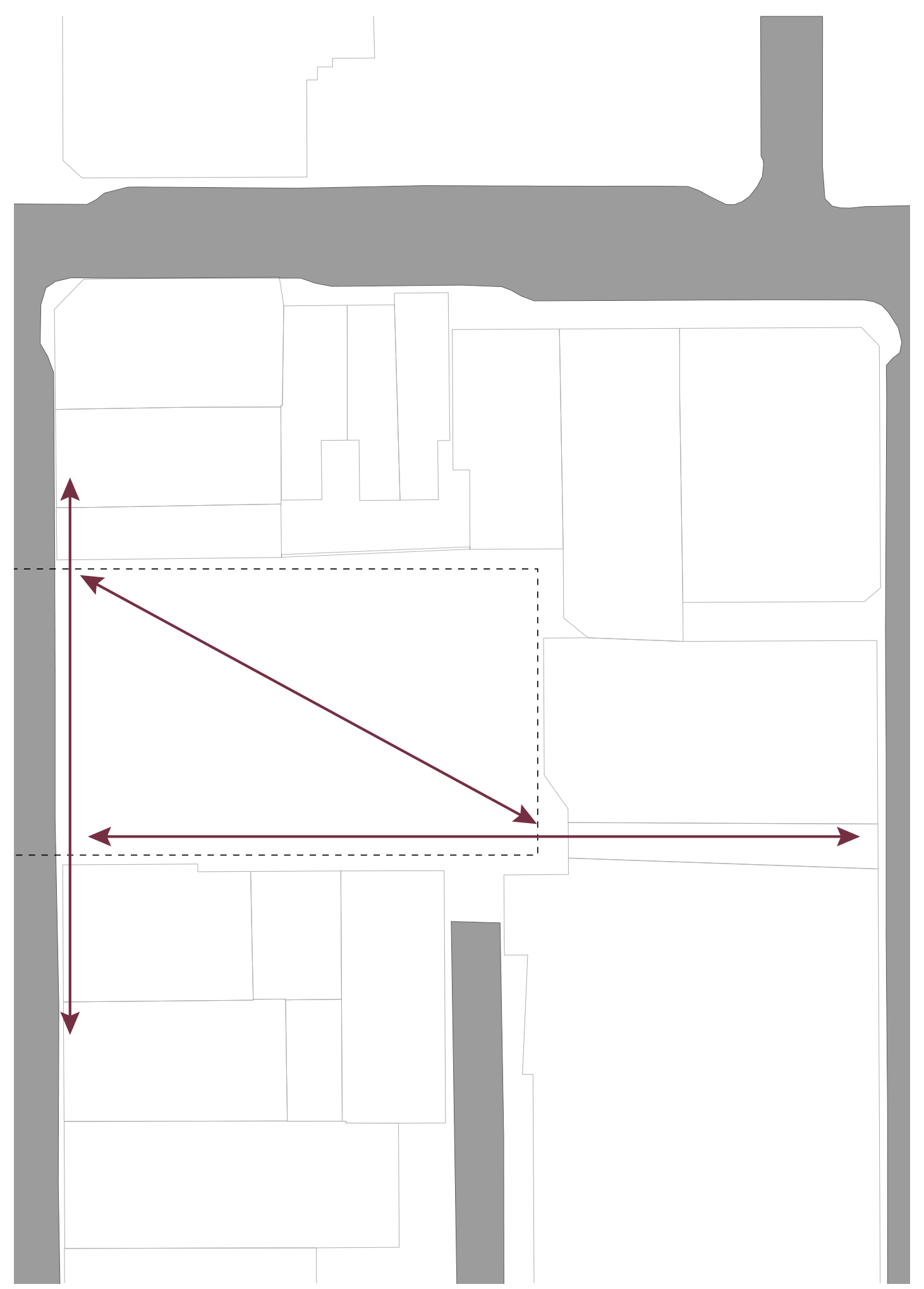

Figure 90 - Plan - 1:600

Path design - Stage 1 - Site 1 
The first stage is based on the desire line through the site. The space has a strong set of axis running through it, and the beginnings of the path reflect that to allow for the site to still seem light a shortcut for those moving past. It implies that it still has the main desire line through the space and draws walkers in.

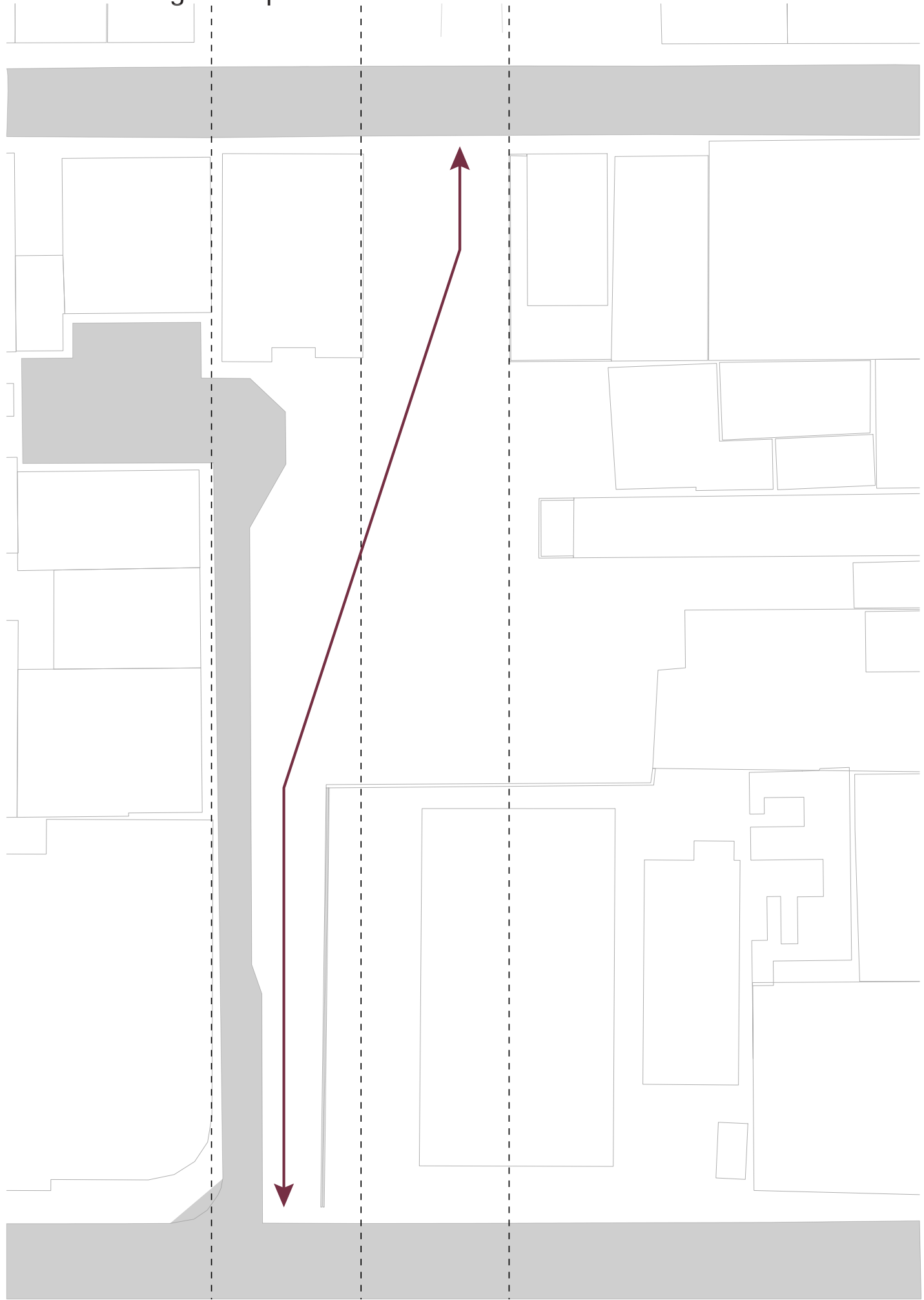

Figure 91 - Plan - 1:600

Path design - Stage 1 - Site 2 
The second stage focuses on breaking up the space.

The shape of this space lends itself to a design that fits within the norm of the city, where as this design aims to skew paths and points. This stage, while manipulating the paths based on the main axis and focal point, also introduces the corner gallery space as an outlier path.

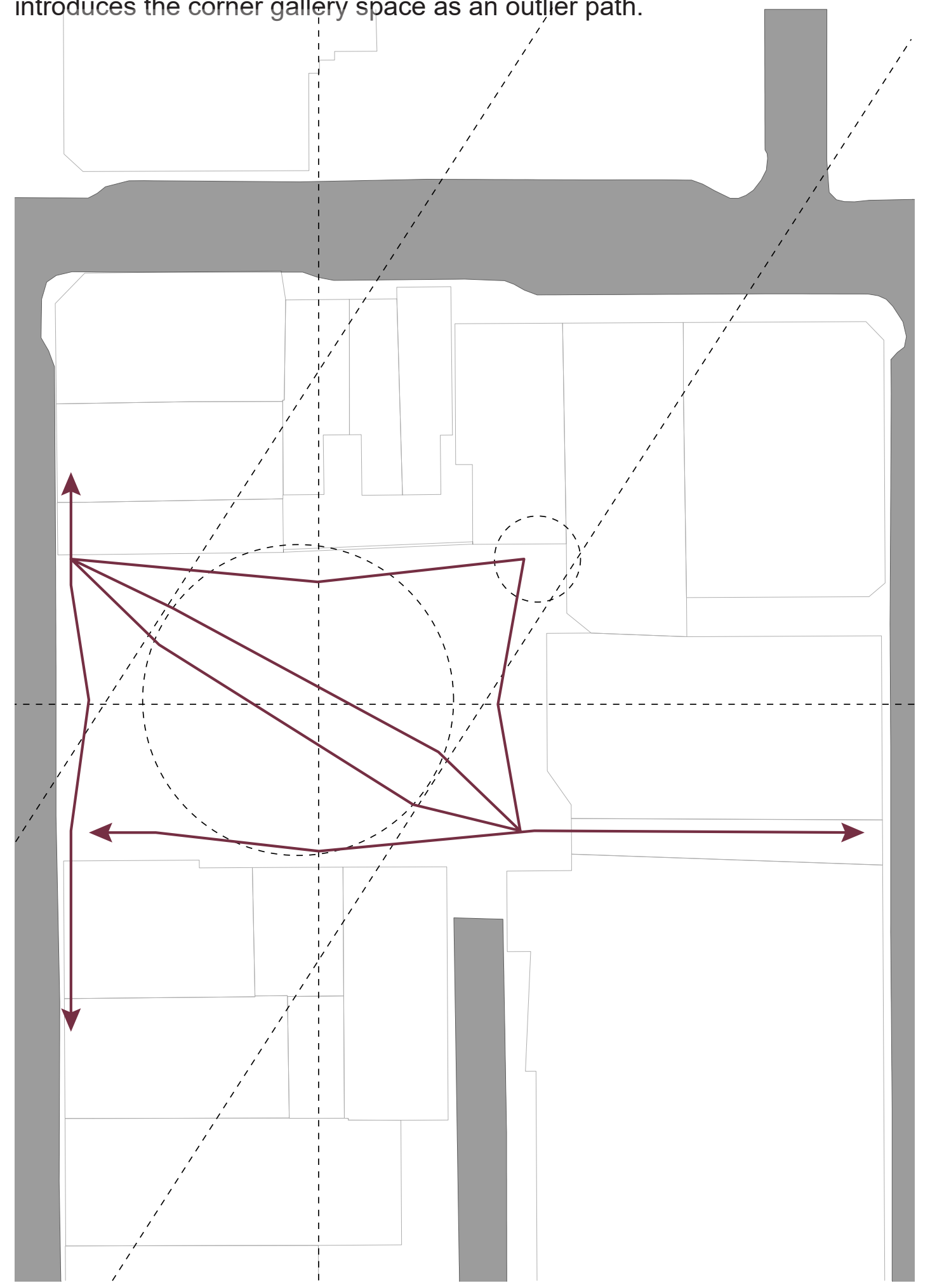

Figure 92 - Plan - 1:600

Path design - Stage 2 - Site 1 
The second stage is focused around the opening up of space. These points are where thresholds of surroundings buildings open up, and the area becomes more open compared to the corridor like entrances.

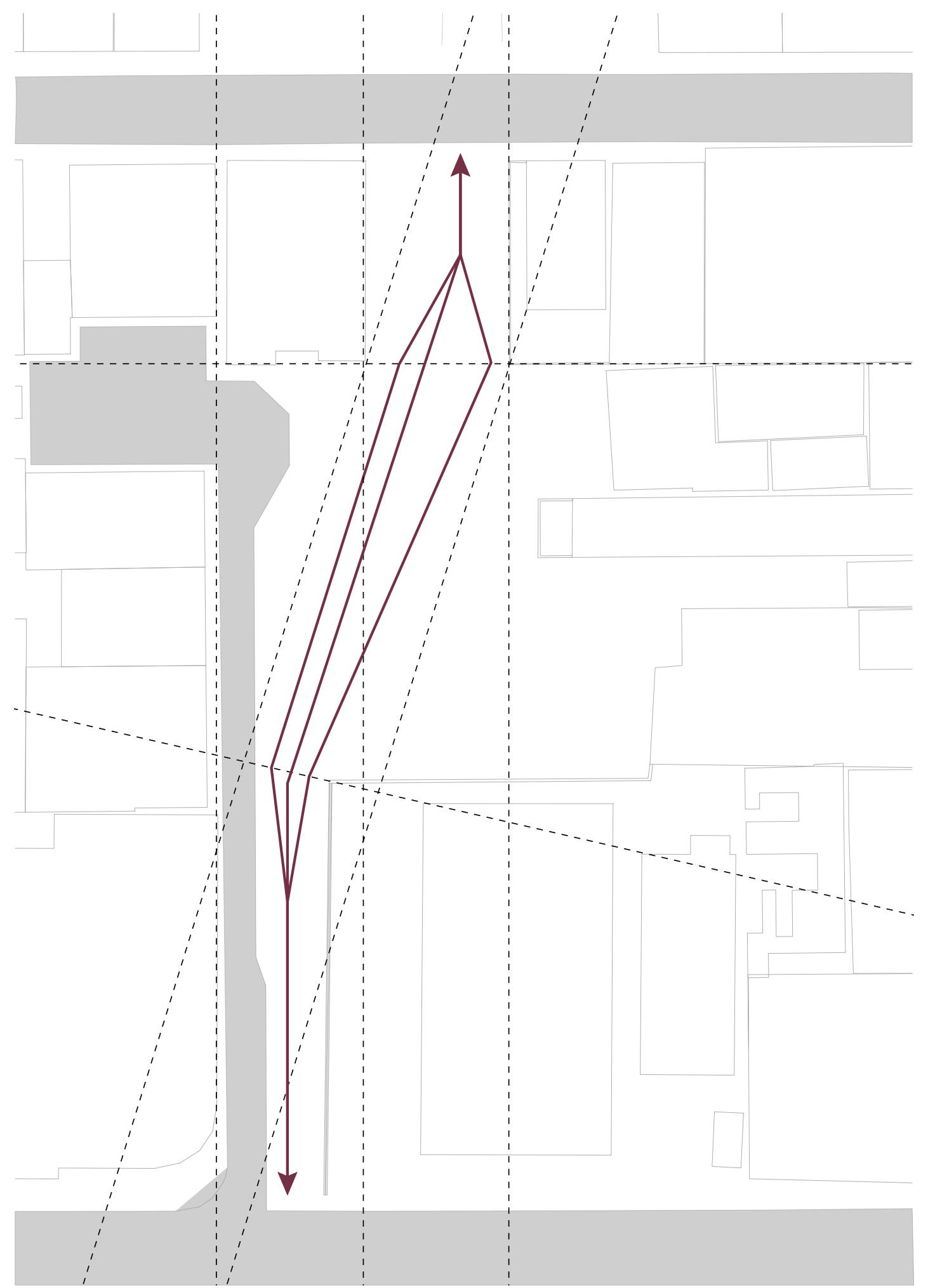

Figure 93 - Plan - 1:600

Path design - Stage 2 - Site 2 
The third stage once again focuses on the central point, skewing the paths more to counteract the simple nature of the desire lines in this space, creating directions and paths unlike the rest of the urban surroundings.

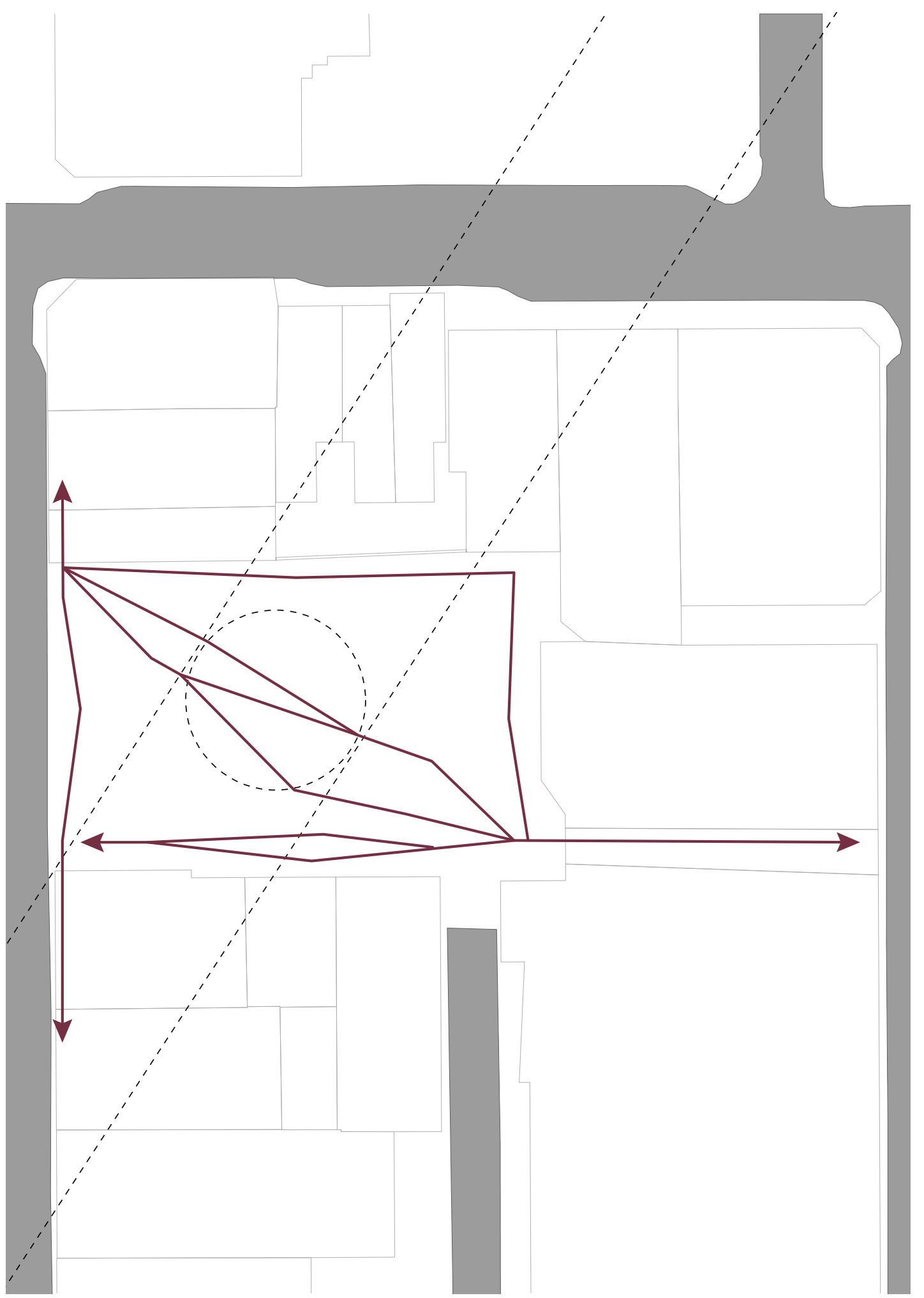

Figure 94 - Plan - 1:600

Path design - Stage 3- Site 1 
The third stage embraces the diagonality of the desire line. Due to the offset nature of the openings, there is a center points with a contrasting shape. This stage splits off more, following these diagonal angles.

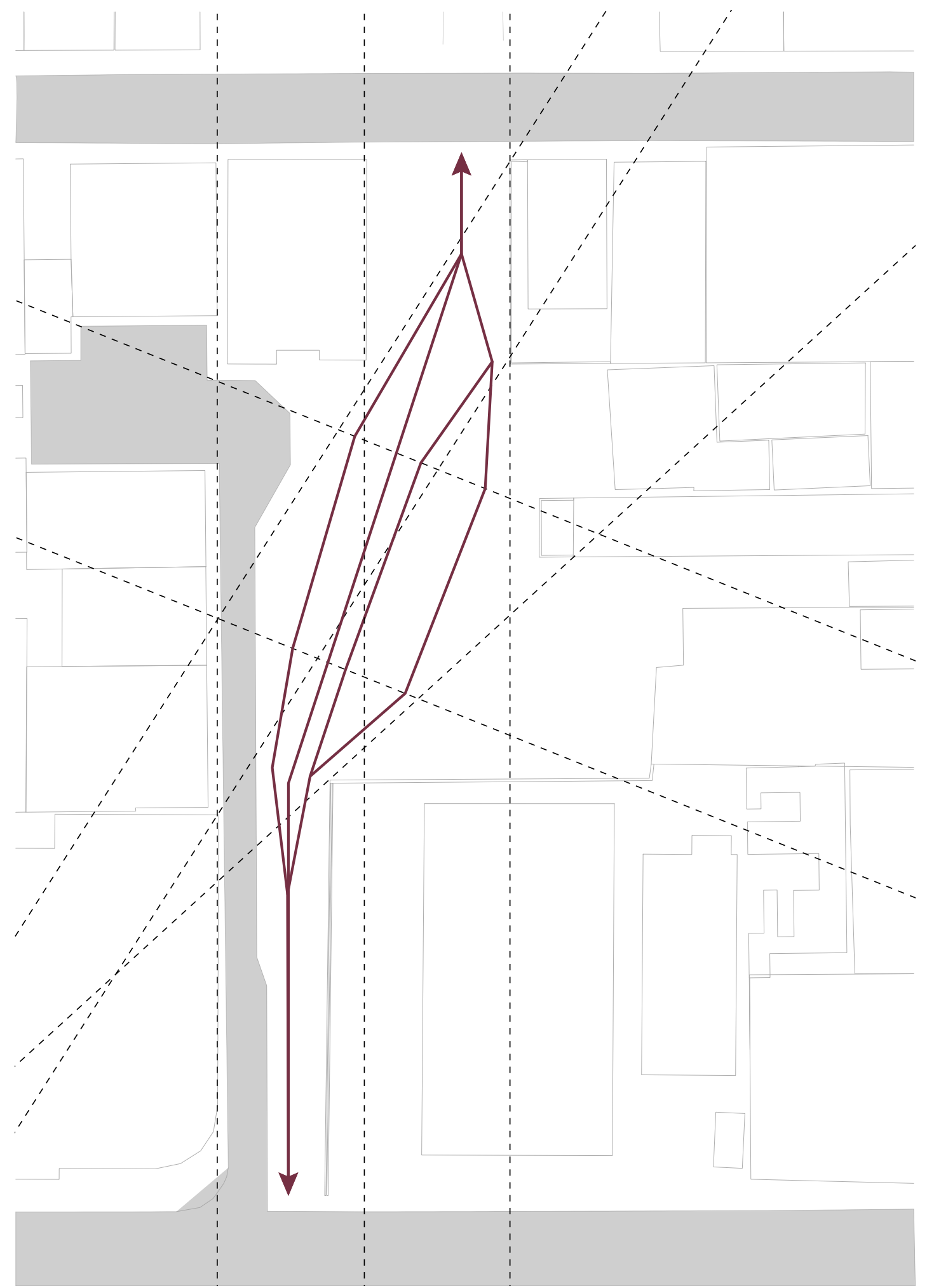

Figure 95 - Plan - 1:600

Path design - Stage 3 - Site 2 
The final stage is the final creak in the space, creating points where paths cross. It counteracts the overall design of the space, as the rest of the journey has been about disconnection where this has the potential to engage with other people. Unlike the other site, which would be jarring to run into people on these smaller paths, this site has the added air of people and life.
This shifts the atmosphere from that of the disconnected site, through sound, scent and general movement, to a more open and social atmosphere where running into another person would only add to the experience.

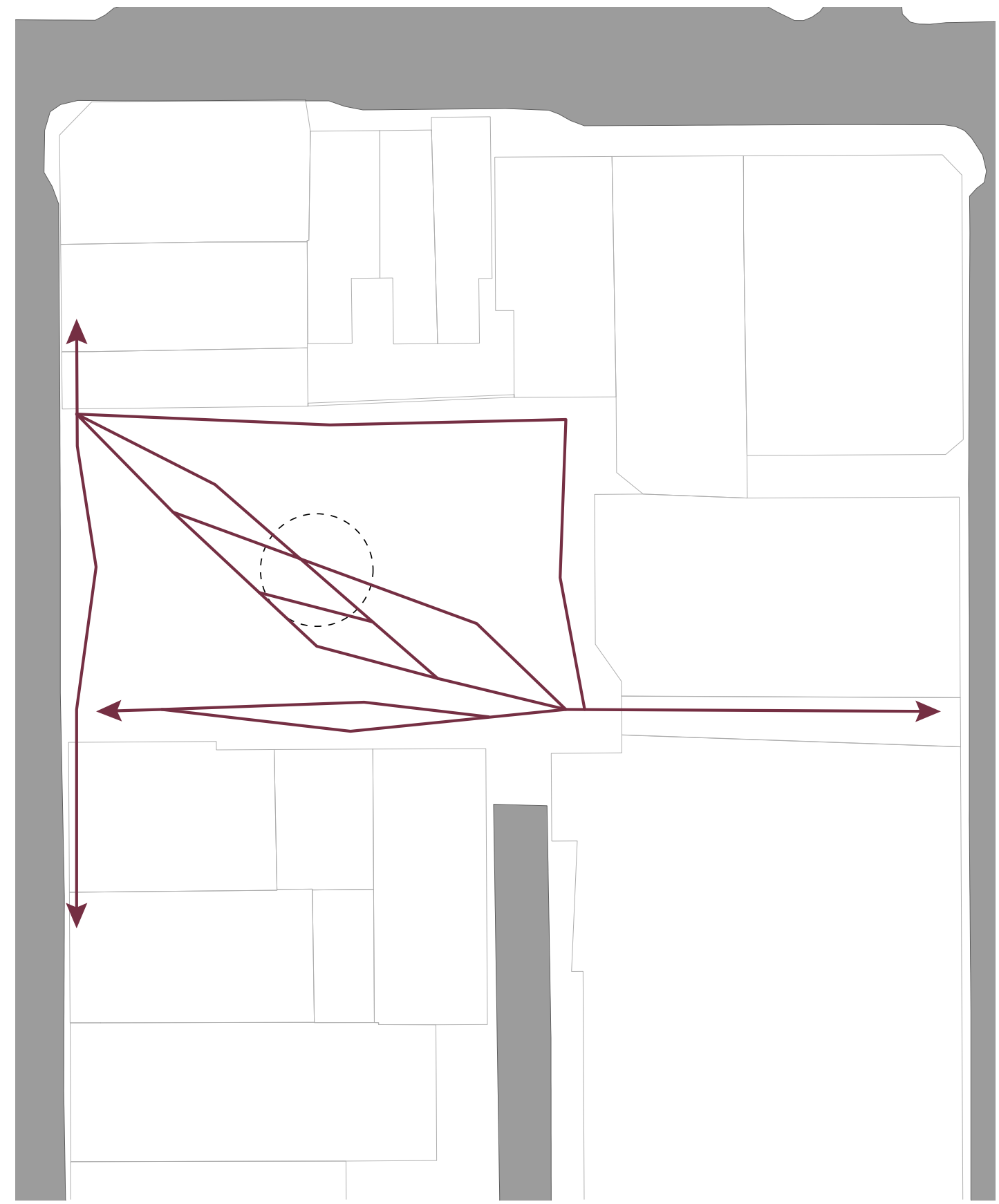


Finally, the center point skews from the expected diagonal. At this point the walker has made their decision to pass through, and now the site can move them in unexpected ways, creating new angles and walks different from that of the wider grid.

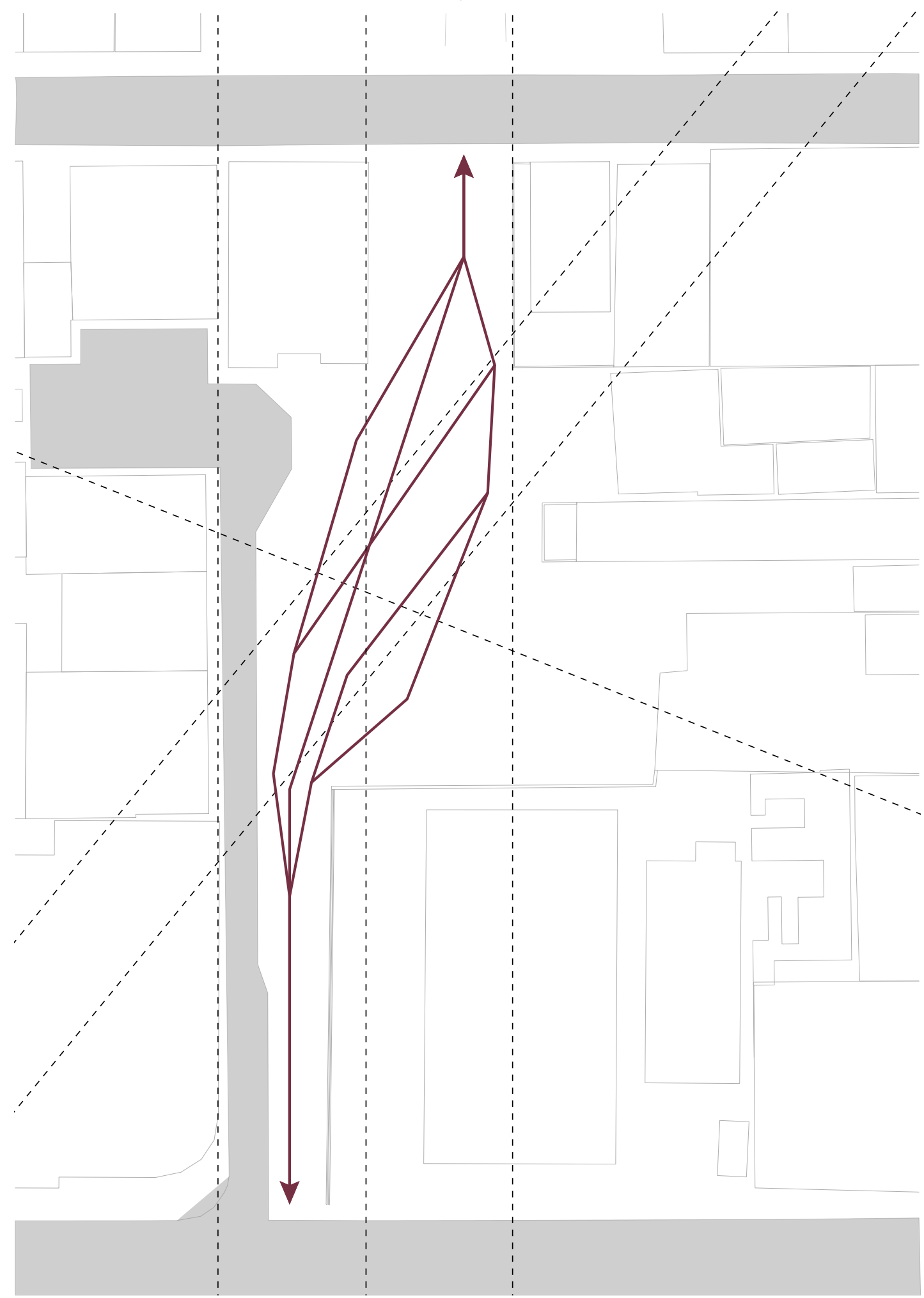

Figure 97 - Plan - 1:600

Path design - Stage 4 - Site 2 
Dealing with the water in the space was important due to the atmospheric value water has. The sound of water flowing and the site of water pooling in an ephemeral wetland adds a nuanced layer to an atmosphere, creating not only option for positive reflection, but another element of association with the walkers. Water can be very individual in terms of its connection to a person or culture, but it has an intrinsic spatial value that tends to resonate with all in some way.

At a detailed level, the site uses the vegetated edges to the paths to create hidden points of water flow. The focus here was to create the sound and sense of water flow, but hide it from the walker, adding a layer to atmosphere that they cannot totally identify. Showing the water creates a visual and audio connection and could overpower the subtle and delicate network of parts, where as just the sound and sense of flowing water creates a equal part of the atmospheric network.

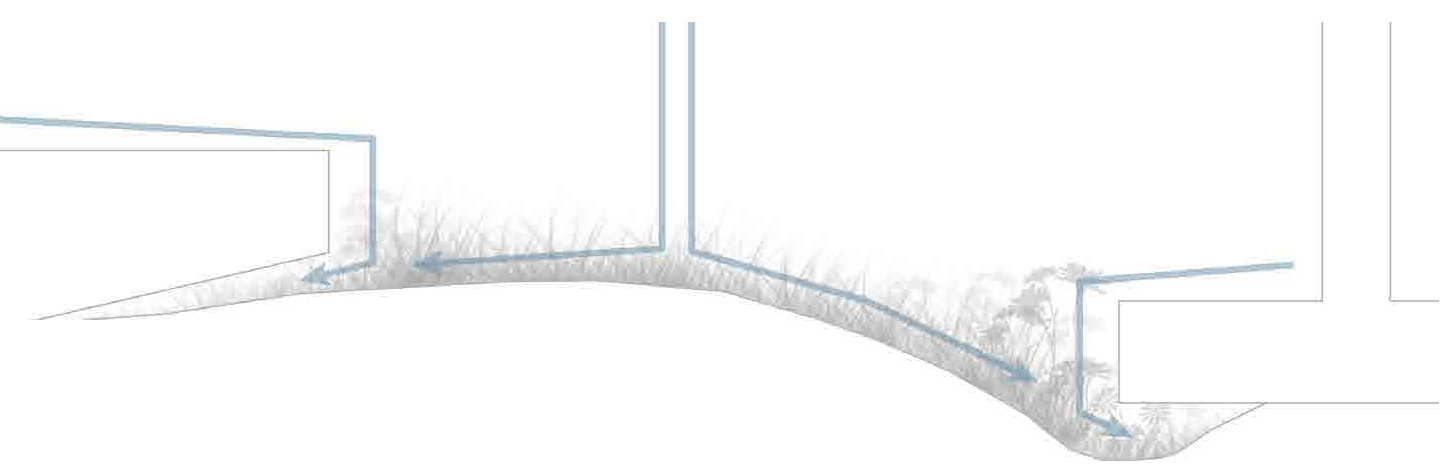


At a larger scale, the site is designed to move and transport water. The paths acting as the main waterways through the site. Water is either directed towards the nearest path, or down towards the central ephemeral wetland.
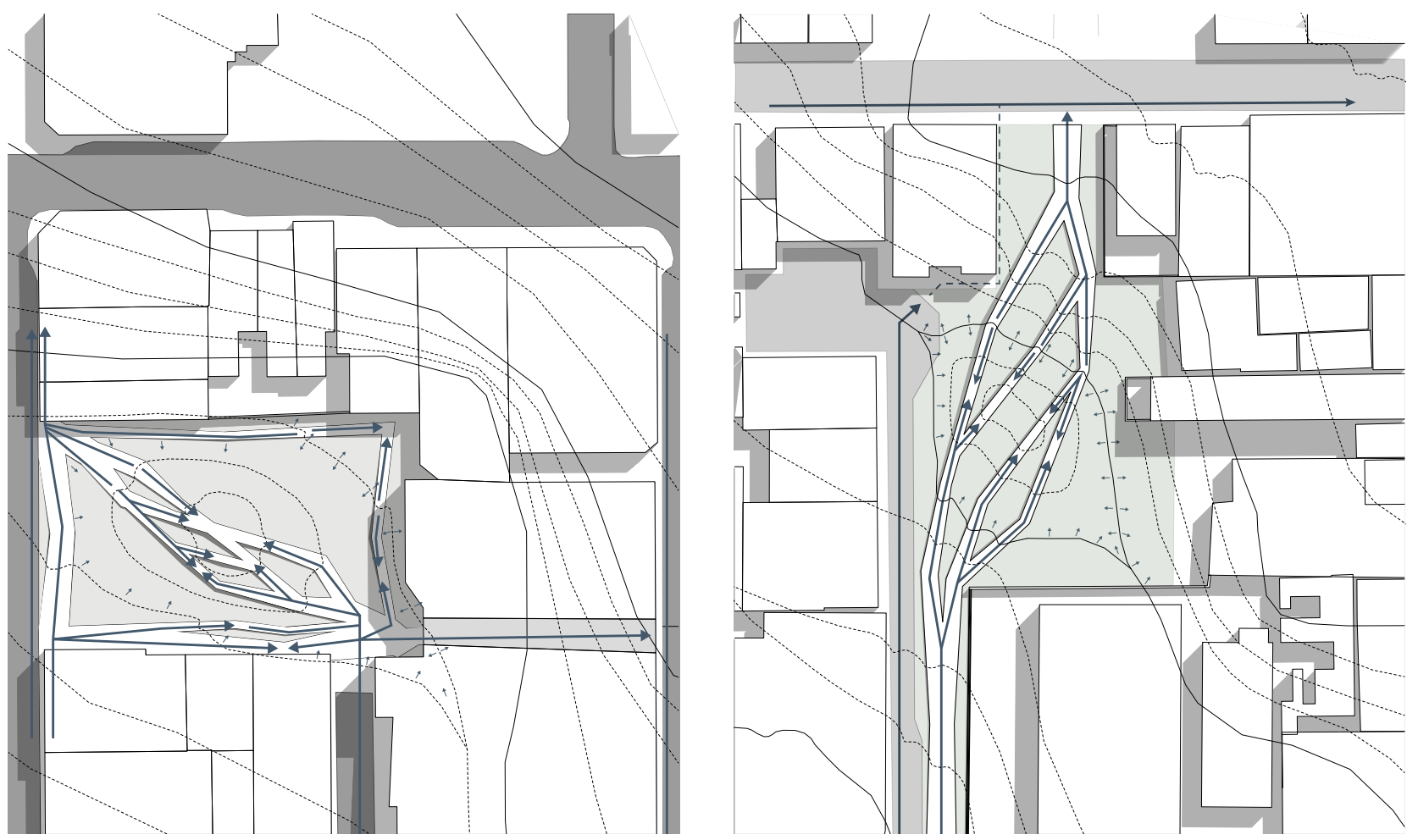

Figure 99 - Plans

Site Drainages

Due to this the level changes to the site are minimal. The dip within the space, although noticeable, is subtle and creates a gradual shifts, making ti seem like the site was always intended to be sloped in this way
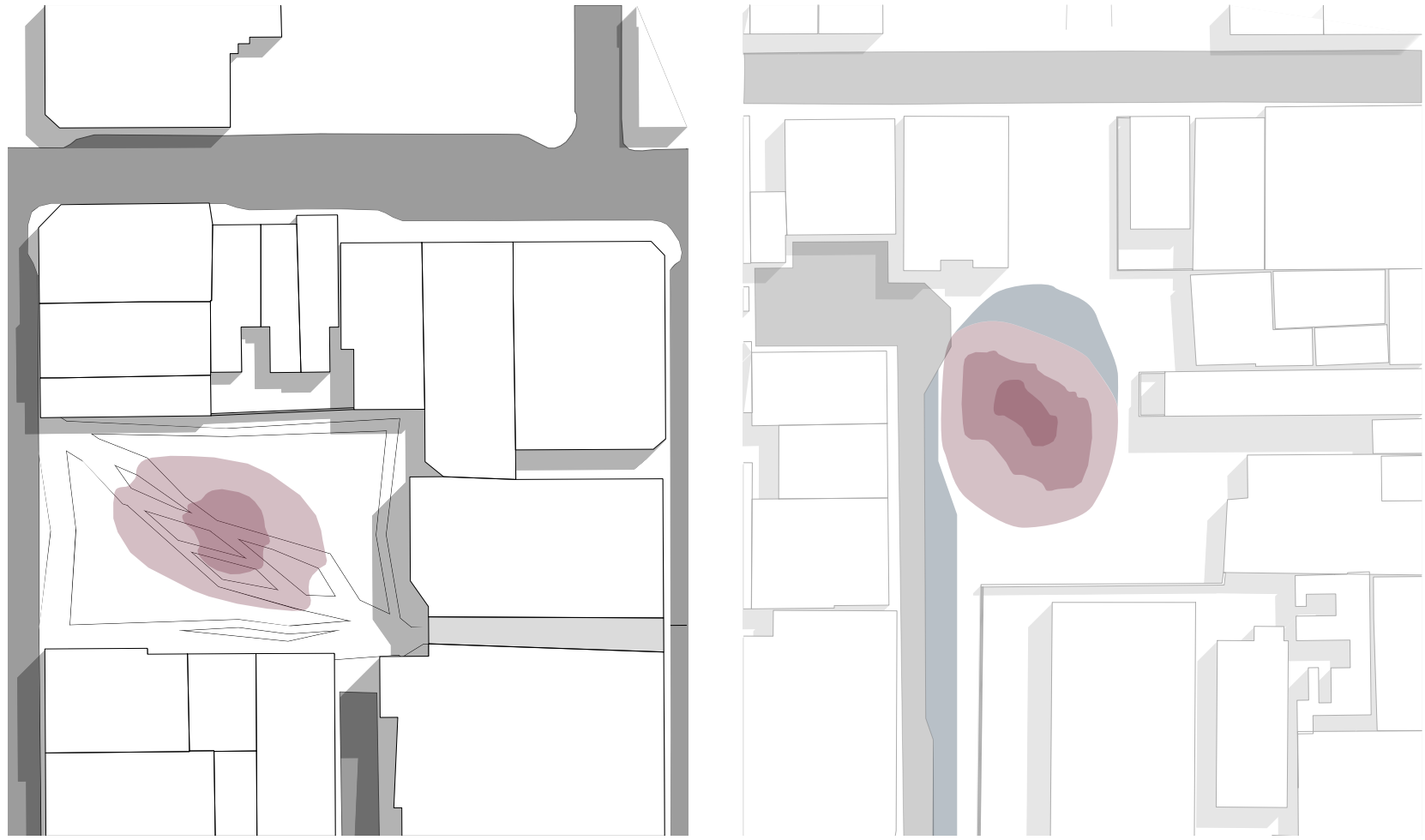

Figure 99 - Plans

Site cut and fill 
Due to the subtle and balanced approach to this investigation, planting would need to reflect and aid the networks within the space. Due to this the planting is seemingly basic, focusing on a few key types of vegetation that create a sense of continuity throughout the space, while also creating points of contrast.

The planting would be introduced at a juvenile state, being allowed to grow. This did not alter the choices of plants as allowing for different elements to age and grow at their own pace staggers progression and creates a small sense of randomness and chaos in the design that aids to the imperfection of its atmosphere. Planting, when it is over design, can create a sterile and inorganic space.

The main idea of the space was to allow it disconnection for the city, while retaining semblance of the surrounding urban space. Due to this a tree with a light canopy would be the base for the planting selection as it would create some disconnect from the city, while still allowing it's views to permeate the space. The kanuka was chosen as the main canopy plant in the space because along with it's very light and forgiving canopy, it has thin and wiry trunks. These trunks will allow for view throughout the space, as well as out to the city. This allows the walker to be able to see their path ahead so they can subconsciously plan their journey. The kanuka also has white flowers and attracts both insect life and bird life, adding to the sense of life in the space.

To break the mundane canopy of the kanuka were lancewood and cabbage tree. These had vertical shapes that contrasted the kanuka, allowing for a fluctuating canopy top. They also have thinner trunks that don't obstruct the space, and white flowers that engage with local bird and insect life.

The floor below the canopy will mostly be a standard grass, which will change in growth throughout depending on the breaks in the canopy. To break this flatness is the gully fern which is paired with the kanuka to mimic it's wider branching shape, as well as it's iconic relationship to New Zealand's canopy floors.
In the soft clearing spaces, ribbon wood trees are used due to their deciduous nature and their contrast to the kanuka. They mark a subtle shift in space as they are sparingly used at the edges of the cleanings, amongst the dominant kanuka. This adds to the seasonality of the space.

Finally are the ephemeral turfs. These were chosen from the selection of native ephemeral tufs because of their flowering. All the planting used within the space that has prominent flowering have white flowers that flower in the springtime. This adds to both the continuity of the space, creating a linked network of colour throughout the space, and a sense of time progression through seasonality. The turf species that best fit these characteristics are 3 species of Pennywort, the Pratia and the Dwarf Musk. 


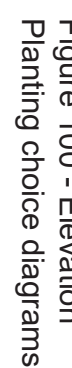

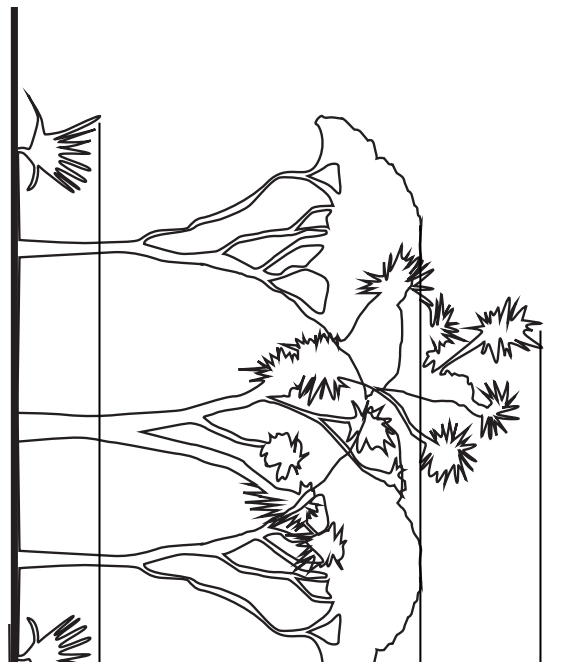

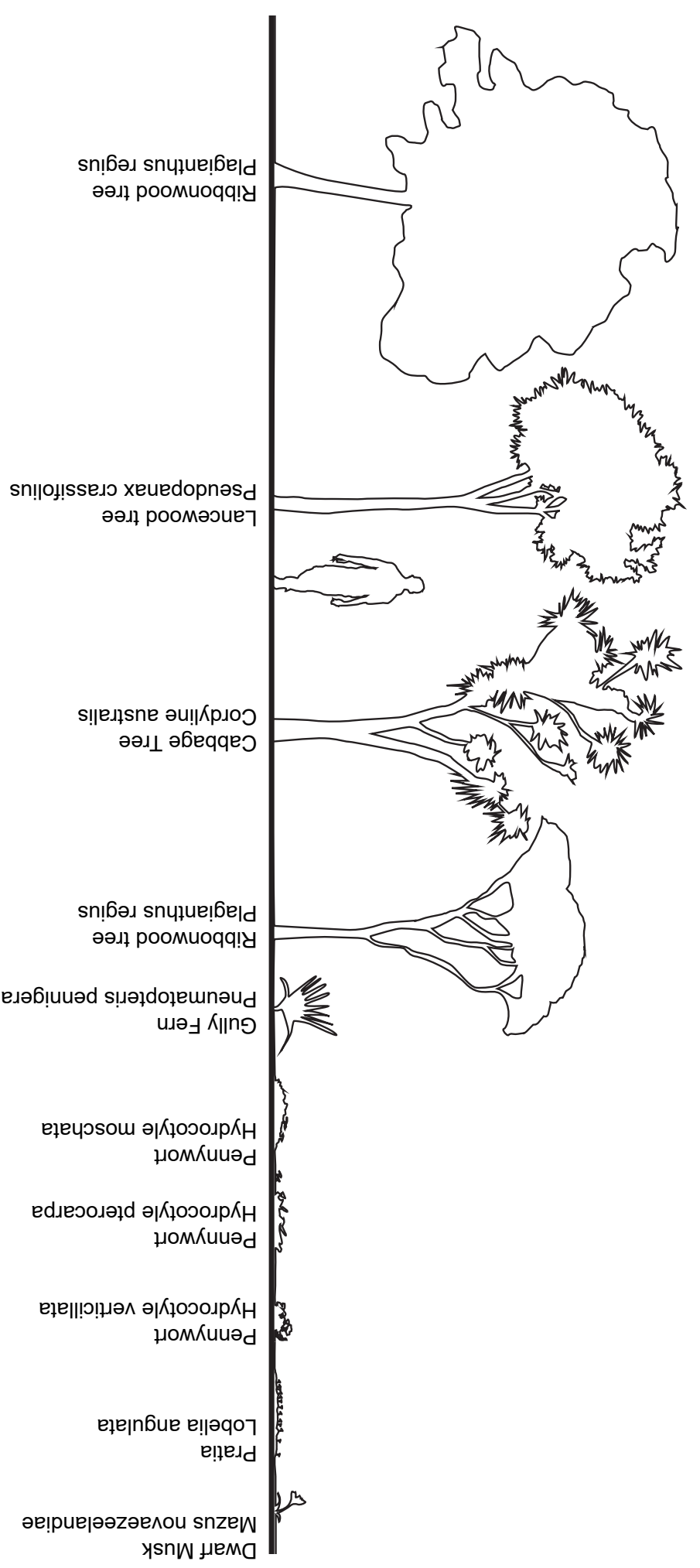

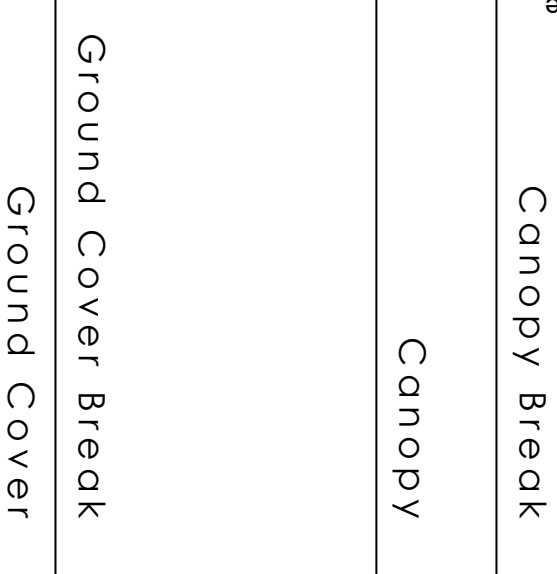

$\Omega$
0
$\frac{0}{2}$
0
0
$<$
0
$\frac{0}{10}$
0
$\frac{0}{\pi}$

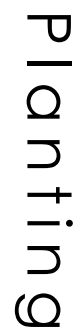




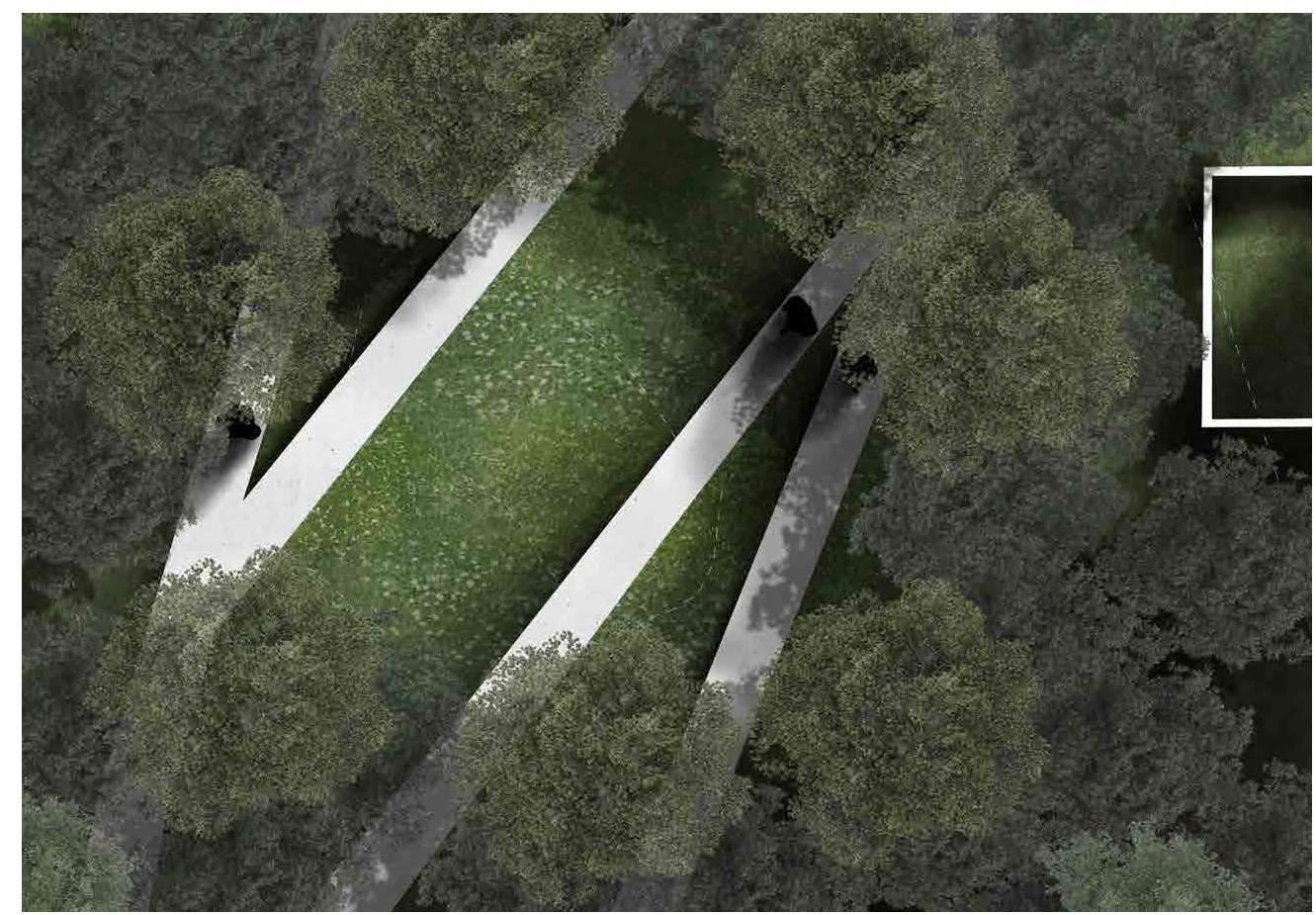

The planting creates a sense of seasonality within the spaces, and focused in the soft clearing. In summer the space is open and bright, vibrant with insect and bird life. When autumn arrives, some of the trees begin to lose their leaves and leaves can be found throughout the space, although in small quantity. Winter rains begin to fill the ephemeral wetlands, creating central ponds within the urban setting. Spring envelopes the site in white flowers and increased insect life.

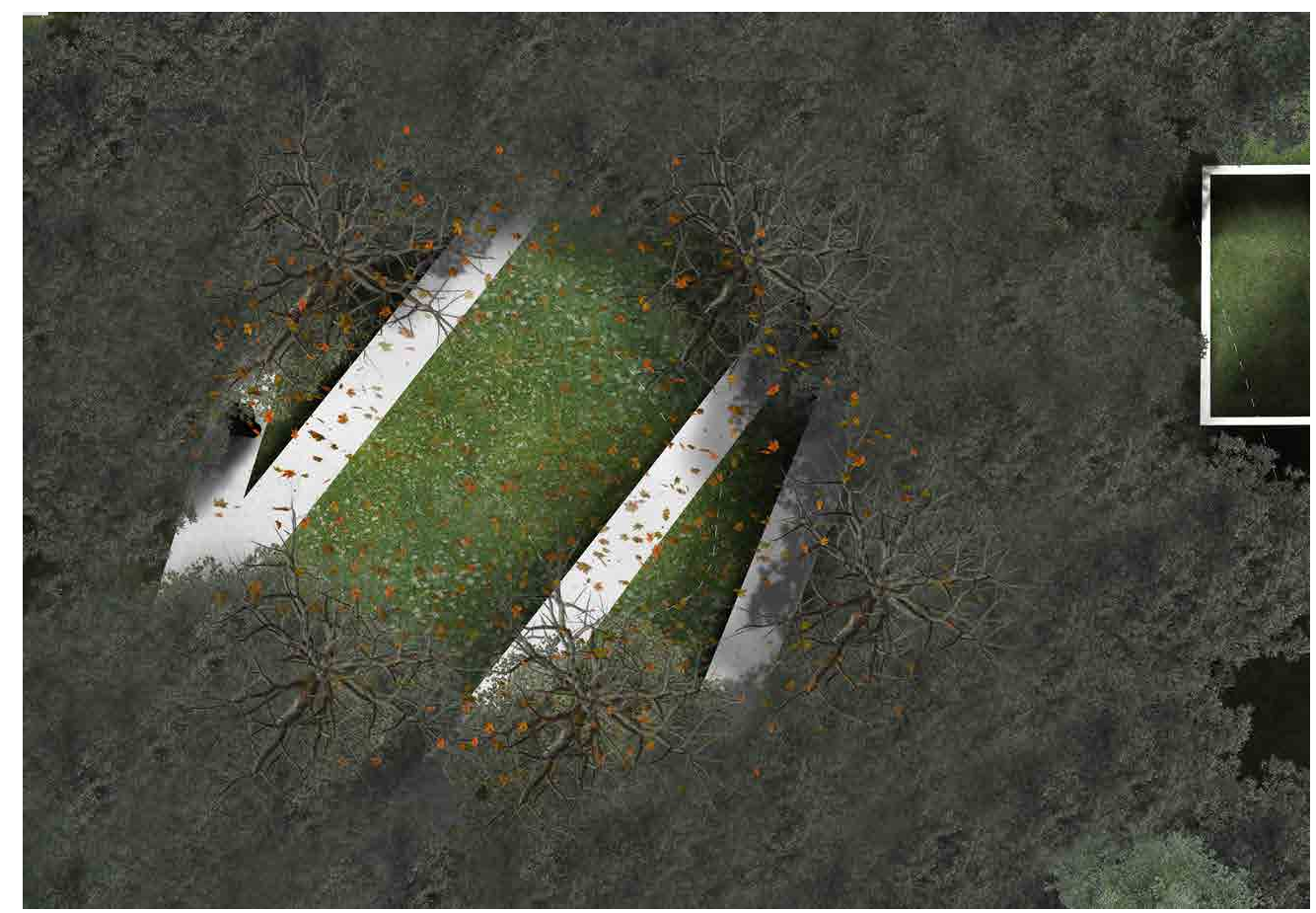




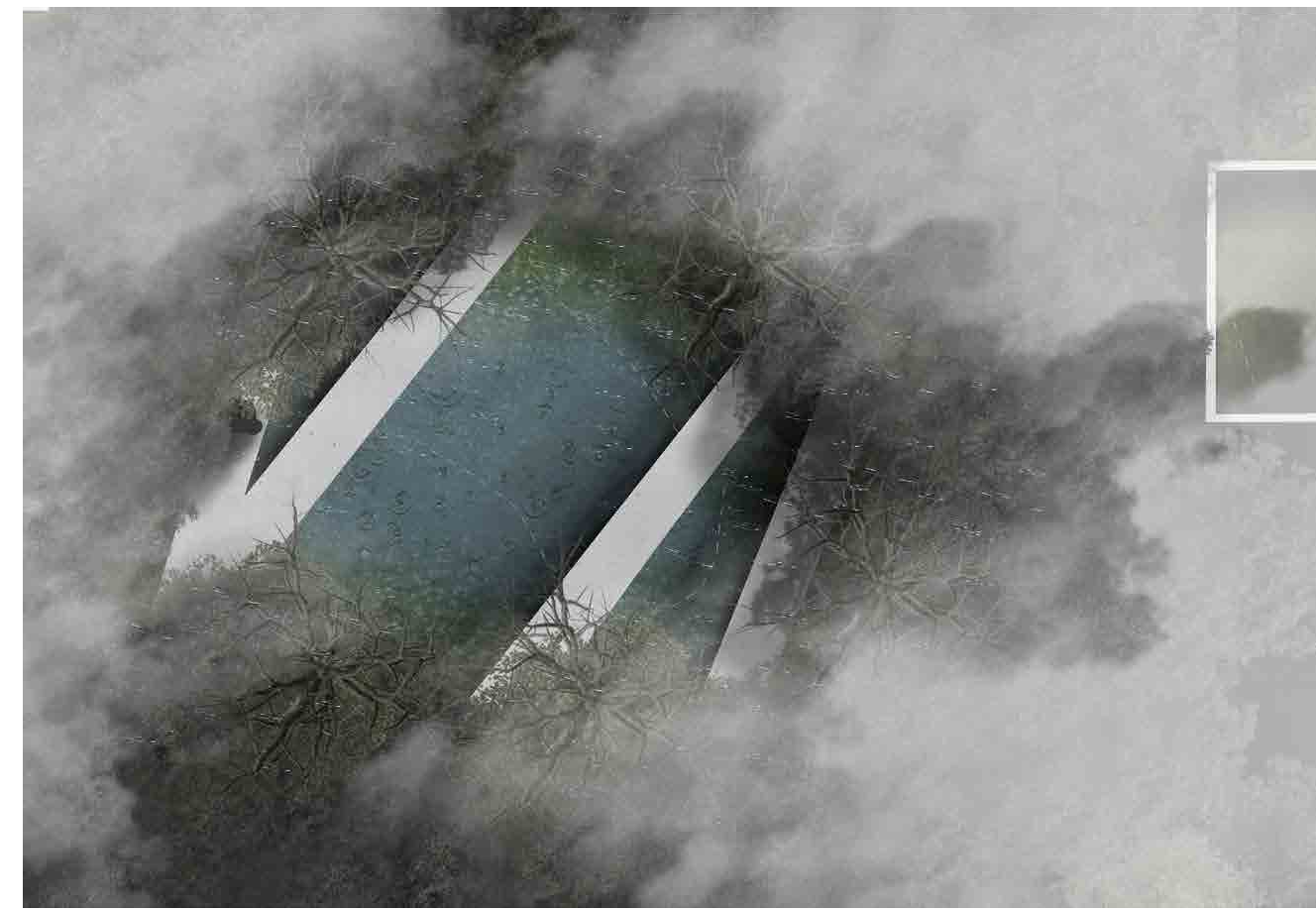

These changes are bold when isolated, but when looked as a cycle they are a series of small subtle shifts that allow a walker to realise the space has changed since they last inspected it, but also allows a walker to progress through the site with these changes going unnoticed.

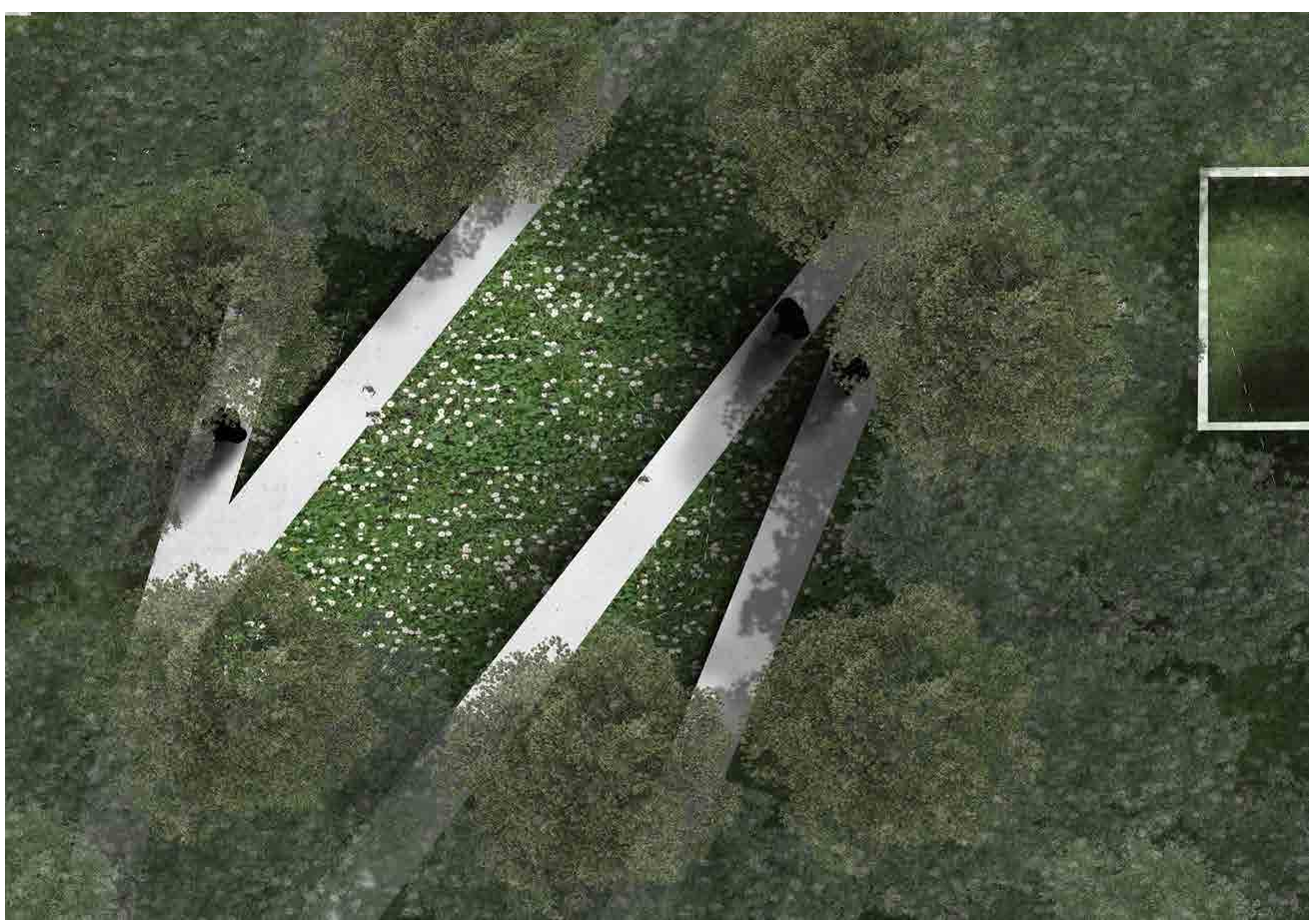




\section{Design Stages.}

This project uses the tools created in the literature investigation to create a design implementation process that reflects and aids a healthy recovery process. The tools creates to understand the grief process and they various elements of it are then used to create a design that is introduced at various stages. Not only does this help aid and reflect the recovery process but it creates a timeless design that moves through various states to create an evolving design with longevity.

The stages were based on the tools created to break down grief into stages. These four stages were than designed through the vignettes to create a series of design introductions.
The first stage is the internal stage of 'grief'. At this stage movement is the main focus creating paths that allow for meandering with an indirect but subconsciously navigable pathway. The typography and grassing is introduced at this stage and they spaces have a bare and wandering atmosphere. This new blank space creating a urban canvas for a design to emerge.
Figure 102 - Sections

Design stage 1
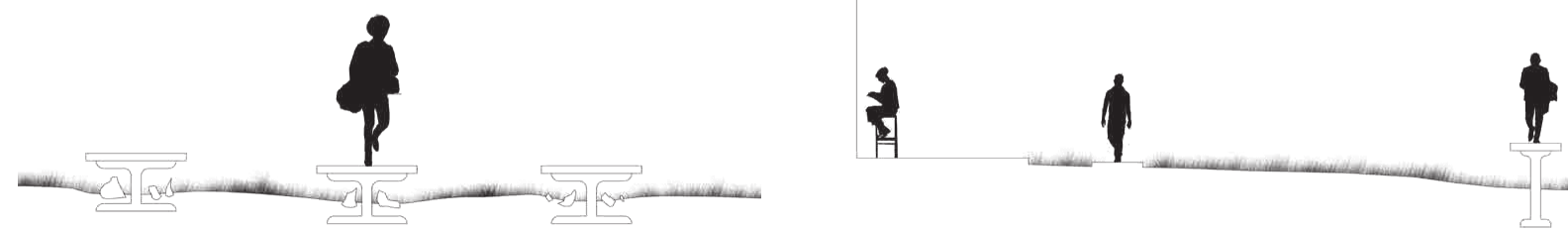

The second stage is that of 'healing' which focuses on ta persons new perspective on life after experiencing grief. At this stage the smaller details of expression and beauty become apparent to the griever. To reflect this, the paths are lined with ephemeral turfs with similar white flowering, as well as introducing the first notion of the clearing, with a large patch of turf in the center of the design. This creates a more details but still open atmosphere with room to grow.
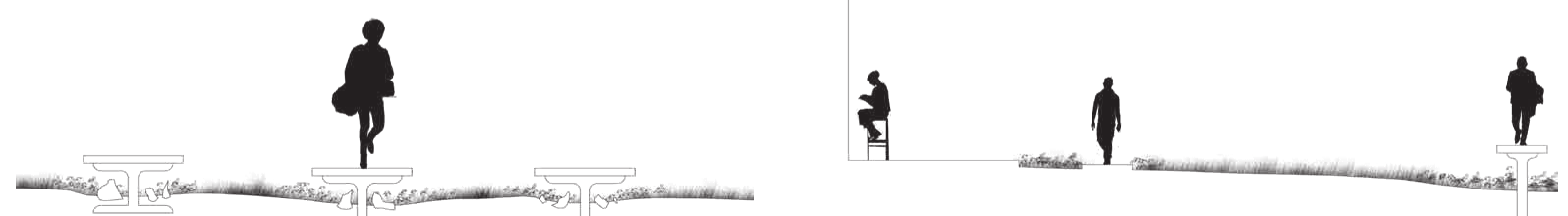

Figure 103 - Sections

Design stage 2 
The third stage is 'growth' which in terms of a griever is about time and progression. Here is when the majority of vegetation is introduced at a juvenile stage to allow for the space to shift and grow and change. This relationship between the walker and the progressing space creates a constant reminder of time passing and one's own journey.
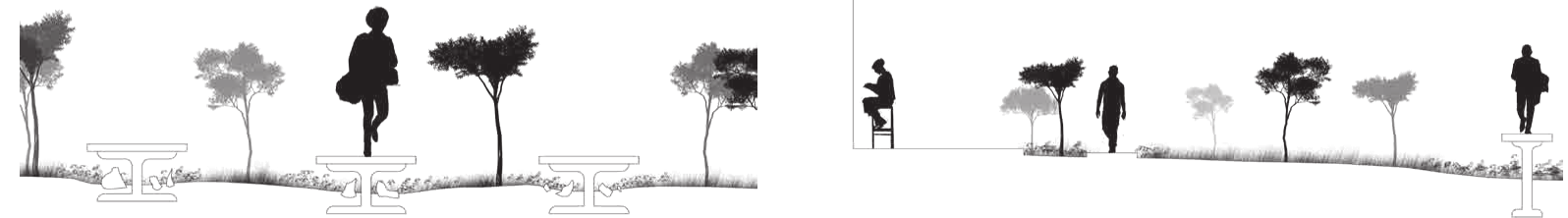

The final stage of maturity is simple focused on the relationship to a person and their life after grief. They will continue to experience new grief and shift and change from it, appreciating the imperfection of life. This is reflected in the design at this stage as it is allowed to shift and change on it's own. Plants can die or spread creating an imperfect and unpredictable design that creates an uncertain but inherently unique atmosphere for the walker.
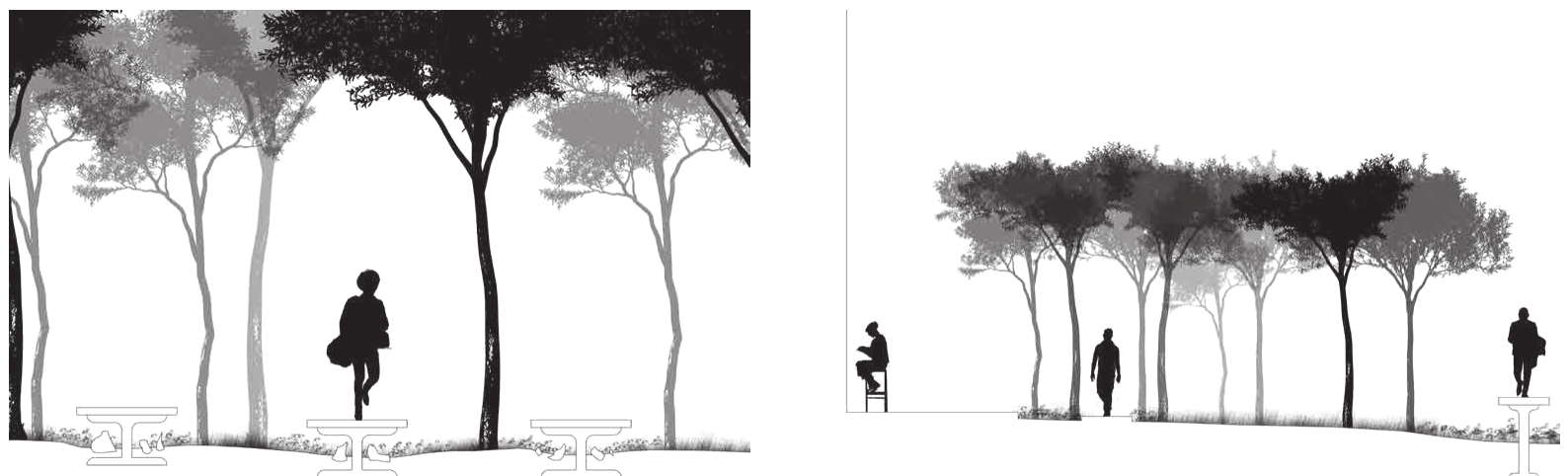

Figure 105 - Sections

Design stage 4 


\section{Design Response.}

The culmination of all these elements produced two final design responses that use all the information found throughout this investigation to create a series of atmospheric networks in design.

The design comes across as simple when first looked at, due to it's subtle and nuanced nature. This is a by product of the softer engagement with the walker created by the network of parts that were discovered through the use of grief tools.

To understand the complexity of the design and it's false simplicity both of the design responses will be investigated under two lenses, the first being a spatial lense where the design is show as it is intended to be, and secondly with a more atmospheric lense, identifying networks. 


\section{Intersection.}

The design response to this site will at first appear very similar to the other site. It is a open area within the middle of the design, surrounded by a light canopy. There are paths weaving through the site and around the edges. The main difference with this site response is how it uses and reacts to people within the atmosphere of the space. Due to the more socal space this site is in, simple disconnecting people from the public would be difficult. Rather than working against people as to not dilute the atmosphere in the space, the public and surrounding walkers are introduced as a part of the atmosphere.



Figure 105 - Plan - $1: 450$

Site 1 
While in the center of the space, you will still hear and see the surrounding life of the city. The paths cross and join in the middle to create points of engagement, while the edges are lined with paths to allow for an interaction with the cafes, restaurants, bars and street art in the surroundings. The path along the road bends in partially to entice walkers into the space. Every part and decision in this space was driven by the social aspect of both atmosphere and grief. How the injection of life can aid with atmospheric connections and networks to create a meaningful engagement with site that can spark positive reflection.

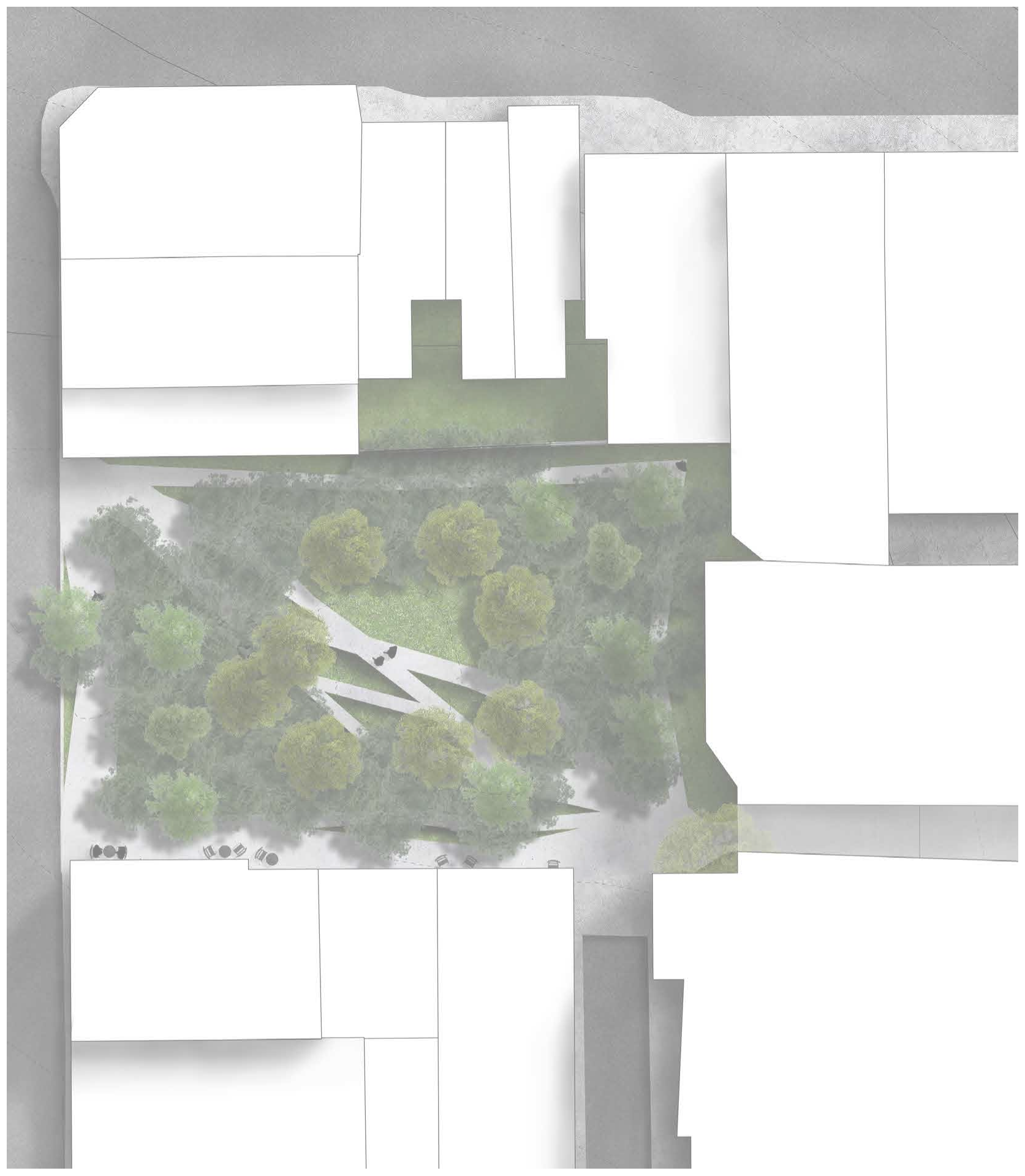

Figure 105 - Plan - $1: 450$

Site 1 
The design response to this site will at first appear very similar to the other site. It is a open area within the middle of the design, surrounded by a light canopy. There are paths weaving through the site and around the edges. The main difference with this site response is how it uses and reacts to people within the atmosphere of the space. Due to the more socal space this site is in, simple disconnecting people from the public would be difficult. Rather than working against people as to not dilute the atmosphere in the space, the public and surrounding walkers are introduced as a part of the atmosphere.
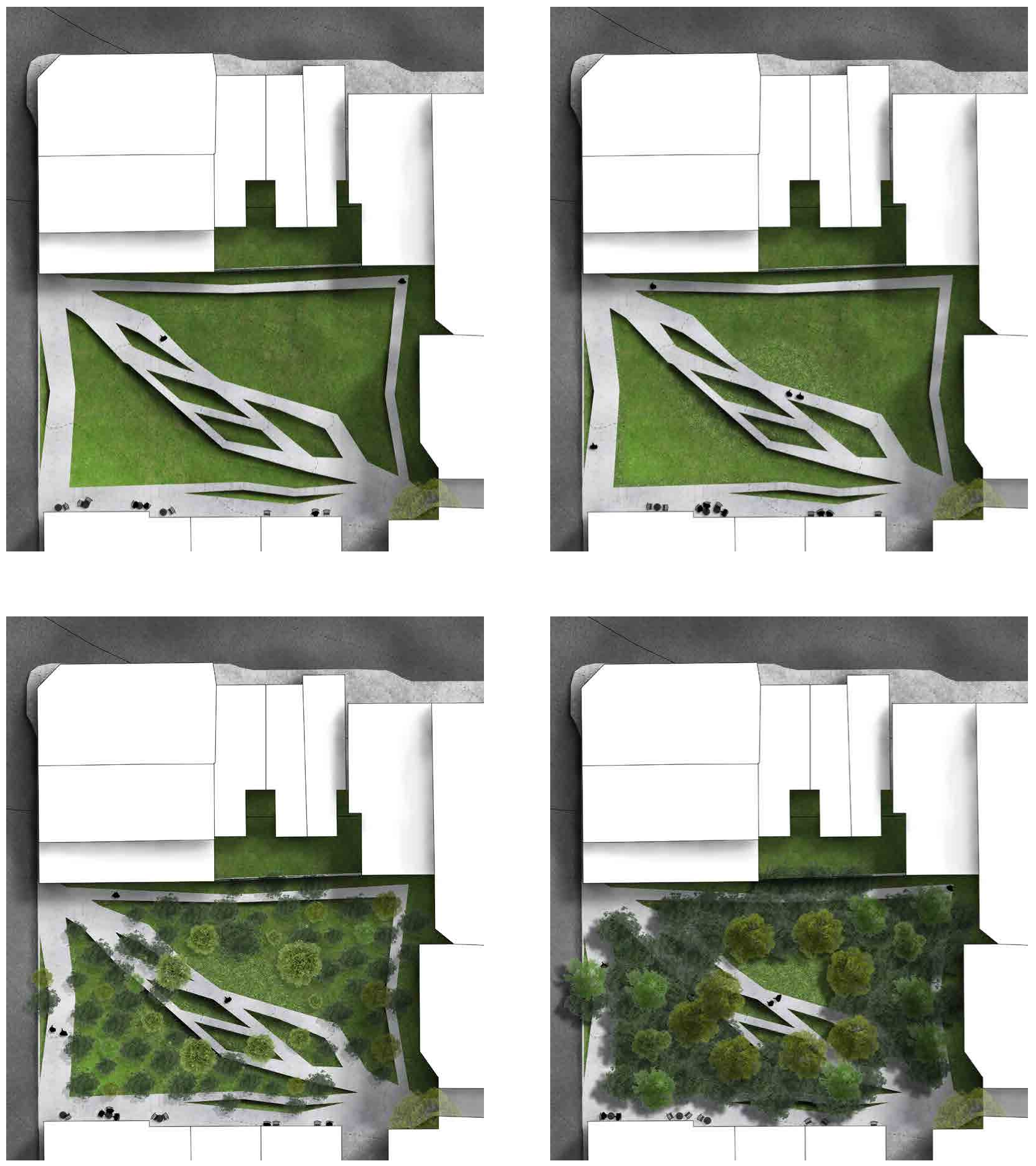

Figure 106 - Plan - 1 : 750

Design stages 
This space has a series of different journeys that can be taken through it, allowing for a variety of different experiences and levels of social engagement.

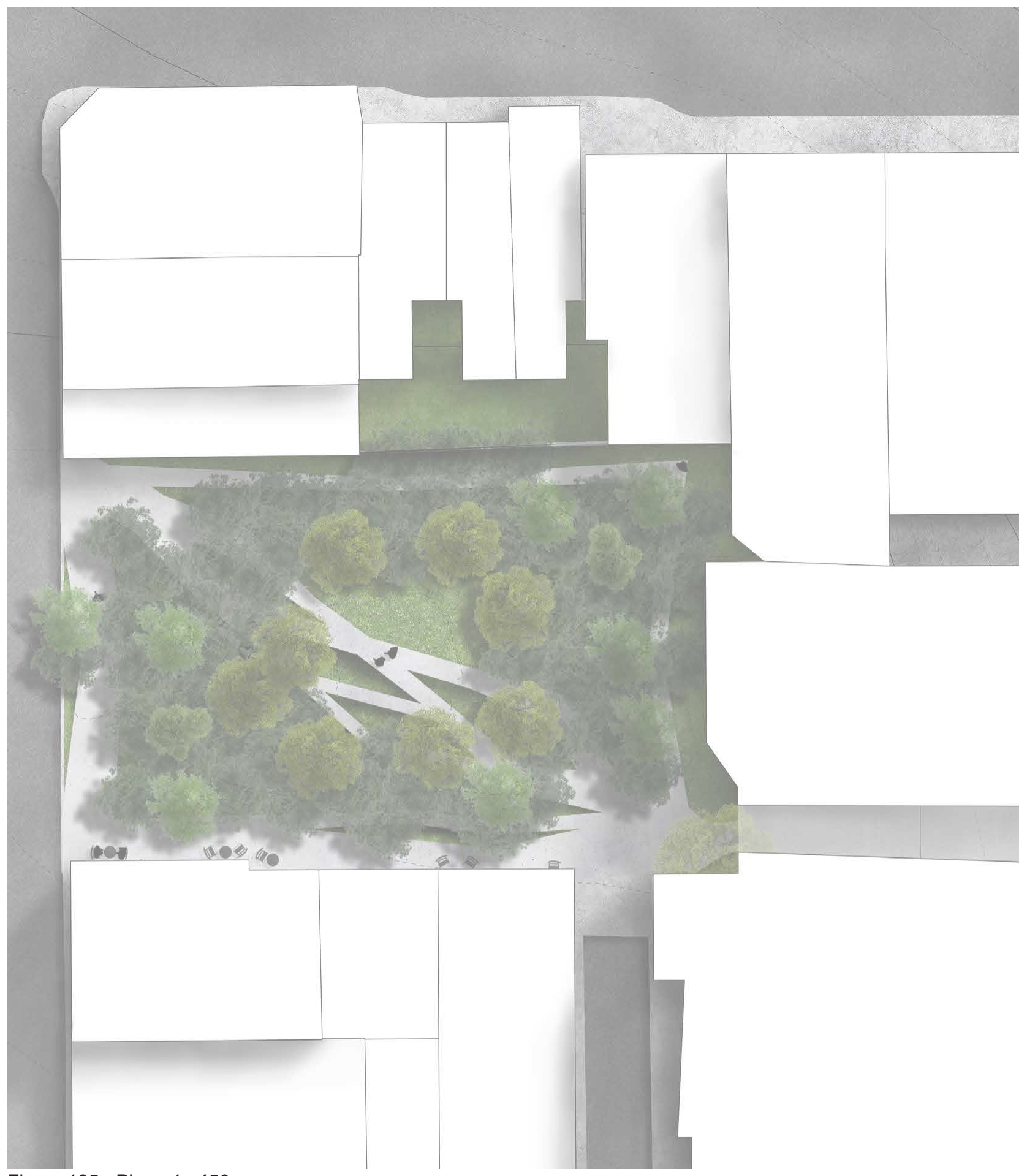

Figure 105 - Plan - $1: 450$

Site 1 
The first journey is the along the edge of the design, along cuba street. Here a walker transitions between two buildings into an open area and are pulled slightly towards the site, allowing a tree to separate the walker from the road for a moment. This entices the walker to turn in and explore.

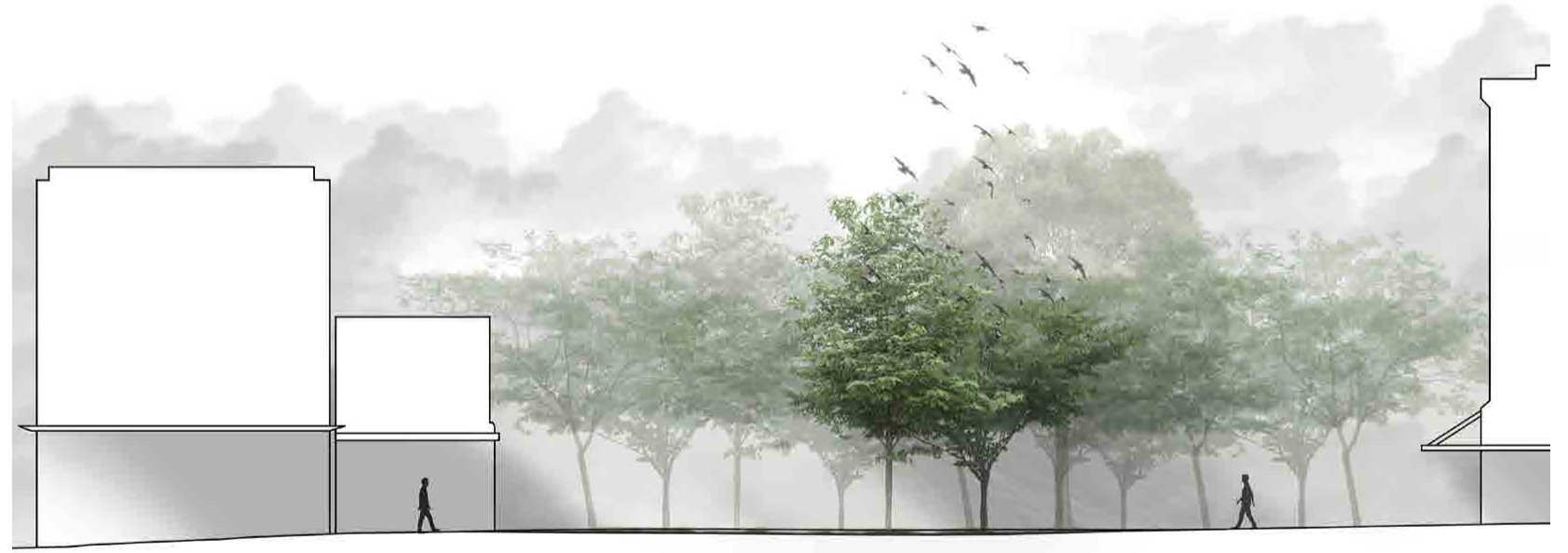

Figure 107 - Section - $1: 300$

Journey section A

The second journey focuses on the shop front and cutting between the streets. This brings the walker through the show front area, engaging with the public and weaving between tables and trees. This soft and informal edge creates a more relatable and less directed walk, mimicking the meandering nature of the main paths.

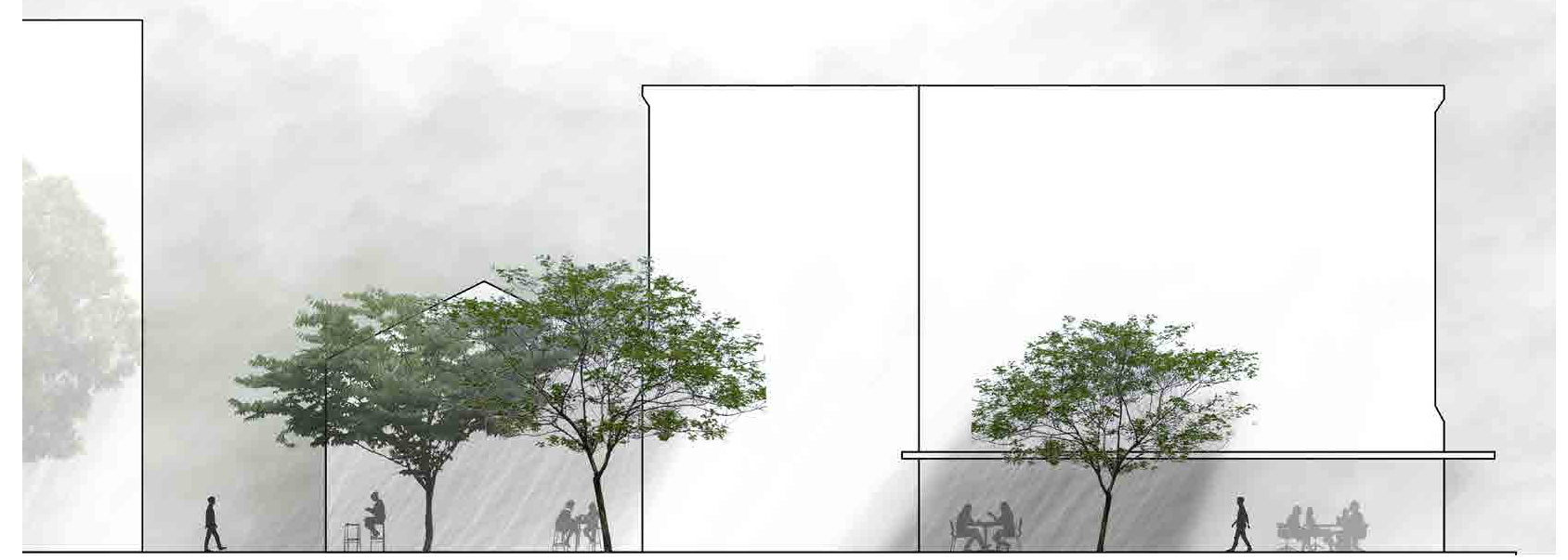

Figure 108 - Section - $1: 300$

Journey section B 
The final walk is the one through the middle of the site. Here a walker cuts across the space, weaving along a series of paths into an open area, before transitioning back through a light canopy and back into the urban setting. This transition is not a strong and monumental shift, but a series of smaller shifts that creates a softer transition.

Although a very simple design, the end result has a variety of different atmosphere and feelings throughout.

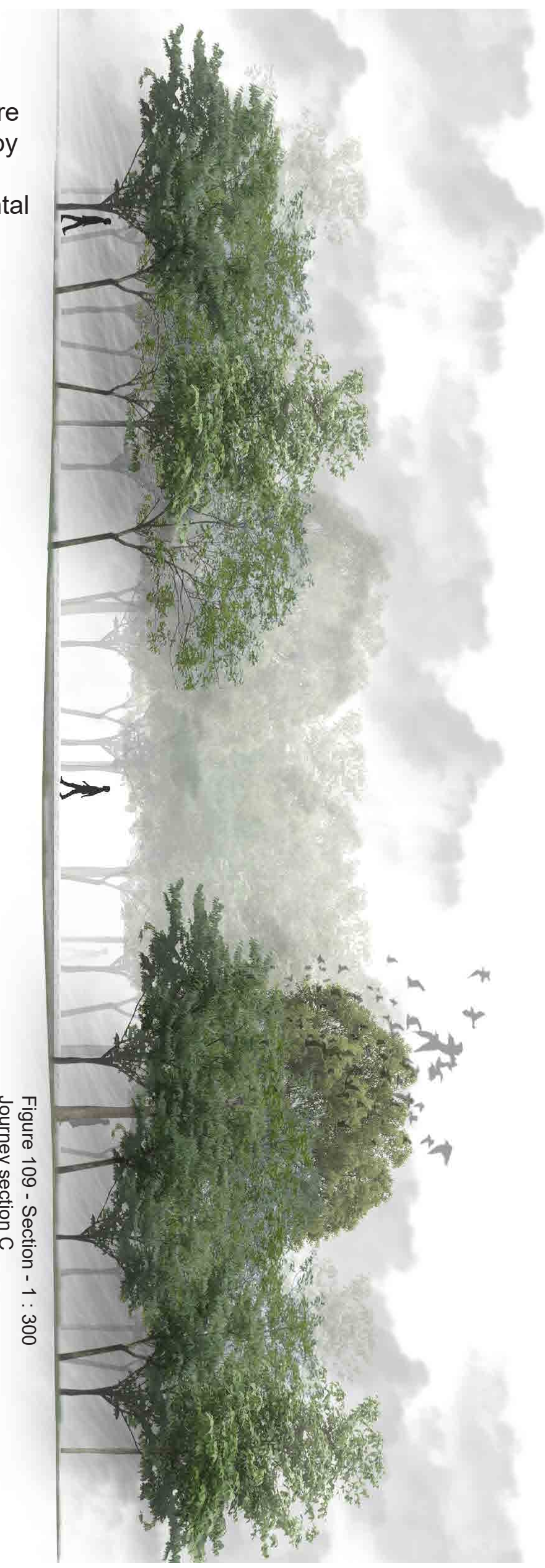


The shop front is a unique space because the spill out area is informal and will shift and change daily. The centre of the opening will be just in view through the manuka and allow for an engagement with that space. The various openings along the edge that allow for a more integrated feeling with the space create a series of thresholds as the typography drops away, making the walker and sitter alike want to cross into the space.

This creates not only a social and engaging atmosphere for the daily walker, but through a network of parts allows a canvas for a mourner to impress their own memories or reflection in the space.

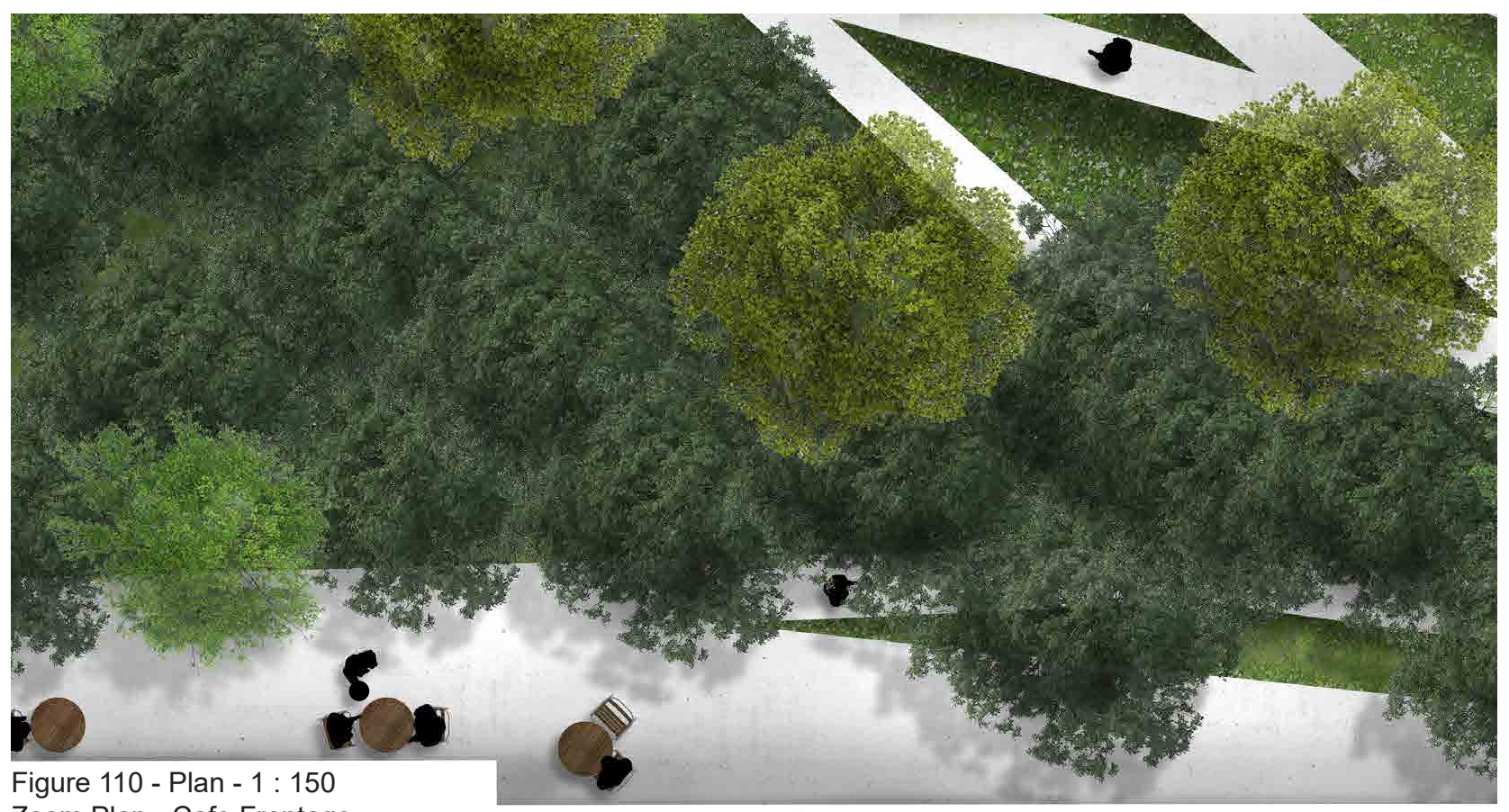

Zoom Plan - Cafe Frontage

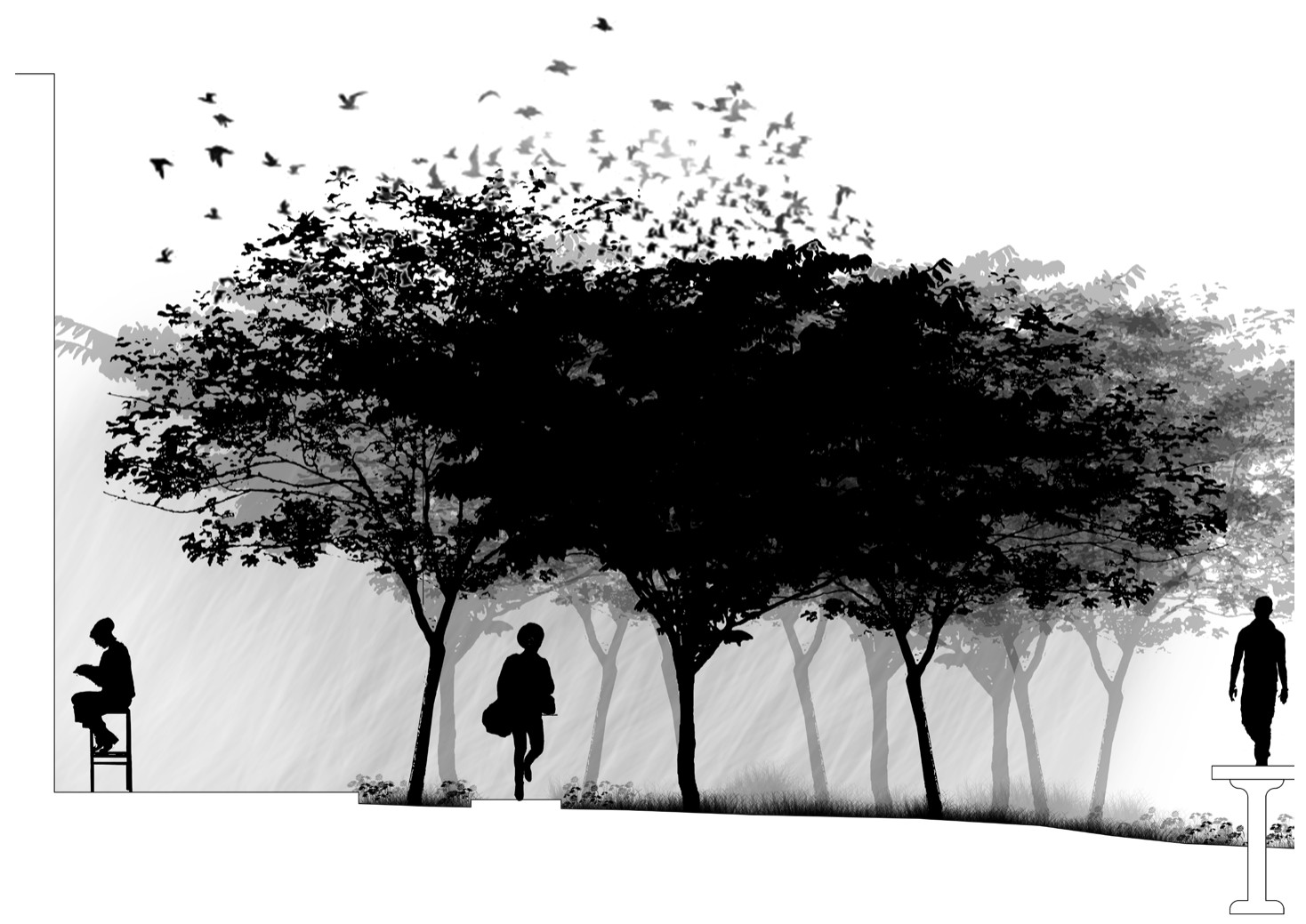


The road side is create to entice the daily walker to engage with the site, making them want, while also already submerging them in atmosphere. This is done through the balance of anticipation and want, and an atmospheric network. The walker is diverted slightly into the site, engaging with parts of the atmosphere and allow the ground to drop away below them, creating the sense of threshold and potential. They will be able to make out the opening and seeing it's open and sunny space, creating a want, while they are already experiencing the light canopy and ephemeral elements of the atmospheric network.

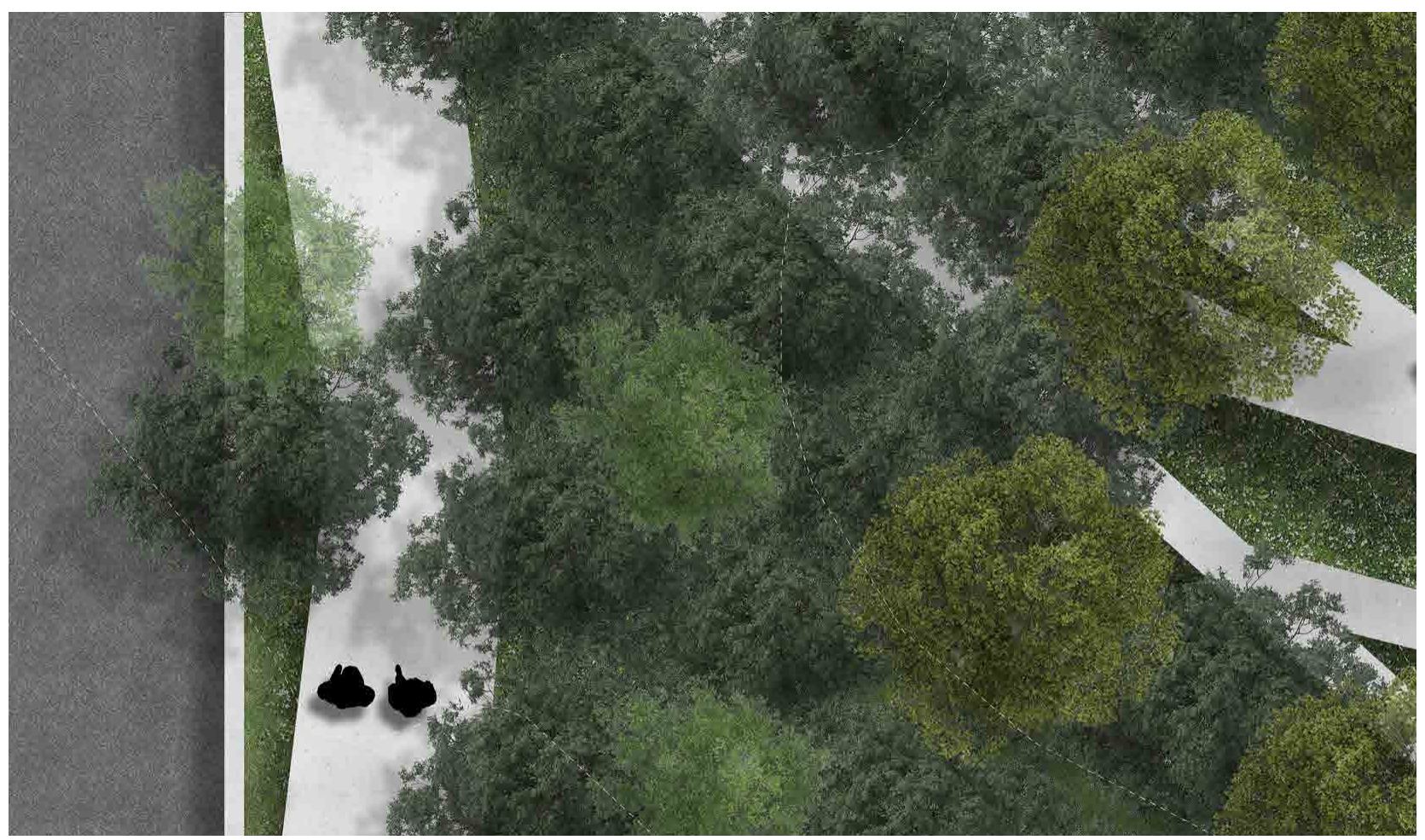

Figure 112 - Plan - $1: 150$

Zoom Plan - Roadside path

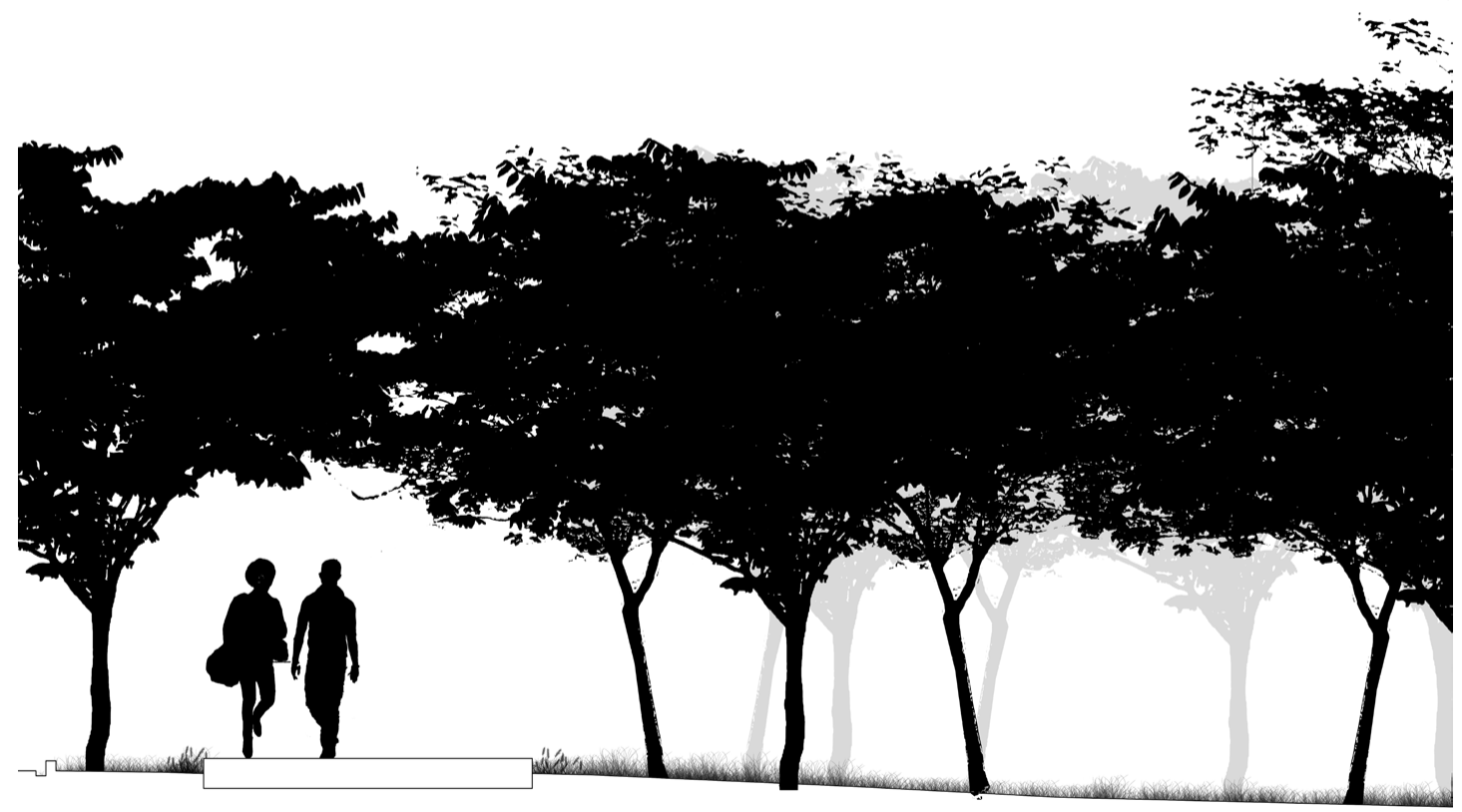

Figure 113 - Section

Zoom Section - Roadside path 
In the corner of the site is a wall used for street art and public expression. This design creates a detour path that goes against the convention of small angles corners and meanders towards the corver, creating a sharp edge to make the walker have to stop. The exhibition space is separated from most of the park space to allow for more engagement with the atmosphere created by the art in the area.

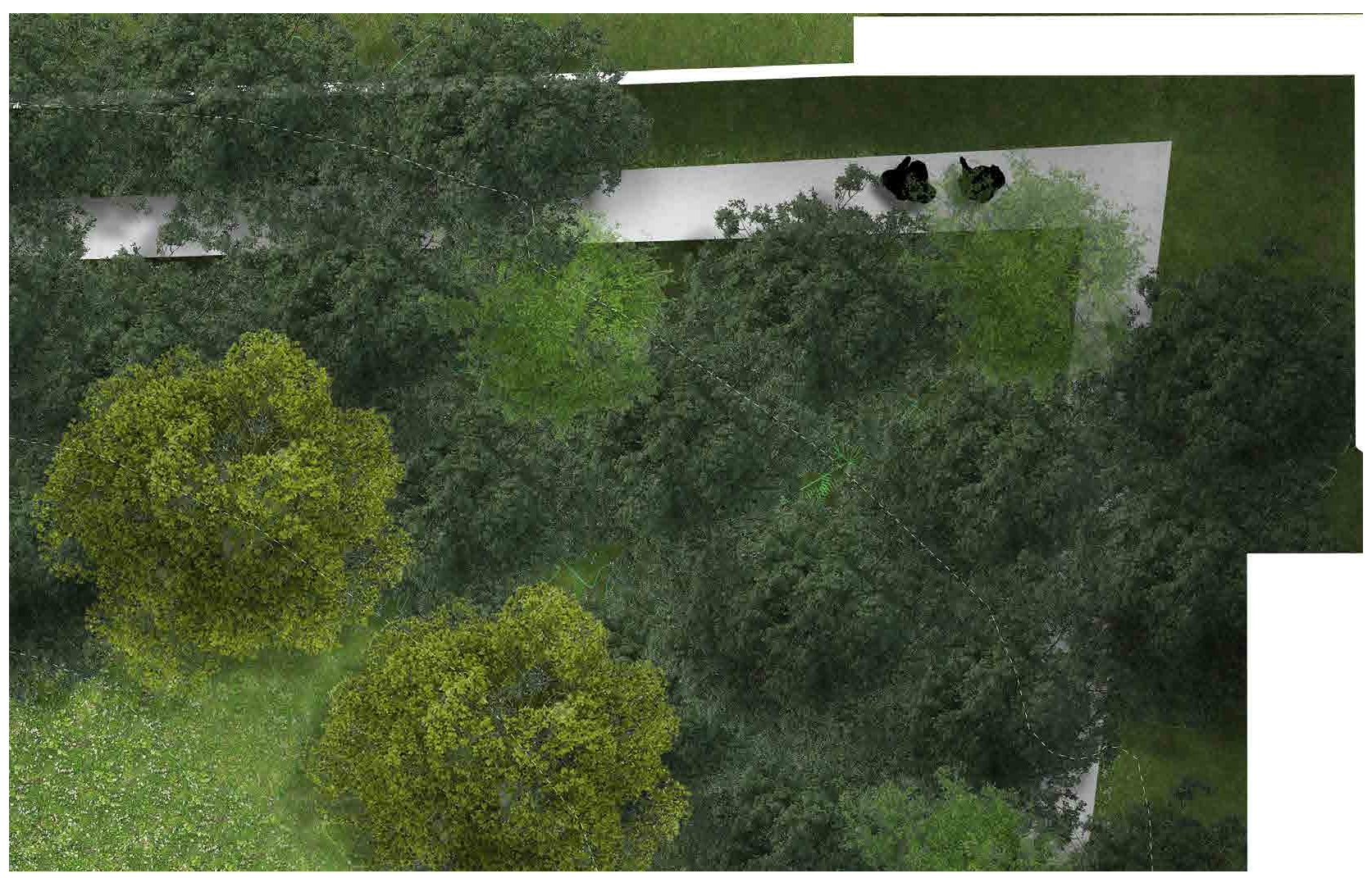

Figure 114 - Plan - 1 : 150

Zoom Plan - Exhibition space

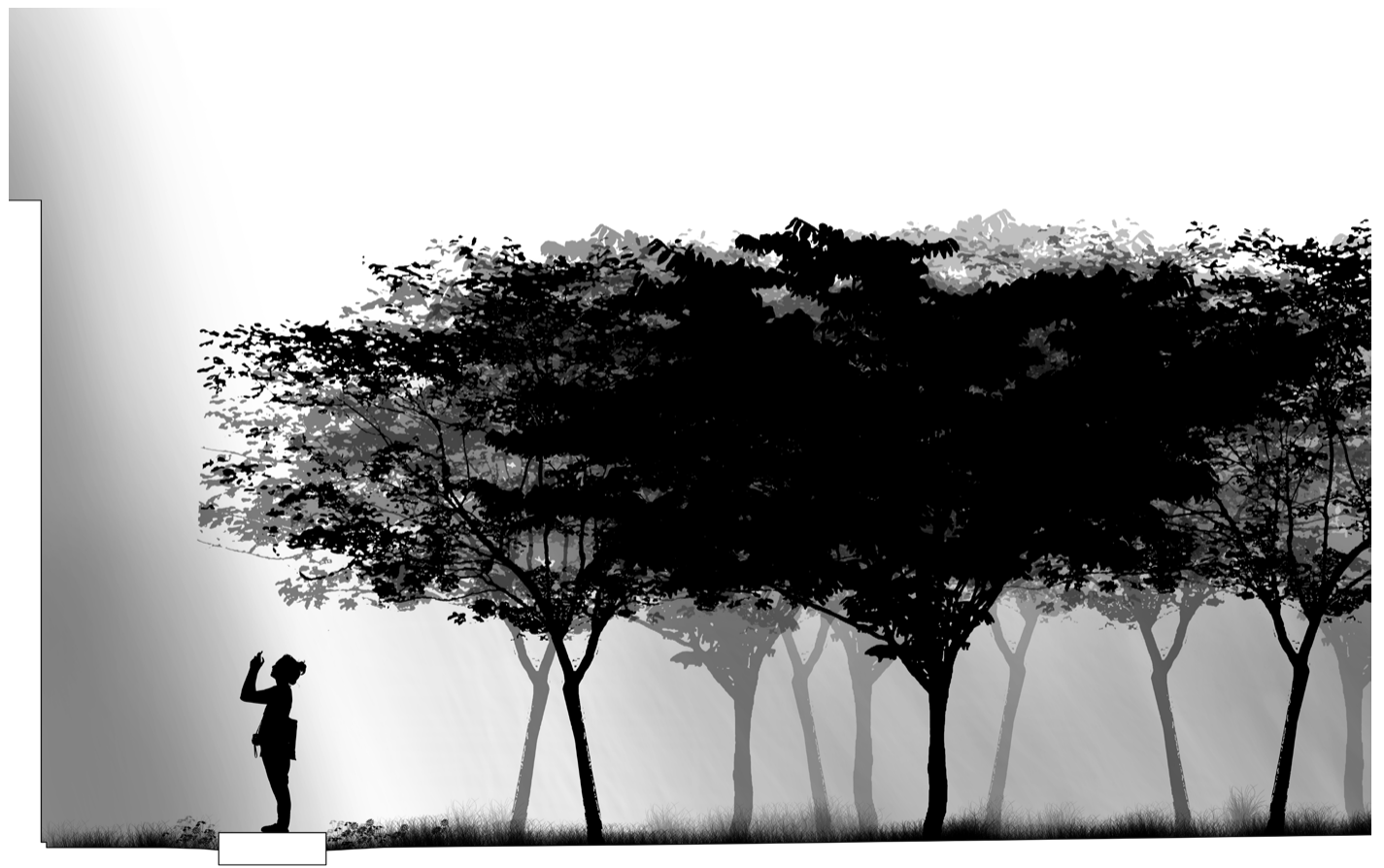

Figure 115 - Section

Zoom Section - Exhibition space 
The journey space, as the name suggests, is more linear than the social space with facades and edges with little to no interaction. Because of this the design for this space can focus more on the transitions throughout the space, and the longer space allows for more liberties in a smooth transitions between spaces.

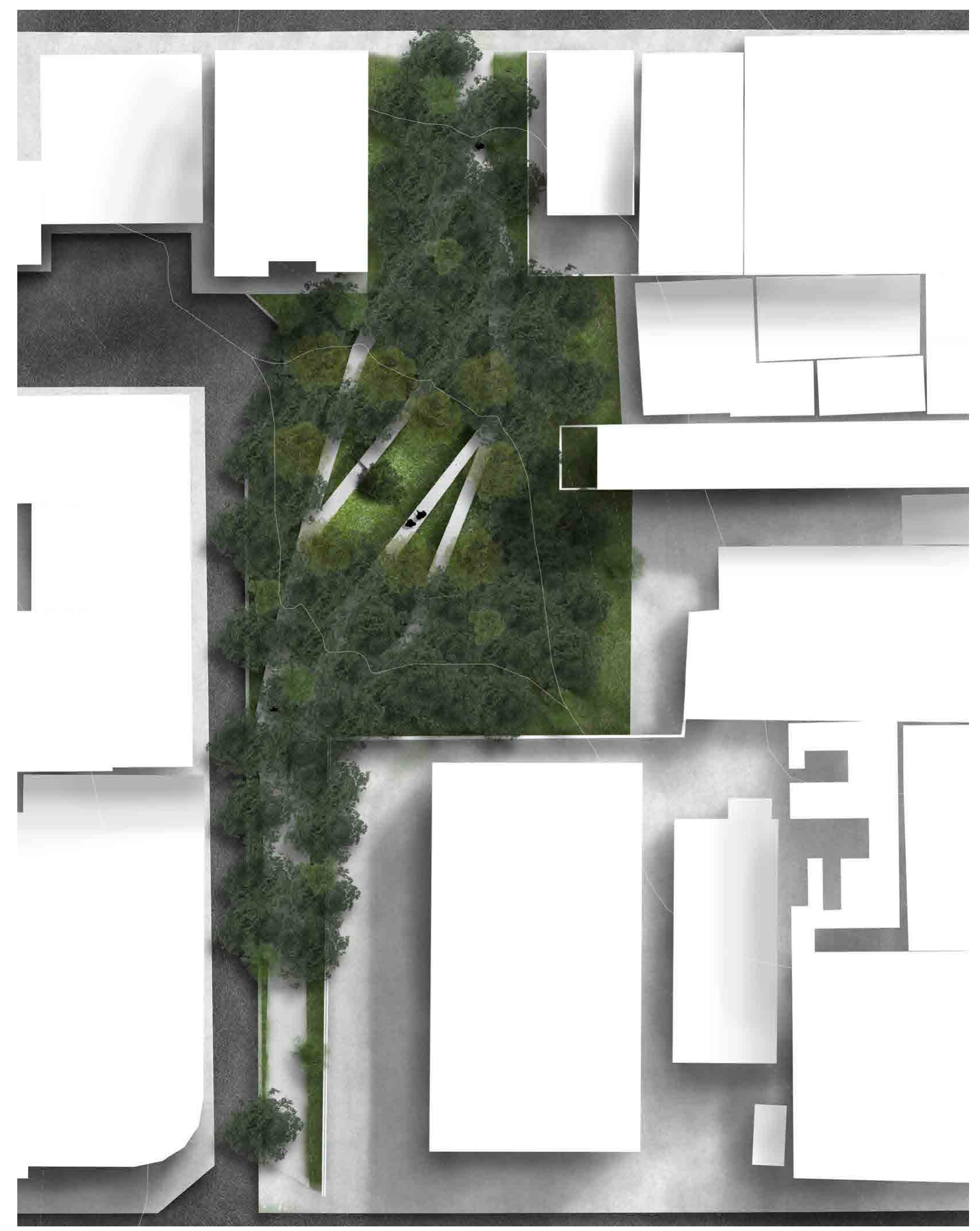

Figure 116 - Plan - 1 : 450

Site 2 
This lead to a design that, rather than instantly introducing the light canopy like the previous space, take a little time for it to encapsulate the walker. This creates, with the very low drop in typology below the path, a very gradual and subtle shift. Because of the lack of program in the site, the focus was on the journey and how it can take people away from the more desolate urban surroundings without blocking it completely. The paths split and separate to isolate walkers and groups, submerging them into an individual atmosphere.

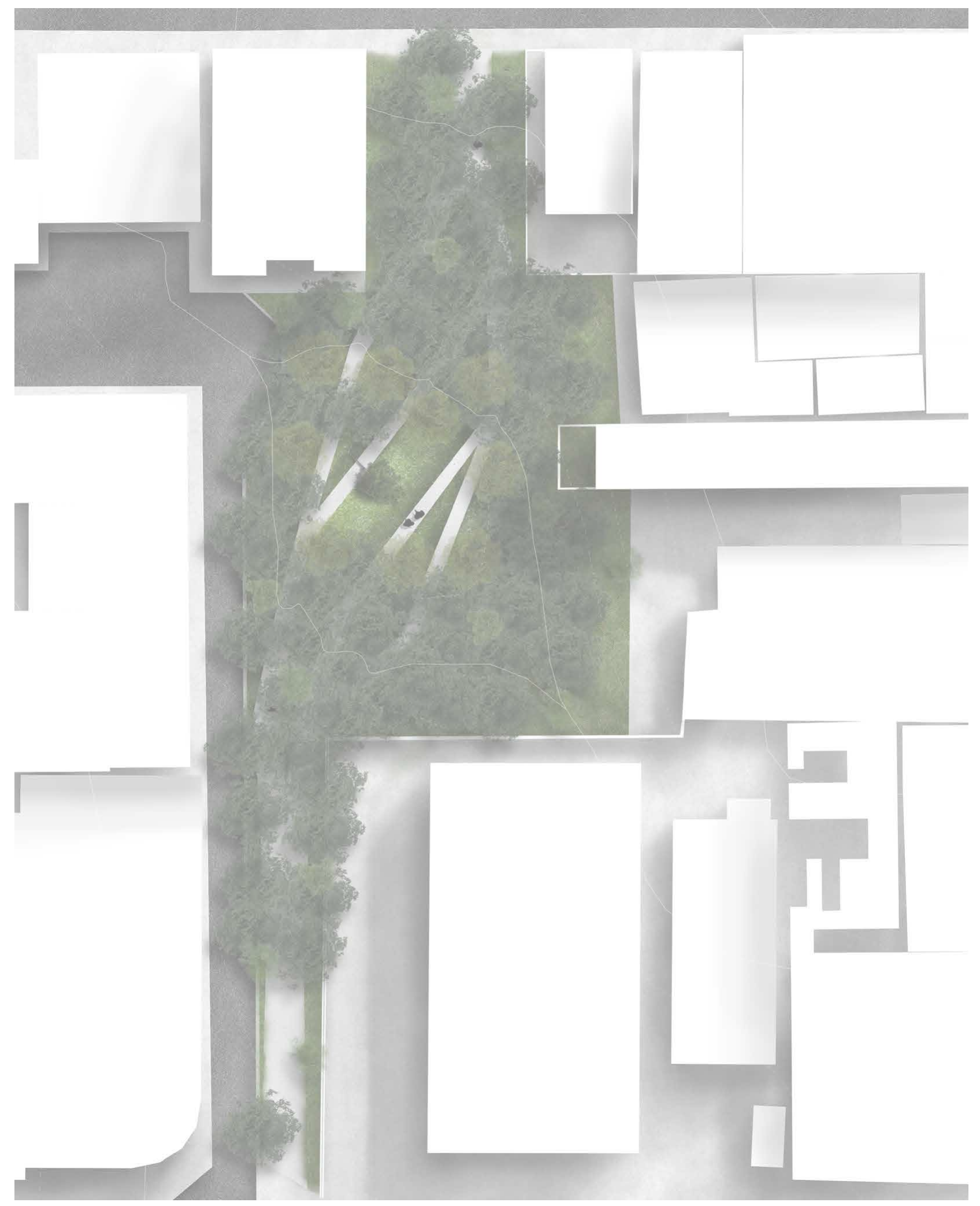

Figure 116 - Plan - $1: 450$ 
The design follows the four stages developed throughout the thesis to create an evolving and timeless design.
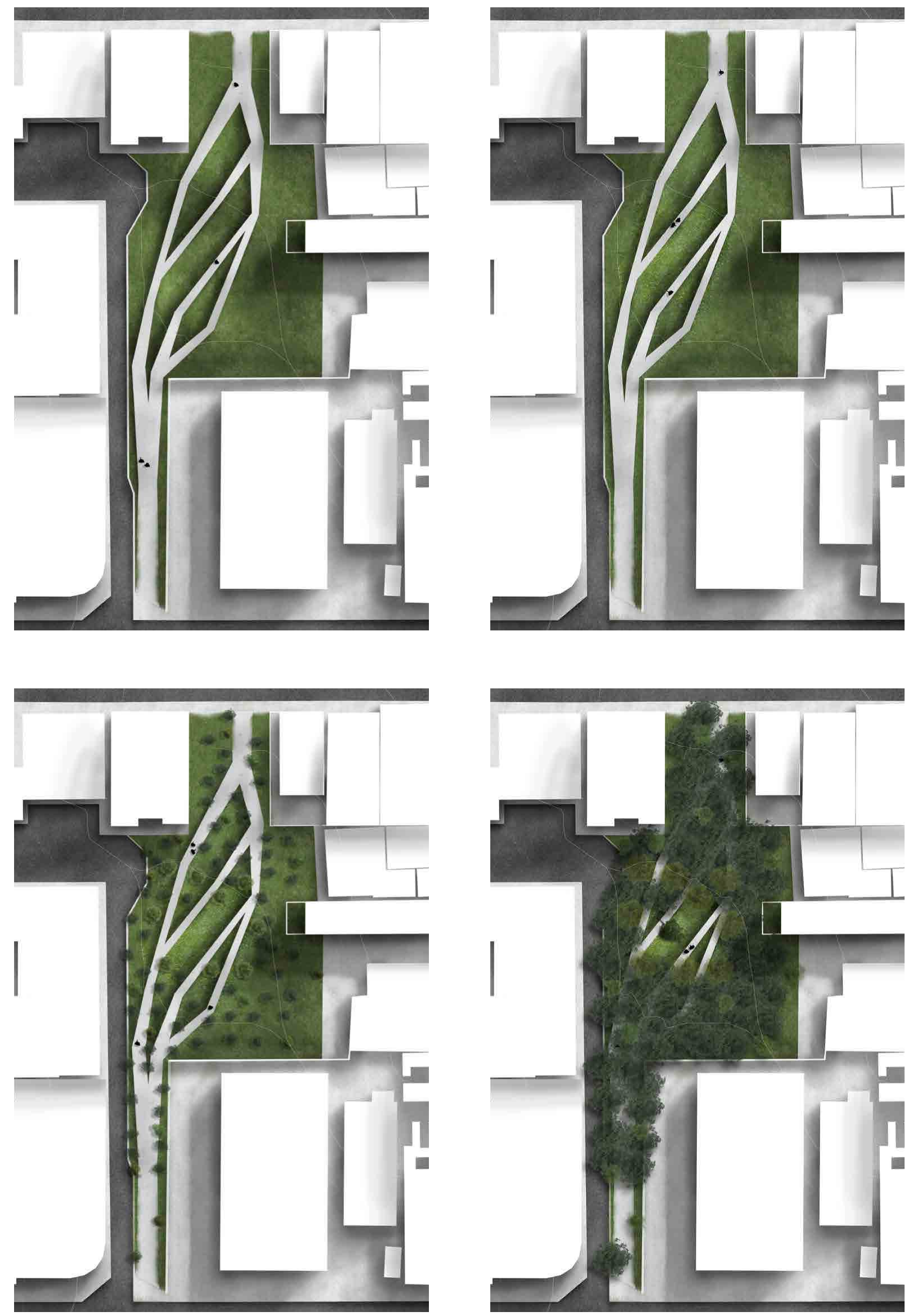

Figure 117 - Plan - $1: 750$

Design stages 
This journey is creates of three main typologies of space that blend together to create this general shift through space.

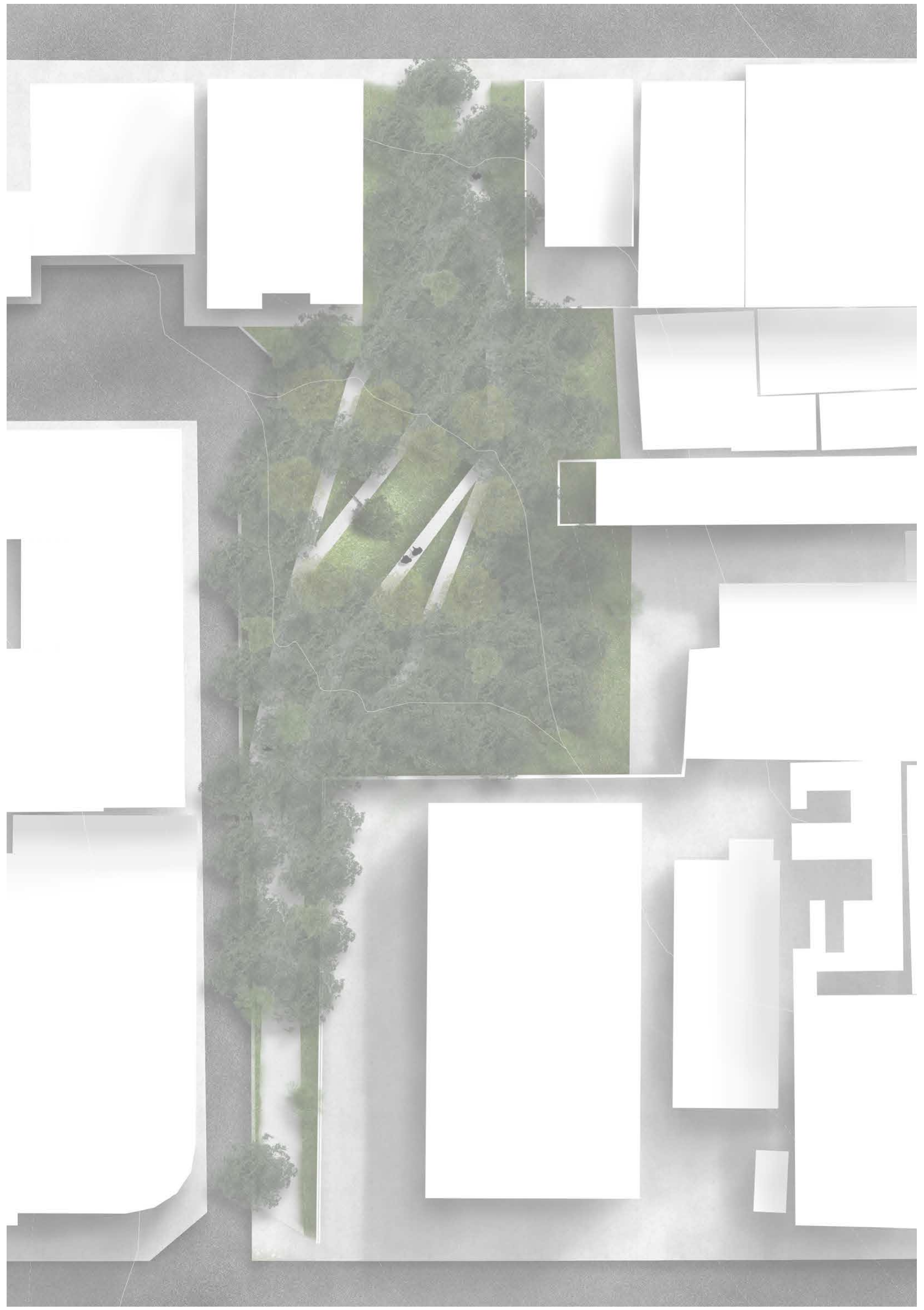

Figure 116 - Plan - $1: 450$

Site 2 
The first of which is the opening to the design, one of the two main entrances to the design. Here the ground starts at the same level as the path, but slowly drops below the walker. The trees are spread thinner than the rest of the design, creating some points of shadow on the path but mostly light. These eventually group more as the path breaks down. The path here is around $4 \mathrm{~m}$ wide, allowing for larger groups to move through together.
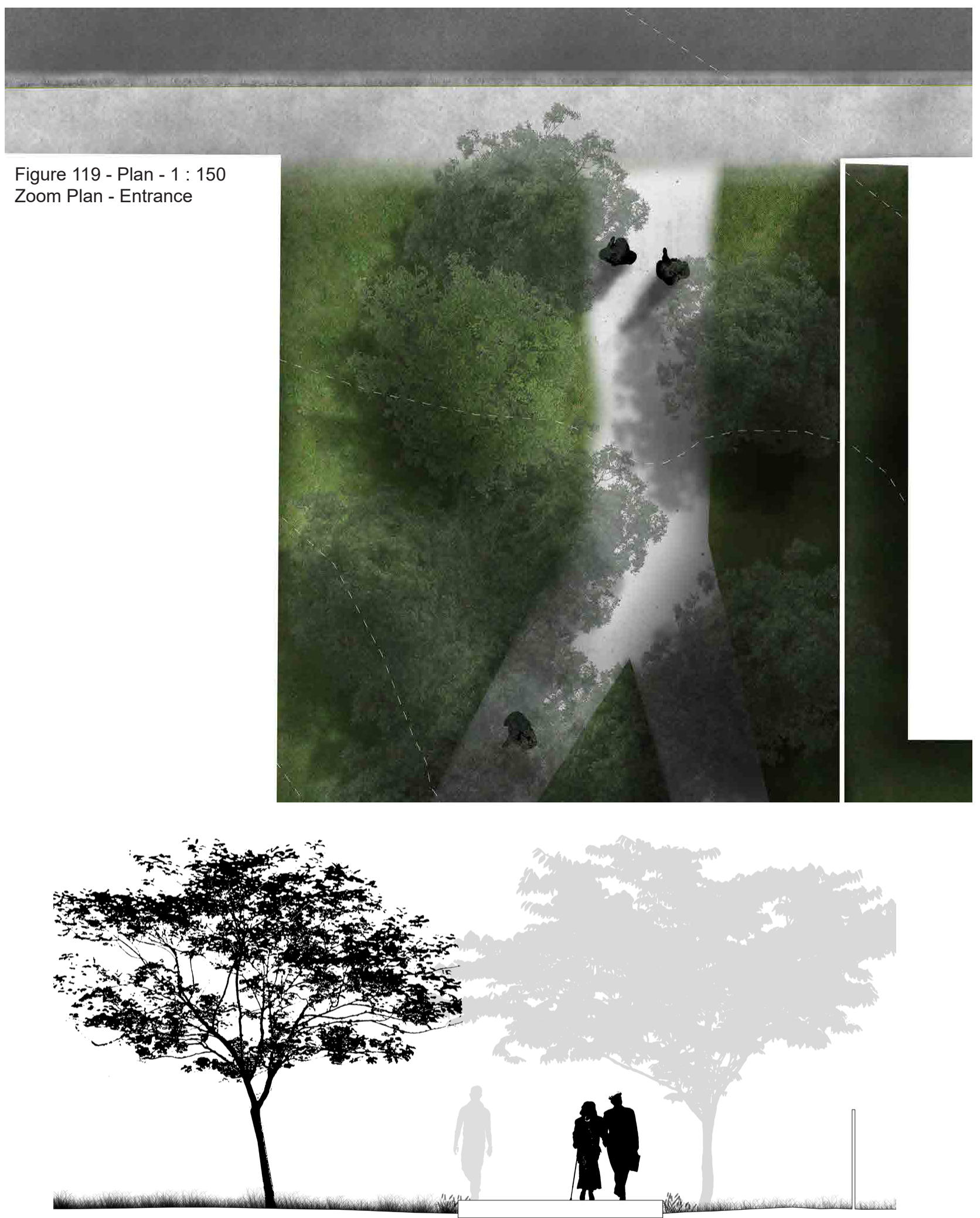

Figure 120 - Section

Zoom Section - Entrance 
The second spatial typology is the light canopy area. Here the path breaks down more, creating smaller paths for groups of 2 or individuals. The ground drops gradually, creating an ever increasing threshold as a person moves through the space.

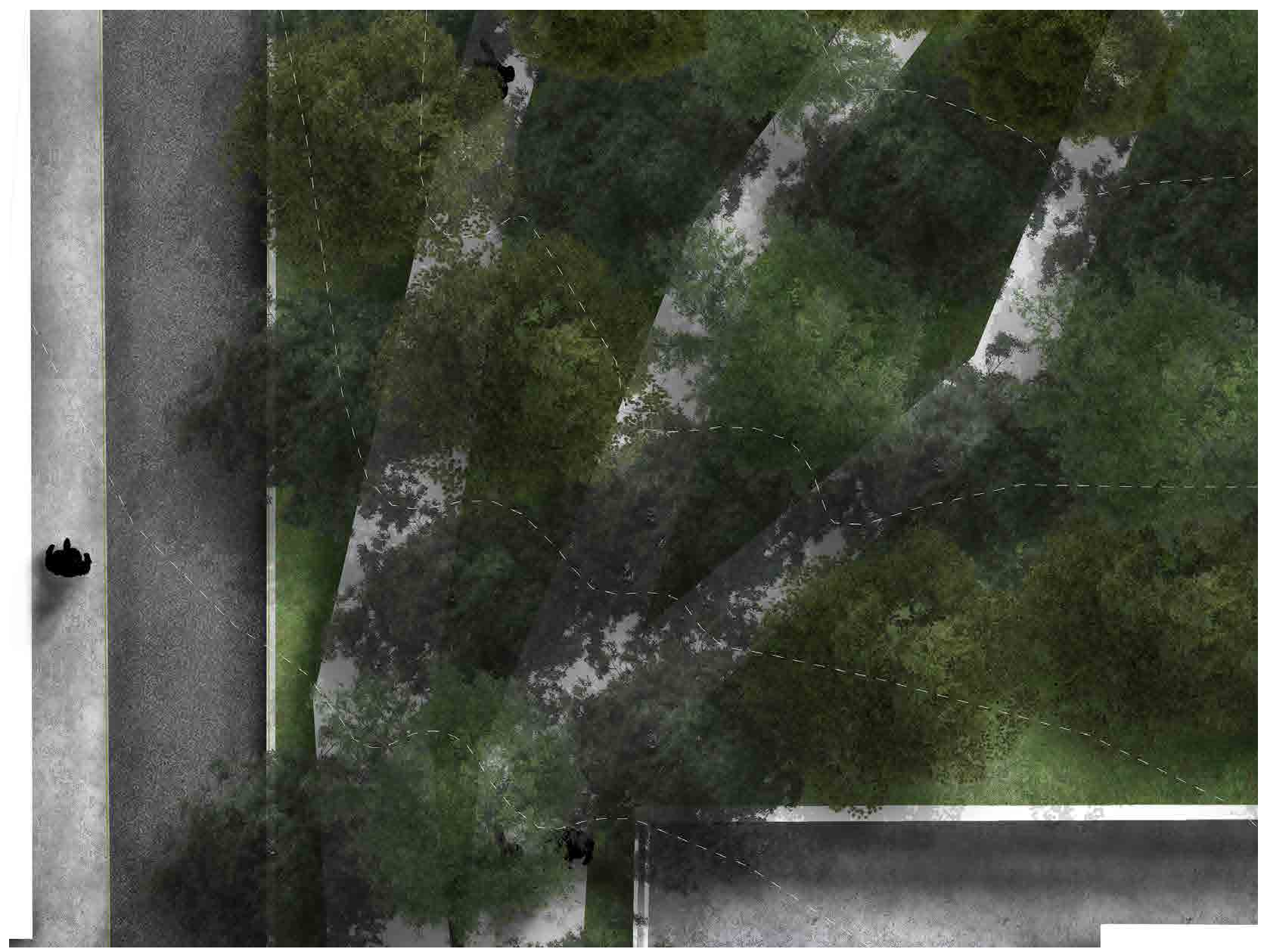

Figure 121 - Plan - $1: 150$

Zoom Plan - Forest
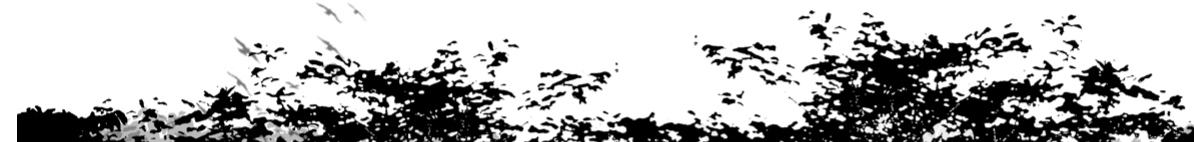
in
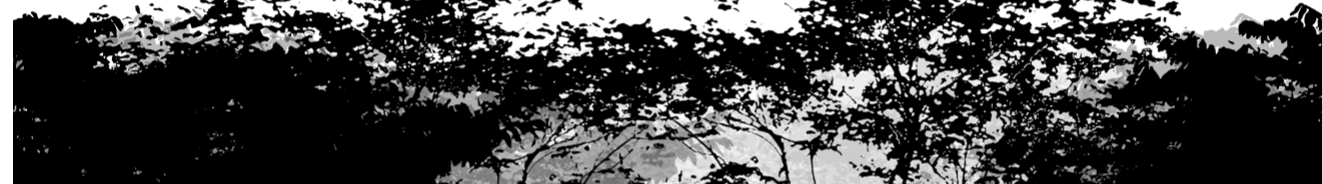

the

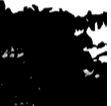

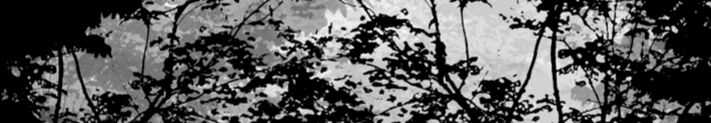

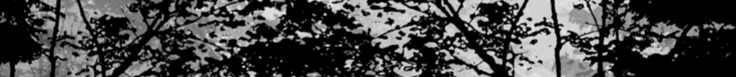

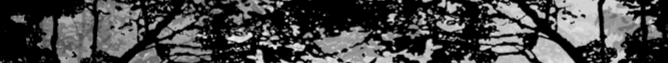

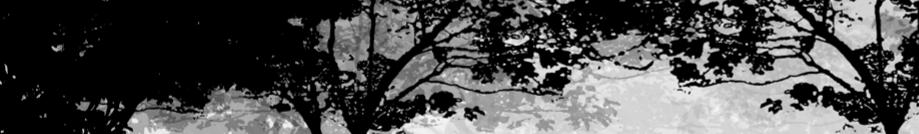

.
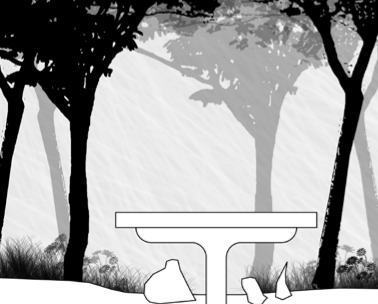

$\longrightarrow$

Figure 122 - Section

Zoom Section - Forest 
The final space is the opening from the canopy where the ephemeral turfs and deciduous trees create a sense of seasonality. All the paths are split into individual paths to allow for a pull engagement with the space.

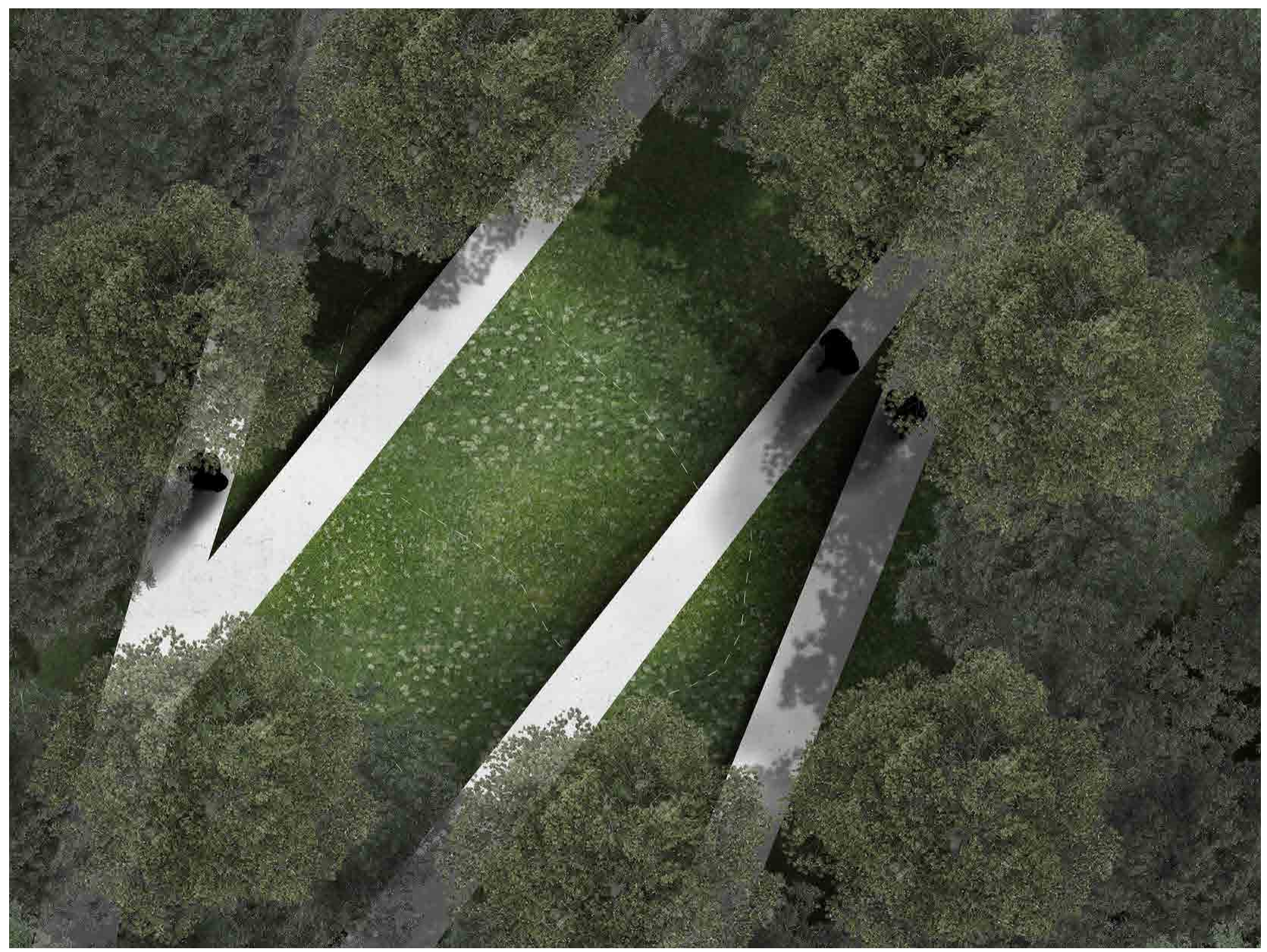

Figure 123 - Plan - 1 : 150

Zoom Plan - Soft openeing

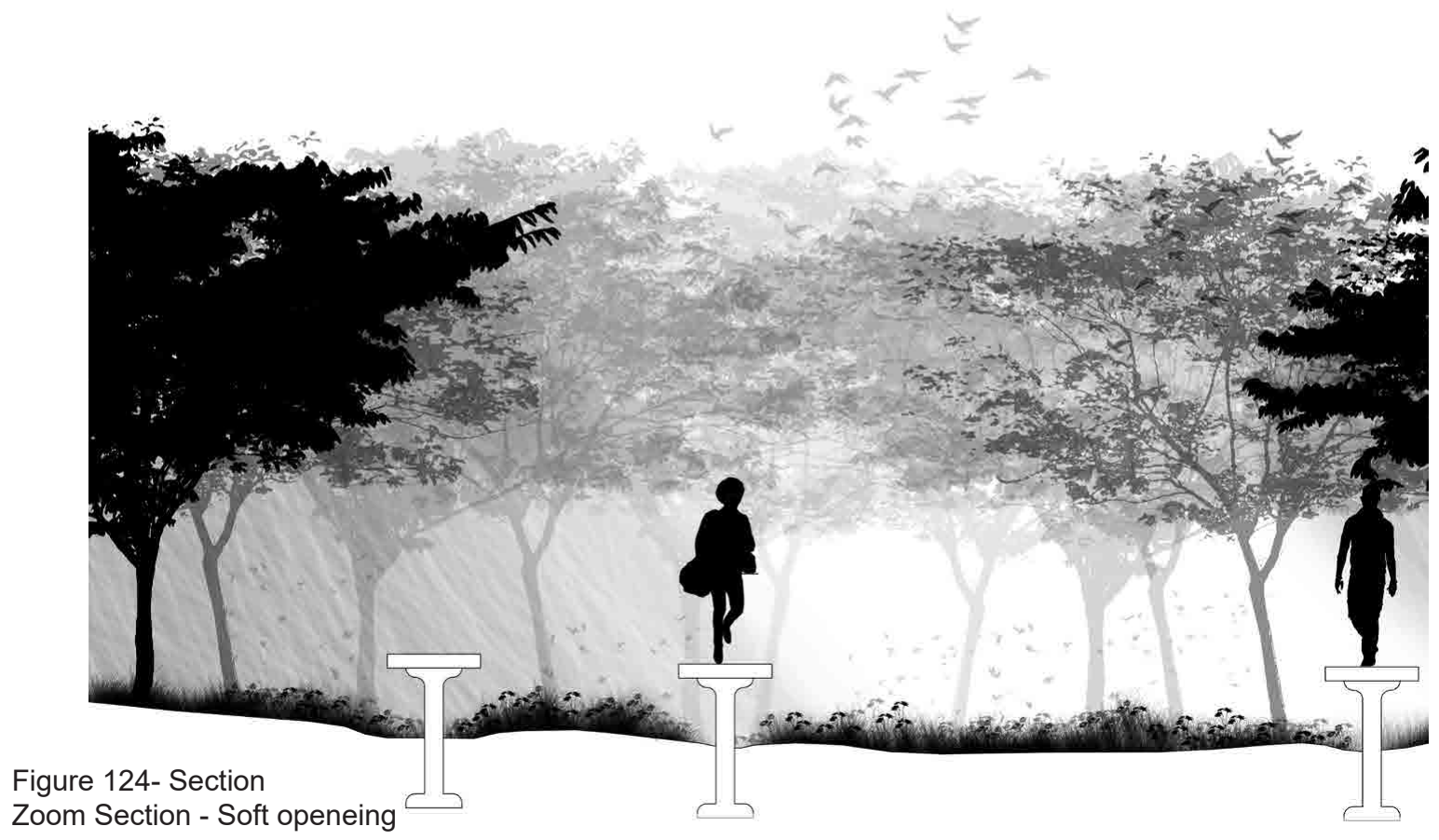




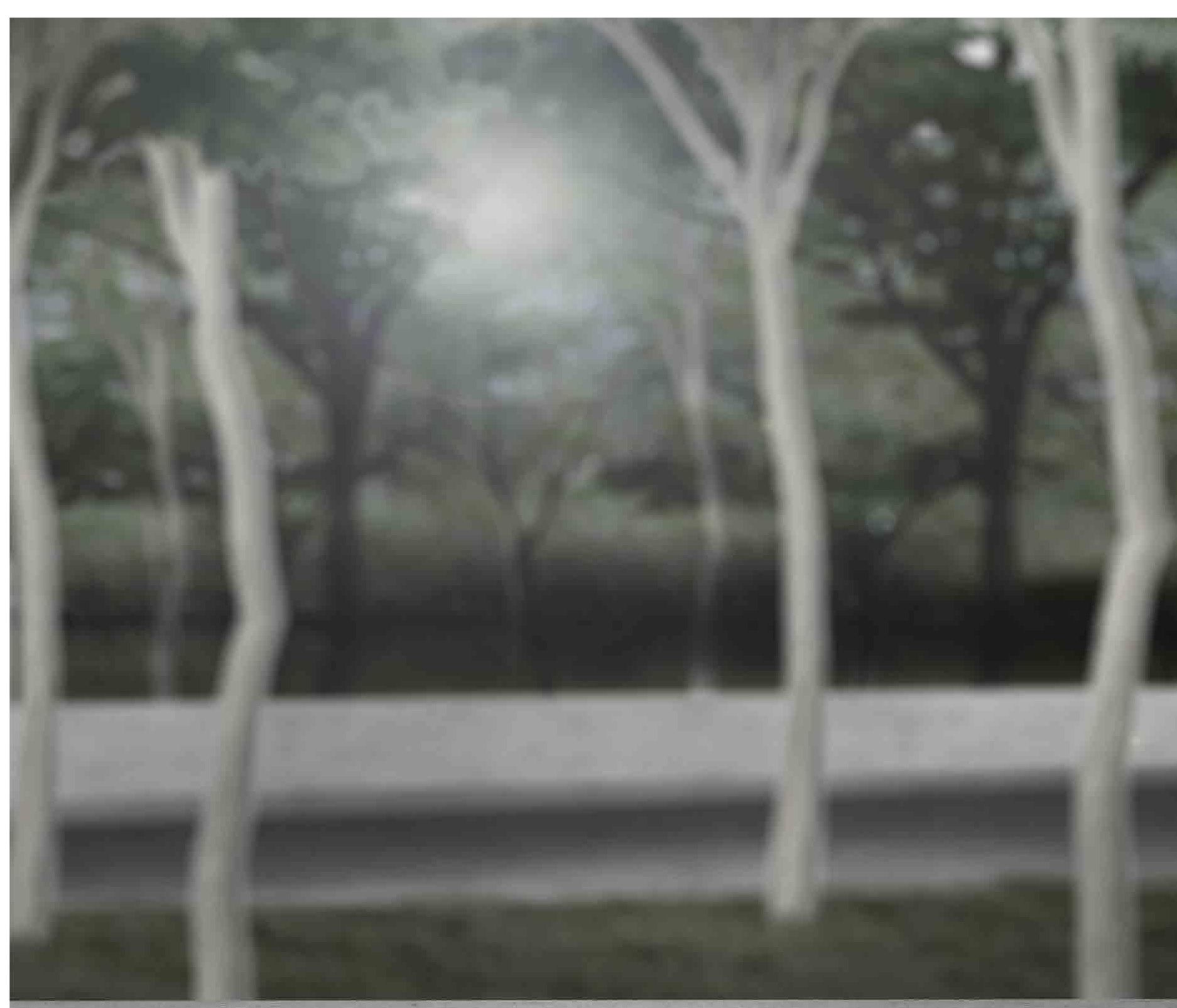

Figure 125 - Perspective

Forest space 
Whilst this project has demonstrated synergies can be found between the grief process and the design process, it foregrounded a particular conflict in regards to applicability. One of the most important goals at the outset of this investigation was to make it a design that will realistically integrate with and affect the daily walker. It became clear that this has produced a layered design that is effective at some scale to each passer through, but has a very niche application of grief reflection.

However I do not take this as a negative attribute to the design but is infact a honest representation on what a daily space could be. Engaging with mourning is often through negative association of emotion and a broad design that attempts to engage with all. This design ended up helping some of those in a grieving process, but widely created a reflective space for more than grief. The atmospheric aspect of the design creates avenues to more engagement than with grief, and on reflect became the main element of the study.

This is not to say that those in various stages of grief will not find solace and positive reflection within the space as although it is a niche design, it has been designed for that niche through an in depth analysis on how to spatialise various grief elements.

What this investigation has produced is more than how to engage with one experiencing grief, but a possibility in atmospheric design for allowing a daily space to engage with the user and let them impart themselves on it. This creates a closer relationship between the user and the space, and allows them to reflect themselves in the elements through metaphor, memory or association.

Atmospheric networks were initially a byproduct of understanding the mourning process as grief was the main focus at the outset of this design but became the tool that was used to begin to understand atmospheric networks. Towards the end of the investigation it became clear that although engaging with the daily griever and aiding them was an important design element, understanding the complex simplicity of an atmospheric network was the true production of this project.
The question on engaging with the daily griever is answered,

The application of atmospheric design is understood,

The possibility of a deep and rich engagement of design with a person through atmospheric networks is discovered and applied. 


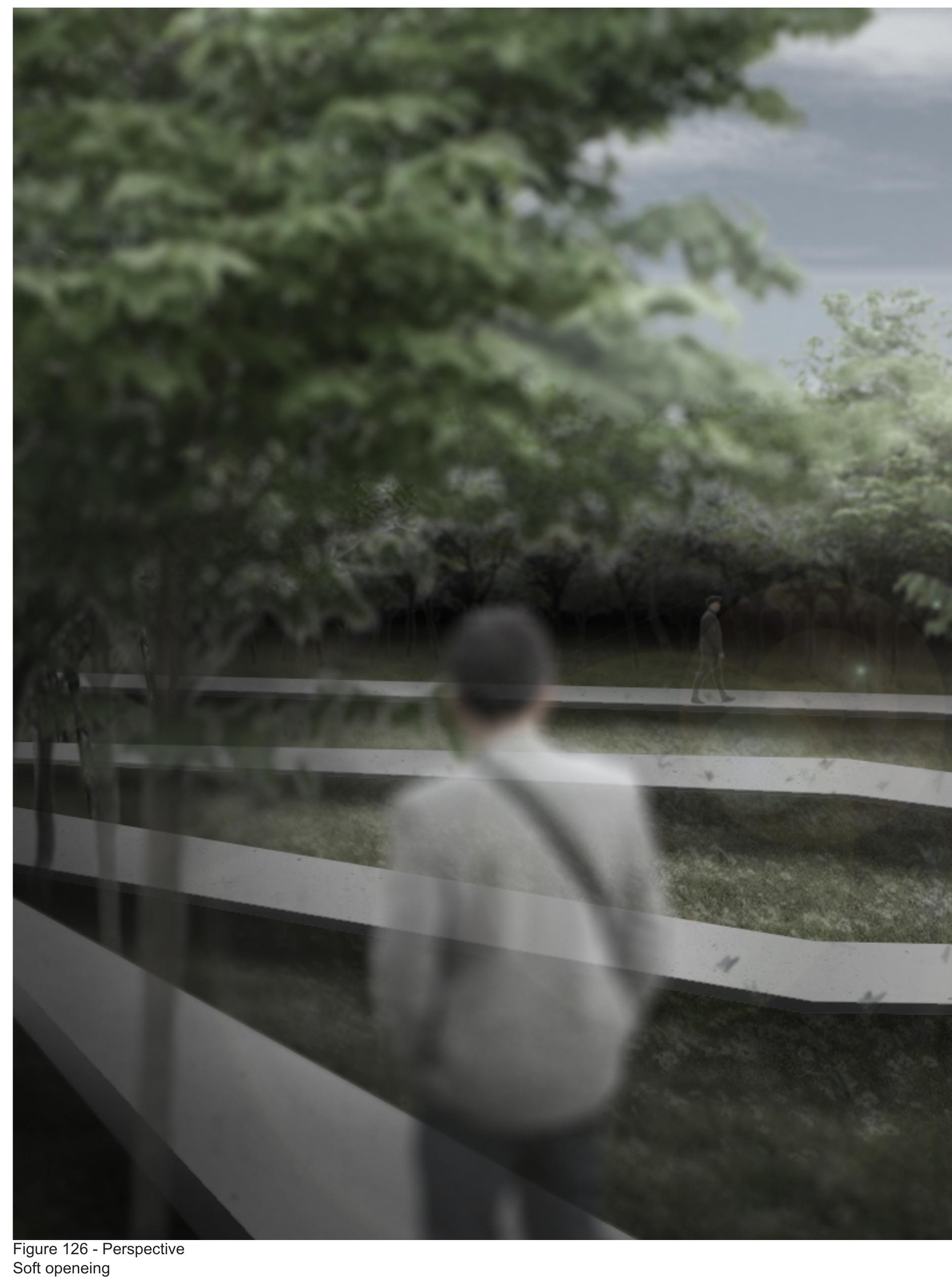




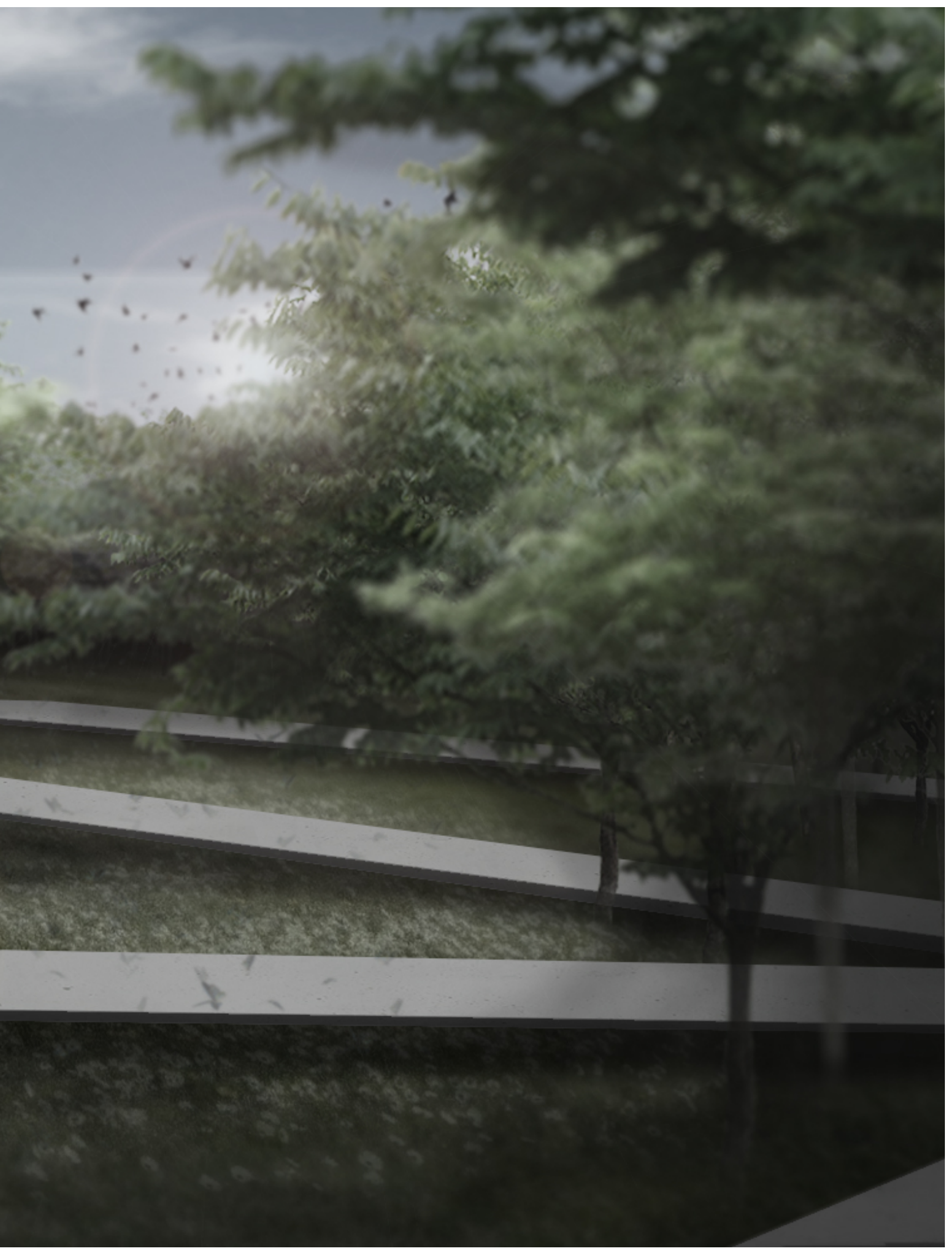


Figure 1 - Meaningful space section

Figure 2 - Atmopheric section

Figure 3 - Method Diagram

Figure 4 - Woodland cemetery sketch

8

13

Figure 5 - Igualada cemetery sketch

Figure 6 - Memorial to Victims of Violence in Mexico Netowrk diagram 13

Figure 7 - Memorial to the murdered Jews of Europre sketch 15

Figure 8 - Threshold diagram - Farum Midtpunkt 16

Figure 9 - Threhold Diagram - Symantec Chengdu Campus 16

Figure 10 - Network Diagram - Farum Midtpunkt 17

Figure 11 - Network diagram - Symantec Chengdu Campus 17

Figure 12 - Multilevel spatial analysis network - Symantec Chengdu Campus 18

Figure 13 - Multilevel spatial analysis network - Farum Midtpunkt 19

Figure 14 - Drawing - Life and grief relationship interpretation 22

Figure 15 - Drawing - Eveolution of relationship between space and grief from the grievers perspective 23

Figure 16 - Drawing - Moments and stages of grief $23 / 40$

Figure 16 - Drawing - Concious and subconcious shifts of spacetial relationship and grief 24

Figure 17 - Drawing - Atmosphere 28

Figure 18 - Drawing - Beauty 29

Figure 19 - Drawing - Dilluted solitude 30

Figure 20 - Drawing - Change 31

Figure 21 - Drawing - Detail 32

Figure 22 - Drawing - Disconnection 33

Figure 23 - Drawing - Expression $\quad 34$

Figure 24 - Drawing - Internal $\quad 35$

Figure 25 - Drawing - Notions of life $\quad 36$

$\begin{array}{ll}\text { Figure } 26 \text { - Drawing - Outerlife } & 37\end{array}$

Figure 27 - Drawing - Social 38

Figure 28 - Drawing - Time $\quad 39$

Figure 29 - Drawing - Interpretations of various ways to move through grief 40

Figure 30 - Drawing - Interpretations of various stage lengths through grief 41

Figure 31 - Drawing - Grief as a process 42

Figure 32 - Drawing - Healing as a process 43

Figure 33 - Drawing - Growth as a process 44

Figure 34 - Drawing - The continuation or 'Maturity' of grief 45

Figure 35 - Drawing - Monumental atmosphere 46

Figure 36 - Drawing - Integrated atmosphere 46

Figure 39 - Diagram - Wandering 48

Figure 40 - Diagram - Progression $\quad 49$

Figure 41 - Diagram - Threshold 50

Figure 42 - Diagram - Local Artists

Figure 43 - Diagram - Flora $\quad 52$

Figure 44 - Diagram - Space $\quad 53$

Figure 45 - Diagram - Flora $\quad 53$

Figure 46 - Diagram - Space $\quad 55$

Figure 47 - Diagram - Flora $\quad 56$

$\begin{array}{ll}\text { Figure } 48 \text { - Diagram - Space } & 57\end{array}$

Figure 49 - Diagram - Growth 58

Figure 50 - Diagram - Canopy $\quad 59$

Figure 51 - Diagram - Spatial Relationship $\quad 60$

Figure 52 - Diagram - Imperfection $\quad 61$

Figure 53 - Diagram - Sensory networks $\quad 66$

Figure 54 - Diagram - Visual network $\quad 67$

Figure 55 - Diagram - Aromatic network 67

Figure 56 - Diagram - Audio network $\quad 68$

Figure 57 - Diagram - Taste network 68

Figure 58 - Diagram - Kinethetic network 69

Figure 59 - Photo collage - Forest $\quad 72$

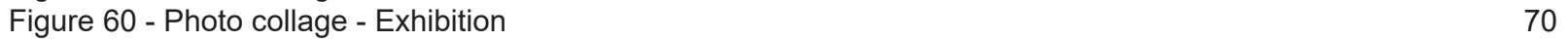

Figure 61 - Photo collage - Soft clearing $\quad 71$

Figure 62 - Photo collage - Cafe frontage $\quad 71$

Figure 63 - Plane - No scale - New Zealand with the location of Wellington 74

Figure 63 - Plan - 1: 15000 - Te Aro Movement

Figure 64 - Plan - 1 : 15000 - Reflective space network in Te Aro 76 
Figure 65 - Plan - 1: 15000 - Chosen focus area 77

Figure 66 - Plan - 1:3000 - Te Aro drainage 78

Figure 67 - Plan - 1:4000 - Pedestrain movement vs Car park network 79

Figure 68 - Plan - 1:500 - Site 1 - Facade Study 80

Figure 69 - Plan - 1:500 - Site 2 - Facade Study 81

Figure 70 - analysis network - Site 1

Figure 71 - analysis network - Site $2 \quad 83$

Figure 72 - Diagram - Material Network - Site $1 \quad 84$

Figure 73 - Diagram - Material Network - Site 2

Figure 74 - Drawing - Atmospheric relationship of space and research 88

Figure 75 - Drawing - Four design stages 88

Figure 76 - Drawing - Elevation possibilities 89

Figure 77 - Drawing - Path districution $\quad 89$

Figure 78 - Drawing - Spatial Network Diagrams 89

Figure 79 - Drawing - Staging drawings 90

Figure 80 - Compilation - Intergrated design concept - Site 1

Figure 81 - Compilation - Intergrated design concept - Site 2

Figure 82 - Compilation - Social design concept - Site 1

Figure 82 - Compilation - Social design concept - Site 2

Figure 84 - Compilation - Disconnected design concept - Site 1

Figure 85 - Compilation - Disconnected design concept - Site 2

Figure 86 - Sections - Design stages - Stage 1 - 1:600 102

Figure 87 - Sections - Design stages - Stage 2 - 1:600 103

Figure 88 - Sections - Design stages - Stage 3 - 1:600 103

Figure 89 - Sections - Design stages - Stage 4 - 1:600 105

Figure 90 - Plan - 1:600 - Path design - Stage 1 - Site 1

Figure 91 - Plan - 1:600 - Path design - Stage 1 - Site 2

Figure 92 - Plan - 1:600 - Path design - Stage 2 - Site 1

Figure 93 - Plan - 1:600 - Path design - Stage 2 - Site 2

Figure 94 - Plan - 1:600 - Path design - Stage 3- Site 1

Figure 95 - Plan - 1:600 - Path design - Stage 3 - Site 2

Figure 96 - Plan - 1:600 - Path design - Stage 4 - Site 1

Figure 97 - Plan - 1:600 - Path design - Stage 4 - Site 2

Figure 98 - Sections - Edge Drainage 114

Figure 99 - Plans - Site Drainages $\quad 115$

Figure 99 - Plans - Site cut and fill $\quad 115$

Figure 100 - Elevation - Planting choice diagrams 117

Figure 101 - Plans - Sesonal shifts 118

Figure 102 - Sections - Design stage 1

Figure 103 - Sections - Design stage $2 \quad 120$

Figure 104 - Sections - Design stage $3 \quad 121$

Figure 105 - Sections - Design stage 4

Figure 105 - Plan - 1:450 - Site 1 123

Figure 106 - Plan - 1:750 - Design stages 125

Figure 107 - Section - 1:300 - Journey section A 127

Figure 108 - Section - 1:300 - Journey section B 127

Figure 109 - Section - 1:300 - Journey section C 128

Figure 110 - Plan - 1: 150 - Zoom Plan - Cafe Frontage 129

Figure 111 - Section - Zoom Section - Cafe Frontage 129

Figure 112 - Plan - 1 : 150 - Zoom Plan - Roadside path 130

Figure 113 - Section - Zoom Section - Roadside path 130

Figure 114 - Plan - 1 : 150 - Zoom Plan - Exhibition space 131

Figure 115 - Section - Zoom Section - Exhibition space

Figure 116 - Plan - 1:450 - Site 2

Figure 117 - Plan - 1: 750 - Design stages 134

Figure 118 - Section - 1:300 - Journey Section D 136

Figure 119 - Plan - 1: 150 - Zoom Plan - Entrance 127

Figure 120 - Section - Zoom Section - Entrance 127

Figure 121 - Plan - 1 : 150 - Zoom Plan - Forest

Figure 122 - Section - Zoom Section - Forest 138

Figure 123 - Plan - 1: 150 - Zoom Plan - Soft openeing 139

Figure 124- Section - Zoom Section - Soft openeing 139

Figure 125 - Perspective - Forest space 140

Figure 126- Perspective - Soft openeing 144 


\section{Bibliography.}

Anderson, Eric G. 'Grief Recovery: Helping Those Who've Had to Say Goodbye'. Geriatrics, vol. 52, no. 9, 1997, pp. 103-05.

Andersson, Stig L. 'Atmosphere: Quality, Perception and the Concept of Time in Landscape Architecture.(Views and Criticisms)'. Landscape Architecture Frontiers, vol. Vol.2(1), 2014, p. p.72(6).

Beaglehole, Ernest, and Pearl Beaglehole. 'Contemporary Maori Death Customs'. The Journal of the Polynesian Society, vol. 54, no. 2, June 1945, p. 26.

Bond, John. 'Life After A Death'. Sociology of Health \& IIlness, vol. 6, no. 1, Mar. 1984, pp. 105-06, doi:10.1111/1467-9566.ep10778162.

Clements, Paul, et al. 'Cultural Perspectives of Death, Grief, and Bereavement'. Journal of Psychosocial Nursing \& Mental Health Services;, July 2003, pp. 18-27.

Colebrook, Claire. Understanding Deleuze. Allen \& Unwin, 2002.

Connolly, Peter. An Open Systems Conception of How to Design Landscape. RMIT University, 2013.

Deleuze, Gilles. 'Expressionisn in Philosophy: Spinoza'. Expressionisn in Philosophy: Spinoza, Zone Books, in English, Hardcover, 1990, p. 448.

Dellasega, Cheryl. 'The Grief Train'. American Journal of Nursing, vol. 113, no. 10, 2013, p. 72, doi:10.1097/01.NAJ.0000435358.91652.a3.

Down, Jennifer. 'The End.(Overcoming Grief)'. Overland, vol. Summer, no. 217, 2014, p. P.17 (3).

Fountain, Henry. 'At Chernobyl, Hints of Nature's Adaptation'. The New York Times, 5 May 2014, https://www.nytimes.com/2014/05/06/science/nature-adapts-to-chernobyl.html.

Fulton, Amy, and Julie Drolet. 'Responding to Disaster-Related Loss and Grief:

Recovering From the 2013 Flood in Southern Alberta, Canada'. Journal of Loss and Trauma, vol. 23, no. 2, Feb. 2018, pp. 140-58, doi:10.1080/15325024.2018.1423873.

Gill, Victoria. 'Wild Mammals "have Returned” to Chernobyl'. BBC News, 5 Oct. 2015, https://www.bbc.com/news/science-environment-34414914.

Griffero, Tonino. 'The Atmospheric "Skin” of the City'. Ambiances, Nov. 2013, p. 17, doi:10.4000/ambiances.399.

Guillaume, Laura, and Joe Hughes. Deleuze and the Body. 1st ed., Edinburgh University Press, 2011, https://ebookcentral.proquest.com/lib/vuw/detail.action?doclD=714132. 
Hazinga, Cynthia. 'The Art of a Zen Garden: Peace in Place'. Garden Guide, no. Annual 2010, 2010, p. 46.

Hyrkäs, Kristiina, et al. 'Recovering from the Death of a Spouse'. Journal of Advanced Nursing, vol. 25, no. 4, Apr. 1997, pp. 775-79, doi:10.1046/j.13652648.1997.1997025775.x.

Jacob, S. 'An Analysis of the Concept of Grief.' Journal of Advanced Nursing, vol. 18, 1993, pp. 1787-94.

James, Kerry. 'The Cost of Custom: A Recent Funeral in Tonga'. The Polynesian Society, vol. 111, no. 3, Sept. 2002, pp. 223-38.

Jen Der Pan, Peter, et al. 'Development and Validation of a Christian-Based Grief Recovery Scale'. Ritish Journal of Guidance \& Counselling, vol. 41, no. 1, 2014, pp. 99-114, doi:10.1080/03069885.2013.852158.

Meyer, Elizabeth. 'Sustaining Beauty: The Preformance of Appearance'. Landscape Architecture, 2008, pp. 92-131.

Mills, Tessa, et al. PHYTOREMEDIATION - A LONG-TERM SOLUTION FOR CONTAMINATED SITES. Environment and Risk Management Group HortResearch, P.B. 11030, Palmerston North, http://www.wasteminz.org.nz/wp-content/uploads/ PHYTOREMEDIATION-\%E2\%80\%93-A-LONG-TERM-SOLUTION-FORCONTAMINATED.pdf.

Nuclear Energy Agency. Chernobyl: Assessment of Radiological and Health Impackts. Organisation for economic co-operation and development, 2002, http://www.oecd-nea. org/rp/pubs/2003/3508-chernobyl.pdf.

Sala, Ilaria Maria. Resurrecting China's Customs. Wall Street Journal , 2008.

Shan-Lin Hou, Frank. Phytoremediation and Bioremediation of Petroleum Contaminated Soils and Wastes. University of Canterbury Christchurch, New Zealand, 2000.

Shepherd, Dean, and Donald Kuratko. 'The Death of an Innovative Project: How Grief Recovery Enhances Learning'. Business Horizons, vol. 52, no. 5, 2009, pp. 451-58, doi:10.1016/j.bushor.2009.04.009.

Sorensen, Julia. Overcoming Loss : Activities and Stories to Help Transform Children's Grief and Loss. Jessica Kingsley Publishers, 2008, https:// tewaharoa.victoria.ac.nz/primo-explore/fulldisplay?docid=64VUW_ INST21152701800002386\&context=L\&vid=VUWNUI\&lang=en_ NZ\&search_scope=64VUW_ALL\&adaptor=Local\%20 Search\%20Engine\&tab=all\&query=any,contains,overcoming $\% 20$ grief\&sortby=rank\&facet=rtype,exclude,newspaper_articles\&facet=rtype,exclude,reviews. 
Overcoming Loss : Activities and Stories to Help Transform Children's Grief and Loss. Jessica Kingsley Publishers, 2008.

Staudacher, Carol. Beyond Grief : A Guide for Recovering from the Death of a Loved One. Oakland, CA : New Harbinger Publications.

Tonder, Gert Van, et al. 'Visual Structure of a Japanese Zen Garden'. Nature, vol. 419, Sept. 2002, pp. 359-360.

Vaughn, Bruce. 'RECOVERING GRIEF IN THE AGE OF GRIEF RECOVERY'. Journal of Pastoral Theology, vol. 13, no. 1, Apr. 2003, pp. 36-45, doi:10.1179/jpt.2003.13.1.005.

Viladas, Pilar. 'Zen Rock Garden'. The New York Times Magazine, Sept. 2005, p. 6006047.

Wilson, Liz. Living and the Dead. State University of New York Press, 2003, https:// ebookcentral.proquest.com/lib/vuw/detail.action?doclD=3408528. 




$$
\Delta
$$

